PNL-2731

UC-11

\title{
Mathematical Simulation of Transport of Sediment and Kepone in the James River Estuary
}

Yasuo Onishi

Stacy E. Wise

September 1978

Prepared for the U.S. Department of Energy under Contract EY-76-C-06-1830

Pacific Northwest Laboratory

Operated for the U.S. Department of Energy by 


\title{
NOTICE
}

This report was prepared as an account of work sponsored by the United States Government. Neither the United States nor the Department of Energy, nor any of their employees, nor any of their cantractors, subcontractors, or their employees, makes any warranty, express or implied, or assumes any legal liability or responsibility for the accuracy, completeness or usefulness of any information, apparatus, product or process disclosed, or represents that its use would not infringe privately owned rights,

The views, opinions and conclusions contained in this report ary those of the contractor and do not necessarily represent those of the United States Government or the United States Department of Energy.

\author{
PACIFIC NORTHWEST LABORATORY \\ operated by \\ BATTELLE \\ for the \\ UNITED STATES DEPARTMENT OF ENIERGY \\ Under Contract EY-76-C-06-1830
}

\author{
Psinted in the United States of America \\ Avallable from \\ National Technical Iniormation Service \\ United States Department of Commeter \\ 5285 Port Royal Rosd \\ Springlield, Virginia 22151 \\ Price: Printed Conys \\ *: Microfiche 53.00
}

- Pages

NTIS

$001-025$

Selling Price

026-050

$\$ 4.00$

$051-075$

54.50

$076-100$

55.25

$101-125$

126-750

$151-175$

$176-200$

$201-225$

$226-250$

$251-275$

$206-300$

$\$ 6.00$

56,50

57.25

58.00

$\$ 9.00$.

59.25

5950

310.75

571.00 
33679000491748

MATHEMATICAL SIMULATION

OF TRANSPORT OF SEDIMENT AND

KEPONE IN THE JAMES RIVER

ESTUARY

Yasuo Onishi

Stacy E. Wise

September 1978

Prepared for

the U.S. Department of Energy under Contract EY-76-C-06-1830

Pacific Northivest Laboratory Richiand, Washington 99352 
: 


\section{EXECUTIVE SUMMARY}

The mathematical simulation of sediment and Kepone (a highly chlorinated pesticide) transport in the James River estuary was conducted by applying the sediment and contaminant transport model, FETRA, to an $85-\mathrm{km}$ river reach between Bailey and Burwell Bays. The FETRA code is an unsteady, two-dimensional, finite element model, utilizing the Galerkin weighted residual method. The model consists of three submodels coupled together to take into account sediment-contaminant interaction. The submodels are: 1) sediment transport model, 2) dissolved contaminant transport model, and 3) particulate contaminant (contaminants adsorbed by sediment) transport model. Transport of sediment and particulate contaminants is simulated for each sediment type or size fraction. The modeling procedure of the FETRA code involves simulation of sediment transport. The results are then used to simulate dissolved and particulate contaminants by accounting for interaction with the sediments. Changes in river bed conditions are calculated including: 1) river bed elevation change, 2) distributions of ratio of each bed sediment component in the bed and bed armoring, and 3) distribution of contaminants within the river bed.

The FETRA code was applied to simulate the migration of sediment and Kepone for three river discharges. Tidally influenced depth and velocity distributions in the study area were obtained by the unsteady, one-dimensional code, EXPLORE. These results were used by the two-dimensional code, FETRA, to obtain longitudinal distributions of sediment and Kepone. Hence, the results presented here are cross-sectionally averaged values changing with tidal flow. Comparison of computed results and field data for both sediment and Kepone concentrations indicates very good agreement, confirming the validity of the model. Mathematical simulation of Kepone transport under most probable flow conditions yields an estimate of $89.1 \mathrm{~kg} / \mathrm{yr}$ of Kepone transported seaward from Burwe11 Bay. of this $89.1 \mathrm{~kg}$ of total Kepone, $25.3 \%$ is carried by sediment, while $74.7 \%$ is in a dissolved phase. Since it is estimated that approximately $9600 \mathrm{~kg}$ of Kepone is present in the top 1 ft of bottom sediment in the river, with this flushing rate, it may take at least $108 \mathrm{yr}$ for natural water-sediment flushing mechanisms alone to clean the James River. Effectiveness of 10 partial Kepone cleanup activities to reduce Kepone concentrations in the river was also studied by simulating 10 hypothetical conditions by the FETRA code. 


\section{ACKNOWLEDGMENTS}

The study reported in this paper was corducted as a part of the Kepone Mitigation Feasibility Study. This study was sponsored by the U.S. Environmental Protection Agency through an interagency agreement between EPA and the Department of Energy, whose Pacific Northwest Laboratory is operated by Battelle Memorial Institute under Contract EY-76-C-06-1830. The authors wish to express their gratitude to Messrs. M. W. Brossman and G. W. Dawson for their support. The authors are also grateful to Dr. L. D. Kannberg and Mr. R. M. Ecker for their assistance in the hydrodynamic madeling. 


\section{TAELE OF CONTENTS}

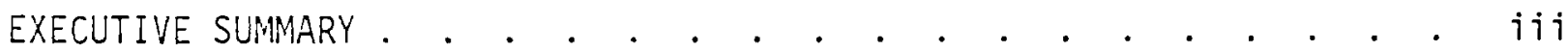

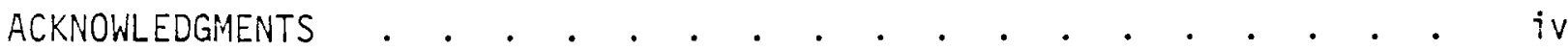

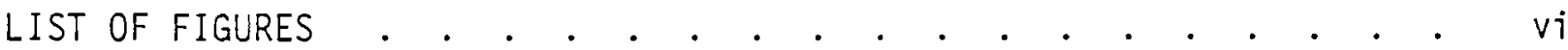

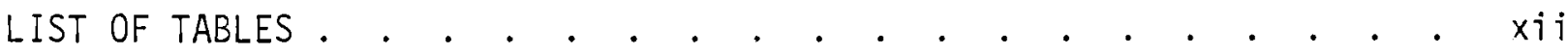

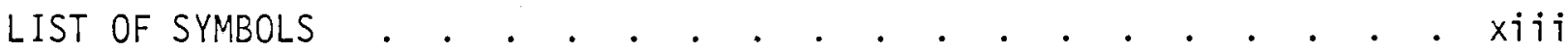

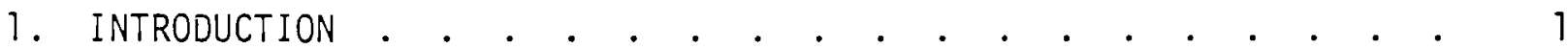

2. MATHEMATICAL MODEL FORMULATION OF TRANSPORT MODEL, FETRA . • • 3

2.2 Dissolved Contaminant Transport Model . • . . . . . . . 8

2.3 Particulate Contaminant Transport Model . . . . . . . 12

2.4 Finite Element Method . . . . . . . . . . . . . 14

3. VERIFICATION OF BASIC COMPUTATIONAL SCHEME OF FETRA MODEL . $\quad . \quad$. 17

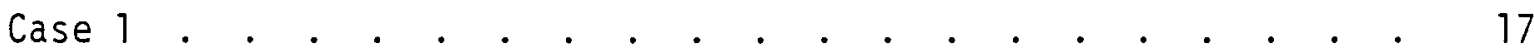

Case 2 .

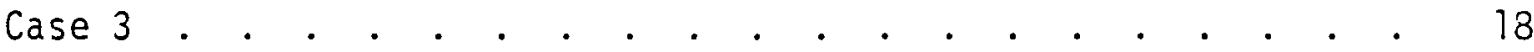

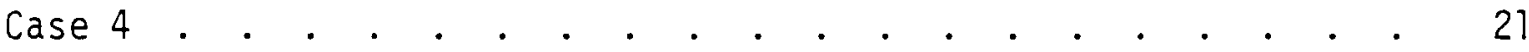

4. COMPUTER SIMULTATION RESULTS • • • • • • • • • • • • • • • • 23

4.1 Calibration of the Model . . . . . . . . . . . . . . . . 27

4.2 Verification of the Model . . . . . . . . . . . . . 28

4.3 Case 1 - Net Fresh-Water Discharge of $58.3 \mathrm{~m}^{3} / \mathrm{sec}$. . . . 31

4.4 Case 2 - Net Fresh-Water Discharge of $681 \mathrm{~m}^{3} / \mathrm{sec}$. . . . 35

4.5 Case 3 - Net Fresh-Water Discharge of $581 \mathrm{~m}^{3} / \mathrm{sec}$. . . . 38

4.6 Case 4 - Overall Evaluation Through Combination of Results on Cases 1, 2 and 3 . . . . . . . . . . . 40

4.7 Sensitivity Analysis . . . . . . . . . . . . . . . . . . . 41

4.8 Kepone Cleanup Activities . . . . . . . . . . . . . 43

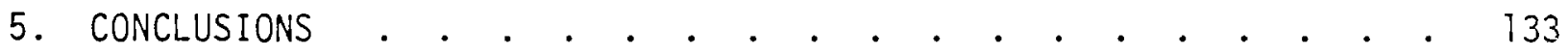

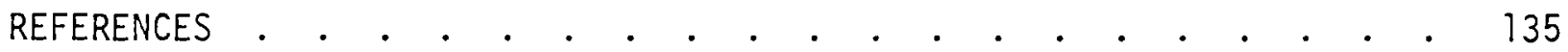

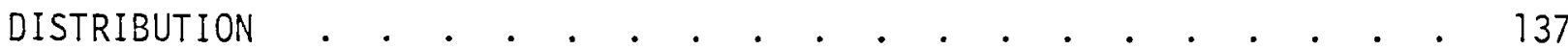




\section{LIST OF FIGURES}

1 Comparison of Numerical Solution with Analytical Solution of One-Dimensional Steady Convection-Diffusion Equation with a Source Term . . . . . . . . . . . . . . 18

2 Comparison of Numerical Solution with Analytical Solution of One-Dimensional Steady Convection-Diffusion Equation with a Decay Term . • . . • • . . • . . . . • . . 19

3 Convergence of Unsteady-State One-Dimensional Diffusion Equation to Steady-State Solution . . . . . . . . . . 20

4 Comparison of Numerical Solution with Analytical Solution to Two-Dimensional Diffusion Equation . . . • . . . . . . 22

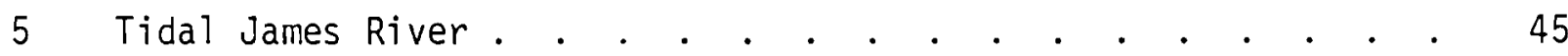

6 Longitudinal Distributions of Total Sediment Concentration at the Maximum Ebb Tide for the Fresh-Water Discharge of $58.3 \mathrm{~m}^{3} / \mathrm{sec}$, Together with Field Data . . . . . . . . . 46

7 Longitudinal Distributions of Total Sediment Concentration at the Slack Tide for the Fresh-Water Discharge of $58.3 \mathrm{~m} 3 / \mathrm{sec}$, Together with Field Data . . . . . . . . . . . .

8 Longitudinal Distributions of Total Sediment Concentration at the Maximum Flcod Tide for the Fresh-Water Discharge of $58.3 \mathrm{~m} / \mathrm{sec}$, Together with Field Data . . . . . . . . . 48

9 Tidal Averaged Sediment Concentration of Each Sediment Type for the Fresh-Water Discharge of $58.3 \mathrm{~m}^{3} / \mathrm{sec} . . \quad . \quad . \quad$.

10 Longitudinal Distribution of Sediment Concentration of Each Sediment Type at Slack Tide for the Fresh-Water Discharge of $245 \mathrm{~m}^{3} / \mathrm{sec}$

11 Tidal Averaged Sediment Concentration of Each Sediment Type for the Fresh-Water Discharge of $247 \mathrm{~m} 3 / \mathrm{sec}$. . . . . . . . 51

12 Longitudinal Distributions of Particulate Kepone Concentrations at Maximum Ebb Tide for the Fresh-Water Discharge of $58.3 \mathrm{~m}^{3} / \mathrm{sec}$

13 Longitudinal Distributions of Particulate Kepone Concentrations at Slack Tide for the Fresh-Water Discharge of $58.3 \mathrm{~m} 3 / \mathrm{sec}$.

14 Longitudinal Distribtuions of Particulate Kepone Concentrations at Maximum Flood Tide for the Fresh-Water Discharge of $58.3 \mathrm{~m}^{3} / \mathrm{sec}$.

15 Tidal Averaged Particulate Kepone Concentrations for the Fresh-Water Discharge of $58.3 \mathrm{~m} / \mathrm{sec} . . \quad . \quad . \quad . \quad . \quad$.

16 Longitudinal Distributions of Tidal Averaged Particulate Kepone Concentrations Per Unit Volume of Water for the Fresh-Water Discharge of $58.3 \mathrm{~m}^{3} / \mathrm{sec}$ 
17 Longitudinal Distributions of Tidal Averaged Total, Dissolved and Particulate Kepone Concentrations for the Fresh-water Discharge of $58.3 \mathrm{~m}^{3} / \mathrm{sec}$

18 Longitudinal Velocity Distributions at Maximum Ebb, Siack and the Maximum Flood Tides for Fresh-Water Input Discharge of $58.3 \mathrm{~m}^{3} / \mathrm{sec}$.

19 Longitudinal Depth Variation at Maximum Ebb Tide for the Fresh-Water Discharge of $58.3 \mathrm{~m} 3 / \mathrm{sec}$ Discharge of $58.3 \mathrm{~m}^{3} / \mathrm{sec}$

21 Longitudinal Depth Variations at Maximum Flood Tide for the Fresh-Water Discharge of $58.3 \mathrm{~m} 3 / \mathrm{sec}$

\section{Longitudinal Depth Variation at Slack Tide for the Fresh-Water}

Longitudinal Distributions of Total Sediment Concentration at the Maximum Ebb Tide for the Fresh-Water Discharge of

$58.3 \mathrm{~m}^{3} / \mathrm{sec}$, Together with Fieid Data $\cdot \cdot \cdot \cdot \cdot \cdot \cdot \cdot$

23 Longitudinal Distributions of Total Sediment Concentration at the Slack Tide for the Fresh-Water Discharge of $58.3 \mathrm{~m}^{3} / \mathrm{sec}$, Together with Field Data

24 Longitudinal Distributions of Total Sediment Concentration at the Maximum Flood Tide for the Fresh-Water Discharge of $58.3 \mathrm{~m}^{3} / \mathrm{sec}$, Together with Field Data

25 Longitudinal Distribution of Sediment Concentration of Each Sediment Type at Maximum Ebb Tide for the FreshWater Discharge of $58.3 \mathrm{~m} 3 / \mathrm{sec}$

26 Longitudinal Distribution of Sediment Concentration of Each Sediment Type at Slack Tide for the Fresh-Water Discharge of $58.3 \mathrm{~m}^{3} / \mathrm{sec}$

27 Longitudinal Distributions of Sediment Concentration of Each Sediment Type at Maximum Flood Tide for the FreshWater Discharge of $58.3 \mathrm{~m}^{3} / \mathrm{sec}$

29 Tidal Averaged Sediment Concentration of Each Sediment Type for the Fresh-Water Discharge of $58.3 \mathrm{~m}^{3} / \mathrm{sec} . \cdot \cdot \cdot \cdot$..

30 Longitudinal Distributions of Particulate Kepone Concentrations

30 Longitudinal Distributions of Particulate Kepone Conce $58.3 \mathrm{~m}^{3} / \mathrm{sec}$

3 Longitudinal Distributions of Particulate Kepone Concentrations at Slack Tide for the Fresh-Water Discharge $58.3 \mathrm{~m} / \mathrm{sec}$. . . 71

32 Longitudinal Distributions of Particulate Kepone Concentrations of Maximum Flood Tide for the Fresh-Water Discharge of $58.3 \mathrm{~m}^{3} / \mathrm{sec}$. 
33 Changes of Particulate Kepone Concentrations with Time at River Kilometer 75.7 for the Fresh-Water Discharge of $58.3 \mathrm{~m}^{3} / \mathrm{sec}$.

34 Tidal Averaged Particulate Kepone Concentrations for the Fresh-Water Discharge of $58.3 \mathrm{~m}^{3} / \mathrm{sec}$

35 Longitudinal Distributions of Particulate Kepone Concentrations per Unit Volume of Water at Maximum Ebb Tide for the Fresh-Water Discharge of $58.3 \mathrm{~m}^{3} / \mathrm{sec}$

36 Longitudinal Distributions of Particulate Kepone Concentrations per Unit Volume of Water at Slack Tide for the Fresh-Water Discharge of $58.3 \mathrm{~m}^{3} / \mathrm{sec}$

37 Longitudinal Distributions of Particulate Kepone Concentrations per Unit Volume of Water at Maximum Flood Tide for the FreshWater Discharge of $58.3 \mathrm{~m}^{3} / \mathrm{sec}$

38 Longitudinal Distributions of Tidal Averaged Particulate Kepone Concentrations per Unit Volume of Water for the Fresh-Water Discharge of $58.3 \mathrm{~m} 3 / \mathrm{sec}$

39 Longitudinal Distributions of Total, Dissolved and Particulate Kepone Concentrations at Maximum Ebb Tide for the FreshWater Discharge of $58.3 \mathrm{~m}^{3} \mathrm{sec}$.

40 Longitudinal Distributions of Total, Dissolved and Particulate Kepone Concentrations at Slack Tide for the Fresh-Water Discharge of $58.3 \mathrm{~m}^{3} / \mathrm{sec}$

41 Longitudinal Distributions of Total, Dissolved and Particulate Kepone Concentrations at Maximum Flood Tide for the Fresh-Water Discharge of $58.3 \mathrm{~m}^{3} / \mathrm{sec}$

42 Changes of Total, Dissolved and Particulate Kepone Concentration with Time at River Kilometer 75.7 for the Fresh-Water Discharge of $58.3 \mathrm{~m}^{3} / \mathrm{sec} \cdot \cdot \cdot \cdot \cdot \cdot \cdot \cdot \cdot \cdot \cdot \cdot \cdot \cdot \cdot \cdot \cdot \cdot \cdot$

43 Longitudinal Distributions of Tidal Averaged Total, Dissolved and Particulate Kepone Concentrations for the Fresh-Water Discharge of $58.3 \mathrm{~m}^{3} / \mathrm{sec}$

44 Variation of River Bed Elevation Changes Due to Sediment

Deposition and/or Bed Scouring at Maximum Ebb Tide for the

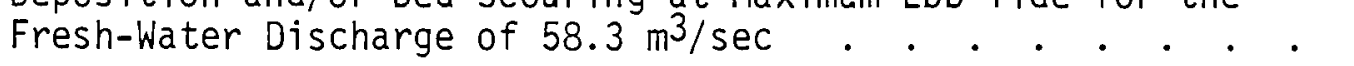

45 Change on Bed Surface Kepone Concentration Occurred During 1-Month Simulation for the Fresh-Water Discharge of $58.3 \mathrm{~m}^{3} / \mathrm{sec}$

46 Longitudinal Velocity Distributions at Maximum Ebb, Slack and the Maximum Flood Tides for Fresh-Water Input Discharge of $247 \mathrm{~m}^{3} / \mathrm{sec}$ 
48 Longitudinal Depth Variation at Slack Tide for the

Fresh-Water Discharge of $247 \mathrm{~m}^{3} / \mathrm{sec}$. . . . . . . . . . 88

49 Longitudinal Depth Variation at Maximum Flood Tide for the

Fresh-Water Discharge of $247 \mathrm{~m}^{3} / \mathrm{sec}$. . . . . . . . . . 89

50 Longitudinal Distribution of Sediment Concentration of Each

Sediment Type at Maximum Ebb Tide for the Fresh-Water

Discharge of $247 \mathrm{~m}^{3} / \mathrm{sec}$. . . . . . . . . . . . . . . 90

51 Longitudinal Distribution of Sediment Concentration of Each

Sediment Type at Siack Tide for the Fresh-Water Discharge

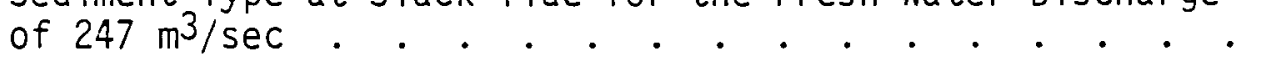

52 Longitudinal Distributions of Sediment Concentration of Each

Sediment Type at Maximum Flood Tide for the Fresh-water

Discharge of $247 \mathrm{~m} / \mathrm{sec}$. . . . . . . . . . . . . . . . . . . 92

53 Tidal Averaged Sediment Concentration of Each Sediment Type

for the Fresh-Water Discharge of $247 \mathrm{~m} / \mathrm{sec} \cdot . \cdot \cdot \cdot \cdot$.

54 Longitudinal Distributions of Particulate Kepone Concentrations at Maximum Ebb Tide for the Fresh-Water Discharge of

$247 \mathrm{~m}^{3} / \mathrm{sec}$

55 Longitudinal Distributions of Particulate Kepone Concentrations at Slack Tide for the Fresh-Water Discharge of $247 \mathrm{~m} / \mathrm{sec}$. . .

56 Longitudinal Distributions of Particulate Kepone Concentrations at Maximum Flood Tide for the Fresh-Water Discharge $247 \mathrm{~m}^{3} / \mathrm{sec}$

57 Tidal Averaged Particulate Kepone Concentrations for the

Fresh-Water Discharge of $247 \mathrm{~m} / \mathrm{sec}$. . . . . . . . .

58 Longitudinal Distributions of Particulate Kepone Concentrations per Unit Volume of Water at Maximum Ebb Tide for the FreshWater Discharge of $247 \mathrm{~m}^{3} / \mathrm{sec} \cdot \cdot \cdot \cdot \cdot \cdot \cdot \cdot \cdot \cdot \cdot \cdot \cdot \cdot$

59 Longitudinal Distributions of Particulate Kepone Concentrations per Unit Volume of Water at Slack Tide for the Fresh-Water

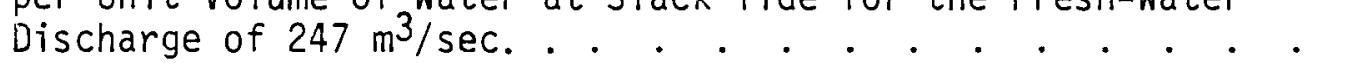

60 Longitudinal Distributions of Particulate Kepone Concentrations per Unit Volume of Water at Maximum Flood Tide for the

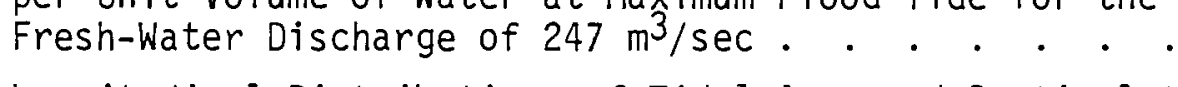

61 Longitudinal Distributions of Tidal Averaged Particulate Kepone Concentrations per Unit Volume of Water for the FreshWater Discharge of $247 \mathrm{~m}^{3} / \mathrm{sec} \cdot \cdot \cdot \cdot \cdot \cdot \cdot \cdot \cdot \cdot \cdot \cdot \cdot \cdot \cdot$

62 Longitudinal Distributions of Total, Dissolved and Particulate Kepone Concentrations at Maximum Ebb Tide for the Fresh-Water Discharge of $247 \mathrm{~m}^{3} / \mathrm{sec}$. 
63 Longitudinal Distributions of Total, Dissolved and Particulate Kepone Concentrations at Slack Tide for the Fresh-Water Discharge of $247 \mathrm{~m}^{3} / \mathrm{sec}$.

64 Longitudinal Distributions of Total, Dissolved and Particulate Kepone Concentrations at Maximum Flood Tide for the FreshWater Discharge of $247 \mathrm{~m}^{3} / \mathrm{sec}$. . . . . . . . . .

65 Longitudinal Distributions of Tidal Averaged Total, Dissolved and Particulate Kepone Concentrations for the Fresh-Water Discharge of $247 \mathrm{~m}^{3} / \mathrm{sec}$

66 Variation of River Bed Elevation Changes Due to Sediment Deposition and/or Bed Scouring at Maximum Ebb Tide for the Fresh-Water Discharge of $247 \mathrm{~m}^{3} / \mathrm{sec}$.

67 Change in Bed Surface Kepone Concentration That Occurred During 1-Month Simulation for the Fresh-Water Discharge of $247 \mathrm{~m}^{3} / \mathrm{sec}$

68 Longitudinal Velocity Distributions at Maximum Ebb, Slack and the Maximum Flood Tides for Fresh-Water Input Discharge of $681 \mathrm{~m}^{3} / \mathrm{sec}$.

69 Longitudinal Depth Variation at Maximum Ebb Tide for the

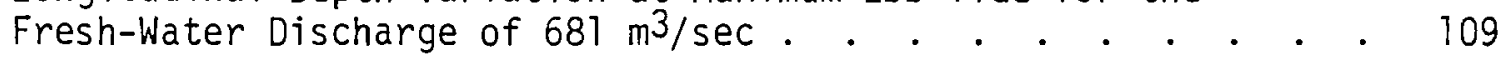

70 Longitudinal Depth Variation at Slack Tide for the Fresh-Water Discharge of $58.3 \mathrm{~m}^{3} / \mathrm{sec}$

71 Longitudinal Depth Variations at Maximum Flood Tide for the Fresh-Water Discharge of $681 \mathrm{~m}^{3} / \mathrm{sec}$

72 Longitudinal Distribution of Sediment Concentration of Each Sediment Type at Maximum Ebb Tide for the Fresh-Water Discharge of $681 \mathrm{~m}^{3} / \mathrm{sec}$

73 Longitudinal Distribution of Sediment Concentration of Each Sediment Type at Slack Tide for the Fresh-Water Discharge of $681 \mathrm{~m}^{3} / \mathrm{sec}$

74 Longitudinal Distributions of Sediment Concentration of Each Sediment Type at Maximum Flood Tide for the Fresh-Water

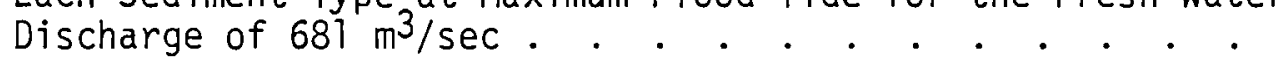

75 Tidal Averaged Sediment Concentration of Each Sediment Type

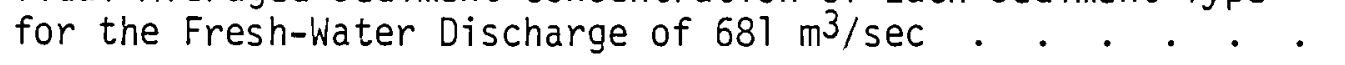

76 Longitudinal Distributions of Particulate Kepond Concentrations at Maximum Ebb Tide for the Fresh-Water Discharge to $681 \mathrm{~m}^{3} / \mathrm{sec}$

77 Longitudinal Distributions of Particulate Kepone Conçentrations at Slack Tide for the Fresh-Water Discharge of $681 \mathrm{~m}^{3} / \mathrm{sec}$. . . Longitudinal Distributions of Particulate Kepone Concentrations at Maximum Ebb Tide for the Fresh-Water Discharge of $681 \mathrm{~m}^{3} / \mathrm{sec}$ 
79 Tidal Averaged Particulate Kepone Concentrations for the Fresh-Water Discharge of $681 \mathrm{~m}^{3} / \mathrm{sec}$. . . . . . . . .

80 Longitudinal Distributions of Particulate Kepone Concentrations per Unit Volume of Water at Maximum Ebb Tide for the FreshWater Discharge of $681 \mathrm{~m} 3 / \mathrm{sec}$. . . . . . . . . . . . 120

81 Longitudinal Distributions of Particulate Kepore Concentrations per Unit Volume of Water at Slack Tide for the Fresh-Water Discharge of $681 \mathrm{~m} 3 / \mathrm{sec}$. . . . . . . . . . . . . . 121

82 Longitudinal Distributions of Particulate Kepone Concentrations per Unit Volume of Water at Maximum Flood Tide for the FreshWater Discharge of $681 \mathrm{~m} 3 / \mathrm{sec}$. . . . . . . . . . .

83 Longitudinal Distributions of Tidal Averaged Particulate Kepone Concentrations per Unit Volume of Water for the Fresh-Water Discharge of $681 \mathrm{~m}^{3} / \mathrm{sec}$. . . . . . . . .

84 Longitudinal Distributions of Total, Dissolved and Particulate Kepone Concentrations at Maximum Ebb Tide for the Fresh-Water

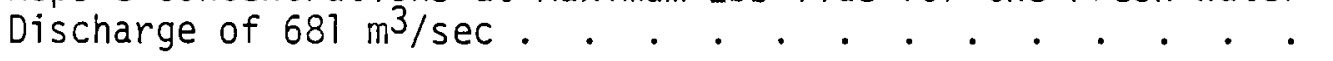

85 Longitudinal Distributions of Total, Dissolved and Particulate Kepone Concentrations at Slack Tide for the Fresh-Water

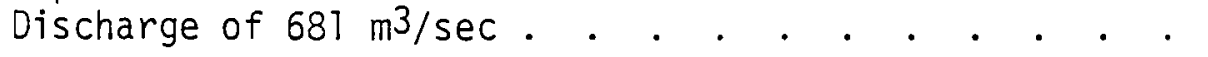

86 Longitudinal Distributions of Total, Dissolved and Particulate Kepone Concentrations at Maximum Flood Tide for the Fresh-

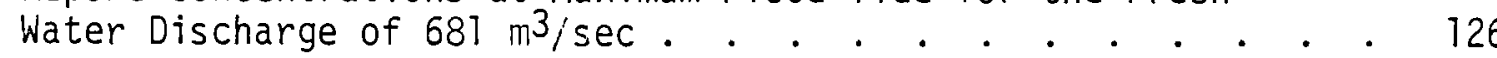

87 Longitudinal Distributions of Tidal Averaged Total, Dissolved and Particulate Kepone Concentrations for the Fresh-Water Discharge of $681 \mathrm{~m} 3 / \mathrm{sec}$. . . . . . . . . . . . .

88 Variation of River Bed Elevation Changes Due to Sediment Deposition and/or Bed Scouring at Maximum Ebb Tide for the Fresh-Water Discharge of $681 \mathrm{~m}^{3} / \mathrm{sec}$. . . . . . . . .

89 Change in Bed Surface Kepone Concentration That Occurred During 1-Month Simulation for the Fresh-Water Discharge of $681 \mathrm{~m}^{3} / \mathrm{sec}$

90 Changes in Total Kepone Concentrations Due to Partial Kepone Cleanup Activities . . . . . . . . . . . . . 130

91 Changes in Dissolved Kepone Concentrations Due to Partial Kepone Cleanup Activities . . . . . . . . . . .

92 Changes in Particulate Kepone Concentrations Due to Partial Kepone Cleanup Activities 


\section{LIST OF TABLES}

1 Test Conditions for Kepone Simulation . . . . . . . . . . 25 .

2 Summary of Simulation Results on Kepone Migration From Burwel1 Bay Seaward for a11 Four Cases. . . . . . . . . . 41

3 Summary of Sensitivity Analysis--Kepone Migration From Burwe11 Bay Seaward . . . . . . . . . . . . . . . . 42 


\section{LIST OF SYMEOLS}

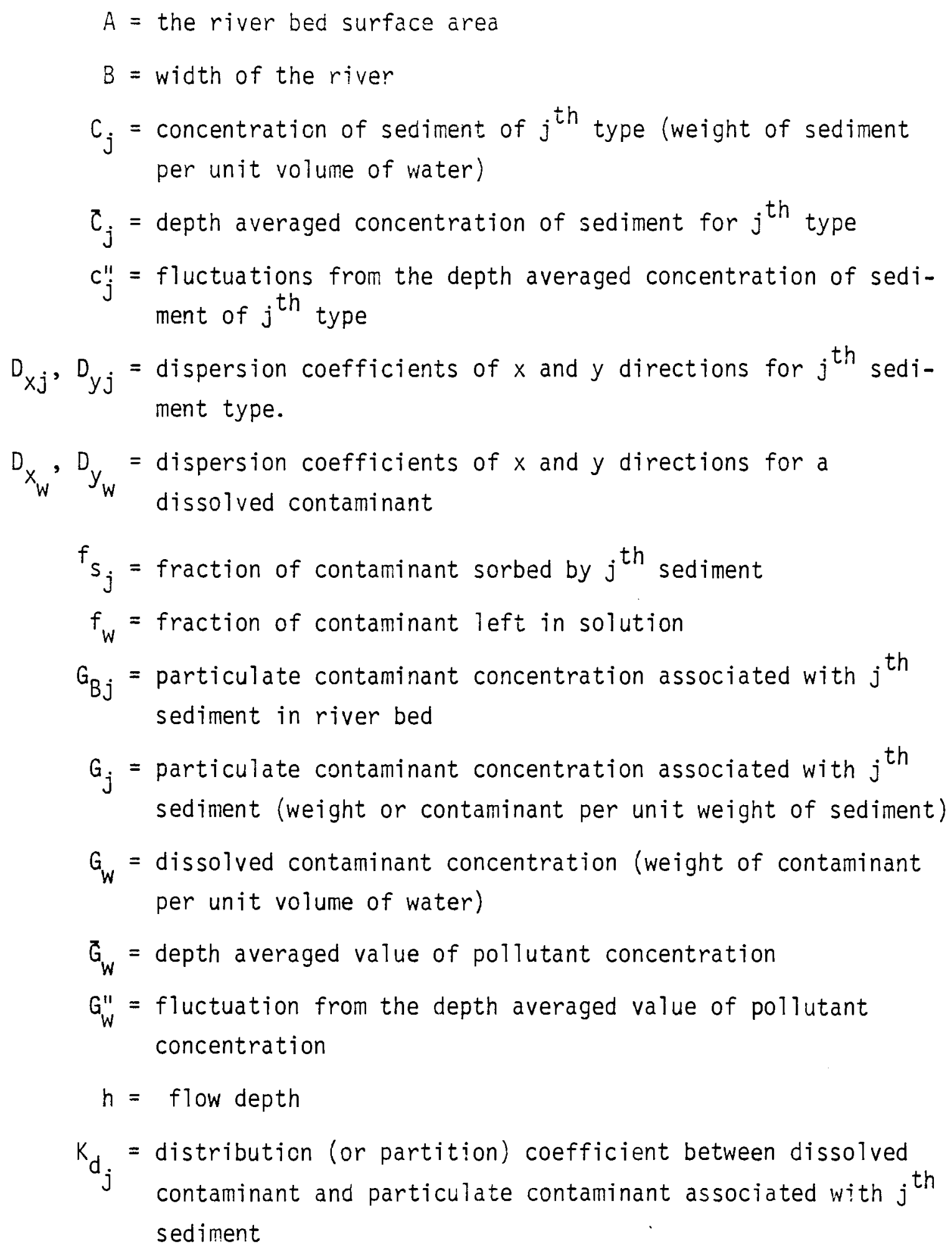




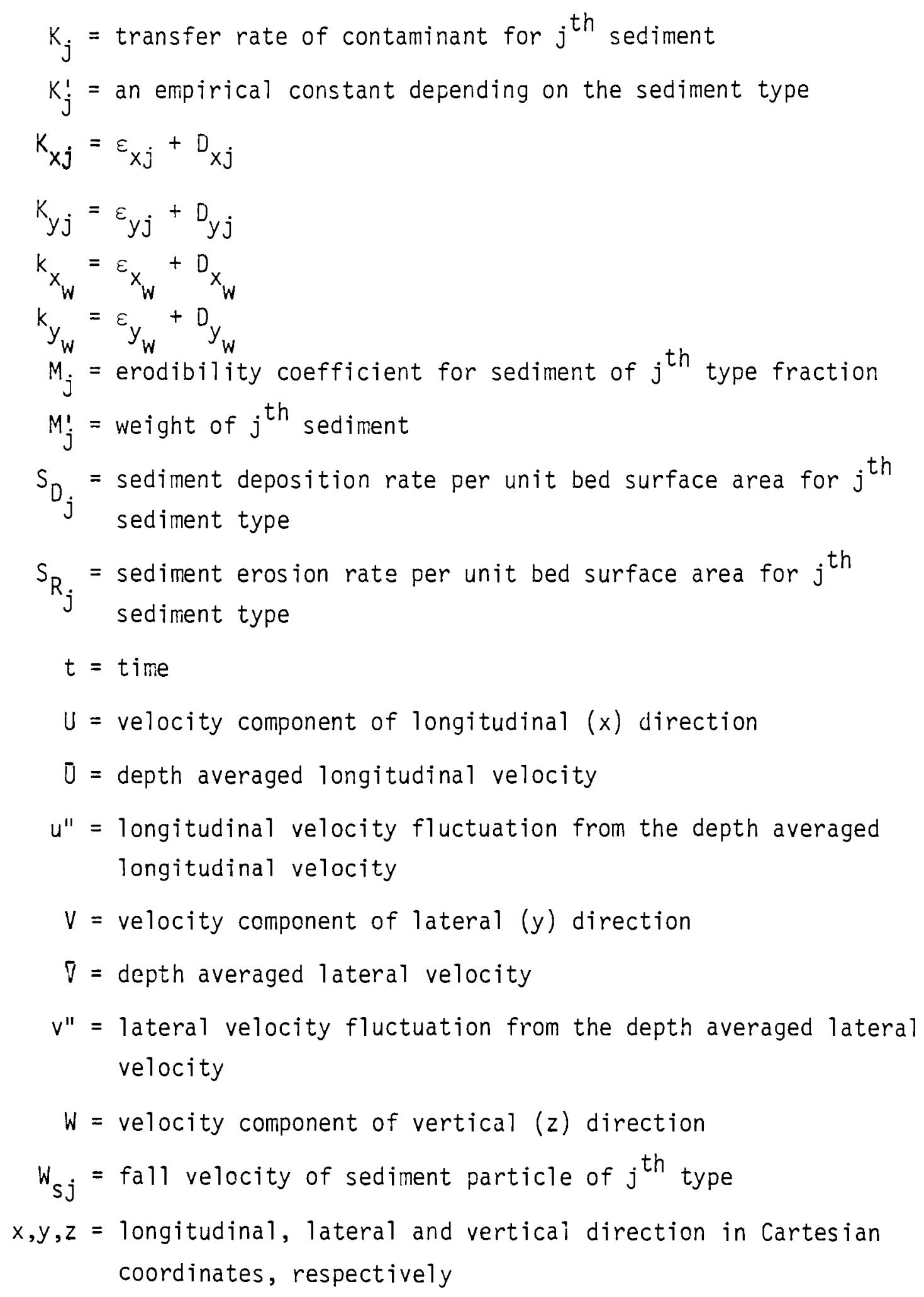




$$
\begin{aligned}
y= & \text { coefficient, } i . e ., \text { probability that particle settling to } \\
& \text { the bed is deposited } \\
\varepsilon_{X j}, \varepsilon_{y j}, \varepsilon_{Z j}= & \text { diffusion coefficients of longitudinal, lateral and vertical } \\
& \text { directions for } j{ }^{\text {th }} \text { sediment type } \\
\varepsilon_{X W}, \varepsilon_{y W}, \varepsilon_{Z W}= & \text { longitudinal, lateral and vertical diffusion coefficients for } \\
& \text { dissolved contaminant } \\
\lambda= & \text { chemical and biological decay rate of contaminant } \\
\tau_{b}= & \text { bed shear stress } \\
\tau_{C D j}= & \text { critical shear stress for sediment deposition for } j \text { th sediment } \\
& \text { type fraction } \\
\tau_{C R j}= & \text { critical shear stress for sediment erosion for } j \text { th sediment } \\
& \text { type fraction. }
\end{aligned}
$$




\section{INTRODUCTION}

During the period of 1966-1975, a highly chlorinated organic pesticide, Kepone, was discharged to the environment around Hopewell, Virginia, from production activities at the Allied Chemical Semi-Works Plant and the Life Science Products Company Plant (Dawson, 1978). Kepone released into the James River estuarine system has been dispersed by turbulent mixing, river inflow and tidal flow. Much of the kepone has been adsorbed by river sediments (both organic and inorganic materials); thus, otherwise dilute Kepone is concentrated (EPA, 1976; Smith, 1976; Dawson, 1978). This process may create a significant pathway to man. For example, contaminated sediments may be deposited onto the river bed. Contaminated bed sediments in turn may become a long-term source of pollution through deposition and resuspension. In contrast, sorption by sediment can be an important mechanism for reducing the area of influence of the pesticide by reducing concentration of dissolved Kepone.

Mathematical modeling of Kepone transport including sediment-Kepone interaction was conducted as a part of Kepone Mitigation Feasibility Study (Dawson, 1978). Several model concepts were evaluated for use in this modeling study. However, as revealed by a recent workshop on the evaluation of mathematical models (Oak Ridge National Laboratory, 1978) there are only two computer models presently available to calculate migration of contaminants by accounting for the interaction between the contaminants and sediment (e.g., contaminant adsorption by sediment or desorption from sediment, transport, deposition and resuspension of contaminated sediment). The two are the FETRA and SERATRA codes (Onishi et a1., 1976; Onishi, 1977a, 1977b). Both models are time-dependent, two-dimensional transport models which calculate the migration of sediment and dissolved and particulate pollutants by including the interaction between sediment and pollutants. The FETRA model solves longitudinal and lateral distributions of these substances, while SERATRA predicts longitudinal and vertical concentrations. Although the SERATRA code was judged to be a verified model by participants of the mathematical model 
evaluation workshop (Oak Ridge National Laboratory, 1978), the FETRA code was selected for this study, because of the importance of lateral distribution of Kepone as well as the longitudinal distributions of Kepone in the river.

Hence, the mathematical simulation of Kepone migration in the tidal James River was conducted by applying the finite element, sediment and contaminant transport model, FETRA (Onishi et a1., 1976; Onishi and Ecker, 1977; Onishi and Wise, 1978), to the river between Bailey and Burwell Bays. Both time-dependent, one-dimensional (longitudinal) simulation and time-dependent, two-dimensional (longitudinal and lateral) simulation were attempted. However, due to the time limitation, only computer results obtained by onedimensional transport simulation through application of the two-dimensional FETRA code and the one-dimensional hydrodynamic model, EXPLORE (Baca et al., 1973) are reported here. Model computations were conducted to predict the migration of sediments and Kepone by including sediment-Kepone interactions in the James River.

Transport of sediment and particulate Kepone (Kepone adsorbed by sediment) was simulated separately for each sediment type. The modeling procedure for FETRA involved simulating the transport of sediments (organic and inorganic materials) within the water body. The results were then used to simulate dissolved and particulate contaminants and sediment interacting. Changes in river bed conditions were calculated including: 1) river bottom elevation change, 2) distributions of ratio of each bed sediment component in the bed, and 3 ) distribution of contaminants in the river bed. 


\section{MATHEMATICAL MODEL FOFMULATION OF TRANSPORT MODEL, FETRA}

The FETRA code consists of the following three submodels: 1) a sediment transport modei, 2) a dissolved contaminant transport model, and 3) a particulate contaminant transport modei.

\subsection{SEDIMENT TRANSPORT MODEL}

Transport of cohesive sediment (silt and clay), noncohesive sediment (sand), and organic material (that being transported independentiy with sand, silt and clay) are modeled separately since movements of sediments and adsorption capacity vary significantly. The model includes the effects of:

1. convection and dispersion of materials

2. fall velocity and cohesiveness

3. deposition on the river bed

4. resuspension from the river bed (bed erosion and armoring)

5. tributaries

Sediment minerology and water quality effects are implicitly included through the above mentioned effects 2,3 and 4 .

Governing Equations--

The governing equation of sediment transport for the three-dimensional case is:

$$
\begin{aligned}
& \left.\frac{\partial C_{j}}{\partial t}+\frac{\partial}{\partial x}\left(U C_{j}\right)+\frac{\partial}{\partial y}\left(V C_{j}\right)+\frac{\partial}{\partial z} \mid\left(W-W_{S j}\right) C_{j}\right\} \\
= & \frac{\partial}{\partial x}\left(\varepsilon_{x j} \frac{\partial C}{\partial x}\right)+\frac{\partial}{\partial y}\left(\varepsilon_{y_{j}} \frac{\partial C}{\partial y}\right)+\frac{\partial}{\partial z}\left(\varepsilon_{z_{j}} \frac{\partial C_{j}}{\partial z}\right)
\end{aligned}
$$

where

$$
\begin{aligned}
C_{j}= & \text { concentration of sediment of } j^{\text {th }} \text { type (weight of sediment per } \\
& \text { unit volume of water) } \\
t= & \text { time } \\
U= & \text { velocity component of longitudinal }(x) \text { direction }
\end{aligned}
$$




$$
\begin{aligned}
V & =\text { velocity component of lateral }(y) \text { direction } \\
W= & \text { velocity component of vertical }(z) \text { direction } \\
W_{s j}= & f a l l \text { velocity of sediment particle of } j \text { th type } \\
x, y, z= & \text { longitudinal, lateral and vertical direction in Cartesian } \\
& \text { coordinates, respectively } \\
\varepsilon_{x j}, \varepsilon_{y j}, \varepsilon_{z j}= & \text { diffusion coefficients of longitudinal, lateral and vertical } \\
& \text { directions for } j \text { th sediment type. }
\end{aligned}
$$

Boundary conditions are:

$$
\begin{array}{ll}
\left(W-W_{S j}\right) C_{j}-\varepsilon_{z j} \frac{\partial C}{\partial z}=0 & \text { at } z=h \\
(1-\gamma) W_{S j} C_{j}+\varepsilon_{z j} \frac{\partial C}{\partial z} j=S_{D_{j}}-S_{R_{j}} & \text { at } z=0 \\
\frac{\partial C}{\partial y} j=0 & \text { at } y=0 \text { and } B
\end{array}
$$

where

$$
\begin{aligned}
B= & \text { width of the river } \\
h= & \text { flow depth } \\
S_{D j}= & \text { sediment deposition rate per unit bed surface area for } j^{\text {th }} \text { sediment } \\
& \text { type } \\
S_{R j}= & \text { sediment erosion rate per unit bed surface area for } j{ }^{\text {th }} \text { sediment } \\
& \text { type } \\
\gamma= & \text { coefficient, } i . e ., \text { probability that particle settling to the bed is } \\
& \text { deposited. }
\end{aligned}
$$

In this study, $\gamma$ was assumed to be unity, that is, for the same flow condition all suspended matter settling on the river bed stays on the river bed without returning to the flow. It is also assumed that the vertical flow velocity, $W$, is negligible.

Let

$$
c_{j}=\bar{C}_{j}+c_{j}^{\prime \prime}
$$




$$
\begin{aligned}
U & =\bar{u}+u^{\prime \prime} \\
v & =\bar{v}+v^{\prime \prime} \\
\frac{\partial c_{j}^{\prime \prime}}{\partial x} & =\frac{\partial c_{j}^{\prime \prime}}{\partial y}=\frac{\partial W_{S j}}{\partial z}=0
\end{aligned}
$$

where

$\bar{C}_{j}, \bar{U}, \bar{V}=$ depth averaged values of concentration of sediment for $j$ th type, longitudinal velocity, and lateral velocity, respectively

$c_{j}^{\prime \prime}, u^{\prime \prime}, v^{\prime \prime}=$ fluctuations from the depth averaged values of concentration of sediment of $j^{\text {th }}$ type, longitudinal velocity, and lateral velocity, respectively.

By substituting the above expressions into Equation (1) and integrating it over the entire river depth, this equation becomes:

$$
\begin{aligned}
& \bar{c}_{j}\left\{\frac{\partial h}{\partial t}+\frac{\partial}{\partial x}(\overline{C h})+\frac{\partial}{\partial y}(\nabla h)\right\}-\left(\bar{c}_{j}+c_{j}^{\prime \prime}\right) \mid{ }_{z}\left\{\frac{\partial h}{\partial t}+\left(\bar{U}+u^{\prime \prime}\right) \mid z=h^{\frac{\partial h}{\partial x}}\right. \\
& \left.+\left(\bar{v}+v^{\prime \prime}\right) \mid \frac{\partial h}{z}\right\}+\left\{w_{s j}\left(\bar{c}_{j}+c_{j}^{\prime \prime}\right)\left|=h+\varepsilon_{z} \frac{\partial\left(\bar{c}_{j}+c_{j}^{\prime \prime}\right)}{\partial z}\right|_{z}=h\right\} \\
& =-h\left(\frac{\partial \bar{C}}{\partial t} j+\overline{0} \frac{\partial \bar{C}}{\partial y} j+\nabla \frac{\partial \bar{C}}{\partial y} j\right)+h \frac{\partial}{\partial x}\left(\varepsilon_{x_{j}} \frac{\partial \bar{C}}{\partial x} j\right)+h \frac{\partial}{\partial y}\left(\varepsilon_{y_{j}} \frac{\partial \bar{C}}{\partial y} j\right) \\
& -\frac{\partial}{\partial x} \int_{0}^{h} u^{\prime \prime} c_{j}{ }^{\prime \prime} d z-\frac{\partial}{\partial y} \int_{0}^{h} v^{\prime \prime} c_{j} " d z-\left\{w_{s_{j}}\left(\bar{c}_{j}+c_{j}^{\prime \prime}\right) ! z=0\right. \\
& \left.+\varepsilon_{z_{j}} \frac{\partial\left(\bar{c}_{j}+c_{j}^{\prime \prime}\right)}{\partial z \quad} \mid=0\right\}
\end{aligned}
$$

The equation of continuity, the kinetic water surface boundary condition and Equation (2) make the left side of Equation (9) zero. As in the Boussinesq diffusion coefficient concept, let:

$$
\int_{0}^{h} u^{\prime \prime} c_{j}{ }^{\prime \prime} d z=\left(\overline{u^{\prime \prime} c_{j}{ }^{\prime \prime}}\right) h=-h D_{x_{j}} \frac{\partial \bar{C}_{j}}{\partial x}
$$

and 


$$
\int_{0}^{h} v^{\prime \prime} c_{j}{ }^{\prime \prime} d z=\left(\overline{v^{\prime \prime} c_{j}}\right) h=-h D_{y_{j}} \frac{\partial \bar{C}}{\partial y}
$$

where $D_{x j}$ and $D_{y j}$ equal the dispersion coefficients of $x$ and $y$ directions for $j^{\text {th }}$ sediment type. Hence Equations (2), (3), (9), (10), and (11) yield the following final expression of sediment transport:

$$
\begin{aligned}
\frac{\partial \bar{C}}{\partial t} j & +\left(\bar{U}-\frac{D_{x j}}{h} \frac{\partial h}{\partial x}\right) \frac{\partial \bar{C}_{j}}{\partial x}+\left(\bar{V}-\frac{D_{y_{j}}}{h} \frac{\partial h}{\partial y}\right) \frac{\partial \bar{C}_{j}}{\partial y} \\
& =\frac{\partial}{\partial x}\left(K_{x_{j}} \frac{\partial \bar{C}}{\partial x}\right)+\frac{\partial}{\partial y}\left(K_{y_{j}} \frac{\partial \bar{C}}{\partial y}\right)+\frac{S_{R_{j}}}{h}-\frac{S_{D_{j}}}{h}
\end{aligned}
$$

where

$$
\begin{aligned}
& K_{x_{j}}=\varepsilon_{x_{j}}+D_{x_{j}} \\
& K_{y_{j}}=\varepsilon_{y_{j}}+D_{y_{j}}
\end{aligned}
$$

The finite element method was used to solve Equations (4) and (12). Erosion and Deposition of Noncohesive Sediments (Sand)--

Erosion and deposition of noncohesive sediments are affected by the amount of sediment the flow is capable of carrying. For example, if the amount of sand being transported is less than the flow can carry for given hydrodynamic conditions, the river will scour sediment from the stream bed to increase the sediment transport rate. This occurs until the actual sediment transport rate becomes equal to the carrying capacity of the flow or until the available bed sediments are all scoured, whichever occurs first. Conversely, the river deposits sand if its actual sediment transport rate is above the flow's capacity to carry sediment. DuBoy's formula is used to estimate the flow capacity, $\eta_{S}$, which is then compared with the actual amount of sand, $Q_{S a}$, being transported in the river water. Hence:

$$
\begin{gathered}
S_{R_{j}}=\frac{Q_{S}-Q_{s a}}{A} \\
S_{D_{j}}=\frac{Q_{S a}-Q_{S}}{A}
\end{gathered}
$$


where

$A=$ the river bed surface area

Erosion and Deposition of Cohesive Sediments (Silt and Clay)--

Sediment erosion and deposition rates, $S_{R_{j}}$ and $S_{D_{j}}$, are also evaluated separately for each sediment size fraction because erosion and deposition characteristics are significantly different for cohesive and noncohesive sediments. Since only Partheniades (1962) and Krone (1962) formulas for erosion and deposition rates, respectively, are presently available, these formulas were adopted in this study:

$$
\begin{aligned}
& S_{R_{j}}=M_{j}\left(\frac{\tau_{b}}{\tau_{C R_{j}}}-1\right) \\
& S_{D_{j}}=2 W_{S j} C_{j}\left(1-\frac{{ }^{{ }_{b}}}{\tau_{C D_{j}}}\right)
\end{aligned}
$$

where

$M_{j}=$ erodibility coefficient for sediment of $j^{\text {th }}$ type fraction

$\tau_{b}=$ bed shear stress

$\begin{aligned} \tau_{C D_{j}}= & \text { critical shear stress for sediment deposition for } j{ }^{\text {th }} \text { sediment type } \\ & \text { fraction }\end{aligned}$

$\begin{aligned} \tau_{C R_{j}}= & \text { critical shear stress for sediment erosion for } j{ }^{\text {th }} \text { sediment type } \\ & \text { fraction. }\end{aligned}$

Values of $M_{j}, \tau C D_{j}$ and $\tau C R_{j}$ must be determined by field and/or laboratory tests for a particular river regime. These values for the Columbia River (Washington) and the $\mathrm{Cl}$ inch River (Tennessee) were reported in recent mathematical simulation studies concerning sediment and radionuclide transport in these two rivers (Onishi, 1977a; Onishi, 1977b). The availability of bed sediments to be resuspended was also examined to determine the actual amount of sediment erosion. 
When the fall velocity, $w_{s j}$, depends on sediment concentration and no aggregation occurs, the fall velocity may be assumed (Krone, 1962):

$$
w_{s j}=K_{j}^{\prime} C_{j}^{4 / 3}
$$

where

$K_{j}^{\prime}=$ an empirical constant depending on the sediment type.

Erosion and Deposition of Organic Materials--

Recent studies (Shupe and Dawson, 1977; Huggett et a1., 1977) revealed that the Kepone is not only adsorbed by inorganic suspended sediment (mainly cohesive sediments) but also adsorbed by organic matter. Unfortunately, there have not been enough studies on transport characteristics of organic materials. Since the mechanics of erosion and deposition of organic matter are somewhat similar to those of cohesive fine sediment, Equations (15) and (16) were utilized for this case. The selection of the values of $W_{s j}, M_{j}, \tau_{C D_{j}}$ and $\tau_{C R j}$ should reflect the characteristics of these materials, e.g., density, size, cohesiveness, compatibility, etc.

\subsection{DISSOLVED CONTAMINANT TRANSPORT MODEL}

In tris study, it was assumed that the association of a dissolved contaminant (such as dissolved Kepone) with suspended sediments (both organic and inorganic matter) is the primary mechanism of Kepone uptake. The model includes the effects of:

1. convection and dispersion of dissolved contaminant within the river

2. adsorption (uptake) of dissolved contaminant by sediments (cohesive and noncohesive inorganic sediments and organic matter) or desorption from the sediments into water

3. chemical and biological decay of contaminant

4. tributaries. (Contaminant contributions from wastewater discharges, overland runoff flow, fallout and ground water to a river system may be treated as a part of tributary contributions.) 
Effects of water quality (․g., pH, water temperature, salinity, etc.) and sediment characteristics, (e.g., clay minerals), are taken into account through changes in the distribution (or partition) coefficient, $K_{d_{j}}$.

The governing equation of dissolved Kepone transport for the threedimensional case is:

$$
\begin{aligned}
\frac{\partial G_{W}}{\partial t} & +\frac{\partial}{\partial x}\left(U G_{w}\right)+\frac{\partial}{\partial y}\left(V G_{W}\right)+\frac{\partial}{\partial z}\left(W G_{w}\right) \\
& =\frac{\partial}{\partial x}\left(\varepsilon_{x_{W}} \frac{\partial G_{W}}{\partial x}\right)+\frac{\partial}{\partial y}\left(\varepsilon_{y_{W}} \frac{\partial G_{W}}{\partial y}\right)+\frac{\partial}{\partial z}\left(\varepsilon_{z_{W}} \frac{\partial G_{W}}{\partial z}\right) \\
& -\lambda G_{W}-\sum_{j} K_{j}\left(K_{d_{j}} C_{j} G_{W}-C_{j} G_{j}\right)
\end{aligned}
$$

In addition to the previously defined symbols:

$$
\begin{aligned}
\mathrm{K}_{\mathrm{d}_{j}}= & \text { distribution (or partition) coefficient between dissolved } \\
& \text { contaminant and particulate contaminant associated with } j \\
& \text { sediment } \\
\mathrm{K}_{\mathrm{j}}= & \text { transfer rate of contaminant for } j^{\text {th }} \text { sediment } \\
\mathrm{G}_{\mathrm{j}}= & \text { particulate contaminant concentration associated with } j \\
& \text { sediment (weight or contaminant per unit weight of sediment) } \\
\mathrm{G}_{\mathrm{w}}= & \text { dissolved contaminant concentration (weight of contaminant per } \\
& \text { unit volume of water) } \\
= & \text { longitudinal, lateral and vertical diffusion coefficients for } \\
& \text { dissolved contaminant } \\
\varepsilon_{\mathrm{x}_{\mathrm{W}}, \varepsilon_{\mathrm{y}_{\mathrm{W}}}, \varepsilon_{\mathrm{z}_{\mathrm{W}}}} & \text { chemical and biological decay rate of contaminant (nil for } \\
& \text { Kepone) }
\end{aligned}
$$


Distribution coefficient, $K_{d_{j}}$, is defined by:

$$
K_{d_{j}}=\frac{f_{s j} / M_{j}^{\prime}}{f_{w} / V_{w}}=\frac{f_{s j}}{f_{w} C_{j}}
$$

where

$$
\begin{aligned}
& f_{S_{j}}=\text { fraction of contaminant sorbed by } j^{\text {th }} \text { sediment } \\
& f_{w}=\text { fraction of contaminant left in solution } \\
& M_{j}=\text { weight of } j \text { th sediment } \\
& V_{w}=\text { volume of water } \\
& \frac{f_{s_{j}}}{f_{w}}=\frac{C_{j} G_{j}}{G_{W}}
\end{aligned}
$$

Hence Equation (19) may be rewritten as:

$$
G_{j}=K_{d_{j}} G_{W}
$$

The adsorption of contaminant by sediments or desorption from the sediments is assumed to occur toward an equilibrium condition with the mass transfer rate, $K_{j}$, if the particulate contaminant concentration differs from its equilibrium values as expressed in Equation (20).

The boundary conditions for dissolved pollutant transport are:

$$
\begin{aligned}
W G_{W}-\varepsilon_{Z_{W}} \frac{\partial G_{W}}{\partial z} & =0 & & \text { at } z=h \\
\frac{\partial G_{W}}{\partial z} & =0 & & \text { at } z=0 \\
\frac{\partial G_{W}}{\partial y} & =0 & & \text { at } y=0 \text { and } B
\end{aligned}
$$

Let:

$$
\begin{aligned}
& G_{W}=G_{W}+G_{W}^{\prime \prime} \\
& \frac{\partial G_{W}^{\prime \prime}}{\partial x}=\frac{\partial G_{W}^{\prime \prime}}{\partial y}=0
\end{aligned}
$$


where

$\bar{G}_{W}=$ depth averaged value of pollutant concentration

$G_{W}^{\prime \prime}=$ fluctuation from the depth averaged value of pollutant concentration

By substituting the above expressions, together with those in Equations (5) through (8), into Equation (18) and integrating it over the entire river depth, Equation (18) becomes:

$$
\begin{aligned}
& \bar{G}_{w}\left\{\frac{\partial h}{\partial t}+\frac{\partial}{\partial x}(0 h)+\frac{\partial}{\partial y}(\nabla h)\right\}-\left(\bar{G}_{w}+G_{w}^{\prime \prime}\right) \mid{ }_{z}=h\left(\frac{\partial h}{\partial t}+\left.\left(\bar{U}+u^{\prime \prime}\right)\right|_{z=h} \frac{\partial h}{\partial x}\right.
\end{aligned}
$$

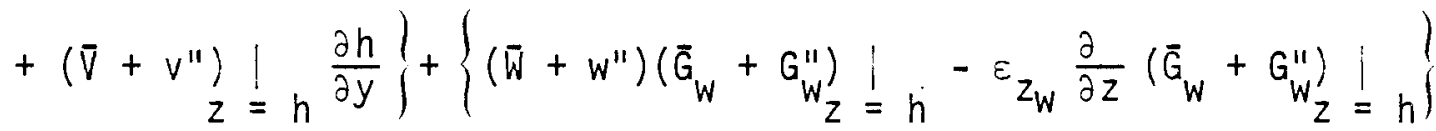

$$
\begin{aligned}
& +\varepsilon_{z_{W}} \frac{\partial}{\partial z}\left(G_{W}+G_{W}^{\prime \prime}\right) \underset{z=0}{\mid} \\
& =-h\left(\frac{\partial \bar{G}_{w}}{\partial t}+\bar{U} \frac{\partial \bar{G}_{w}}{\partial x}+\nabla \frac{\partial \bar{G}_{w}}{\partial y}\right)+D_{x_{W}} \frac{\partial h}{\partial x} \frac{\partial \bar{G}_{w}}{\partial x}+D_{y_{W}} \frac{\partial h}{\partial y} \frac{\partial \bar{G}_{w}}{\partial y} \\
& +h \frac{\partial}{\partial x}\left\{\left(\varepsilon_{x_{W}}+D_{x_{W}}\right) \frac{\partial \bar{G}_{W}}{\partial x}\right\}+h \frac{\partial}{\partial y}\left\{\left(\varepsilon_{y_{W}}+D_{y_{W}}\right) \frac{\partial \bar{G}_{W}}{\partial y}\right\} \\
& -\lambda h \bar{G}_{W}-h \sum_{j} K_{j} \bar{c}_{j}\left(K_{d_{j}} \bar{G}_{W}-G_{j}\right)
\end{aligned}
$$

where $D_{x_{W}}$ and $D_{y_{W}}$ are dispersion coefficients of $x$ and $y$ directions defined by:

$$
\begin{aligned}
& \int_{0}^{h} u^{\prime \prime} G_{w}{ }^{\prime \prime} d z=-h D_{x_{W}} \frac{\partial G_{W}}{\partial x} \\
& \int_{0}^{h} V^{\prime \prime} G_{W}{ }^{\prime \prime} d z=-h D_{y_{W}} \frac{\partial G_{w}}{\partial y}
\end{aligned}
$$

The equation of continuity, the kinetic water surface boundary condition and boundary conditions shown in Equations (21) and (22) then make the left side of Equation (26) zero. Hence, the final transport equation of dissoived pollutant is: 


$$
\begin{aligned}
\frac{\partial \bar{G}_{W}}{\partial t} & +\left(\bar{U}-\frac{D_{X_{W}}}{h} \frac{\partial h}{\partial x}\right) \frac{\partial \bar{G}_{W}}{\partial x}+\left(\bar{V}-\frac{D_{y_{W}}}{h} \frac{\partial h}{\partial y}\right) \frac{\partial \bar{G}_{W}}{\partial y} \\
& =\frac{\partial}{\partial x}\left(k_{X_{W}} \frac{\partial \bar{G}_{W}}{\partial x}\right)+\frac{\partial}{\partial y}\left(k_{y_{W}} \frac{\partial \bar{G}_{W}}{\partial y}\right)-\left(\lambda+\sum_{j} k_{j} k_{d_{j}} \bar{C}_{j}\right) \bar{G}_{W} \\
& +\sum_{j} k_{j} \bar{C}_{j} G_{j}
\end{aligned}
$$

where

$$
\begin{aligned}
& k_{x_{W}}=\varepsilon_{x_{W}}+D_{x_{W}} \\
& k_{y_{W}}=\varepsilon_{y_{W}}+D_{y_{W}}
\end{aligned}
$$

The boundary conditions for this equation are those in Equation (23).

\subsection{PARTICULATE CONTAMINANT TRANSPORT MODEL}

The transport model of pollutants (such as Kepone in this study) attached to sediments is solved separately for those adsorbed by cohesive and noncohesive sediments, and organic material (that being transported independently with the inorganic-sediments). This model aiso includes the effects of:

1. convection and dispersion of particulate pollutant

2. adsorption (uptake) of dissolved pollutant by sediments or desorption from sediments into water

3. chemical and biological decay of pollutant

4. deposition of particulate pollutant on the river bed or resuspension from the river bed

5. tributaries. (Pollutant contributions from wastewater discharges, overland runoff flow, fallout and ground water to a river system may be treated as a part of the tributary contributions.)

As in the transport of sedimerits and dissolved pollutant, the threedimensional transport equation for contaminants adsorbed by the $j$ th sediment type (cohesive sediment, noncohesive sediment or organic materials) may be expressed as: 


$$
\begin{aligned}
\frac{\partial C_{j} G_{j}}{\partial t} & \left.+\frac{\partial}{\partial x}\left(U C_{j} G_{j}\right)+\frac{\partial}{\partial y}\left(V C_{j} G_{j}\right)+\frac{\partial}{\partial z}\left((i)-W_{S j}\right) C_{j} G_{j}\right)=\frac{\partial}{\partial x}\left(\varepsilon_{x_{j}} \frac{\partial C_{j} G_{j}}{\partial x}\right) \\
& +\frac{\partial}{\partial y}\left(\varepsilon_{y_{j}} \frac{\partial C_{j} G_{j}}{\partial y}\right)+\frac{\partial}{\partial z}\left(\varepsilon_{z j} \frac{\partial C_{j} G_{j}}{\partial z}\right)-\lambda C_{j} G_{j}-K_{j}\left(C_{j} G_{j}\right. \\
& \left.-K_{d_{j}} C_{j} G_{W}\right)
\end{aligned}
$$

where the Kepone concentration, $G_{j}$, is assumed to be independent of $z$ (Onishi, 1977a; Onishi, 1977b). All symbols in Equation (30) were previously defined. Noting Equations (2), (3), and (4), boundary conditions for this case become:

$$
\begin{array}{ll}
\left(W-W_{S j}\right) G_{j} G_{j}-\varepsilon_{z j} \frac{\partial C_{j} G_{j}}{\partial z}=G_{j}\left\{\left(W-W_{S j}\right) C_{j}-\varepsilon_{z j} \frac{\partial C_{j}}{\partial z}\right\}=0 & \text { at } z=h \\
(1-Y) W_{S_{j}} C_{j} G_{j}+\varepsilon_{z j} \frac{\partial C_{j} G_{j}}{\partial z}=G_{j} S_{D_{j}}-G_{B_{j}} S_{R_{j}} & \text { at } z=0 \\
\frac{\partial C_{j} G_{j}}{\partial y}=C_{j} \frac{\partial G_{j}}{\partial y}+G_{j} \frac{\partial C_{j}}{\partial y}=C_{j} \frac{\partial G_{j}}{\partial y}=0 & \text { Hence } \frac{\partial G_{j}}{\partial y}=0 \quad \text { at } y=0 \text { and } B
\end{array}
$$

where $G_{B j}$ is a particulate contaminant concentration associated with $j$ th sediment in river bed. Equation (34) is derived by $i)$ substituting Equations (5) through (8) into Equation (30), ii) integrating it over the river depth, iii) then subtracting Equation (9) multiplied by $G_{j}$ from the resulting equation, and iv) substituting the boundary conditions, Equations (31) and (32)

$$
\begin{aligned}
& \frac{\partial G_{j}}{\partial t}+\left\{\bar{U}-\frac{2 \varepsilon_{x_{j}}}{\bar{C}_{j}} \frac{\partial \bar{C}_{j}}{\partial x}-\frac{D_{x_{j}}}{\bar{C}_{j}} \frac{\partial \bar{C}_{j}}{\partial x}+\left.\frac{\varepsilon_{x_{j}}}{\bar{C}_{j} h} \frac{\partial h}{\partial x} \quad c_{j}^{\prime \prime}\right|_{z=h}\right\} \frac{\partial G_{j}}{\partial x} \\
& +\left\{\bar{V}-\frac{2 \varepsilon_{y_{j}}}{\bar{C}_{j}} \frac{\partial \bar{C}_{j}}{\partial y}-\frac{D_{y_{j}}}{\bar{C}_{j}} \frac{\partial \bar{C}_{j}}{\partial y}+\left.\frac{\varepsilon_{y}}{\bar{C}_{j} h} \frac{\partial h}{\partial y} \quad c_{j}^{\prime \prime}\right|_{z=h}\right\} \frac{\partial G_{j}}{\partial y} \\
& =\frac{\partial}{\partial x}\left(\varepsilon_{x_{j}} \frac{\partial G_{j}}{\partial x}\right)+\frac{\partial}{\partial y}\left(\varepsilon_{y_{j}} \frac{\partial G_{j}}{\partial y}\right)-\left(\frac{S_{R_{j}}}{\bar{C}_{j} h}+\lambda+K_{j}\right) G_{j} \\
& +\left(K_{j} K_{d} G_{w}+\frac{G_{B_{j}} S_{R_{j}}}{\bar{C}_{j} h}\right)
\end{aligned}
$$


Since the two terms containing $c^{\prime \prime}$ in the above equation are at least one order of magnitude smaller than the rest of the terms, these two-terms may be deleted. Hence, the final expression becomes:

$$
\begin{aligned}
& \frac{\partial G_{j}}{\partial t}+\left\{\overline{0}-\frac{2 \varepsilon_{x_{j}}}{\bar{C}_{j}} \frac{\partial \bar{C}_{j}}{\partial x}-\frac{D_{x_{j}}}{\bar{C}_{j}} \frac{\partial \bar{C}_{j}}{\partial x}\right\} \frac{\partial G_{j}}{\partial x}+\left|\bar{V}-\frac{2 \varepsilon_{y_{j}}}{\bar{C}_{j}} \frac{\partial \bar{C}_{j}}{\partial y}-\frac{D_{y_{j}}}{\bar{C}_{j}} \frac{\partial \bar{C}_{j}}{\partial y}\right| \frac{\partial G_{j}}{\partial y} \\
& =\frac{\partial}{\partial x}\left(\varepsilon_{x_{j}} \frac{\partial G_{j}}{\partial x}\right)+\frac{\partial}{\partial y}\left(\varepsilon_{y_{j}} \frac{\partial G_{j}}{\partial y}\right)-\left(\frac{S_{R_{j}}}{C_{j} h}+\lambda+K_{j}\right) G_{j} \\
& +\left(K_{j} K_{d} G_{w}+\frac{{ }_{B}{ }_{j}{ }^{S_{R}}}{\bar{c}_{j} h}\right)
\end{aligned}
$$

The boundary conditions for this case are those expressed in Equation (33).

\subsection{FINITE ELEMENT METHOD}

High-speed digital computers have enabled engineers to employ various numerical discretization techniques for approximating solutions to complex mathematical equations. The finite element method is one such technique (Desai, 1972) and has recently gained popularity for solving both linear and nonlinear partial differential equations. Because of its increased solution accuracy and ready accommodation to various boundary geometrics (e.g., Onishi, 1977a; Onishi, 1977b; Norton et a1., 1973; Brandstetter et a1., 1976) this method was used for this study. The finite element solution technique with the Galerkin weighted residual method is used to solve Equations (12), (29) and (35) with the boundary conditions of Equations (4), (23) and (33).

The flow domain is divided into a series of triangular elements interconnected at node points. Six nodes are associated with each triangle, three at the vertices called corner nodes and three on the mid-sides called mid-side nodes. A quadratic approximation is made for the sediment and contaminant concentrations within each element. Either linear or quadratic interpolation is used for the variation of flow depth and velocity within an element. For 
the present Kepore study, the Tinear approximation of depth and velocity was used. The computer program is written in FORTRAN IV language to implement the model for a CDC 7600 computer. A more detailed description of the FETRA code programming is discussed in Onishi et al. (1976).

The FETRA code, consisting of the above three models, then computer the following:

a) Sediment simulation for any given time,

- longitudinal and lateral distributions of total sediment (sum of suspended and bed load) concentration for each sediment type

- three-dimensional (longitudinal, lateral and vertical) distributions of ratio of different sediment type in the river bed

- change in river bed elevation (elevation changes due to sediment deposition and/or scour)

b) Contaminant simulation

for any given time,

- longitudinal and lateral distributions of dissolved contaminant concentration

- longitudinal and lateral distributions of contaminant concentration adsorbed by sediment for each sediment type

- longitudinal and lateral distribution of concentrations of total particulate contaminants associated with all types of sediment (sum of particulate contaminant concentration for each sediment type)

- three-dimensional distributions of contaminant concentrations in the river bed sediment for each sediment type

- three-dimensional distributions of total contaminant in the river bed 


\section{VERIFICATION OF BASIC COMPUTATIONAL SCHEME OF FETRA MODEL}

Prior to the application of the FETRA code to the present tidal James River study, the accuracy and convergence of the numerical solutions calculated by the finite element sediment and contaminant transport model, FETRA, had been evaluated to confirm the validity of the basic computational scheme of the model. This verification involved solving equations by the FETRA code and comparing the resulting numerical solutions with known analytical solutions to the problems.

Unfortunately, the general unsteady two-dimensional convection-diffusion equation with decay and source (or sink) terms [e.g., Equations (29) and (35)] does not have known analytical solutions. Therefore, some simplified special cases were used for the analysis. The following four cases were selected as test cases.

Case 1

In this case the following one-dimensional steady convection-diffusion equation with a source term was solved:

$$
U \frac{d C}{d x}=\varepsilon \frac{d^{2} C}{x_{d x^{2}}}+\beta
$$

with the boundary conditions of:

$$
\begin{aligned}
& C=C_{0} \quad \text { at } x=0 \\
& \frac{d C}{d x}=0 \quad \text { at } x=\ell
\end{aligned}
$$

An analytical solution to this problem is:

$$
C=C_{0}+\frac{\beta \varepsilon x}{U^{2}}\left\{\exp \left(-\frac{U l}{\varepsilon_{x}}\right)-\exp \left[-\frac{U}{\varepsilon_{x}}(l-x)\right]\right\}+\frac{\beta x}{U}
$$

Figure 1 shows computer results and the analytical solution, assuming:

$$
U=5.0 ; \varepsilon_{X}=0.2, \beta=2.0, C_{0}=1.0 \text { and } \ell=1.0
$$

An excellent agreement between these two solutions was obtained in this case. 


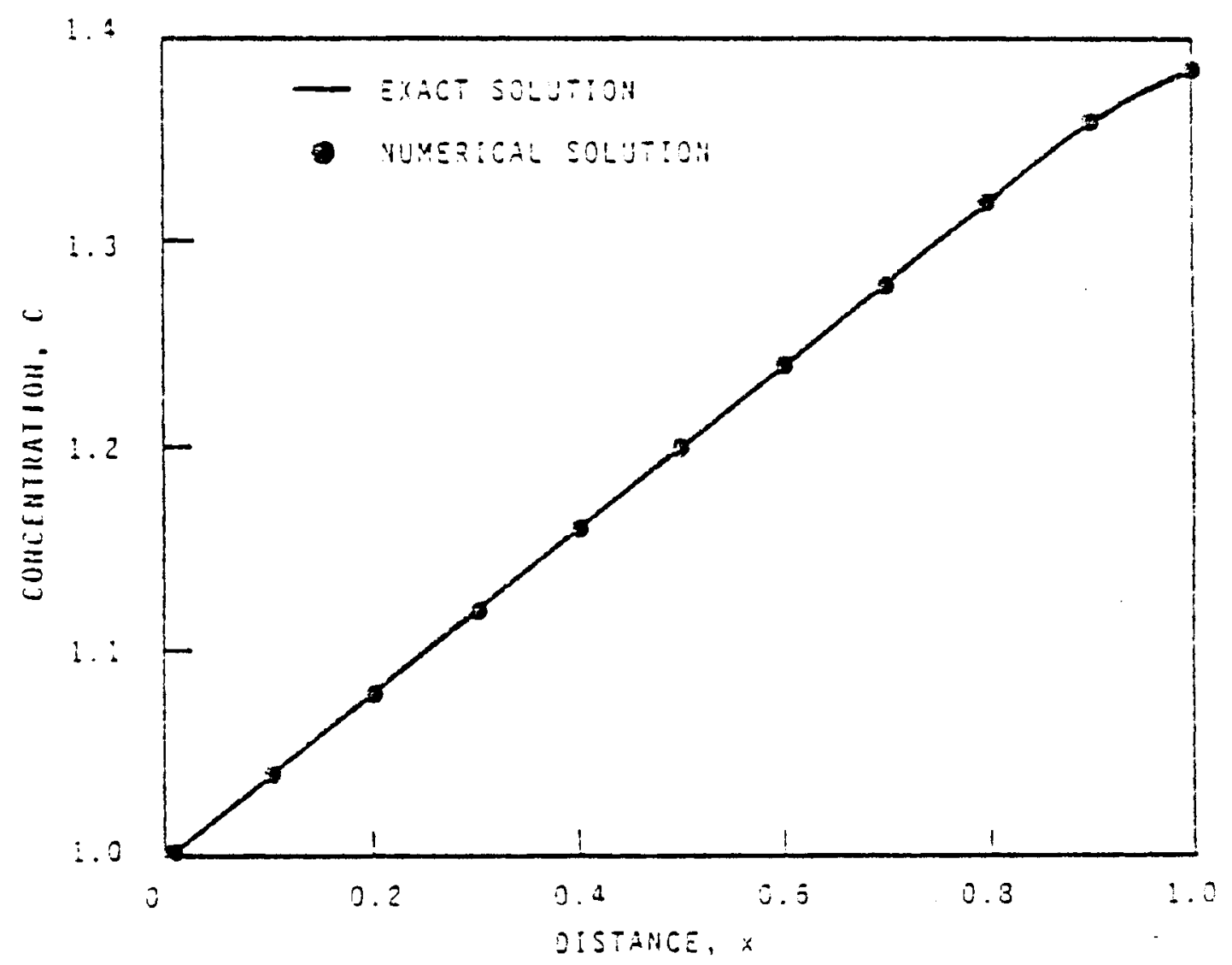

FIGURE 1. Comparison of Numerical Solution with Analytical Solution of One-Dimensional Steady ConvectionDiffusion Equation with a Source Term

\section{Case 2}

In this case, the following convection-diffusion equation with a decay term was solved with the same boundary conditions as Case 1.

$$
U \frac{d C}{d x}=\varepsilon_{x} \frac{d^{2} C}{d x^{2}}-a C
$$

With $U=5.0, \varepsilon_{x}=0.2, \alpha=10.0, C_{0}=1.0$ and $\ell=1.0$, an excellent agreement between these two solutions was obtained, as shown in Figure 2.

Case 3

In this case, convergence of a time-dependent, one-dimensional solution to a steady-state solution was tested. The governing equation was: 


$$
\frac{\partial C}{\partial t}=\varepsilon \frac{\partial^{2} C}{x \frac{x^{2}}{\partial}}-\alpha C
$$

with the following conditions:

$$
\begin{aligned}
& C=0 \text { in } 0 \leq x \leq l \quad \text { at } \quad t=0 \\
& c=c_{0} \text { at } x=0 \text { at } t>0 \\
& \frac{\partial C}{\partial t}=0 \text { at } x=l \quad \text { for all } t
\end{aligned}
$$

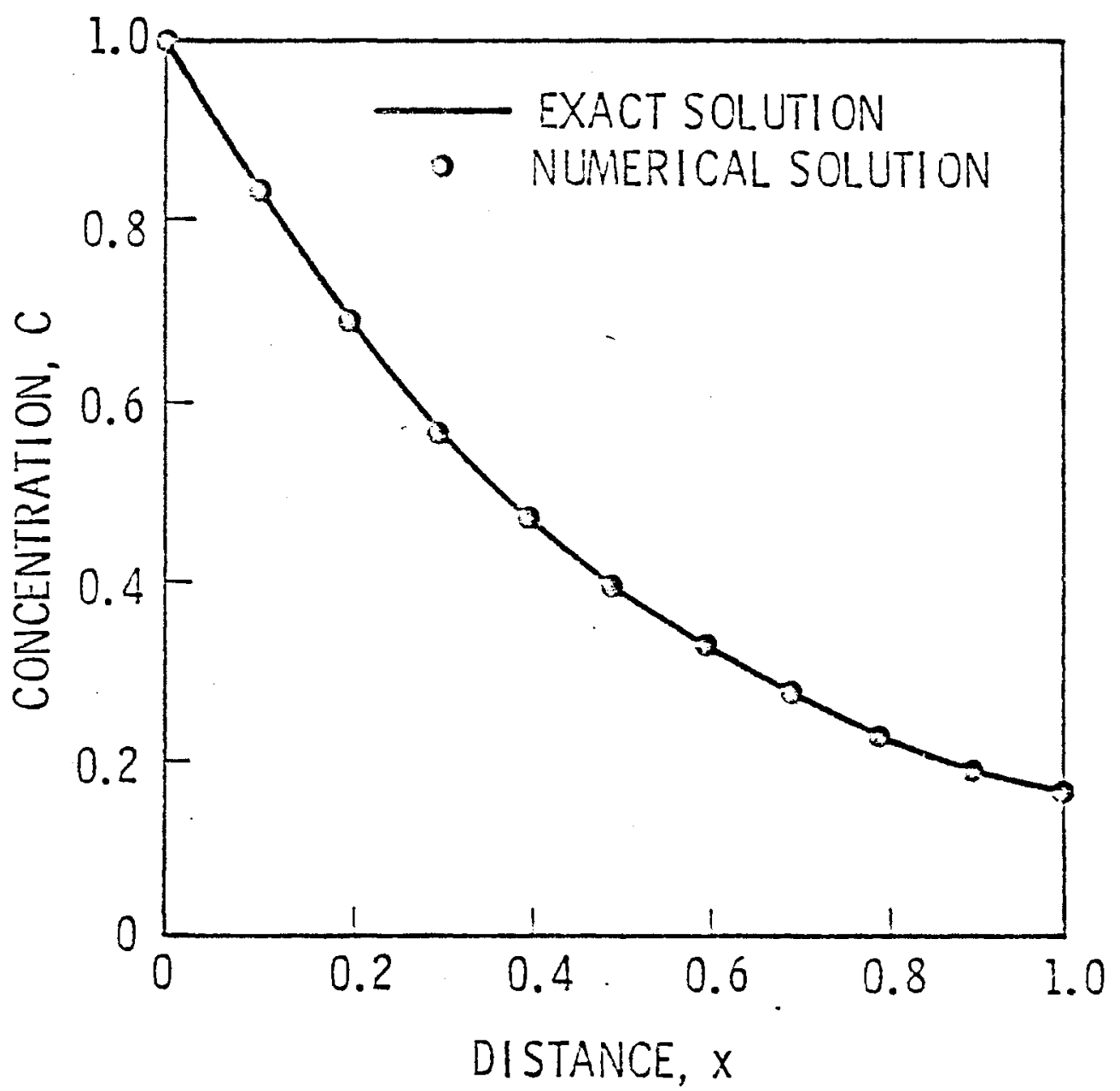

FIGURE 2. Comparison of Numerical Solution with Analytical Solution of One-Dimensional Steady ConvectionDiffusion Equation with a Decay Term 
Assuming $\varepsilon_{x}=0.2, \alpha=1.0, C_{0}=1.0$ and $2=1.0$, solutions are plotted in Figure 3, together with steady analytical and numerical solutions of the following equation:

$$
\varepsilon \frac{\partial^{2} c}{x_{\partial x^{2}}}-a c=0
$$

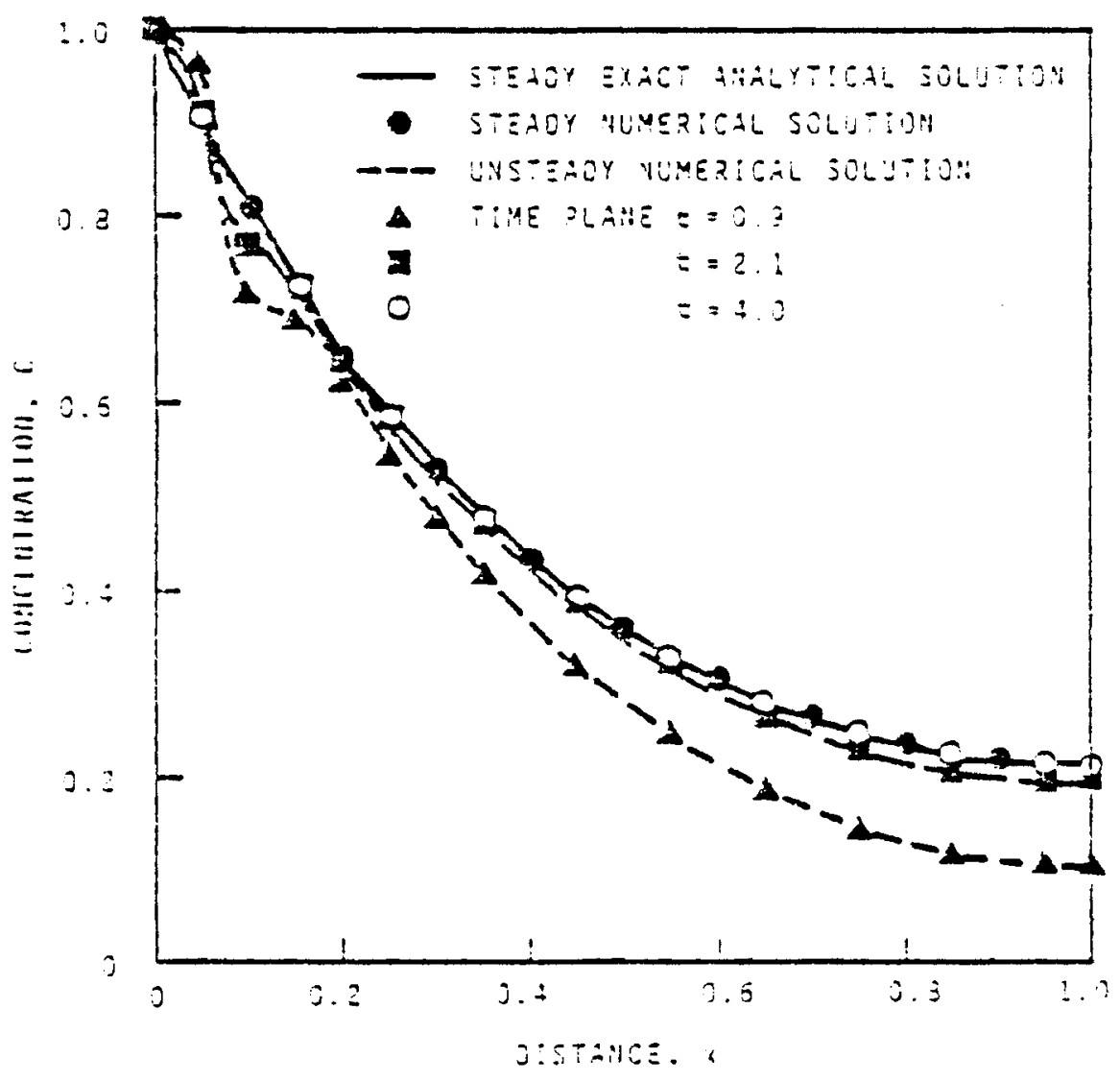

FIGURE 3. Convergence of Unsteady-State OneDimensional Diffusion Equation to Steady-State Solution

As shown in Figure 3 , there is convergence to the steady exact solution of Equation (41). For runs with time $t$ greater than 4.0 , the numerical solutions coincide with the analytical solution. The steady-state numerical solution also agrees well with the exact solution. 
Case 4

The following two-dimensionai equation was solved numerically and computed results were compared with an analytical solution:

$$
\varepsilon \frac{\partial^{2} c}{x} \frac{\hat{o}^{2} c}{\partial x^{2}}+\varepsilon \frac{y^{2}}{\partial y^{2}}=0
$$

with boundary conditions of:

$$
\begin{array}{lll}
C=0 & \text { at } & x=0 \\
c=0 & \text { at } & x=\ell \\
c=0 & \text { at } & y=0 \\
c=C_{0} \sin \left(\frac{\pi x}{l}\right) & \text { at } & y=\ell
\end{array}
$$

where $\varepsilon_{x}=\varepsilon_{y}=2=1.0$ and $C_{0}=10$. The analytical solution for this case is:

$$
C(x, y)=0.866 \sinh (\pi y) \sin (\pi x)
$$

The computer results and analytical solutions are shown in Figure 4. Numbers in the figure are values of concentration $C$. Since the solutions are symmetric with respect to $x=0.5$, computer results are given in the region of $0.5 \leq x \leq 1.0$, and analytical solutions are plotted in the region of $0 \leq x<0.5$. Comparison of these results reveals that there is an excellant agreement between the computed and analytical solutions.

As illustrated in Figures 1 through 4 the agreements of the model solutions and the exact solutions were excellent. These results confirm the validity of the basic numerical computation scheme of the transport model, FETRA. 


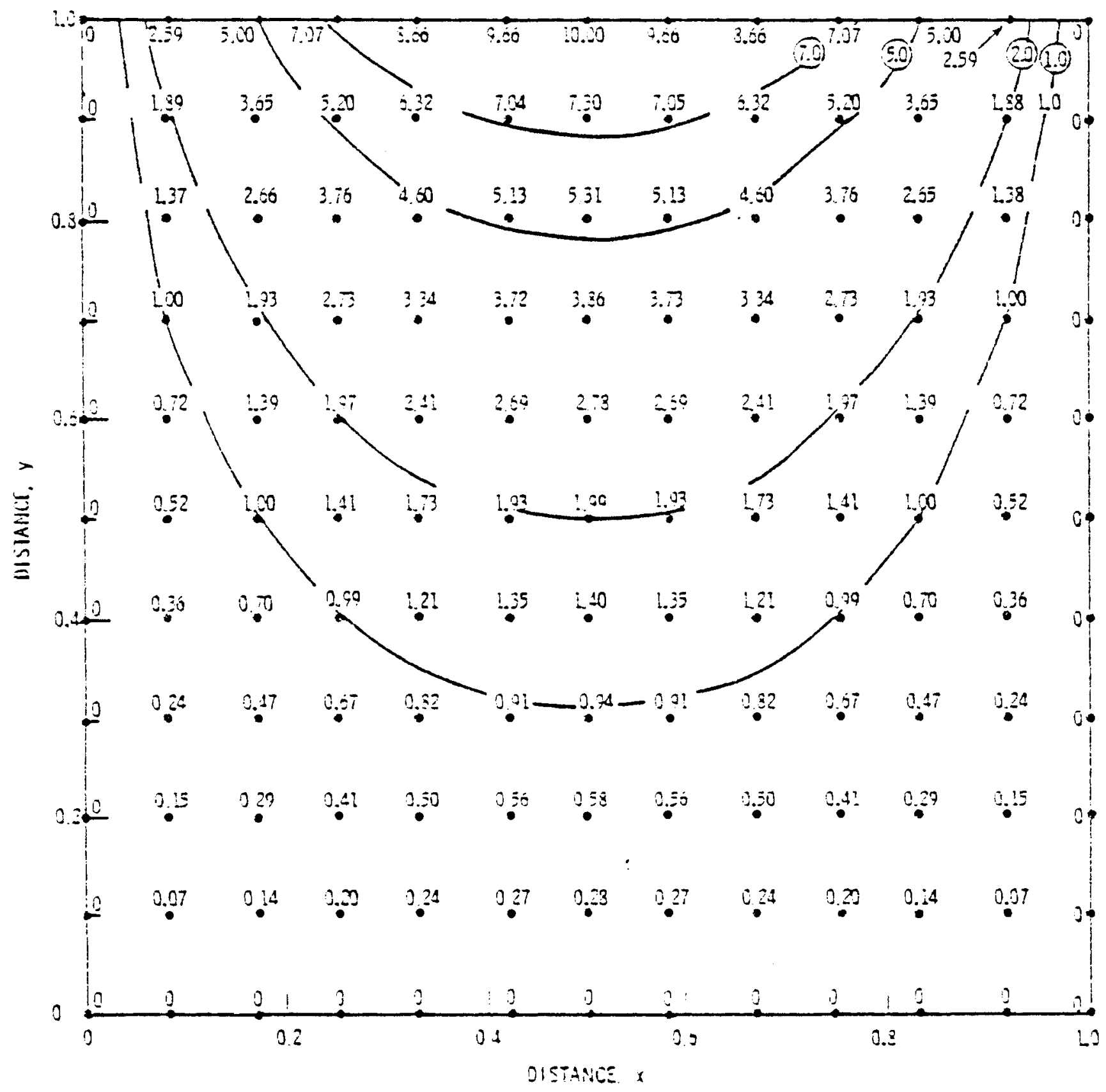

FIGURE 4. Comparison of Numerical Solution with Analytical Solution to Two-Dimensional Diffusion Equation 


\section{COMPUTER SIMULATION RESULTS}

The FETRA code was employed in combination with hydrodynamic models to calculate Kepone transport in the tidal James River.

As stated earlier, both one (longitudinal) and two (longitudinal and lateral) dimensional simulations have been attempted. However, due to the time availability, only the computer results obtained by one-dimensional simulation will be presented in this report. The one-dimensional EXPLORE code was used to obtain depth and velocity distributions in the study area. These were in turn fed to the time-dependent, two-dimensional sediment and pollutant transport code, FETRA, to obtain longitudinal distributions of sediment and Kepone in the tidal James River. Hence, the results presented here are crosssectionally averaged values changing with tidal flow.

The modeling procedure for FETRA involved simulating the transport of sediments (organic and inorganic materials). The results were then used to simulate dissolved and particulate kepone by taking into account interaction with sediments. Finally, changes in river bed conditions were recorded, including: 1) river bottom elevation change, 2) ratio of cohesive sediment, noncohesive sediment and organic material, and 3) distribution of Kepone in the river bed.

The model was applied to an $86-\mathrm{km}$ reach between City Point (River Kilometer 123) and Burwell Bay (River Kilometer 37), as shown in Figure 5. Mathematical simulation was not extended seaward beyond Burwell Bay because of limitations on the availability of field data necessary to run the hydrodynamic code, EXPLORE. Hence, as will be discussed later the prediction of Kepone levels leaving the James River and entering Chesapeake Bay may be somewhat conservative.

Three flow discharge cases were simulated here: 1) a net fresh-water input discharge of $\left.58.3 \mathrm{~m}^{3} / \mathrm{sec}(2,060 \mathrm{cfs}), 2\right)$ a net fresh-water input discharge of $247 \mathrm{~m}^{3} / \mathrm{sec}(8,700 \mathrm{cfs})$, and 3) a net fresh-water input discharge of $681 \mathrm{~m}^{3} / \mathrm{sec}(24,000 \mathrm{cfs})$ (a11 measured at city Point). The net fresh-water input discharge of $58.3 \mathrm{~m}^{3} / \mathrm{sec}$ at city Point corresponds to that of approximately 
the 10 percentile discharge (Virginia Department of Conservation and Economic Development, 1970). The second discharge of $247 \mathrm{~m}^{3} / \mathrm{sec}$ corresponds to the average annual discharge, and the third discharge of $681 \mathrm{~m}^{3} / \mathrm{sec}$ corresponds to approximately the 90 percentile discharge.

Test conditions for these three cases are shown in Table 1. The river sediments consist of cohesive sediment (silt and clay), organic matter and sand. Their particle sizes were assumed to be $0.030 \mathrm{~mm}, 0.100 \mathrm{~mm}$ and $0.150 \mathrm{~mm}$, respectively. Longitudinal dispersion coefficients for all sediment and dissolved Kepone, $D_{x_{j}}$ and $D_{x_{w}}$, were assumed to be $14 \mathrm{~m}^{3} / \mathrm{sec}$. While all longitudinal diffusion coefficients, $\varepsilon_{x_{j}}$ and $\varepsilon_{x_{W}}$, were assumed to be $0.14 \mathrm{~m}^{2} / \mathrm{sec}$. Since there have not been any fieid or laboratory studies to estimate three parameters, $M_{j},{ }^{\tau} C_{R_{j}}$, and ${ }^{{ }}{ }_{C D_{j}}$ to estimate erosion and deposition rates, $S_{R_{j}}$ and $S_{D_{j}}$ (see Equations 15 and 16 ), they were determined to fit measured sediment concentrations for the case of the fresh-water discharge of $58.3 \mathrm{~m}^{3} / \mathrm{sec}$. The bed shear stresses at each location, for each time step, were calculated by the FETRA code internally with a known velocity.

Since the new contribution of Kepone from tributaries to the James River is presentiy very small as compared to the total amount of Kepone already in the James River, and the flow rate of the tributaries is insignificant as compared to the James River tidal flow rate, it was assumed that no Kepone was added into the James River through tributaries during the simulation period. Since there is no significant chemical and biological degradation, or volatilization (Dawson, 1978). The decay rate, $\lambda$, was assumed to be zero in this study.

The distribution coefficient of Kepone for water and sediments was theoretically estimated to be $5.7 \times 10^{4} \sim 1.1 \times 10^{5} \mathrm{~cm}^{3} / \mathrm{g}$, if organic materials are not considered (Dawson, 1978). Field and laboratory data obtained by Battelle and the Virginia Institute of Marine Science (Huggett et al., 1978) reveal that the $K_{d}$ value for the James River sediment varies from approximately $2 \times 10^{3}$ to $2 \times 10^{4} \mathrm{~cm}^{3} / g$ with the exception of Bailey Creek which has a $K_{d}$ value of up to $3 \times 10^{5} \mathrm{~cm}^{3} / \mathrm{g}$. $K_{d}$ values depend strongly on sediment sizes and organic matter, as well as some water quality parameters. Based on results obtained by the theoretical analysis arid available measured data 


\section{TABLE 1. Test Conditions for Kepone Simulation}

\begin{tabular}{|c|c|c|c|}
\hline & Case ! & Case ? & Case 3 \\
\hline Eresn-water Discharge $\left(\mathrm{m}^{3} / \mathrm{sec}\right)$ & $\Xi 3 . \hat{3}$ & 247 & 681 \\
\hline $\begin{array}{l}\text { River Sediment Size (mm) } \\
\text { Cohesive sediment } \\
\text { Organic matter } \\
\text { Sand }\end{array}$ & $\begin{array}{l}0.030 \\
0.100 \\
0.150\end{array}$ & $\begin{array}{l}0.030 \\
0.700 \\
0.150\end{array}$ & $\begin{array}{l}0.030 \\
0.100 \\
0.150\end{array}$ \\
\hline $\begin{array}{l}\text { Longitudinal Dispersion Coefficients } \\
\text { for all Sediment and Kepone }\left(\mathrm{m}^{2} / \mathrm{sec}\right)\end{array}$ & 14 & 14 & 14 \\
\hline $\begin{array}{l}\text { Longitudinal Diffusion Coefficients } \\
\text { for all Sediment and Kepone }\left(\mathrm{m}^{2} / \mathrm{sec}\right)\end{array}$ & 0.14 & 0.14 & 0.14 \\
\hline Kepone Decay Rate $(1 / h r)$ & 0 & 0 & 0 \\
\hline $\begin{array}{l}\text { Kepone Distribution Coefficients }\left(\mathrm{cm}^{3} / \mathrm{g}\right) \\
\text { Associated with cohesive sediment } \\
\text { Associated with organic matter } \\
\text { Associated with sand }\end{array}$ & $\begin{array}{r}10,000 \\
20,000 \\
1,000\end{array}$ & $\begin{array}{r}10,000 \\
20,000 \\
1,000\end{array}$ & $\begin{array}{r}10,000 \\
20,000 \\
1,000\end{array}$ \\
\hline Kepone Mass Transfer Rate $(1 / h r)$ & 1 & 1 & $i$ \\
\hline $\begin{array}{l}\text { Initial Bed Sediment Constituents }(\%) \\
\text { Cohesive sediment } \\
\text { Organic Matter } \\
\text { Sand }\end{array}$ & $\begin{array}{r}80 \\
15 \\
5\end{array}$ & $\begin{array}{l}80 \\
15 \\
5\end{array}$ & $\begin{array}{r}80 \\
15 \\
5\end{array}$ \\
\hline $\begin{array}{l}\text { Boundary Conditions During Ebb Tide } \\
\text { Sediment Concentrations at City } \\
\text { Point }(\mathrm{mg} / 2)\end{array}$ & & & . \\
\hline $\begin{array}{l}\text { Cohesive sediment } \\
\text { Organic matter } \\
\text { Sand }\end{array}$ & $\begin{array}{r}24 \\
4.5 \\
1.5\end{array}$ & $\begin{array}{r}32 \\
6 \\
2\end{array}$ & $\begin{array}{r}52 \\
9.8 \\
3.2\end{array}$ \\
\hline $\begin{array}{l}\text { Kepone Concentrations at City Point } \\
\text { Dissoived }(\mu g / i) \\
\text { Particulate }(\mu q / q) \text { associated with }\end{array}$ & 0.007 & 0.307 & 0.007 \\
\hline $\begin{array}{l}\text { Conesive sediment } \\
\text { Organic litetter } \\
\text { Sand }\end{array}$ & $\begin{array}{l}0.045 \\
0.090 \\
0.0045\end{array}$ & $\begin{array}{l}0.045 \\
0.090 \\
0.0045\end{array}$ & $\begin{array}{l}0.045 \\
0.090 \\
0.0045\end{array}$ \\
\hline $\begin{array}{l}\text { Boundary Conditions During Flood Tide } \\
\text { Sediment Concentrations at Burwel1 } \\
\text { Bay (mg/l) }\end{array}$ & & & \\
\hline $\begin{array}{l}\text { Cohesive sediment } \\
\text { Organic matter } \\
\text { Sand }\end{array}$ & $\begin{array}{r}24 \\
4.5 \\
1.5\end{array}$ & $\begin{array}{r}32 \\
6 \\
2\end{array}$ & $\begin{array}{l}52 \\
9.8 \\
3.2\end{array}$ \\
\hline $\begin{array}{l}\text { Kepone Concentrations at Burwell Bay } \\
\text { Dissolved }(\mu g / \ell) \\
\text { Particulate }(\mu q / g) \text { associated with }\end{array}$ & 0.007 & 0.007 & 0.007 \\
\hline $\begin{array}{l}\text { Conesive sediment } \\
\text { Organic matter } \\
\text { Sand }\end{array}$ & $\begin{array}{l}0.032 \\
0.064 \\
0.0032\end{array}$ & $\begin{array}{l}0.032 \\
0.064 \\
0.0032\end{array}$ & $\begin{array}{l}0.032 \\
0.064 \\
0.0032\end{array}$ \\
\hline
\end{tabular}


obtained in the James River and in laboratories, $K_{d}$ values for cohesive sediment, organic matter and sand were selected to be $1 \times 10^{4}, 2 \times 10^{4}$, and $1 \times 10^{3} \mathrm{~cm}^{3} / \mathrm{g}$ for the present mathematical simulation. Since the ratio of cohesive sediment, organic material and sand among the James River sediment was initially set to be $0.80,0.15$, and 0.05 for this study, the $K_{d}$ value for the composite James River sediment corresponds to $11,050 \mathrm{~cm}^{3} / \mathrm{g}$.

The transfer rate for Kepone, $k_{j}$, was assumed to be $1.0 / \mathrm{hr}$ for all sediment types. Hence the half-life time for adsorption and/or desorption mechanisms at a given condition is assumed to be $0.69 \mathrm{hr}$ ( $i . e ., k_{j}=\ln 2 / \mathrm{half}$ life time). Sediment and Kepone concentrations used for boundary conditions are also listed in Table 1. Note that most measured dissolved Kepone concentrations were below the detection limit which is approximately 0.01 to $\sim 0.005 \mathrm{\mu g} / 2$ in water. From the measured particulate Kepone concentration and the $K_{d}$ value, the expected dissolved Kepone concentration is somewhat below but roughly the same magnitude of the detection limit. Thus, for this study, as a conservative estimate, the dissolved Kepone concentrations assigned as boundary conditions were set to be $0.007 \mu \mathrm{g} / \mathrm{l}$, as shown in Táble 1 .

Since the field data collected by Battelle in June 1977 are those for $58.3 \mathrm{~m}^{3} / \mathrm{sec}$, a major portion of the calibration and verification of the FETRA code was conducted for this discharge. After the model was calibrated, the other two discharge cases were tested without changing or readjusting the FETRA code except for boundary conditions of sediment concentrations. In order to take into account the effect of the tide, the computer simulation was conducted for 31 days with a 30-min time step by simulating tidal motion. All computer results for sediment and Kepone concentrations presented here were obtained on the 31 st day of the simulation.

Simulation of sediment and Kepone transport was conducted for each of the following substances: 1) cohesive sediment (clay and silt), 2) organic matter moving independent of cohesive sediment, 3) sand, 4) dissolved Kepone 5) particulate Kepone attached to cohesive sediment, 6) particulate Kepone associated with organic matter, and 7) particulate Kepone adsorbed on sand. 
Discussion of the simulation results is presented here as follows: 1) calibration of the mode1,2) verification of the model, 3) computer simulation results on kepone transport for four different discharges (Cases i through 4), 4) sensitivity analysis, and 5) Kepone cleanup activities.

\subsection{CALIBRATION OF THE MODEL}

Calibration of a mathematical model is one of the most important aspects of the simulation process. Calibration is usually performed by "tuning" a model to reproduce a known condition by adjusting some model parameters. As shown in Table 1, in the present study most of the parameters (such as Kepone distribution coefficients, the turbulent diffusion coefficient, sediment sizes, sediment fall velocity, etc.) were determined by theoretical and experimental analyses and field conditions prior to the model simulation rather than by adjustment to match computer results of field data. Hence, the only parameters which can be changed to fit simulation results to the measured data are a dispersion coefficient and three parameters which calculate deposition and erosion rates of sediment. Thus, the major calibration effort was exercised to reproduce sediment distribution patterns similar to the actual longitudinal distribution of sediment concentrations for the 86-km study reach measured by Battelle during June 25-28, 1977 (Dawson, 1978).

As a result of numerous trial runs after adjusting the parameters, final calibration computer results for the fresh-water discharge of $58.3 \mathrm{~m}^{3} / \mathrm{sec}$ are shown in Figures 6 through 8. These figures show computed longitudinal variations of total sediment concentration (sum of cohesive sediment, organic matter and sand being transported as suspended and bed loads) at maximum ebb, stack tide and maximum flood, together with measured data obtained by Battelle for the same fresh-water discharge. Comparison of the computer results with the measured data indicate excellent agreement. Although it is possible to improve the model prediction with more fine tuning, it was judged that the model was calibrated successfully. Figure 9 shows longitudinal distributions 
of tidal averaged sediment concentrations for each sediment component (cohesive sediment, organic material and sand) and the total sediment, together with total sediment concentration data obtained by Battelle and by Virginia Institute. of Marine Science (VIMS, 1977; Huggett et ai., 1978). VIMS data were obtained during August 24-29, 1977. The fresh-water discharge at City Point (River Kilometer 123) during the VIMS sampling period varied from $52.6 \mathrm{~cm}^{3} / \mathrm{sec}$ to $32.5 \mathrm{~cm}^{5} / \mathrm{sec}$ with a 6 -day average of $41.7 \mathrm{~cm}^{3} / \mathrm{sec}$. Although this discharge is slightly less than that which occurred during the Battelle sampling period $\left(58.3 \mathrm{~m}^{3} / \mathrm{sec}\right)$, they are close enough to use for comparison with the computer simulation results. As shown in these figures, the agreement between the computer and measured results is good. Since the VIMS data were not available until the calibration process was completed, the good agreement of predicted results to VIMS data provides verification of the model to some degree.

\subsection{VERIFICATION OF THE MODEL}

The verification of the sediment transport part of the model was conducted for Case 2 (fresh-water discharge of $247 \mathrm{~m}^{3} / \mathrm{sec}$ ) without changing any of the model parameters. Resulting computer simulation of sediment concentrations are shown in Figures 10 and 11 , together with field data. These figures include sediment concentrations of each type of sediment (cohesive sediment, organic materials or sand) and total sediment (sum of those sediment components). Measured total sediment concentrations in these figures were obtained by Nichols (1972) in March 1965 and March 1960. Field data in 1966 were provided by Nichols through personnel communication. Field data in 1965 were those associated with a fresh-water input discharge of $250 \mathrm{~m}^{3} / \mathrm{sec}$, while 1966 data were obtained in 2 days when the fresh-water input discharge changed from $257 \mathrm{~m}^{3} / \mathrm{sec}$ to $144 \mathrm{~m}^{3} / \mathrm{sec}$ with the 2 -day average discharge of $201 \mathrm{~m}^{3} / \mathrm{sec}$. The present simulation was conducted for the discharge of $247 \mathrm{~m}^{3} / \mathrm{sec}$ in this case. Comparison of these field data with computer results at slack tide and tidal average cases (Figures 10 and 11) indicate excellent agreement among these values. Since the present model was calibrated for the discharge of $58.3 \mathrm{~m}^{3} / \mathrm{sec}$ and the model was not readjusted for the $247 \mathrm{~m}^{3} / \mathrm{sec}$ case, this excellent agreement with measured data for the latter case provides solid verification of the model. 
Verification of the Kepone transport part of the model was conducted by comparing computer results to measured data obtained by Battelle and VIMS for Case 1 (fresh-water discharge of $58.3 \mathrm{~m}^{3} / \mathrm{sec}$ ). Again Battelle's data were obtained during June 25-28, 1977 and VIMS data were collected during August $24-29 ; 1977$. Since there were no parameters adjustable to fix the computer results to those field data, comparison between them was regarded to be model verification. Figures 12 through 14 present predicted particulate Kepone concentrations associated with each type of sediment and average particulate Kepone (weighted average of three particulate Kepone values associated with the three sediment types) per unit weight of sediment, together with cross-sectionally averaged field data of average particulate Kepone concentrations obtained by Battelle, for maximum ebb, slack and maximum flood tides, respectively.

Figures 15 and 16 present predicted tidal averaged particulate Kepone concentrations per unit weight of sediment, and those per unit volume of water, respectively, together with measured average particulate Kepone concentrations obtained by Battelle and VIMS. As noted above, Battelle's data in these figures are cross-sectionally averaged values. However, VIMS data are those measured in a main navigation channel of the River. Except for the maximum flood tide case (Figure 14), the agreement between the computer results and the field data are good. For example, Figure 16 reveals excellent agreement except one measured point at River Kilometer 111. The discrepancy between the predicted and measured value at River Kilometer 111 may be explained as follows: in the upper most part of the River, suspended and dissolved Kepone distribution across the River is much less uniform, as compared to distributions in the lower part because of the short distance from the original Kepone discharge source (Bailey Creek). Hence, VIMS measured data obtained in a main channel of the River at River Kilometer 111 are expected to be higher than a cross-sectional average there. However, in the lower part of the River, the measured data in the main channel may be much closer to the cross-sectional average. This trend may be reflected in Figure 16, when the computed and measured vaiues are compared. From the comparisons shown in Figures 12 through 16 , it is judged that the particulate Kepone transport part of the model has been verified with sufficient field data. 
Most of dissolved concentrations that occurred in the James River study reach were below the detection limit which is approximately 0.005 to $0.010 \mathrm{\mu g} / \mathrm{l}$. VIMS also reported from their August 1977 field sampling that the dissolved Kepone level in the James River is below the detection limit. Hence in this study, dissolved concentrations at both ends of the study-reach were set to $0.007 \mathrm{\mu g} / 2$, which is approximately the highest possible value maintained in the River. Figure 17 shows the computed tidal averaged dissolved Kepone concentration together with particulate and total (sum of dissolved and particulate) Kepone concentrations. This figure indicates that dissolved Kepone concentrations vary from approximately 0.0048 to $0.0080 \mathrm{\mu g} / \mathrm{l}$. As stated above, from the measured particulate Kepone concentration and the $k_{d}$ value, expected dissolved Kepone concentration is somewhat below the detection limit but is roughly the same magnitude to the detection limit. Hence, the predicted level of dissolved concentration by the FETRA code is the highest possible value found in the study area but still below the detection limit. From these considerations, the dissolved Kepone transport part of the FETRA code was also judged to be reasonably well verified with available information on dissolved Kepone concentrations in the tidal James River. Prediction of a total Kepone concentration (sum of dissolved and particulate Kepone concentrations) is then considered to be verified. Since measured values were generally below detection limits for dissolved Kepone, estimates will be on the high side.

Although it is desirable to obtain additional sets of field data to further verify the FETRA code, it is very expensive and time consuming to obtain a large number of field data. As discussed at the mathematical model workshop (0ak Ridge National Laboratory, 1978), most simulation models have been applied to some field cases but have never been verified. In light of these situations, it is considered that available field and laboratory data under this study will suffice to judge the validity of the mathematical simulation model, FETRA. As noted earlier, estimates may be high due to use of dissolved Kepone data at the level of detection.

The following sections will discuss the detailed simulation results of the sediment-Kepone transport. 


\subsection{CASE 1 - NET FRESH-WATER DISCH,ARGE OF $58.3 \mathrm{~m}^{3} / \mathrm{seC}$}

Computer results of the longitudinal velocity and depth variations at maximum ebb, slack tide and maximum flood are shown in Figures 18 through 21 , respectively. The velocity gradient with longitudinal distance is very evident.

Figures 22 through 24 show computed longitudinal variations of total sediment concentration (sum of cohesive sediment, organic matter and sand being transported as suspended and bed loads) at maximum ebb, slack tide and maximum flood, respectively. These figures are the same as those of Figures 6,7 and 8 . Comparison of the computer results with the measured data indicate excellent agreement as discussed above. Field data shown in this figure are cross-sectionally averaged values obtained by the measured data. Sediment concentrations vary from approximately $80 \mathrm{mg} / \mathrm{l}$ to $10 \mathrm{mg} / \mathrm{l}$ in the study area. Average total sediment concentrations in this area $a t$ maximum ebb, slack and maximum flood tides are predicted to be 36,29 and $42 \mathrm{mg} / \mathrm{l}$, respectively. Figures 25 through 27 show longitudinal distributions of each sediment component, i.e., cohesive sediment, organic matter, sand and total sediment for maximum ebb, slack and maximum flood tides, respectively. These figures indicate that 70 to $90 \%$ of the suspended sediment is silt and clay. The organic matter comprises 10 to $30 \%$. The suspended sand has an insignificant concentration. These values are comparable to measured values obtained by Battelle under this study and by Nichols (1972). Changes of sediment concentrations with time at River Kilometer 75.7 are shown in Figure 28. The maximum ebb occurs at approximately 3 and $15 \mathrm{hr}$ while the maximum flood occurs at approximately 8 and $21 \mathrm{hr}$. Sediment concentrations oscillate with time due to tidal motion, producing peaks at maximum ebb and flood (with a maximum of $70 \mathrm{mg} / 2$ ) and minimum values (with the lowest concentration of $23 \mathrm{mg} / \mathrm{l}$ ) at near slack tide. This figure indicates that approxinately 64 to $33 \%$ of the sediment remains suspended during slack tide. Note that after $25 \mathrm{hr}$, the sediment concentration level returns to its starting value indicating this periodic pattern reaches its equilibrium condition. Figure 29 (which is the same as Figure 9) shows longitudinal distributions of tidal averaged sediment concentrations for each sediment component and 
the total sediment. The tota? sediment concentration in this $86-\mathrm{km}$ reach varies from approximately $50 \mathrm{mg} / \mathrm{i}$ to $20 \mathrm{mg} / 2$ with the average value of $33.2 \mathrm{mg} / 2$. Tidal averaged sediment concentrations of cohesive sediment, organic material and sand averaged over the study area are $28.9,4.1$ and $0.2 \mathrm{mg} / \mathrm{l}$, respectively. These constitute approximately $87.0,12.4$ and $0.6 \%$ of the total sediment constituents, respectively. The longitudinal variation of sediment concentration is relatively small due to the lack of a clear null zone (area where fresh and saline water intermix), (see Figure 29), because of the very low net fresh-water input for this case. The small but still measurable longitudinal variation may be attributed to the change in the tidal James River topography ranging from wide bays to narrow channels connecting bays.

Figures 30 through 32 (winich are the same as Figures 12, 13 and 14) present predicted particulate Kepone concentrations associated with each type of sediment and average particulate Kepone (weighted average of three particulate Kepone values associated with the three sediment types) per unit weight of sediment, together with cross-sectionally averaged field data, for maximum ebb, slack and maximum flood tides, respectively. Comparison of computer results of total particulate Kepone and the measured data reveals good agreement as discussed eariler. The mathematical simulation results indicate that the particulate Kepone concentration generally increases from $0.05 \mu \mathrm{g} / \mathrm{g}$ to $0.11 \mathrm{\mu g} / \mathrm{g}$ with movement seaward from City Point (River Kilometer 123) to the confluence of the James River and the Chickahominy River (River Kilometer 77) with an intermediate peak around Bailey Bay and Jordan Point (River Kilometer 118). Seaward from the James-Chickahominy River confluence, the particulate Kepone concentration decreases gradually and has a value of approximatel $\mathrm{y} 0.04 \mu \mathrm{g} / \mathrm{g}$ in Burweli Bay (River Kilometer 37.6). These figures also reveal that the Kepore concentration associated with the organic material is approximately twice as high as those attached to the cohesive sediment which in turn have 10 times higher Kepone concentration than those adsorbed by sand. Changes of particulate Kepone concentrations with time at River Kilometer 75.7 are shown in Figure 33. There are sma $1 ?$ peaks associated with maximum ebb and flood tides due to possible erosion of 
bed sediment with high Kepone concentrations. Tidal averaged particulate Kepone concentrations, together with the tidal averaged field data are shown in Figure 34 (which is the same as Figure 15). Good agreement was obtained between the computer results and the measured value. It is shown in this figure that the total particulate Kepone concentration averaged over the $86-\mathrm{km}$ reach is $0.071 \mathrm{~kg} / \mathrm{g}$. This figure also shows that as area wide averages, particulate Kepone adsorbed by the cohesive sediment, organic matter and sand are $0.063,0.126$, and $0.006 \mu \mathrm{g} / \mathrm{g}$, respectively.

Figures 35 through 37 also present particulate Kepone concentration, only on a per unit volume of water basis for the three tidal stages, respectively. These values were obtained by multiplying particulate Kepone concentration per unit weight of sediment times the sediment concentration. Figure 38 (which is the same as Figure 16) shows the tidal averaged particulate Kepone concentration in $\mu \mathrm{g} / 2$. Although the organic matter contains the highest Kepone concentration (see Figure 38), this figure reveals that the suspended cohesive sediments (silt and clay) carries the greatest amount of Kepone among particulate Kepone because of its high sediment concentration in the water. For example, as shown in Figure 38, in the vicinity of the confluence of the James and Chickahominy Rivers (River Kilometer 77), total particulate Kepone concentration is $0.0037 \mu \mathrm{g} / 2$, of which $66 \%$ is transported in a particulate form associated with the cohesive sediment. While approximately $34 \%$ of the particulate Kepone associates with the organic material. No measurable Kepone was associated with suspended sand.

Longitudinal variations of dissolved, particulate and total (sum of dissolved and total particulate Kepone) Kepone concentrations are presented in Figures 39 through 43 . Figure 17 was reproduced here as Figure 43 . These figures reveal that total Kepone concentrations vary from approximately $0.006 \mu \mathrm{g} / \ell$ to $0.0132 \mu \mathrm{g} / \mathrm{l}$ with the peak concentration occurring at River Kilometer 75 (in the vicinity of the Swan Point). Concentrations of dissolved, particulate and total Kepone averaged over the $86-\mathrm{km}$ reach are 0.0065 , 0.0024 , and $0.089 \mu \mathrm{g} / \mathrm{l}$. These values indicate that approximately $27 \%$ of total Kepone is carried by sediment, while $73 \%$ ramains in the dissolved form, as 
overall average values. These figures also show that suspended sediment carries approximately 10 to $50 \%$ of the total Kepone, while 50 to $90 \%$ of the Kepone is transported in a dissolved form for this discharge case. For example, at River Kilometer $77,32 \%$ of Kepone is transported in a particulate form, while $68 \%$ is in a dissolved form at maximum ebb tide. At slack tide, only $13 \%$ of the total Kepone is associated with suspended sediment and $87 \%$ is the dissolved Kepone, due to settling of the suspended sediment during slack tide. At the maximum flood, bottom sediment is again resuspended and $54 \%$ of the total Kepone is being transported by sediment and $46 \%$ is the dissolved Kepone. When these values are tidally averaged, $32 \%$ of the total Kepone is associated with sediment, while $68 \%$ remains in water at this location. Changes of total, dissolved and particulate Kepone concentrations with time at River Kilometer 75.7 are shown in Figure 42. As shown in this figure, dissolved Kepone concentration does not change significantly with time. However, particulate and thus total Kepone concentration changes with time due to the time dependency of sediment concentration.

The mathematical simulation results also reveal that at Burwell Bay, the tidal averaged total kepone concentration is $0.0076 \mu \mathrm{g} / \ell$ and that approximately $14.0 \mathrm{~kg}$ of Kepone per year is transported from the tidal James River towards Chesapeake Bay. Dissolved and particulate Kepone concentrations are $0.0064 \mu \mathrm{g} / \mathrm{l}$ and $0.0012 \mu \mathrm{g} / \mathrm{l}$, respectively. Hence, suspended sediment carries approximately $2.2 \mathrm{~kg}$ of Kepone per year seaward from the tidal James River while $11.8 \mathrm{~kg}$ of Kepone is transported from Burwell Bay each year in a dissolved form. Since there is some possible deposition of contaminated sediment and adsorption of dissolved Kepone by cleaner suspended sediment between Burwell Bay and the river mouth, $14.0 \mathrm{~kg} / \mathrm{yr}$ is a conservative estimate.

Accumulated bed elevation changes after 1-month simulation are shown in Figure 44. In this figure positive values along the vertical axis indicate the amount of sediment deposition in mm during a 1 -month simulation, while negative values show the amount of river bed scoured during the same period. This figure reveals a series of scouring and deposition patterns reflecting the complex geometry of the tidal James River with many bays being connected by narrow channels. For this flow case, an average annual net bed deposition rate for the $86-\mathrm{km}$ tidal james River reach is predicted to be approximately $1.7 \mathrm{~mm} / \mathrm{yr}$. 
Figure 45 shows the change in bed surface Kepone concentration which occurs during a l-month simulation. The Kepone concentrations shown here are those which occur on the very surface of the river bed without any mixing with the Kepone below that level. For example, in Bailey Bay (around River Kilometer 120) Kepone concentrations are reduced dramatically during a 1 -month simulation. As shown in Figure 44, Bailey Bay experienced sediment deposition of approximately $2 \mathrm{~mm}$. Figure 45 indicates that the Kepone concentration in this top 2-mm layer is reduced from the level shown in the solid line to that shown in the dotted line. Another example is around the 70-River $\mathrm{Kilometer} \mathrm{area.} \mathrm{Figure} 44$ reveals that there is a net scour of approximately $1 \mathrm{~mm}$. Hence, the Kepone concentration in the very surface of the river bed after 1-month simulation shown in Figure 45 is the one that appeared in the layer as it existed $1 \mathrm{~mm}$ below the original bed surface. Figure 45 reveals a definite trend of reducing the Kepone level near the upper part of the river and of increasing the level near the lower part of the river.

\subsection{CASE 2 - NET FRESH-WATER DISCHARGE OF $247 \mathrm{~m}^{3} / \mathrm{sec}$}

Computed longitudinal distributions of flow velocities at the three tidal stages, maximum ebb, slack and maximum flood are shown in Figure 46. Figures 47 through 49 present computed longitudinal variations of crosssectional averaged depth of the tidal James River at the three tidal stages, respectively.

Longitudinal distributions of sediment concentrations at maximum ebb, slack and maximum flood tides are shown in Figures 50 through 52 , respectively. The tidal averaged sediment concentrations are shown in Figure 53. Figures 51 and 53 are the same as Figures 10 and 11 . Figures 50 through 53 include sediment concentrations of each type of sediment (cohesive sediment, organic material or sand) and total sediment (sum of those sediment components). Measured total sediment concentrations obtained by Nichols (1972) in March 1965 and March 1960 are also plotted for the purpose of model verification. As discussed earlier, comparison of these field data with computer results at slack tide and tidal average cases (Figures 51 and 53) indicate excellent agreement among these values. Computer results shown in Figures 50 through 52 reveal that there are two peaks of the total sediment distribution 
with both having approximately $100 \mathrm{mg} / \mathrm{l}$ concentrations. One occurs between River Kilometer 75 and 95 , and the other around River Kilometer 55. The former peak is produced due to extensive river bed scouring in the vicinity of this reach and the latter is due to the existence of a clear null zone around the River Kilometer 50 (Nichols, 1972). The tidal averaged total sediment concentration shown in Figure 53 indicates that the concentration varies from approximately $25 \mathrm{mg} / \mathrm{l}$ to $100 \mathrm{mg} / 2$ with an areawide average of $66.5 \mathrm{mg} / 2$. This figure also indicates that cohesive sediment is the dominant suspended sediment with $55.1 \mathrm{mg} / \mathrm{l}$ of the areawide average concentration. This corresponds to $82.9 \%$ of the total sediment concentration. The second largest amount is organic matter having $11.0 \mathrm{mg} / \mathrm{\ell}$, which corresponds to $16.5 \%$ of the total sediment. Suspended sand has the smallest value of $0.4 \mathrm{mg} / \mathrm{l}$ which is oniy $0.6 \%$ of the total sediment concentration. As compared to Case 1 (see Figure 29), al1 three components of sediment increase their concentrations. Percentage of cohesive sediment to the total sediment for Case 2 decreases from 87.0 to $82.9 \%$. On the other hand, crganic matter increases its contribution from 12.4 to $16.5 \%$. Sand contribution remains the same at $0.6 \%$.

Distributions of particulate Kepone at the three tidal stages are shown in Figures 54 through 56 while tidal averaged distributions are presented in Figure 57. The tidal averaged particulate kepone distribution, as shown in Figure 57, indicates that the total particulate Kepone concentration changes from $0.040 \mu \mathrm{g} / \mathrm{g}$ to $0.098 \mu \mathrm{g} / \mathrm{g}$ with the overall average of $0.070 \mu \mathrm{g} / \mathrm{g}$. The peak concentrations occur at approximately River Kilometer 75 . Overall particulate Kepone concentrations associated with suspended cohesive sediment, organic matter and sand are $0.060,0.120$, and $0.006 \mu \mathrm{g} / \mathrm{g}$, respectively.

Figures 58 through 60 show longitudinal distributions of particulate Kepone concentrations per unit volume of water, $\mu \mathrm{g} / \ell$. The tidal averaged distribution is presented in Figure 61. These figures indicate that particulate Kepone concentration varies from $0.0015 \mu \mathrm{g} / \mathrm{l}$ to $0.010 \mathrm{\mu g} / \mathrm{l}$ with two peaks around River Kilometer 75 and 55 . The average particulate Kepone concentration in the entire study reach is $0.00475 \mu \mathrm{g} / 2$. An average particulate Kepone concentration associated with cohesive sediment is $0.00338 \mu \mathrm{g} / 2$ which is $71 \%$ of the total particulate Keporie. Organic matter has $0.00137 \mu \mathrm{g} / 2$ of Kepone 
which is 29: of the particulate Kepone. Kepone adsorbed by the sand has its concentration of $0.000002 \mu \mathrm{g} / \ell$ and is an insignificant amount. As shown here, the suspended silt and ciay carry the greatest amount of particulate Kepone because of their high sediment concentration. However, Figure 61 also reveals that organic matter carries as much or more Kepone than cohesive sediment does in the region between River kilometer 70 and 75 .

Longitudinal variations of dissolved, particulate and total (sum of dissolved and particulate Kepone) Kepone concentrations at three tidal stages are shown in Figures 62 through 64 , while tidal averaged values of these concentrations are shown in Figure 65 . As 111 ustrated by these figures, total Kepone concentration varies from $0.0062 \mu \mathrm{g} / \mathrm{l}$ to $0.0170 \mu \mathrm{g} / \mathrm{l}$ with two peaks at River Kilometer 75 (near Swann Point) and River Kilometer 53 (around the null zone for this net fresh-water discharge case). Figure 65 reveals that concentrations of dissolved, particulate and total Kepone averaged over the study area are $0.006 \mu \mathrm{g} / \mathrm{l}, 0.0048 \mu \mathrm{g} / \mathrm{l}$ and $0.0108 \mu \mathrm{g} / \mathrm{l}$. This implies that approximately $44 \%$ is carried by the sediment, while $56 \%$ of Kepone is in a dissolved form. As compared to Case 1 (net fresh-water discharge of $58.3 \mathrm{~m}^{3} / \mathrm{sec}$ ), the percentage of particulate Kepone to the total Kepone increases from 37 to $44 \%$. This increase is attributed to more scouring of contaminated bed sediment and higher sediment concentrations in this case, as compared to Case 1. At River Kilometer 77, both particulate and dissolved Kepone constitute $50 \%$ of the total Kepone at maximum ebb. At slack tide $44 \%$ of the total Kepone is transported by sediment, while $56 \%$ is in a dissolved form. At maximum flood tide, 59\% of Kepone is associated with sediment and $41 \%$ is in a dissolved mode. When they are tidally averaged, total kepone concentration is $0.0140 \mu \mathrm{g} / \mathrm{l}$ of which $50.5 \%$ is in a particulate form and $49.5 \%$ has a dissolved form at River Kilometer 77 .

The present mathematical study also indicates that at Burwell Bay, the tidal averaged total Kepone concentration is $0.0080 \mathrm{~kg} / 2$ and that approximately $62.3 \mathrm{~kg}$ of Kepone per year is discharged out from the tidal James River towards Chesapeake Bay. Dissolved and particulate Kepone concentrations are estimated to be $0.0064 \mu \mathrm{g} / 2$ and $0.0016 \mu \mathrm{g} / \mathrm{h}$. These values imply that out of $62.3 \mathrm{~kg}$ of total Kepone, $12.5 \mathrm{~kg}$ of Kepone is transported by sediment and $49.8 \mathrm{~kg}$ of Kepone is in a dissolved form. 
Accumulated bed elevation changes due to sediment deposition and river bed scouring after 1 -month simulation are shown in Figure 66. As shown in this figure, bays in generai have sediment deposition and narrow connecting channels between bays experience bed scouring.

For this case an average annual net bed deposition rate for the $86-\mathrm{km}$ tidal James River reach is predicted to be approximately $3.6 \mathrm{~mm} / \mathrm{yr}$. Figure 67 indicates the change in bed surface kepone concentration and reveals a similar trend to that found in Case 1 (Figure 45).

\subsection{CASE 3 - NET FRESH-WATER DISCHARGE OF $681 \mathrm{~m}^{3} / \mathrm{sec}$}

Mathematical simulation results on velocity and flow depth distributions at the three tidal stages are shown in Figures 68 through 71.

Figures 72 through 74 present concentrations of cohesive sediment, organic matter, sand and totai sediment at maximum ebb, slack and maximum flood tides, respectively. Tidal averaged distributions of these concentrations are shown in Figure 75 . These figures show that total sediment concentration changes its values from approximately $20 \mathrm{mg} / \ell$ to $110 \mathrm{mg} / \mathrm{l}$ with a series of peaks at River Kilometer $38,54,72$ and 105 . These figures also reveal that the majority of the sediment being transported in the river at this discharge is cohesive sediment ranging from 94 to $68 \%$ of the total sediment concentration. Organic matter constitutes 6 to $32 \%$ of the total and sand constitutes only a fraction of total sediment. As shown in Figure 75, tidal averaged total sediment concentration over the entire $86-\mathrm{km}$ reach is $74.2 \mathrm{mg} / 2$. Concentrations of cohesive sediment, organic matter and sand averaged over the study area are $59.7 \mathrm{mg} / \mathrm{l}, 13.7 \mathrm{mg} / \mathrm{l}$ and $0.8 \mathrm{mg} / \mathrm{l}$, respectively. This means that cohesive sediment, organic matter, and sand constitute $80.4 \%$, $18.5 \%$ and $1.1 \%$ of the total sediment concentration, respectively. As compared to Cases 1 and 2, all components of sediment have higher concentrations than Cases 1 and 2. Moreover, organic matter and sand increase their contributions to total sediment concentrations but the cohesive sediment decreases its percentage. 
Figures 76 through 78 present longitudinal variations of particulate Kepone concentrations at the three tidal stages, while figure 79 shows the tidal averaged particulate Kepcne concentration. These figures indicate that total particulate Kepone changes its concentrations from $0.035 \mathrm{Hg} / \mathrm{g}$ to $0.10 \mathrm{\mu g} / \mathrm{g}$ and has three peaks, one each at River Kilometer 43, 75, and 118 . Tidal averaged total particulate Kepone over the $86-\mathrm{km}$ reach, as shown in Figure 79 is $0.076 \mathrm{ug} / \mathrm{g}$. Particulate Kepone adsorbed by cohesive sediment, organic material and sand averaged over the entire study reach are $0.064 \mu \mathrm{g} / \mathrm{g}$, $0.129 \mu \mathrm{g} / \mathrm{g}$ and $0.006 \mu \mathrm{g} / \mathrm{g}$, respectively.

Particulate Kepone concentrations per unit volume of water, expressed by $\mu \mathrm{g} / \mathrm{l}$ are shown in Figures 80 through 83 . Figure 83 shows that the tidal averaged total Kepone concentration for this case varies from $0.0012 \mu \mathrm{g} / \mathrm{l}$ to $0.0084 \mathrm{ug} / 2$ with the average value of $0.0057 \mathrm{Hg} / 2$. Also this distribution has two major peaks and two minor peaks at River Kilometer 37, 54, 72 and 105, respectively. Concentrations of particulate Kepone attached to cohesive sediment, organic material and sand are estimated to be $0.0039 \mu \mathrm{g} / \mathrm{\ell}, 0.0018 \mu \mathrm{g} / \ell$ and $0.000004 \mu \mathrm{g} / 2$, respectively. These values correspond to $68.4,31.5$, and $0.07 \%$, respectively, to the total Kepone concentration.

Figures 84 through 87 present longitudinal distributions of dissolved, particulate and total Kepone concentrations. As shown in Figure 87, tidal averaged total Kepone concentration varies from $0.0072 \mu \mathrm{g} / 2$ to $0.0155 \mathrm{\mu g} / \mathrm{l}$ with an average value of $0.0124 \mu \mathrm{g} / \mathrm{l}$. Tidal averaged particulate Kepone concentration obtained over the entire $86-\mathrm{km}$ reach is $0.00575 \mu \mathrm{g} / \mathrm{\ell}$ which corresponds to $46 \%$ of the total Kepone concentration. Similarly, overall dissolved Kepone concentration is $0.00665 \mu \mathrm{g} / \mathrm{l}$ which is $54 \%$ of the total Kepone concentration. As compared to Cases 1 and 2, particulate Kepone for this case has the highest contribution to the total Kepone, due to the higher rate of bed scouring and subsequent sediment concentration under these flow conditions.

The simulation results also reveal that at Burwell Bay, the tidal averaged concentrations of total particulate and dissolved Kepone are $0.0093 \mathrm{ug} / 2$, $0.0026 \mu \mathrm{g} / 2$, and $0.0066 \mu \mathrm{g} / 2$, respectively. Hence, it is estimated that under 
this net fresh-water discharge of $681 \mathrm{~m}^{3} / \mathrm{sec}$, approximately $200 \mathrm{~kg}$ of Kepone per year is flushed out from the tidal James River toward Chesapeake Bay. Of that total, $28 \%$ or $56.0 \mathrm{~kg}$ is being transported by sediment and $72 \%$ or $144 \mathrm{~kg}$ is moved out in a dissolved form.

Changes in accumulated river bed elevation and in Kepone concentration on the river bed surface are shown in Figures 88 and 89 . Unlike Cases 1 and 2 , an overall net erosion of the river bed occurs at a rate of $4.1 \mathrm{~mm} / \mathrm{yr}$ under this high flow condition.

\subsection{CASE 4 - OVERALL EVALUATION THROUGH COMBIIIATION OF RESULTS ON CASES 1, 2 AND 3}

In order to obtain a realistic estimate of Kepone transport, the computer results obtained for Cases 1, 2, and 3 were combined with their frequency of occurrence. As mentioned before, net fresh-water discharges of $58.3 \mathrm{~m}^{3} / \mathrm{sec}$ (Case 1) and $681 \mathrm{~m}^{3} / \mathrm{sec}$ (Case 3) correspond to the 10 and 90 percentile of discharge. The discharge of $247 \mathrm{~m}^{3} / \mathrm{sec}$ (Case 2) is the annual average discharge. To best estimate probable annual Kepone transport, based on the results of these three cases, Case 1, 2, and 3 were assigned to occur 30,40 , and $30 \%$ of the time.

Annual total sediment concentration over the entire $86-\mathrm{km}$ study reach is estimated to be $59.0 \mathrm{mg} / \mathrm{l}$. The annual total Kepone concentration over the area is $0.0108 \mathrm{\mu g} / \mathrm{l}$. The annual particulate Kepone concentration over the area is computed to be $0.072 \mathrm{\mu g} / \mathrm{g}$ or $0.0028 \mathrm{Hg} / \mathrm{l}$, while dissolved Kepone concentration is $0.0064 \mathrm{\mu g} / \mathrm{l}$. Hence, $26 \%$ of the total Kepone is transported with sediment and $74 \%$ is in a dissolved form.

Similarly, the average annual net bed deposition rate for the $86-\mathrm{km}$ tidal James River reach is estimated to be $0.7 \mathrm{~mm} / \mathrm{yr}$ which agrees reasonably with field data obtained during the last 70 years (Nichols, 1972). This also confirms the general validity of the present mathematical simulation.

Finally, it is estimated that $89.1 \mathrm{~kg}$ of Kepone per year is transported from the tidal James River towards Chesapeake Bay. Of that, $22.5 \mathrm{~kg}$ of Kepone is a particulate form associated with sediment, and $66.6 \mathrm{~kg}$ is in a dissolved form. Since there are some possibilities that the contaminated 
sediment is deposited and/or dissolved Kepone adsorbed by cleaner sediment between Burwel1 Bay and the James River mouth, $89.1 \mathrm{~kg} / \mathrm{yr}$ is a conservative estimate. However, since $74 \%$ of the kepone is in the dissolved form, it is judged that changes in the total Kepone concentration between Burweli Bay and the river mouth are not very significant. A summary of simulation results on Kepone migration from Burwell Bay towarc Chesapeake Bay and Atlantic Ocean for all four cases is shown in Table 2 .

Approximately $9,600 \mathrm{~kg}(20,000 \mathrm{lb})$ of Kepone is estimated to be present in the top $1 \mathrm{ft}$ of bed sediment of the James River (Dawson, 1978). Hence, with a flushing rate of $89.1 \mathrm{~kg} / \mathrm{yr}$ Kepone from the James River toward Chesapeake Bay and Atlantic Ocean, it may at least take 108 years for natural watersediment flushing mechanism alone to cleanse the river.

IABLE 2. Summary of Simulation Results on Kepone Migration From Burwell Bay Seaward for all Four Cases

\begin{tabular}{|c|c|c|c|c|}
\hline & Case 1 & Case 2 & Case 3 & Case 4 \\
\hline Net Fresh-water Discharge $\left(\mathrm{m}^{3} / \mathrm{sec}\right)$ & 58.3 & 247 & 681 & 321 \\
\hline Annal Total Kepone Discharge $(\mathrm{kg} / \mathrm{yr})$ & 14.0 & 62.3 & 200 & 89.1 \\
\hline Dissolved Kepone Percentage $(\%)$ & 84.3 & 80.0 & 72.0 & 74.7 \\
\hline Particulate Kepone Percentage $(\%)$ & 15.7 & 20.0 & 28.0 & 25.3 \\
\hline
\end{tabular}

\subsection{SENSITIVITY ANALYSIS}

In order to assess the response of the model FETRA, a sensitivity analysis was conducted for some selected parameters and conditions. They included fresh-water discharge, sizes, fall velocity, density of sediment, and three parameters affecting sediment erosion and deposition (critical shear stresses for erosion and deposition, erodibility constant shown in Equations 15 and 16). Among these variables and parameters, the three sediment erosion and deposition parameters were found to have a strong influence on the sediment transport, as reported by Onishi $(1977 a, b)$.

Because of the strong interaction between Kepone and sediment, the distribution coefficient, $K_{d}$, describing the sorption-desorption equilibrium condition, is one of the most important keys to accurate model prediction. To 
investigate this sensitivity as we 11 as bed Kepone concentration a second series of simulations (Cases 5, 6, 7, and 8) was conducted employing a distribution coefficient of $2000 \mathrm{~cm}^{3} / \mathrm{g}$ with river bed Kepone concentrations twice as much as those used in Cases 1 through 4. The distribution coefficient of $2200 \mathrm{~cm}^{3} / \mathrm{g}$ is representative of those found in Bailey Bay and, as compared to $11,000 \mathrm{~cm}^{3} / \mathrm{g}$ used for Cases 1 through 4 , would reflect a high degree of Kepone availability for desorption from sediment to water as suggested by the laboratory studies conducted at the EPA Research Laboratory in Gulf Breeze (Garnas et a1., 1977; U.S. EPA, 1978).

Test conditions for Cases 5 through 8 are the same as those of Cases 1 through 4 except the values of distribution coefficient and bed Kepone concentrations. Under these conditions, sediment transport is unaffected by a change in partitioning Kepone and therefore remains the same as previousiy reported. However, as expected, the dissolved Kepone levels for all these four cases become higher than those for Cases 1 through 4 and do not correspond as well with field data as the computer results of Cases 1 through 4 . Table 3 indicates the brief summary of results on Kepone migration from Burwel1 Bay toward Chesapeake Bay and Atlantic Ocean for this sensitivity case. As shown in Table 3, the amount of Kepone being transported from Burwel1 Bay toward Chesapeake Bay increases for these cases as compared to those of Cases 1 through 4; the results for the sensitivity analysis cases do not add significantly to the amount of Kepone transported past Burwell Bay each year. Hence, conclusions derived from computer results for Cases 1 through 4, will not change significantiy with variation of the distribution coefficient and bed Kepone level tested in this study.

TABLE 3. Summary of Sensitivity Analysis--Kepone Migration From Burwel1 Bay Seaward

\begin{tabular}{|c|c|c|c|c|}
\hline & Case 5 & Case 6 & Case 7 & Case 8 \\
\hline Fresh-water Input Discharge $\left(\mathrm{m}^{3} / \mathrm{sec}\right)$ & 58.3 & 247 & 681 & 321 \\
\hline Annual Total Kepone Discharge (kg/yr) & 35.8 & 135 & 350 & 170 \\
\hline Dissolved Kepone Percentage (\%) & 95 & 93 & 88 & 92 \\
\hline Particulate Kepone Percentage $(\%)$ & 5 & 7 & 12 & 8 \\
\hline
\end{tabular}




\subsection{KEPONE CLEANUP ACTIVITIES}

The model may also be used to answer questions about mitigation such as:

1. What will happen to the Kepone migration pattern and its concentration level if a part of the kepone in the river bed is removed by physical, chemical or biological methods?

2. Where is the optimal location for Kepone removal to reduce the Kepone level in the River?

In order to answer these questions, further mathematical modeling was conducted for an additional 10 cases (Cases A through $\mathrm{J}$ ) by assuming that for each case, Kepone in the bed at a certain part of the tidal James River was completely removed. This is accomplished by changing boundary conditions to assume no bed kepone in the restored reach. For a 11 cases, fresh-water input discharges were assumed to be $247 \mathrm{~m}^{3} / \mathrm{sec}$. Computer results during the maximum ebb tide after 1 -month simulation for these cases were then compared with those of Case 2 (no cleanup activity was performed for Case 2) in order to assess the effectiveness of the Kepone cleanup activities.

Locations of Kepone cleanup activities are divided into four categories: (1) upper part of the River (Cases A, B, and C), (2) middle part of the River (Cases D through H), (3) lower part of the River (Case I), and (4) combination of (2) and (3) (Case J). Exact cleanup locations are shown in the lower parts of Figures 90 through 92, together with simulation results. Total, dissolved and particulate Kepone concentrations for Cases $A$ through $J$ and Case 2 are shown in Figures 90 through 92, respectively. In these figures, thick solid lines represent Case 2 (no cleanup activity).

In the cases of upper river cleanup activities (Cases $A$ through $C$ ), Cases B (cleanup of Bailey Bay and upper half of Tar Bay) and C (Bailey and Tar Bay) indicate the improvement of river conditions for these cases by reducing concentrations of total, dissolved and particulate Kepone by up to approximately $15 \%$ with in the vicinity of the cleanup locations. The cleanup activity conducted for Case A (cleanup of Bailey Bay) does not reduce the Kepone concentrations, as shown in these three figures. 
In the case of middle river cleanup activities (Cases $D$ through $H$ ), significant reduction of Kepone level (total, dissolved and particulate Kepone concentrations), up to 55 and $48 \%$, was obtained for Cases $D$ and $E$, respectively. . The cleanup area of Case $D$ is a $34.5-\mathrm{km}$ reach between 50.5 and 85.0 River Kilometer, while a cleanup area for Case $E$ is a $22-\mathrm{km}$ reach between 56.0 and 78.0 River Kilometer. Cases $G$ and $H$ also demonstrate some reduction (up to approximately $13 \%$ ); however, Case $F$ does not show any improvement. For these five cases, there is not significant improvement near Burwell Bay, as shown in Figures 90 through 92.

For the case of cleanup activity in the lower river (Case I), there is no measurable reduction in the Kepone concentration. Consequently, the Case $J$ (combination of Cases $G$ and I) computer results are the same as those of Case $G$.

Among these 10 cases, Cases $D$ and $E$ reveal significant reduction of both dissolved and particulate Kepone concentrations. Although Case D (up to 55\% reduction of Kepone concentration) is slightly better than Case $\mathrm{E}$ (up to $48 \%$ reduction), comparison of sizes of cleanup areas for these two cases ( 34.5 and $22.0 \mathrm{~km}$ reaches for Cases $D$ and $E$, respectively) leads to the conclusion that Case $E$ is more efficient to reduce the Kepone concentration in the River per unit area of cleanup activities. 


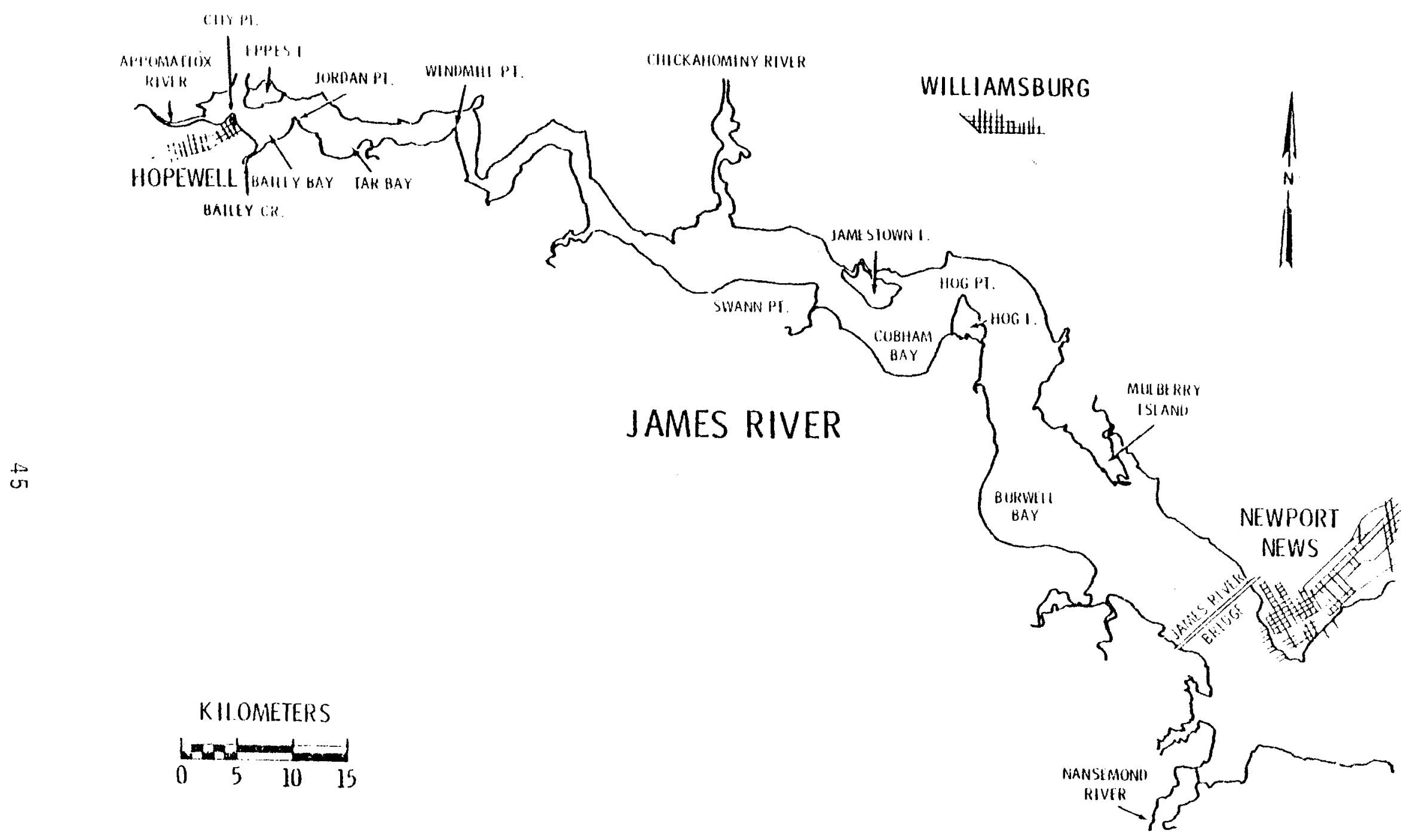

FIGURE 5. Tidal James River 


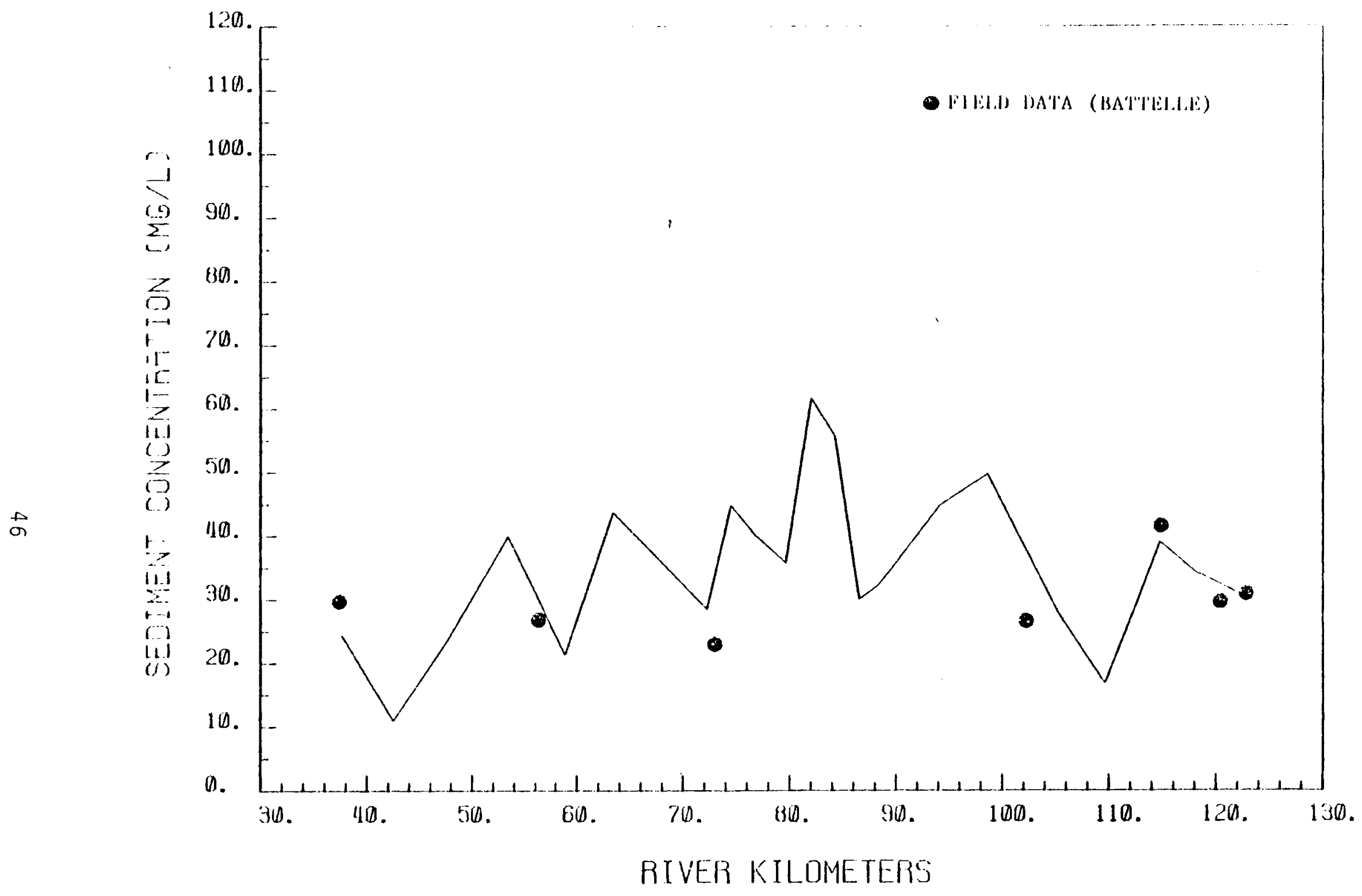
FIGURE 6. Longitudinal Distributions of Total Sediment Concentration at the Maximum Ebb
Tide for the Fresh-Water Discharge of $58.3 \mathrm{~m} / \mathrm{sec}$, Together with Field Data 


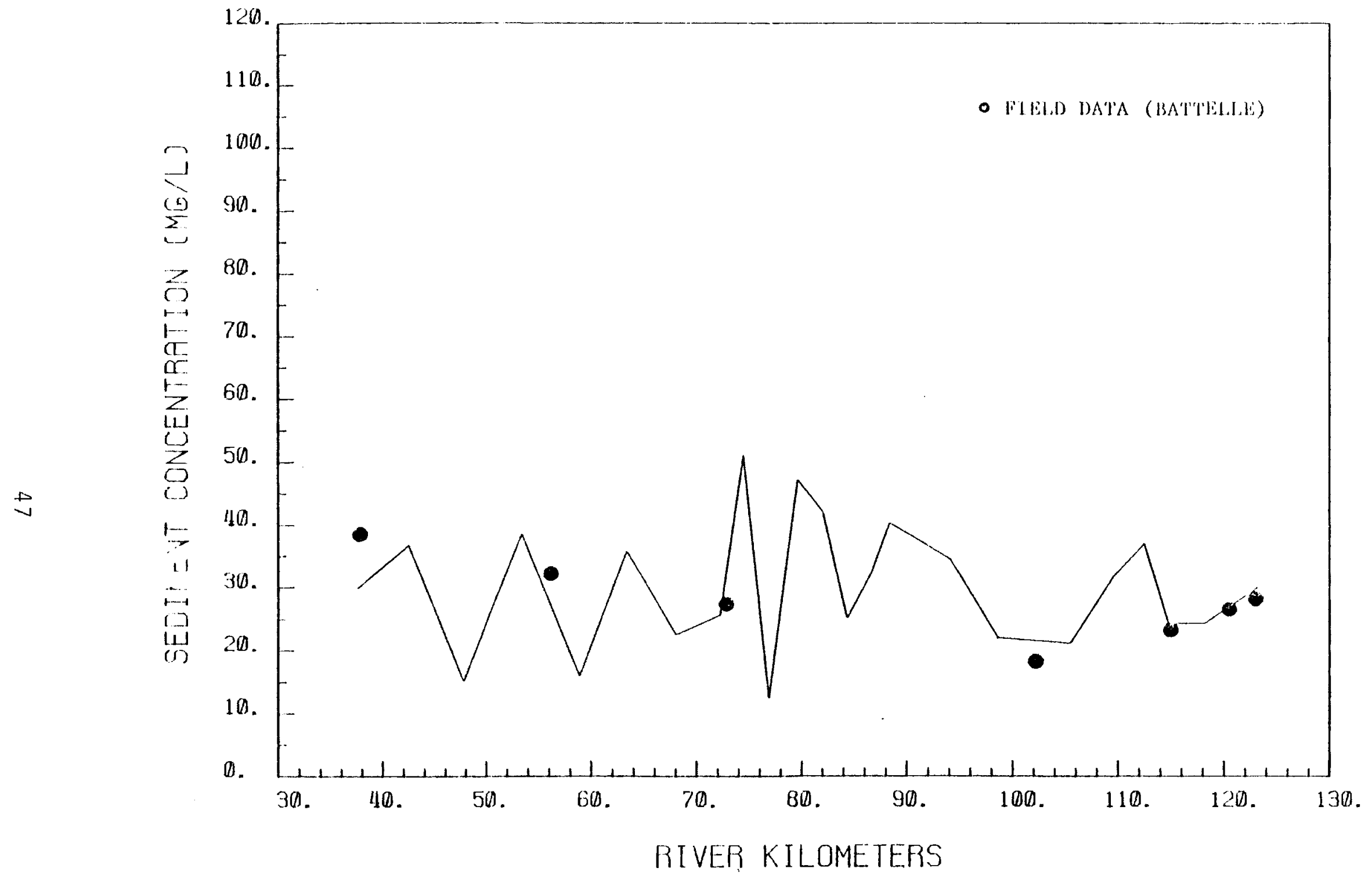

FIGURE 7. Longitudinal Distributions of Total Sediment Concentration at the Slack Tide for the Fresh-Water Discharge of $58.3 \mathrm{~m} 3 / \mathrm{sec}$, Together with Field Data 


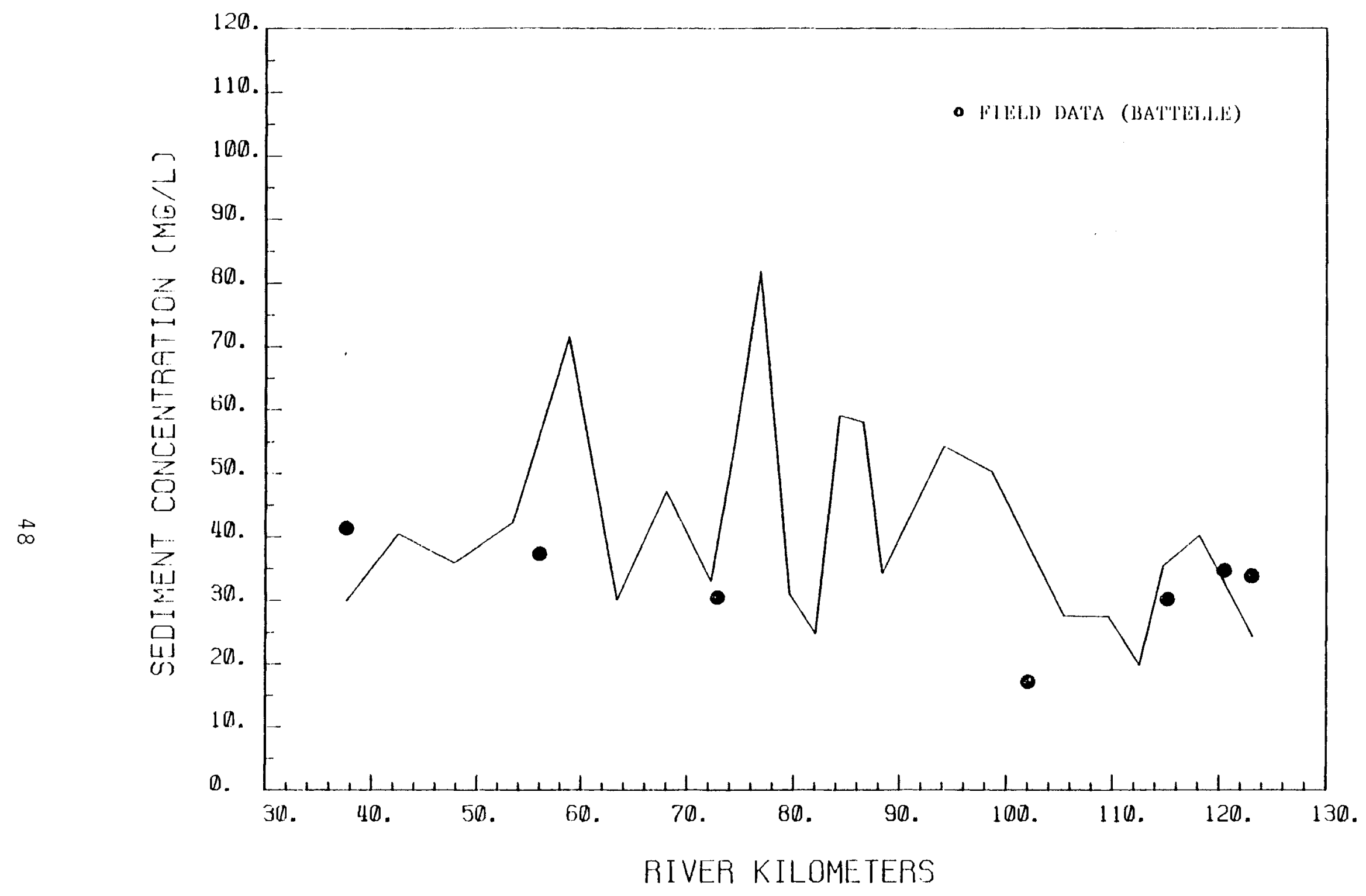

FIGURE 8. Longitudinal Distributions of Total Sediment Concentration at the Maximum Flood Tide for the Fresh-Water Discharge of $58.3 \mathrm{~m}^{3} / \mathrm{sec}$, Together with Field Data 


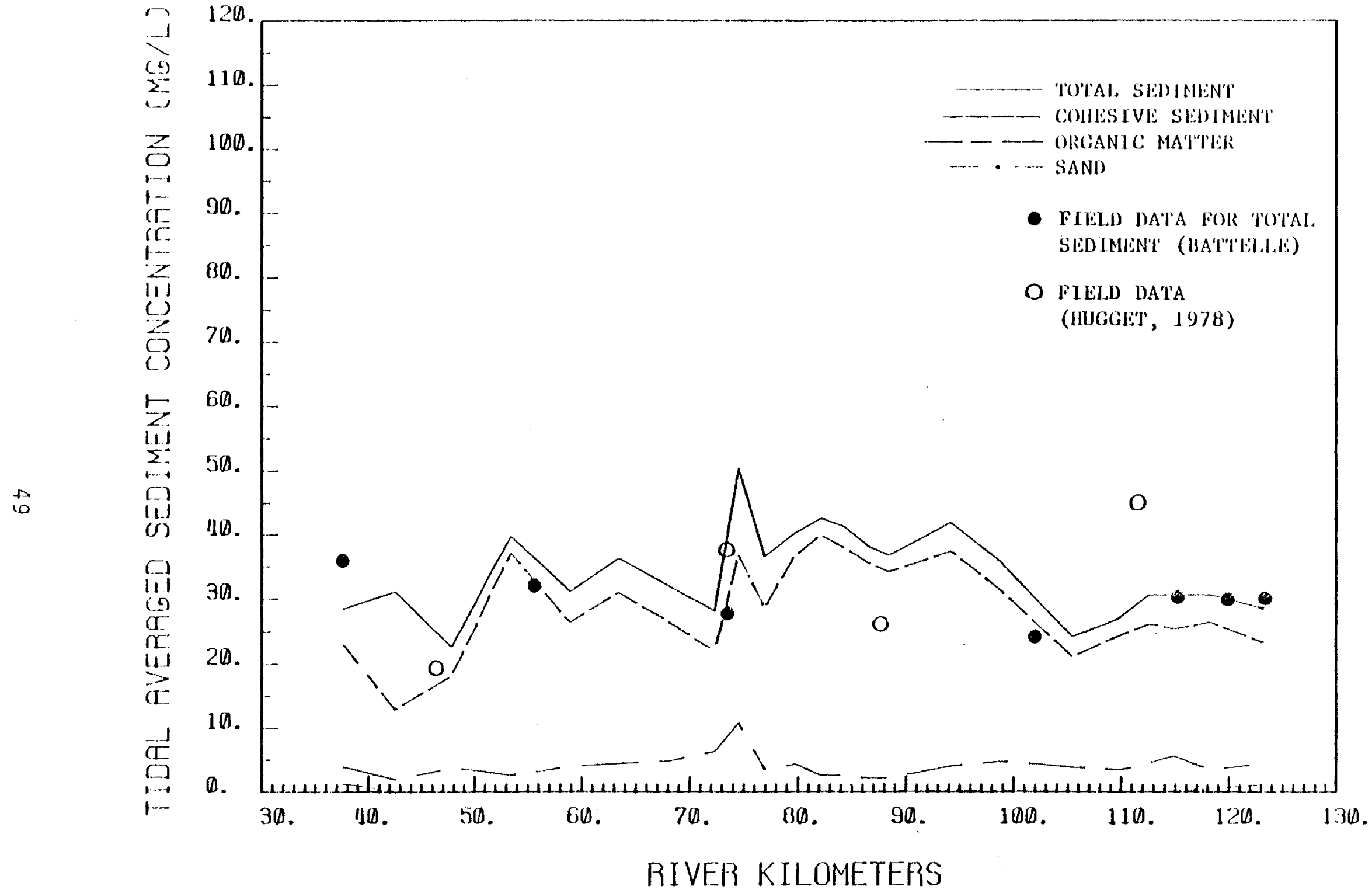

FIGURE 9. Tidal Averaged Sediment Concentration of Each Sediment Type for the FreshWater Discharge of $58.3 \mathrm{~m}^{3} / \mathrm{sec}$ 


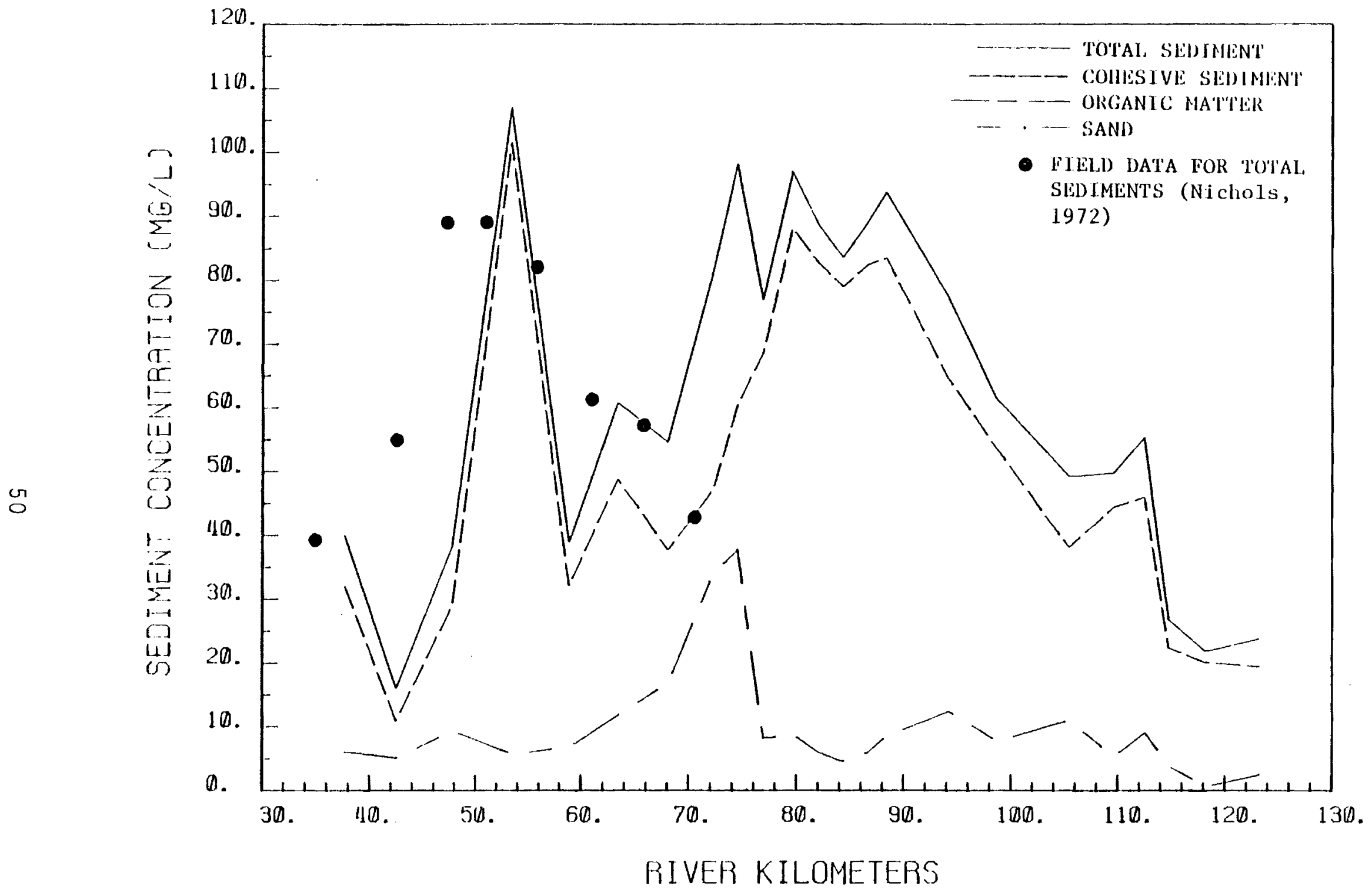

FIGURE 10. Longitudinal Distribution of Sediment Concentration of Each Sediment Type at Slack Tide for the Fresh-Water Discharge of $247 \mathrm{~m} 3 / \mathrm{sec}$ 


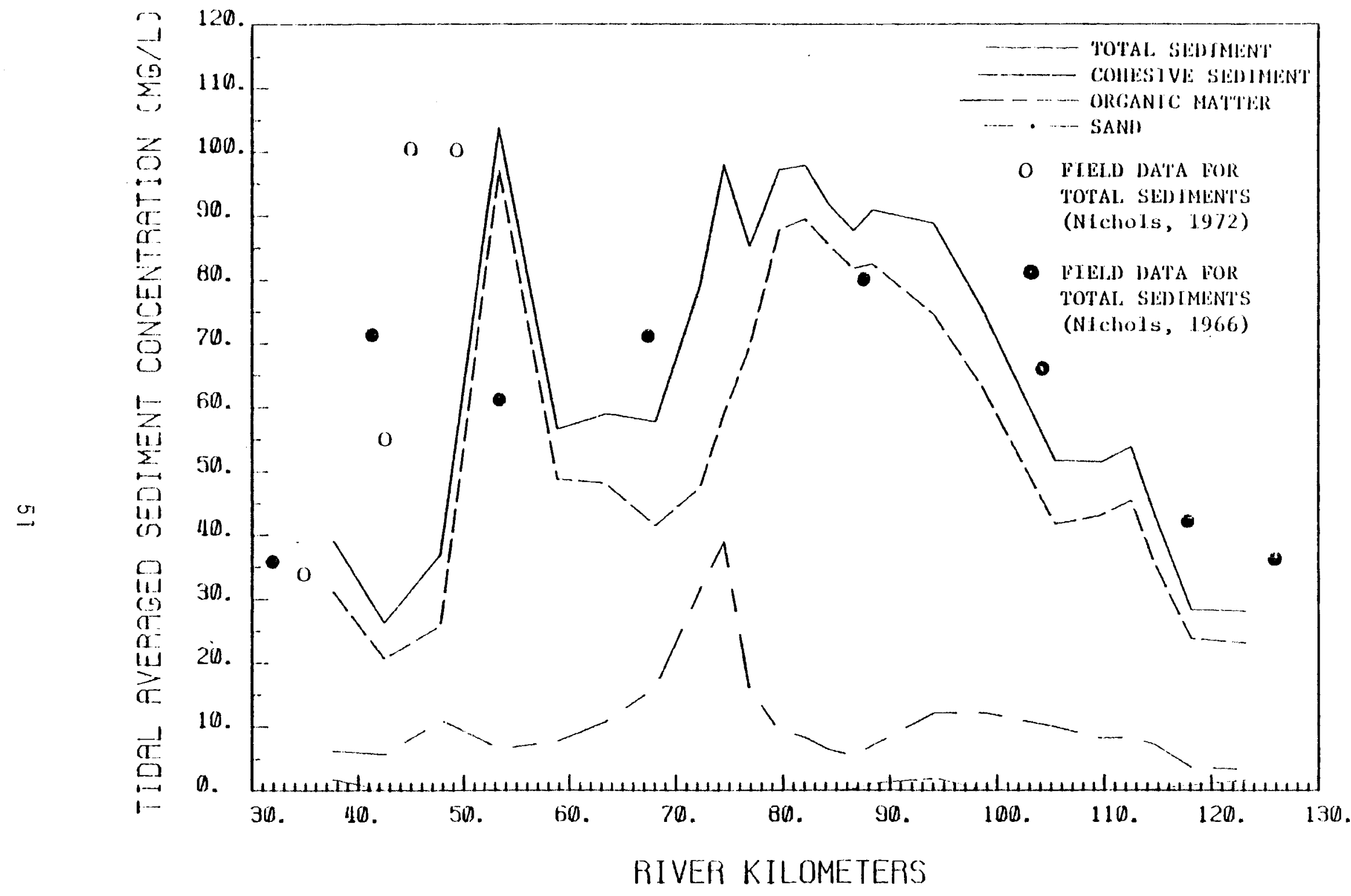

FIGURE 11. Tidal Averaged Sediment Concentration of Each Sediment Type for the FreshWater Discharge of $247 \mathrm{~m}^{3} / \mathrm{sec}$ 


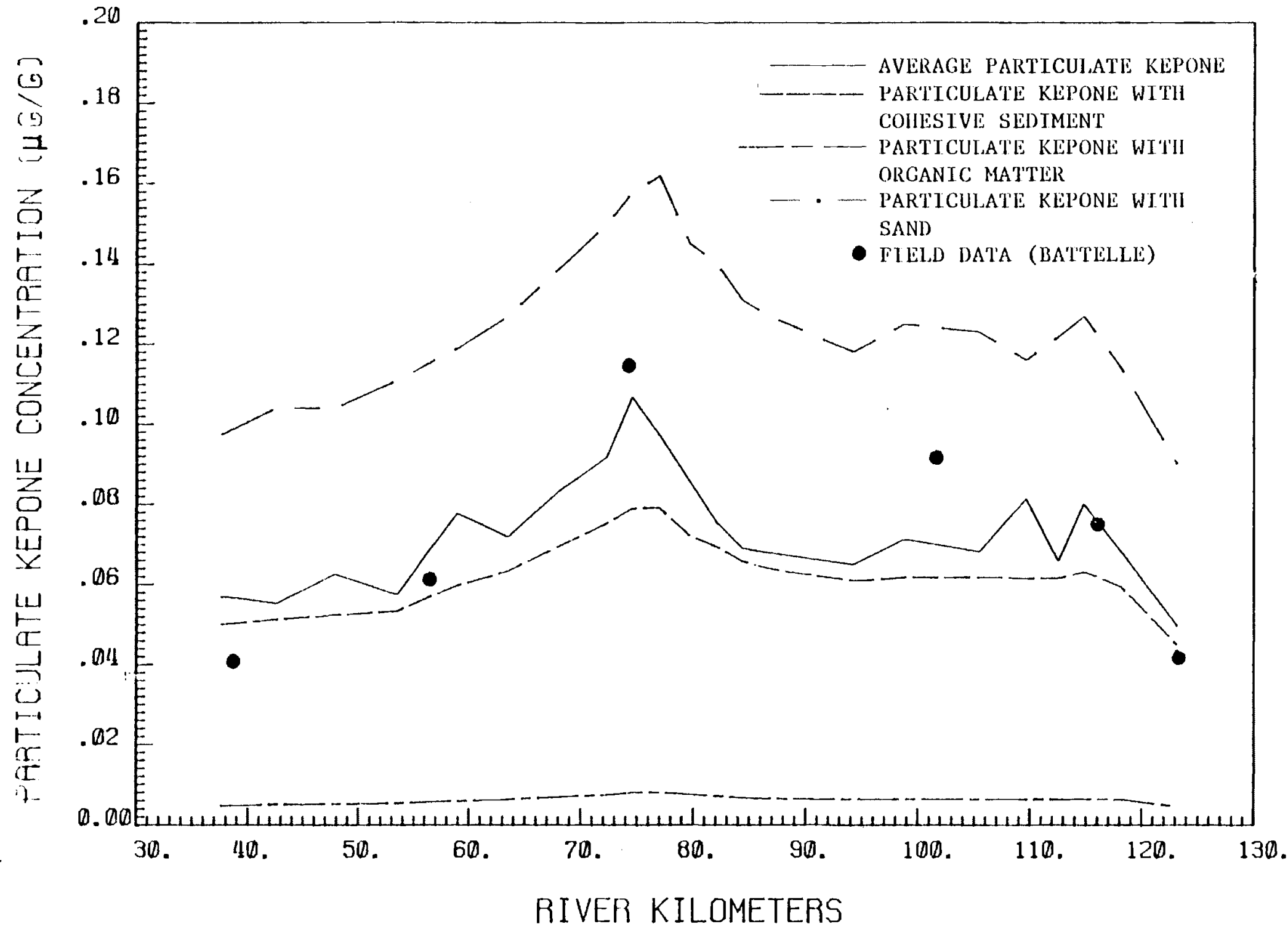

FIGURE 12. Longitudinal Distributions of Particulate Kepone Concentrations at Maximum Ebb Tide for the Fresh-Water Discharge to $58.3 \mathrm{~m} 3 / \mathrm{sec}$ 


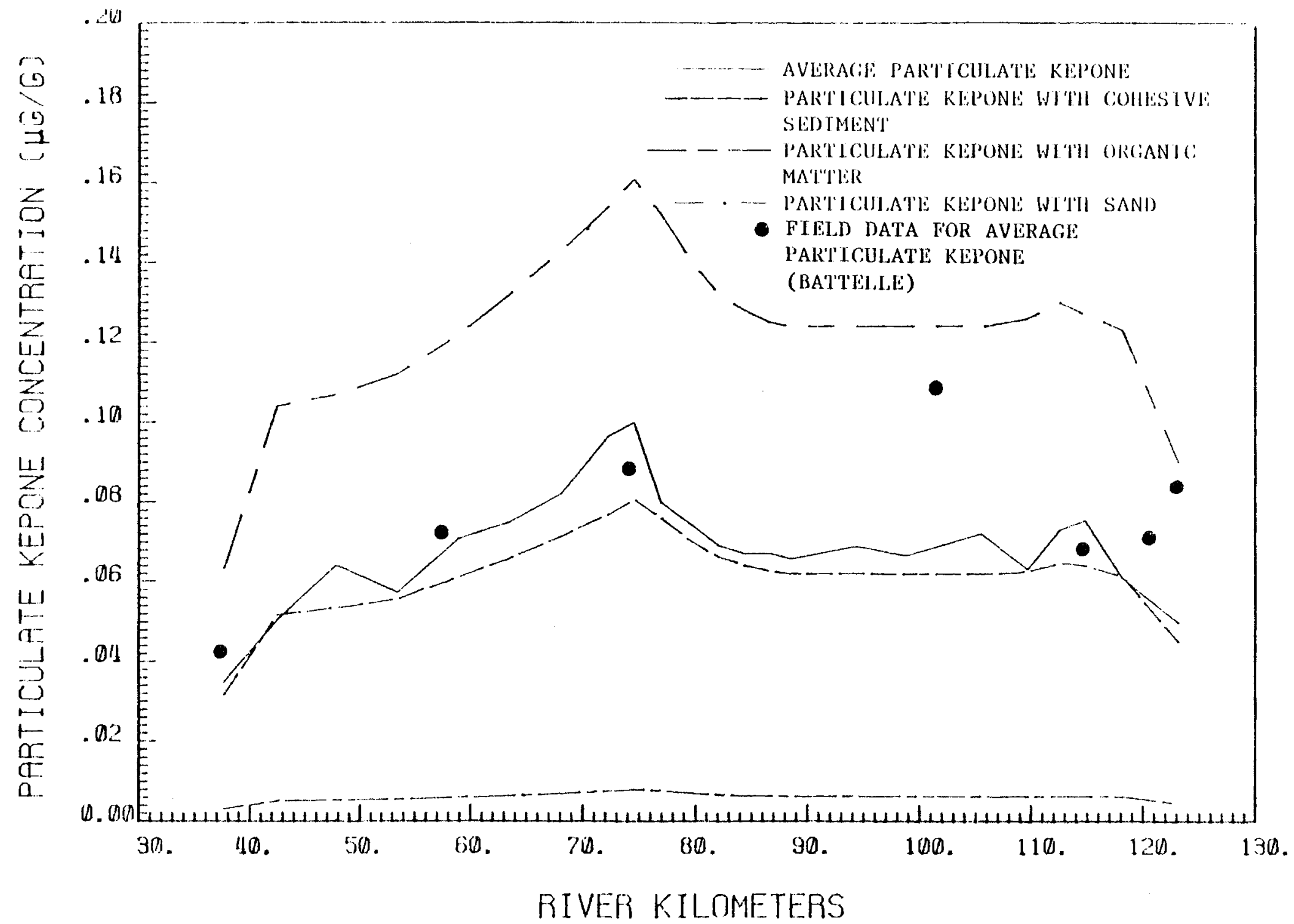

FIGURE 13. Longitudinal Distributions of Particulate Kepone Concentrations at Slack Tide for the Fresh-Water Discharge of $58.3 \mathrm{~m} 3 / \mathrm{sec}$ 


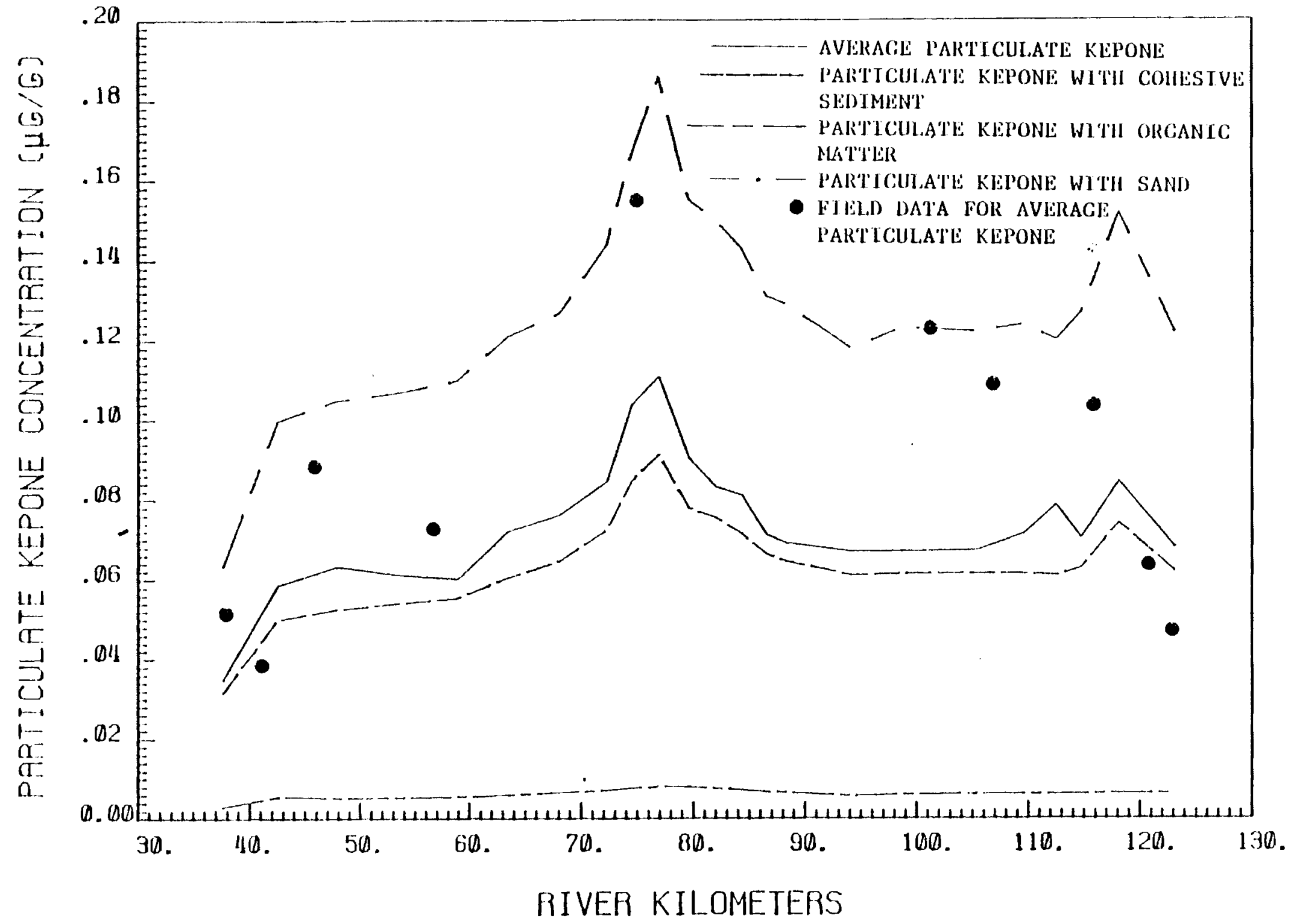

FIGURE 14. Longitudinal Distributions of Particulate Kepone Concentrations at Maximum Flood Tide for the Fresh-Water Discharge of $58.3 \mathrm{~m} 3 / \mathrm{sec}$ 


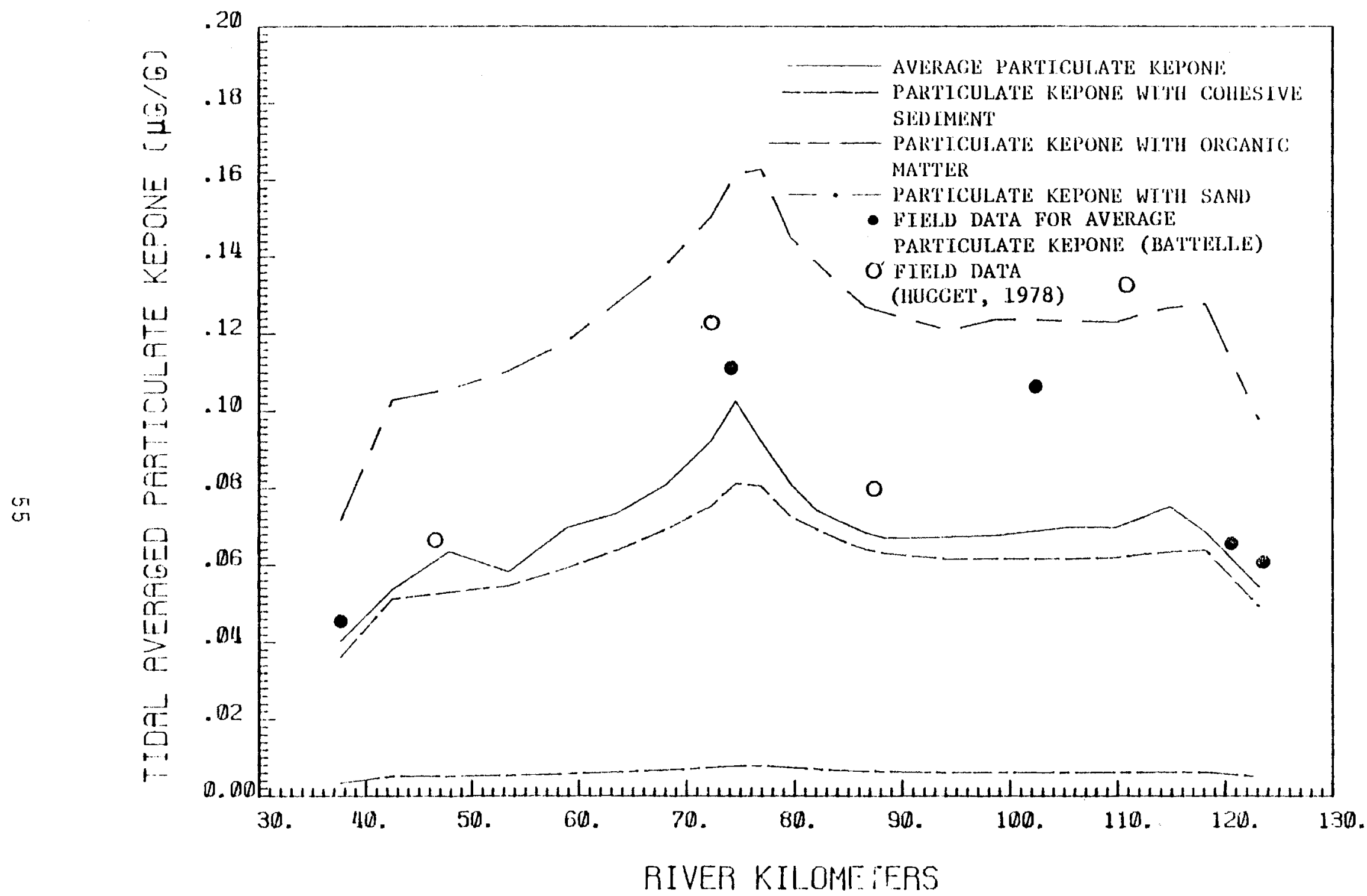

FIGURE 15. Tidal Averaged Particulate Kepone Concentrations for the Fresh-Water Discharge of $58.3 \mathrm{~m}^{3} / \mathrm{sec}$ 


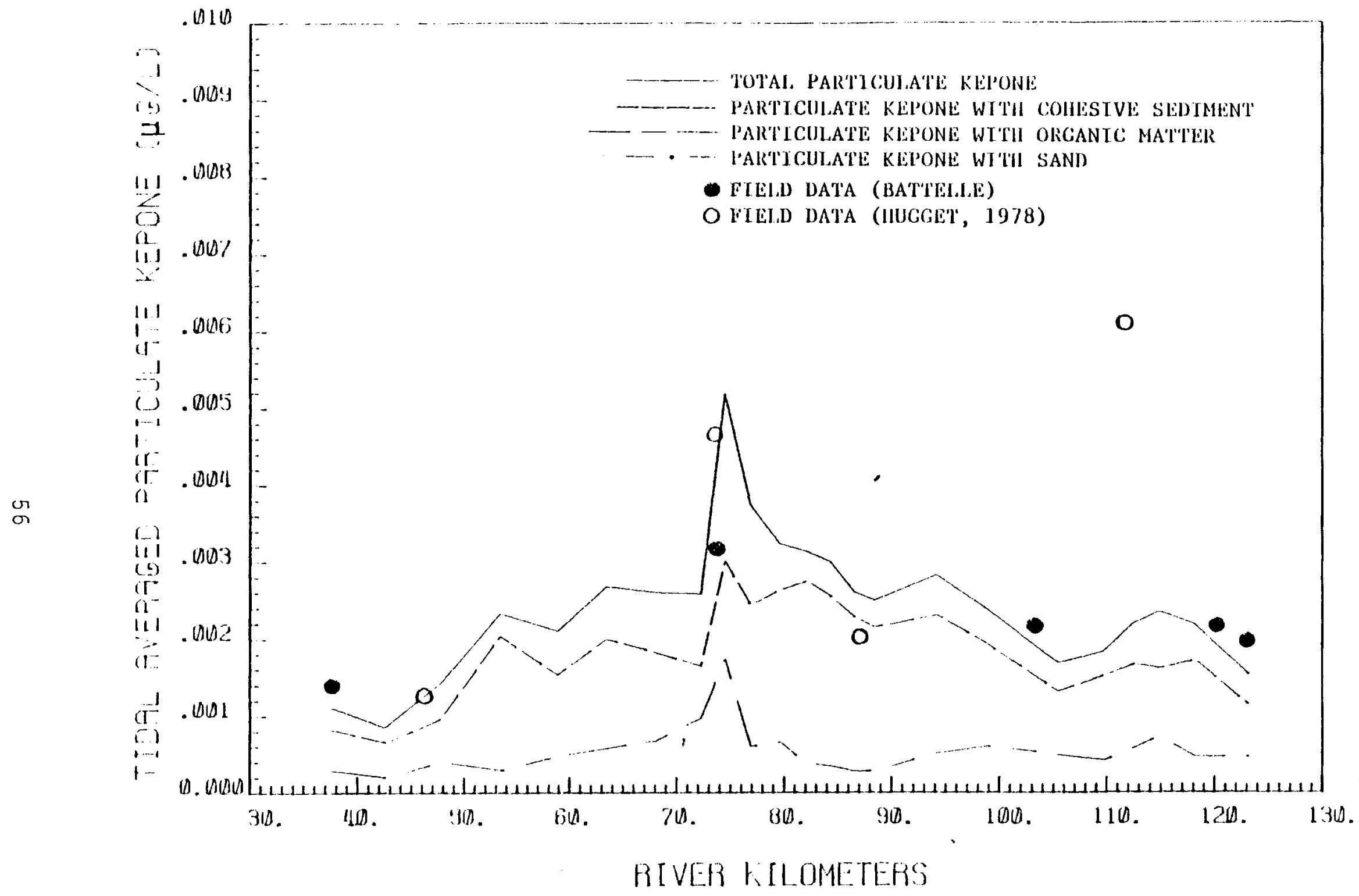

FIGURE 16. Longitudinal Distributions of Tidal Averaged Particular Kepone Concentrations Per Unit Volume of Water for the Fresh-Water Discharge of $58.3 \mathrm{~m} 3 / \mathrm{sec}$ 


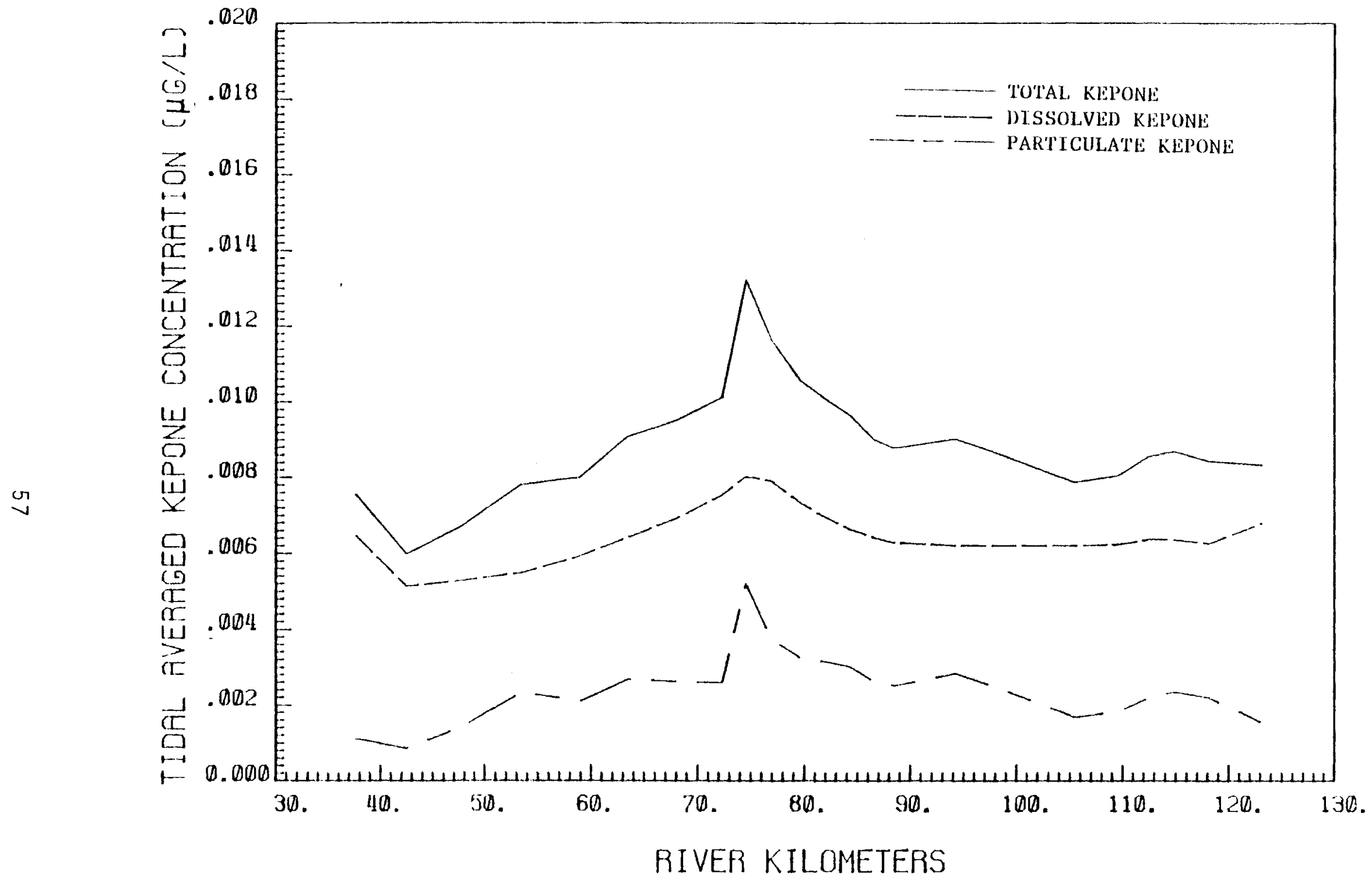

FIGURE 17. Longitudinal Distributions of Tidal Averaged Tota1, Dissolved and Particulate Kepone Concentrations for the Fresh-Water Discharge of $58.3 \mathrm{~m}^{3} / \mathrm{sec}$ 


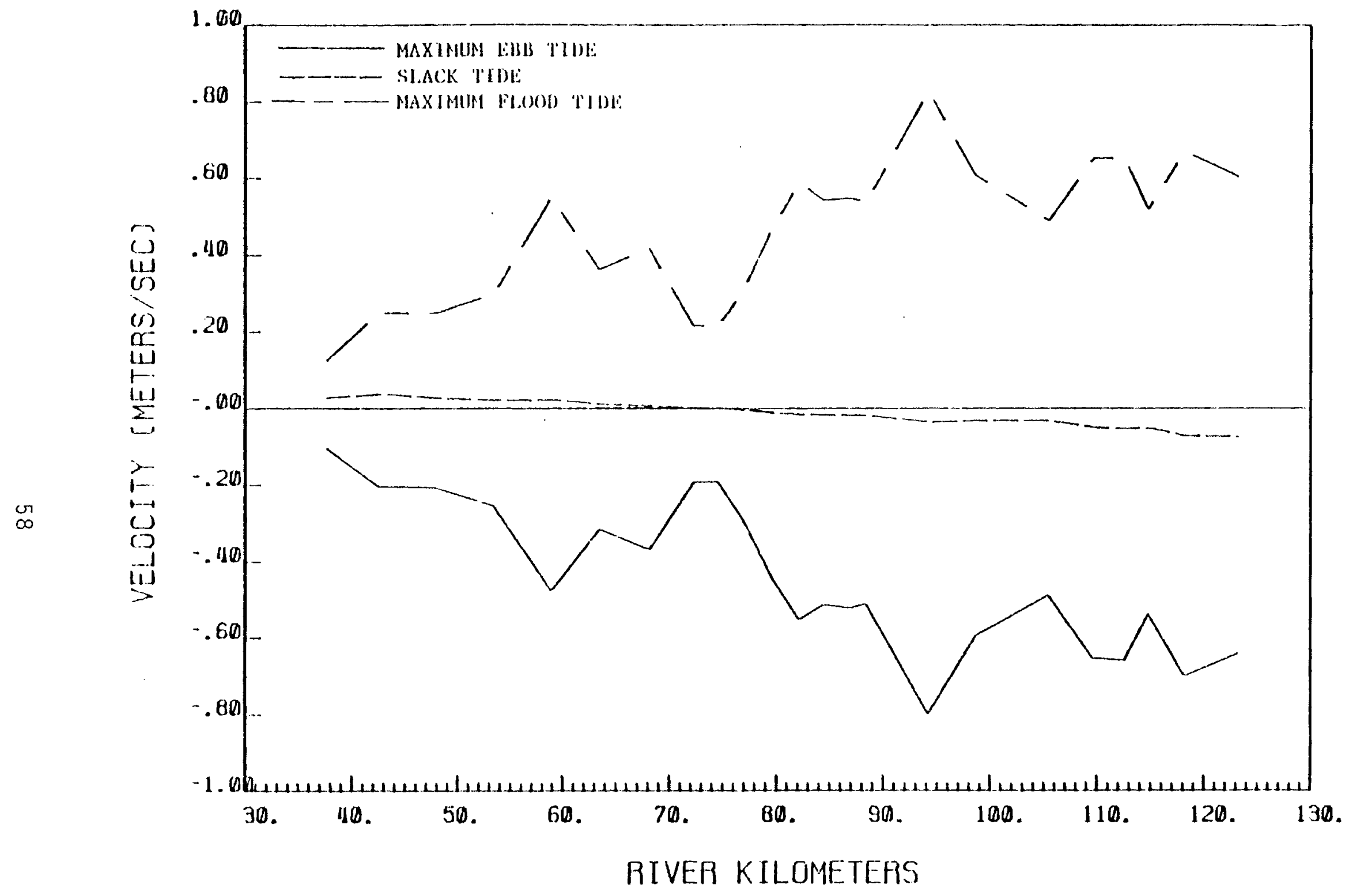

FIGURE 18. Longitudinal Velocity Distributions at Maximum Ebb, Slack and the Maximum Flood Tides for Fresh-Water Input Discharge of $58.3 \mathrm{~m}^{3} / \mathrm{sec}$ 


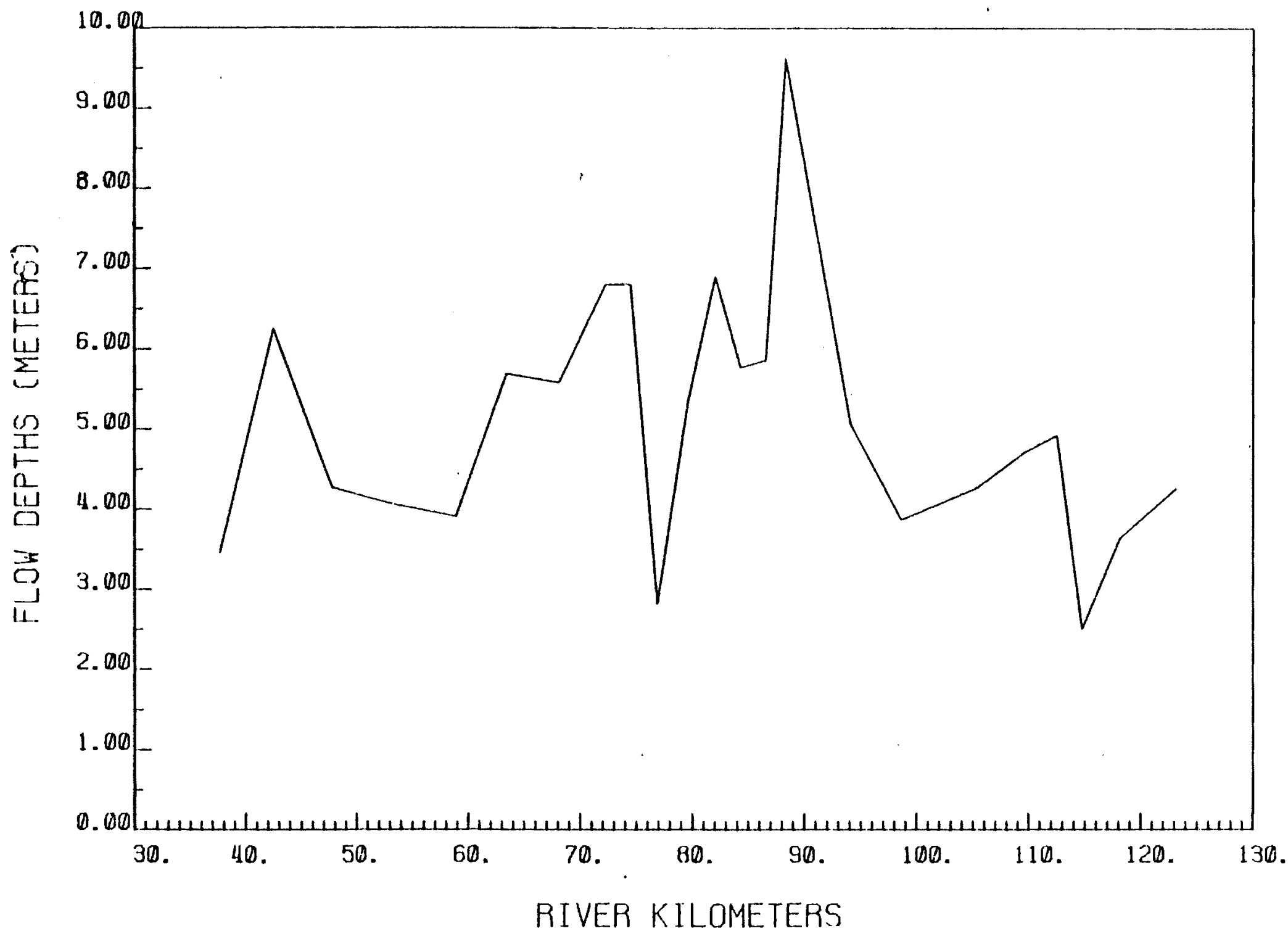

FIGURE 19. Longitudinal Depth Variation at Maximum Ebb Tide for the Fresh-Water Discharge of $58.3 \mathrm{~m}^{3} / \mathrm{sec}$ 


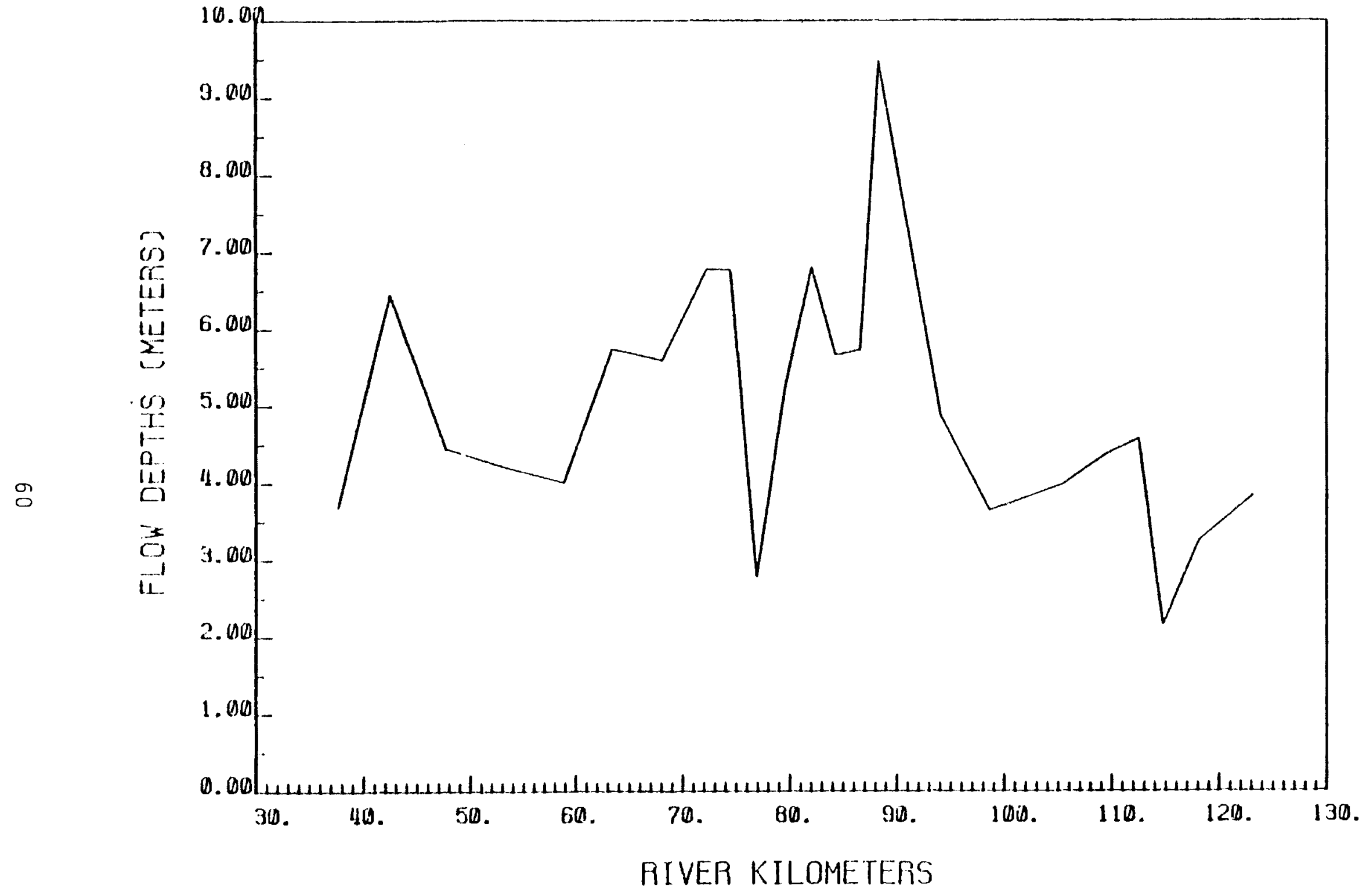

FIGURE 20. Longitudinal Depth Variation at Slack Tide for the Fresh-Water Discharge of $58.3 \mathrm{~m}^{3} / \mathrm{sec}$ 


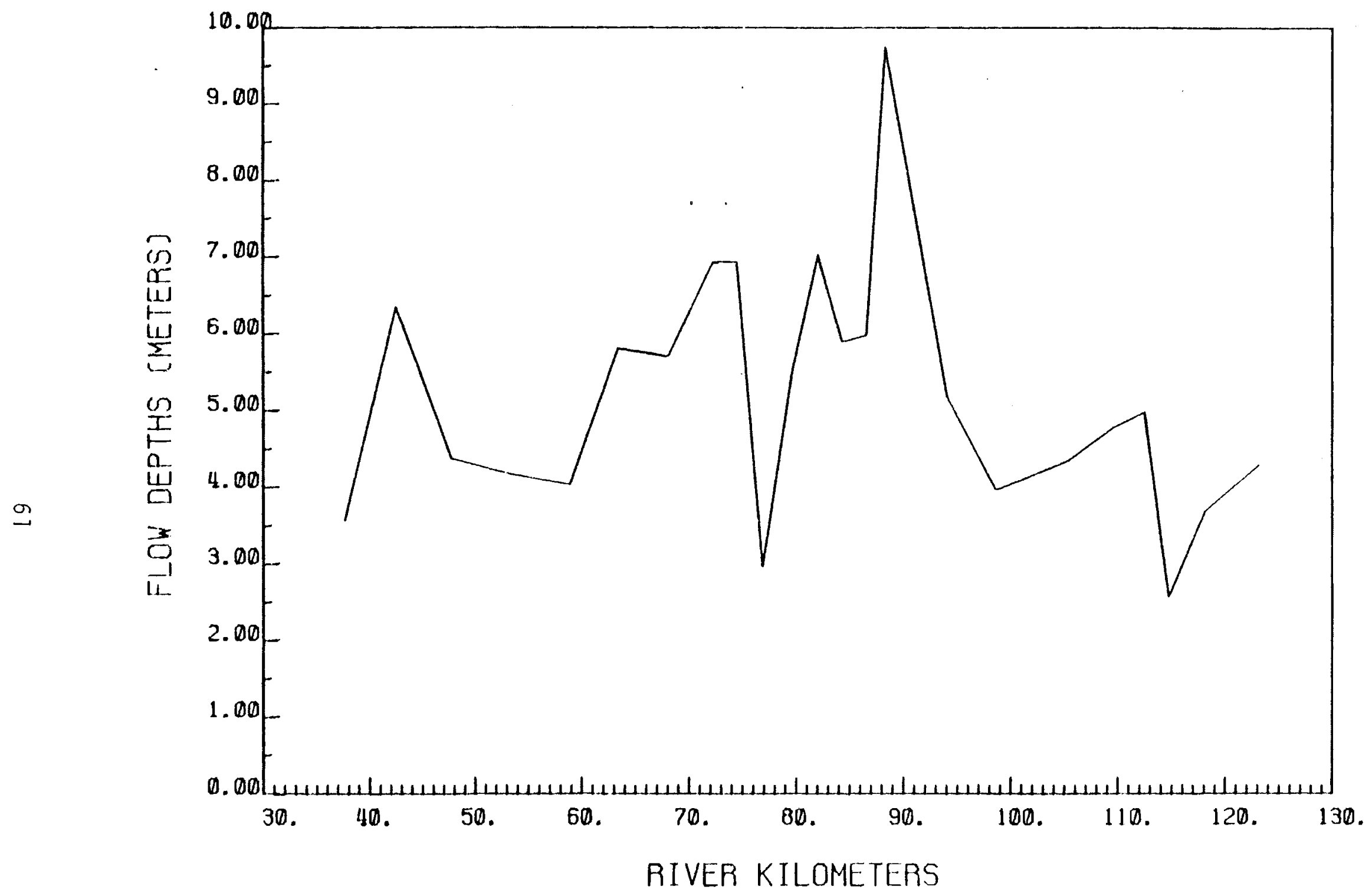

FIGURE 21. Longitudinal Depth Variations at Maximum Flood Tide for the Fresh-Water Discharge of $58.3 \mathrm{~m}^{3} / \mathrm{sec}$ 


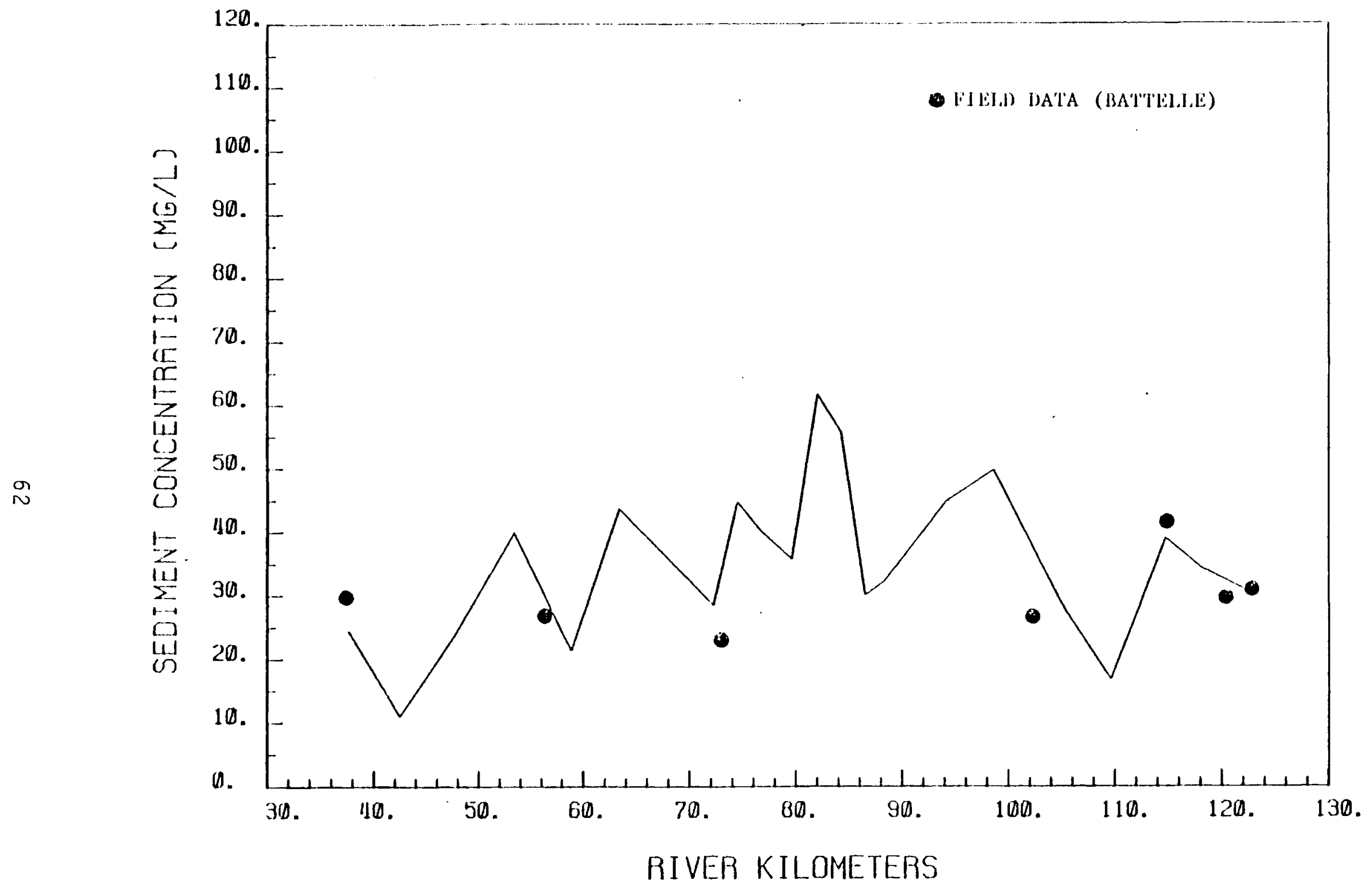

FIGURE 22. Longitudinal Distributions of Total Sediment Concentration at the Maximum Ebb Tide for the Fresh-Water Discharge of $58.3 \mathrm{~m}^{3} / \mathrm{sec}$, Together with Field Data 


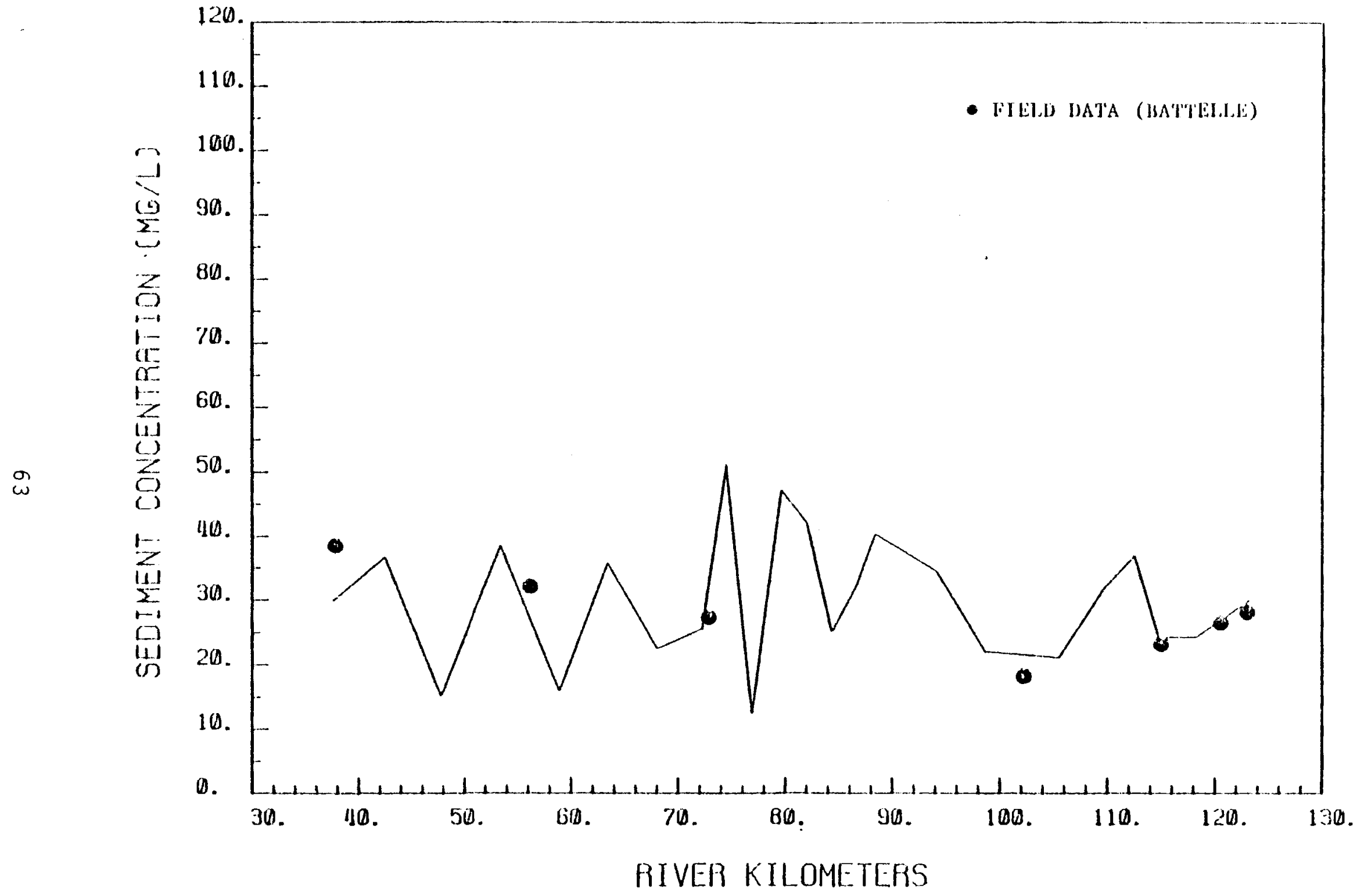

FIGURE 23. Longitudinal Distributions of Total Sediment Concentration at the Slack Tide for the Fresh-Water Discharge of $58.3 \mathrm{~m}^{3} / \mathrm{sec}$, Together with Field Data 


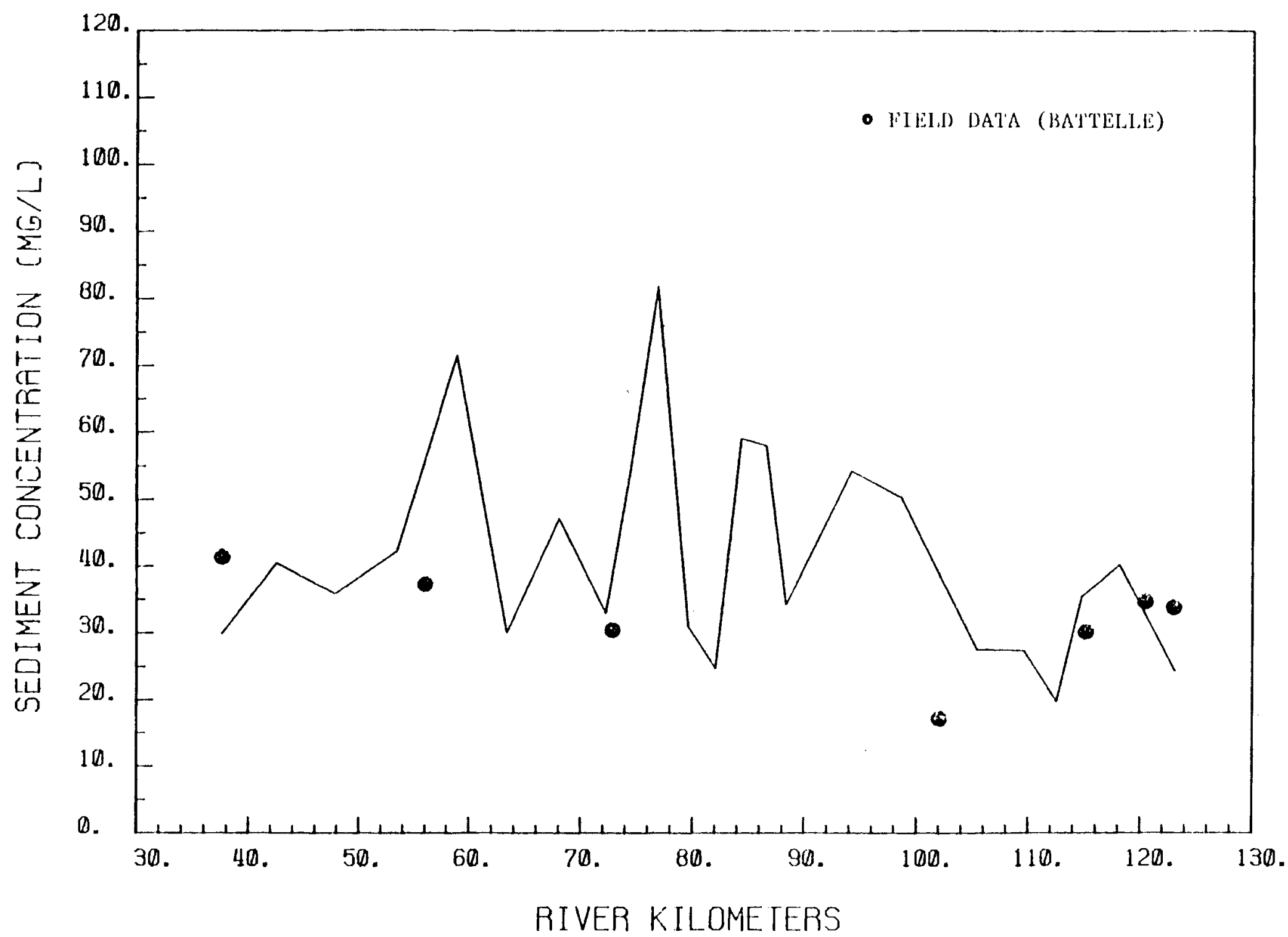

FIGURE 24. Longitudinal Distributions of Total Sediment Concentration at the Maximum Flood Tide for the Fresh-Water Discharge of $58.3 \mathrm{~m}^{3} / \mathrm{sec}$, Together with Field Data 


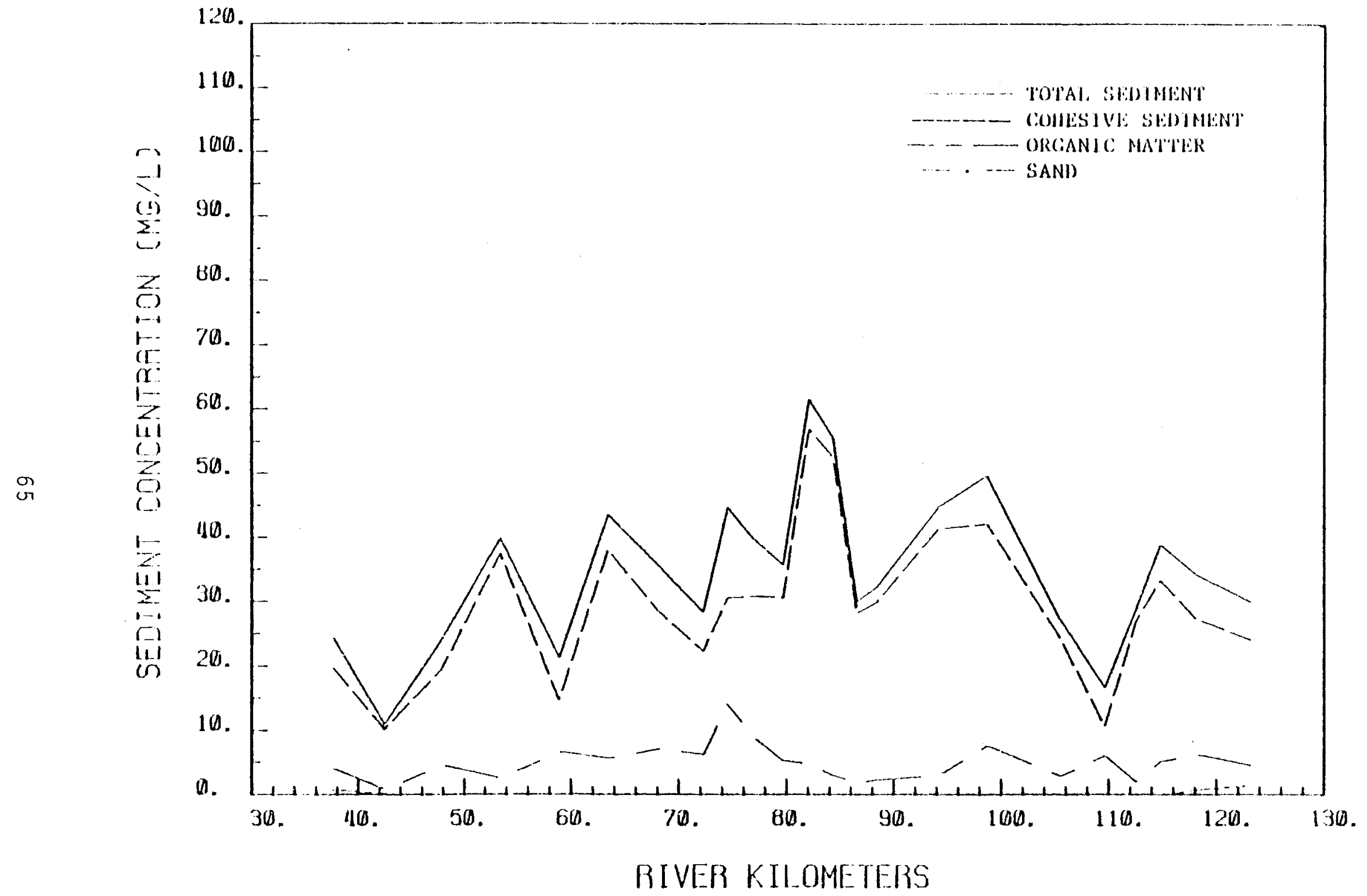

FIGURE 25. Longitudinal Distribution of Sediment Concentration of Each Sediment Type at Maximum Ebb Tide for the Fresh-Water Discharge of $58.3 \mathrm{~m}^{3} / \mathrm{sec}$ 


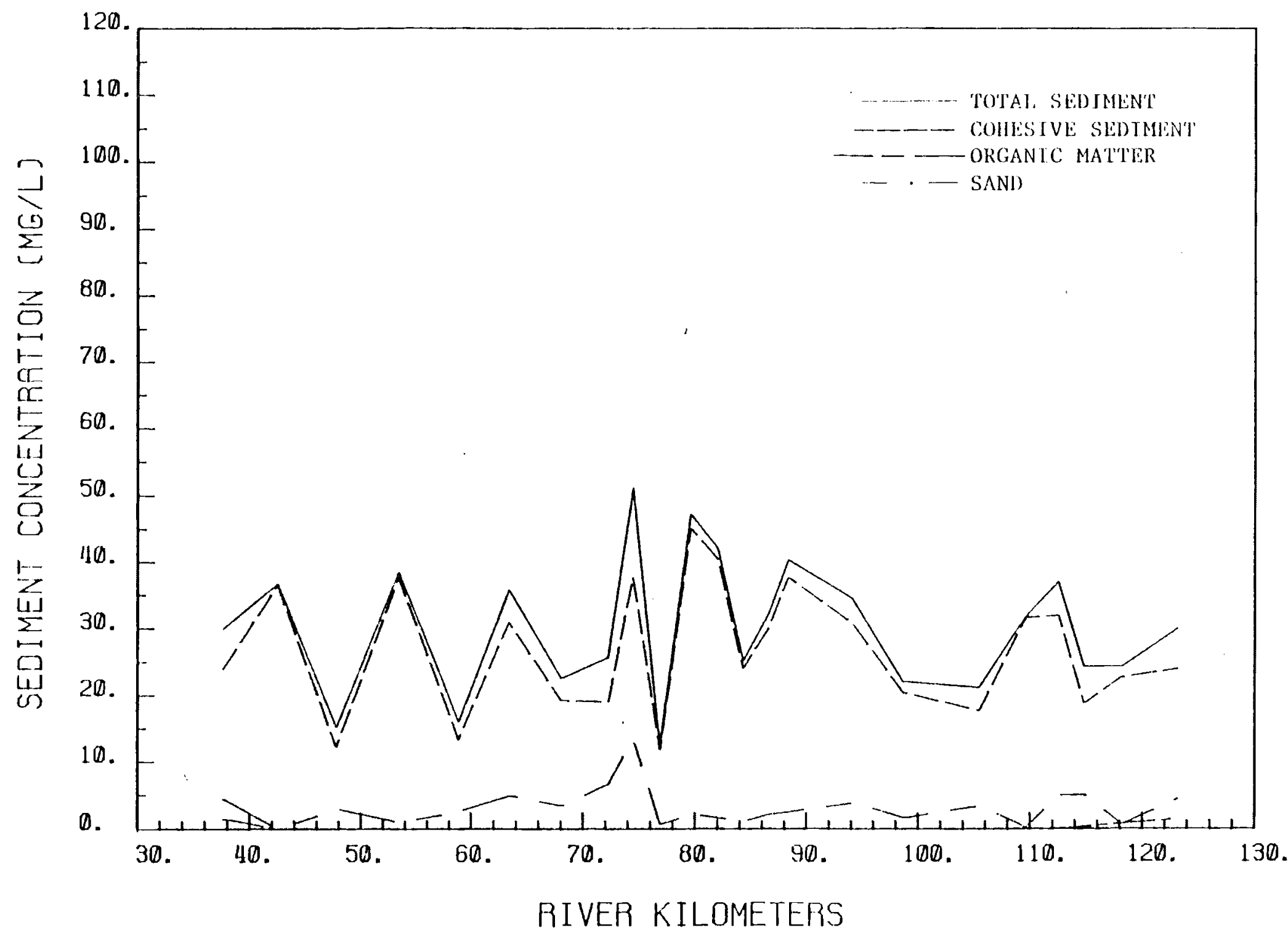

FIGURE 26. Longitudinal Distribution of Sediment Concentration of Each Sediment Type at STack Tide for the Fresh-Water Discharge of $58.3 \mathrm{~m}^{3} / \mathrm{sec}$ 


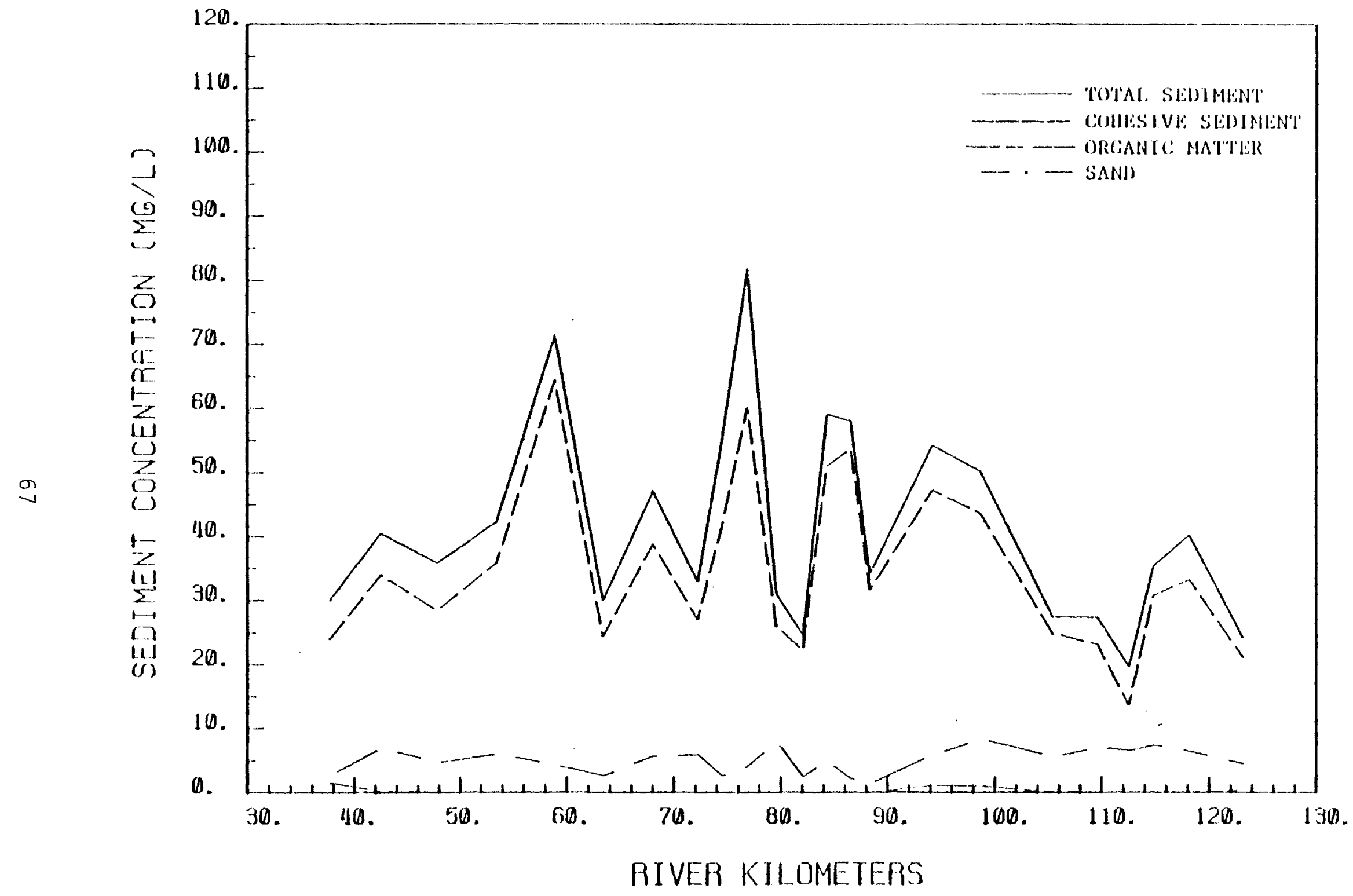

FIGURE 27. Longitudinal Distributions of Sediment Concentration of Each Sediment Type at Maximum Flood Tide for the Fresh-Water Discharge of $58.3 \mathrm{~m}^{3} / \mathrm{sec}$ 


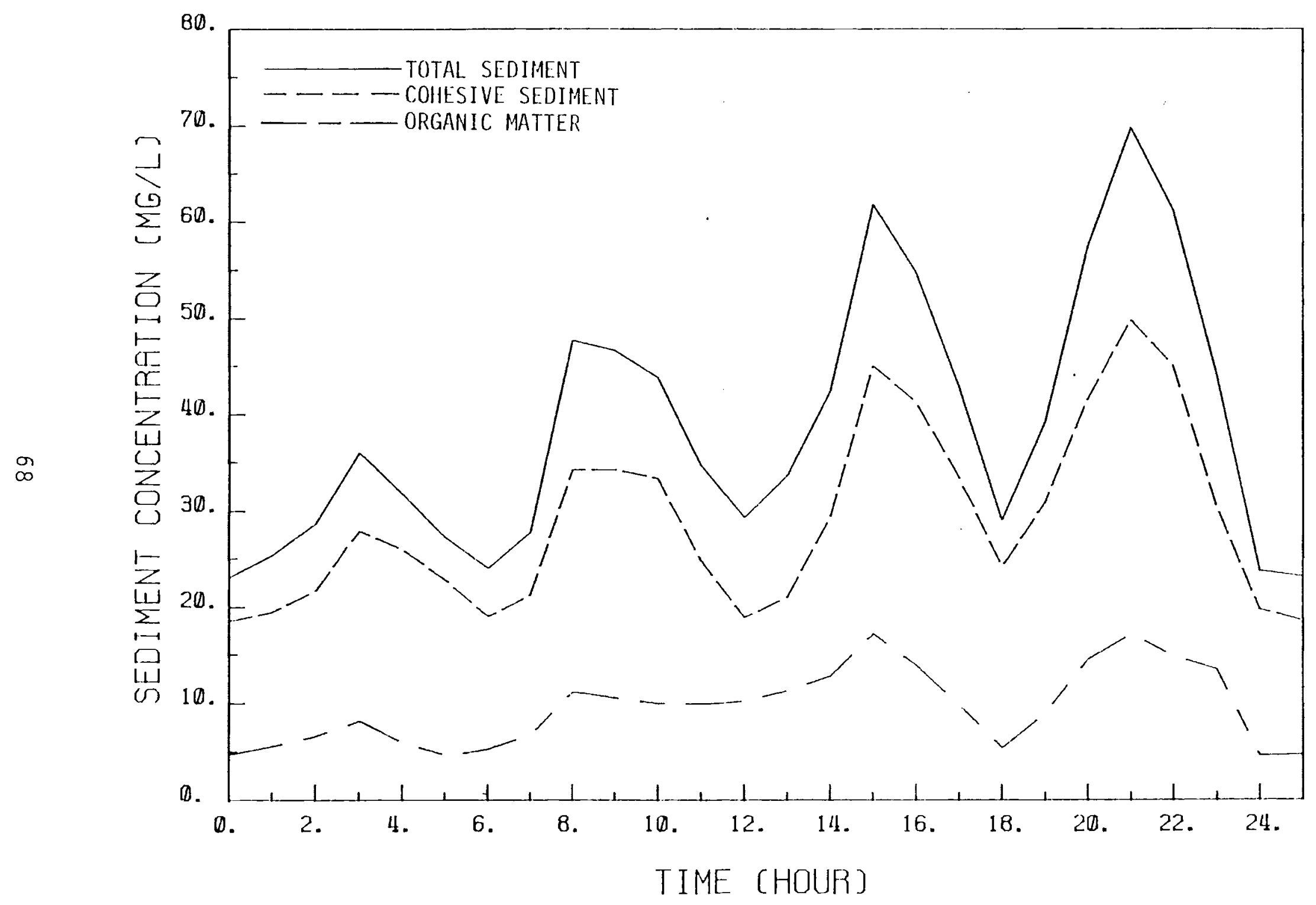

FIGURE 28. Changes of Sediment Concentrations with Time at River Kilometer 75.7 for the Fresh-Water Discharge of $58.3 \mathrm{~m}^{3} / \mathrm{sec}$ 


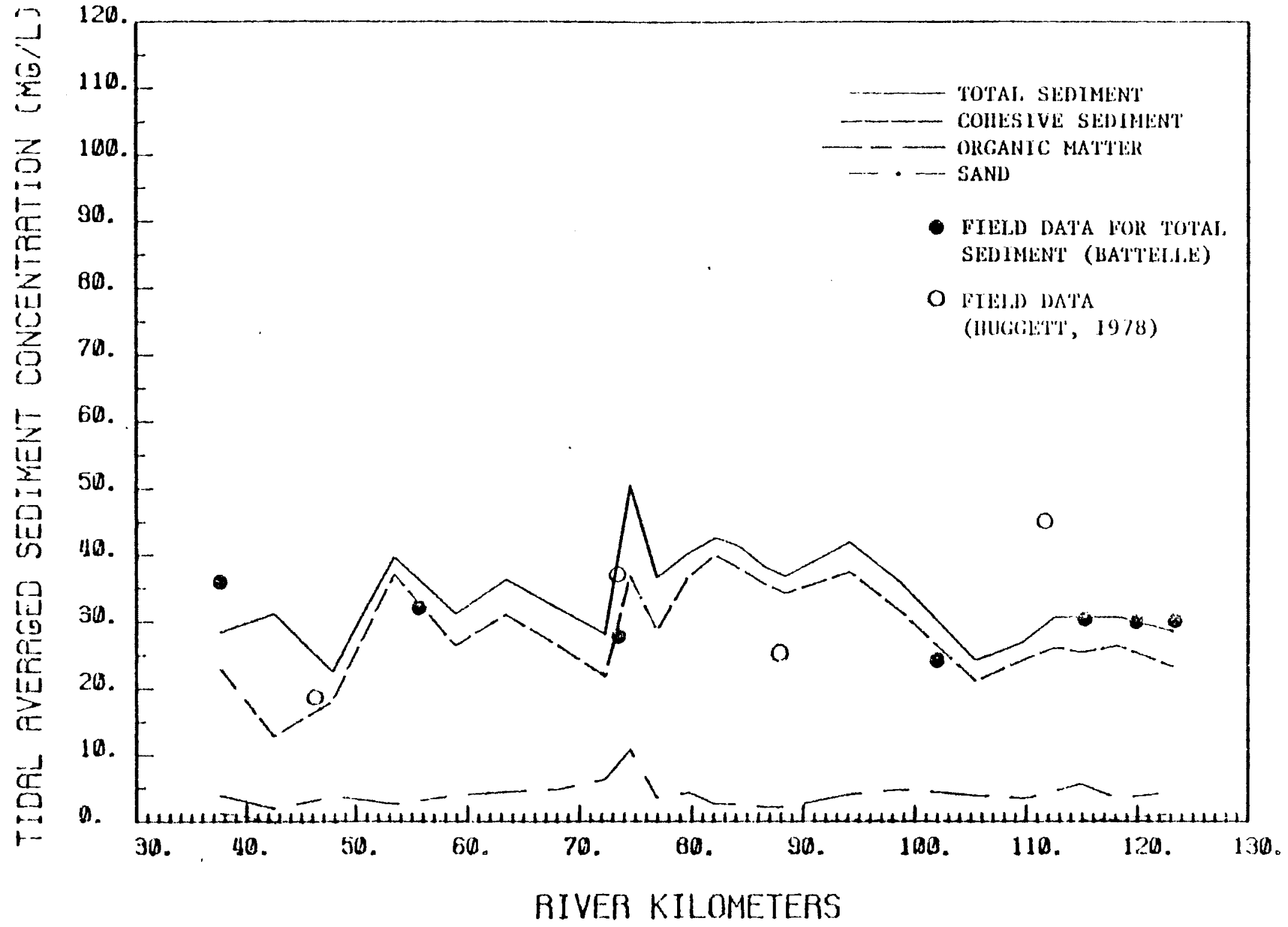

FIGURE 29. Tidal Averaged Sediment Concentration of Each Sediment Type for the Fresh-Water Discharge of $58.3 \mathrm{~m} 3 / \mathrm{sec}$ 


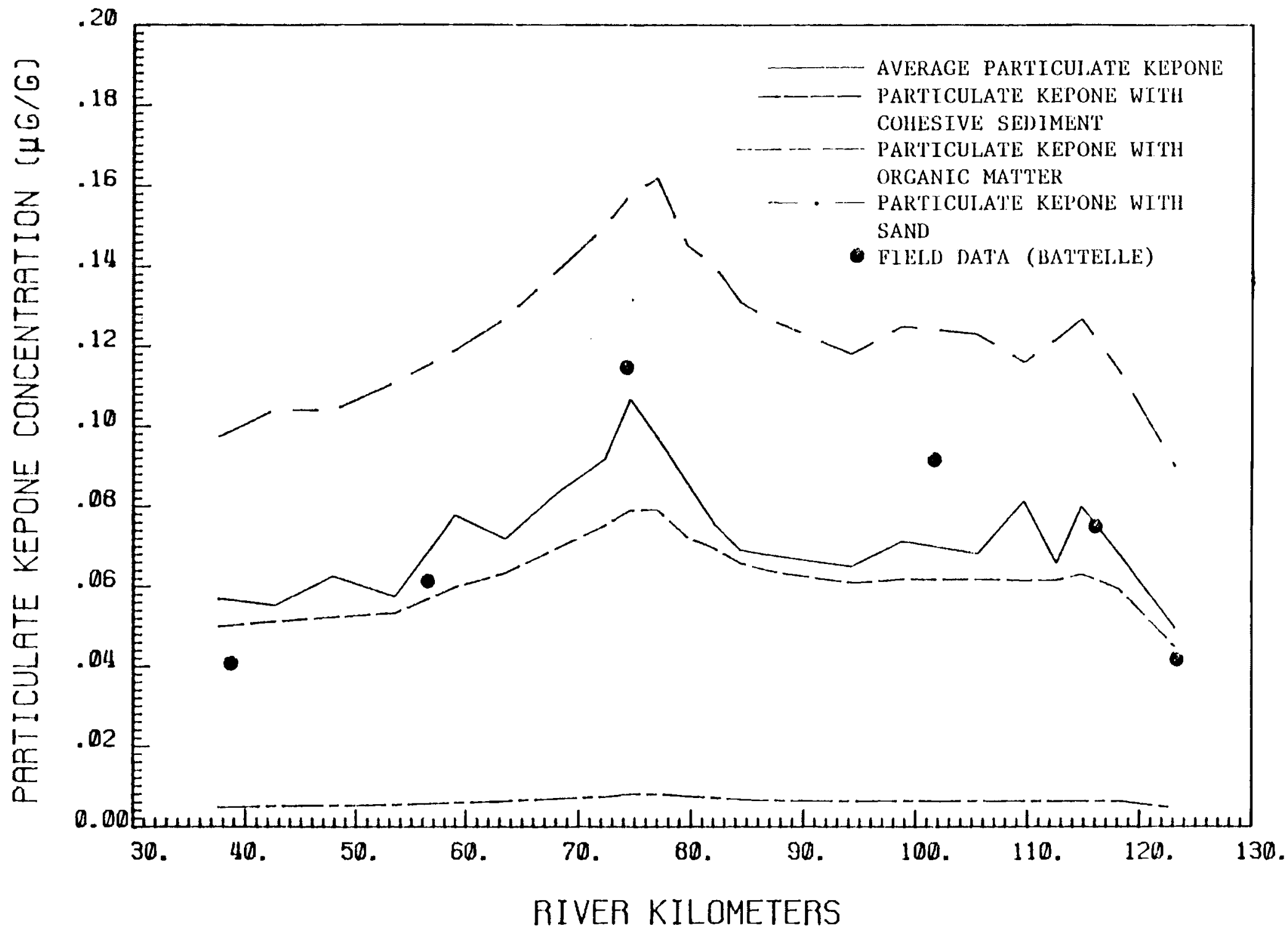

FIGURE 30. Longitudinal Distributions of Particulate Kepone Concentrations at Maximum Ebb Tide for the Fresh-Water Discharge to $58.3 \mathrm{~m}^{3} / \mathrm{sec}$ 


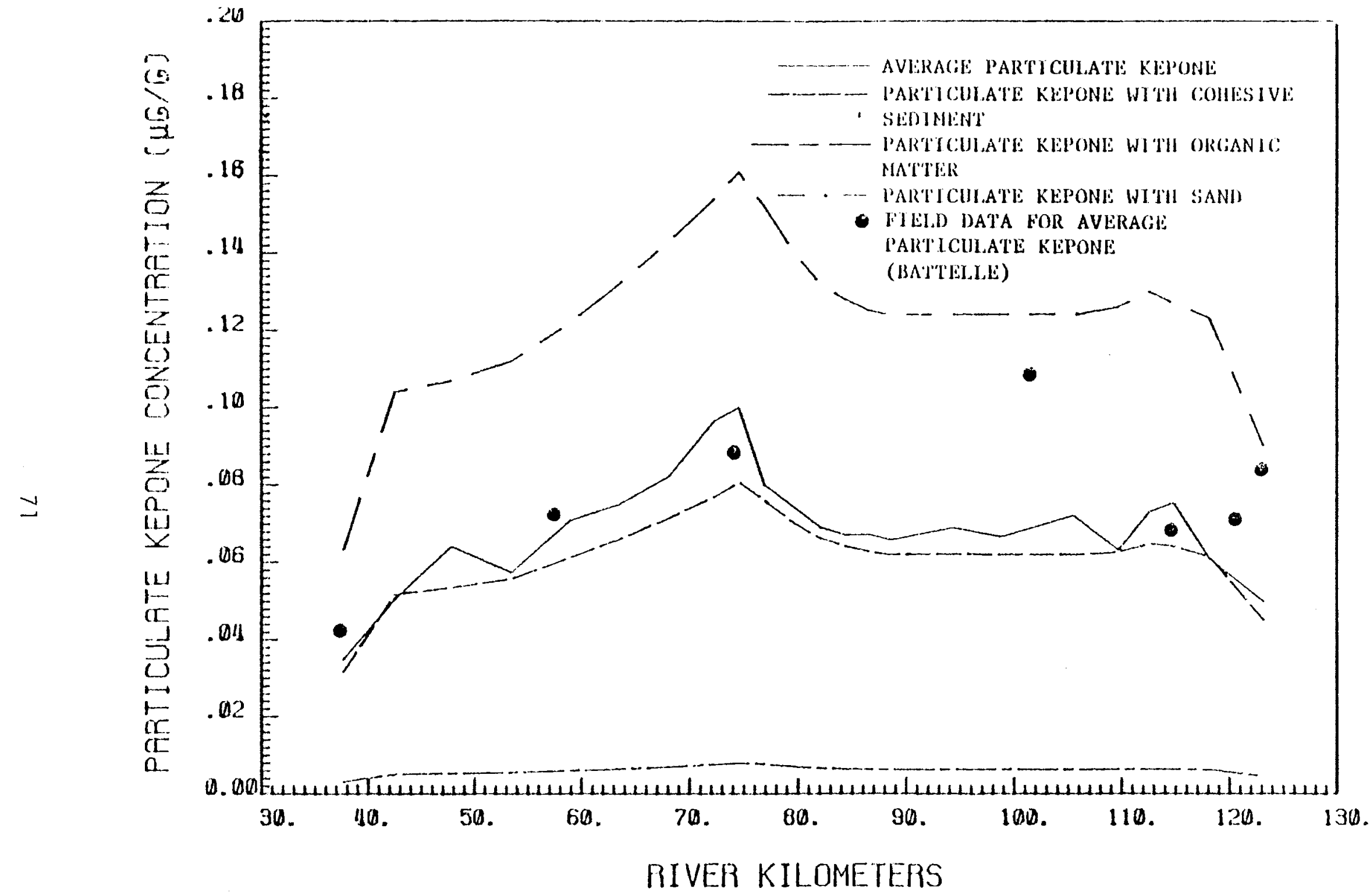

FIGURE 31. Longitudinal Distributions of Particulate Kepone Concentrations at Slack Tide for the Fresh-Water Discharge $58.3 \mathrm{~m} / \mathrm{sec}$ 


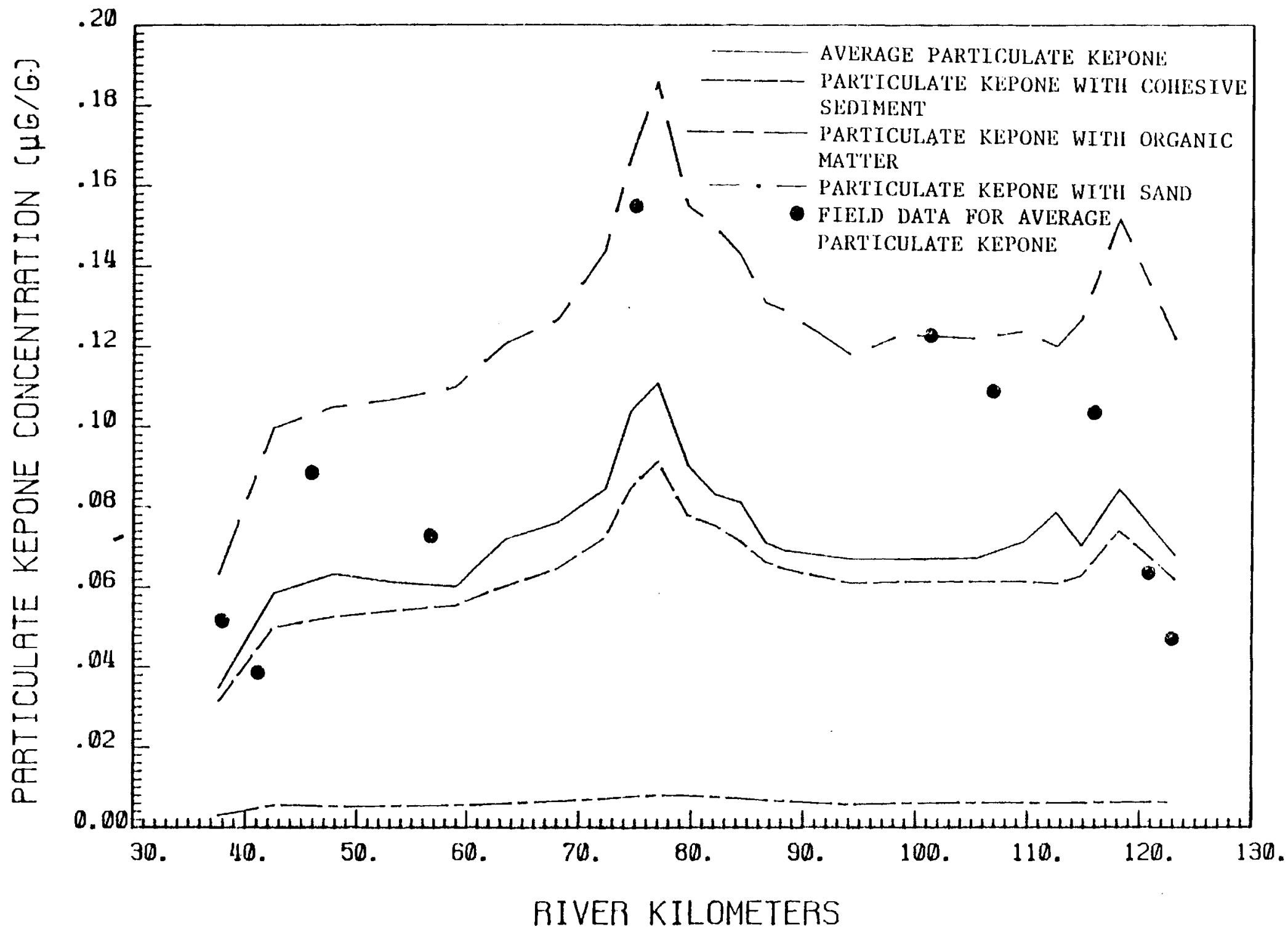

FIGURE 32. Longitudinal Distributions of Particulate Kepone Concentrations of Maximum Flood Tide for the Fresh-Water Discharge of $58.3 \mathrm{~m}^{3} / \mathrm{sec}$ 


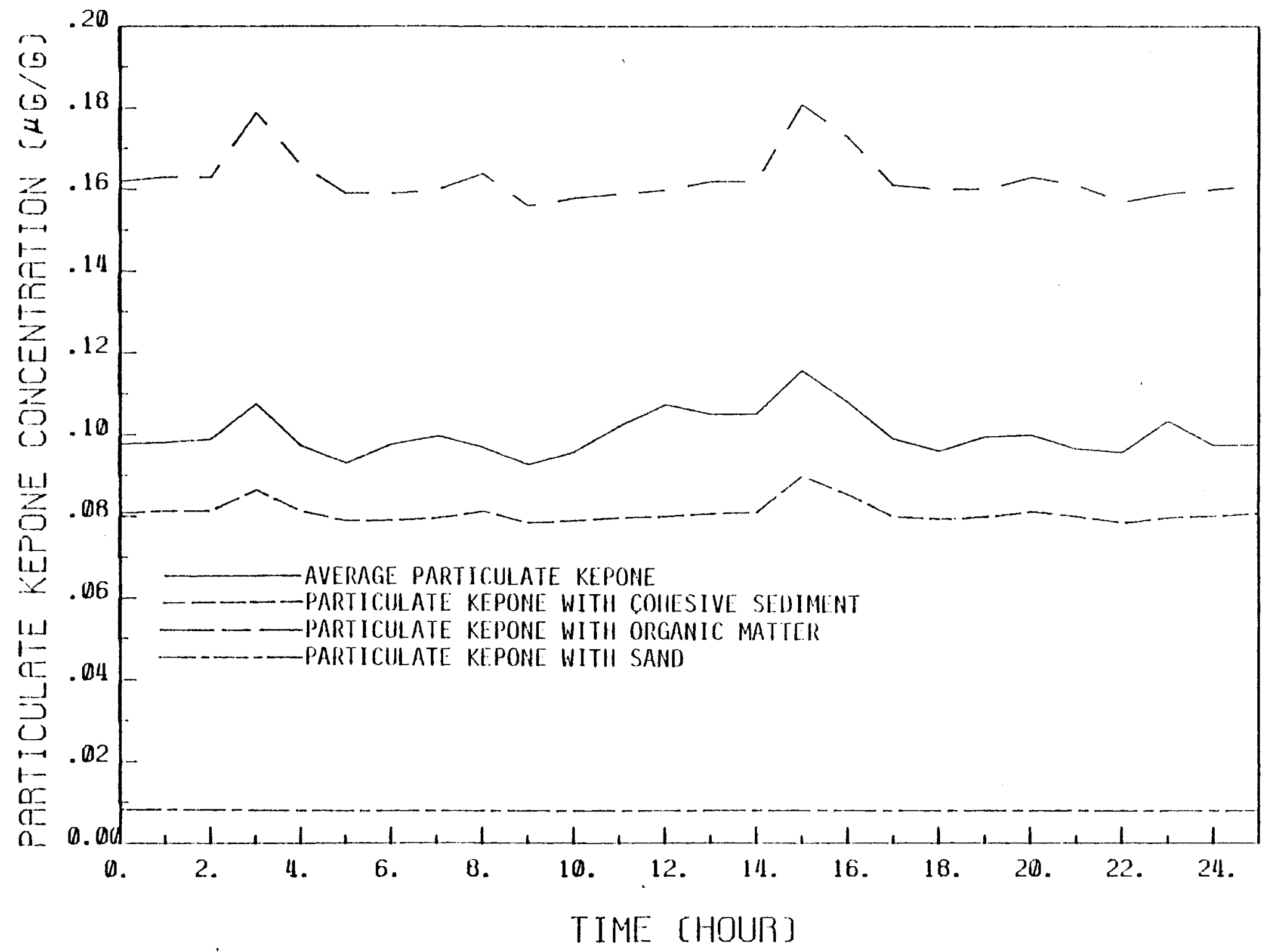

FIGURE 33. Changes of Particulate Kepone Concentrations with Time at River Kilometer 75.7 for the Fresh-Water Discharge of $58.3 \mathrm{~m}^{3} / \mathrm{sec}$ 


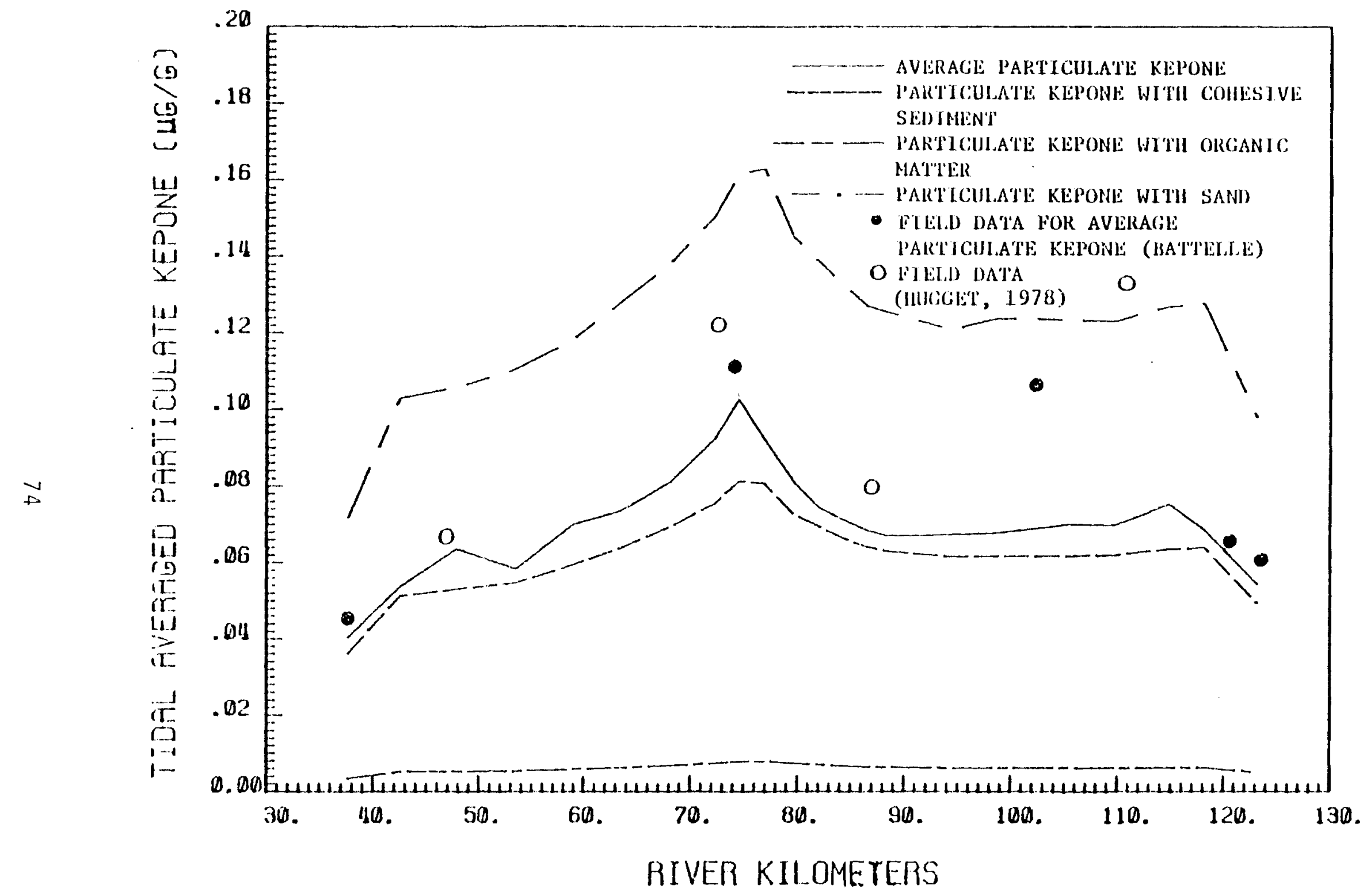

FIGURE 34. Tidal Averaged Particulate Kepone Concentrations for the Fresh-Water Discharge of $58.3 \mathrm{~m}^{3} / \mathrm{sec}$ 


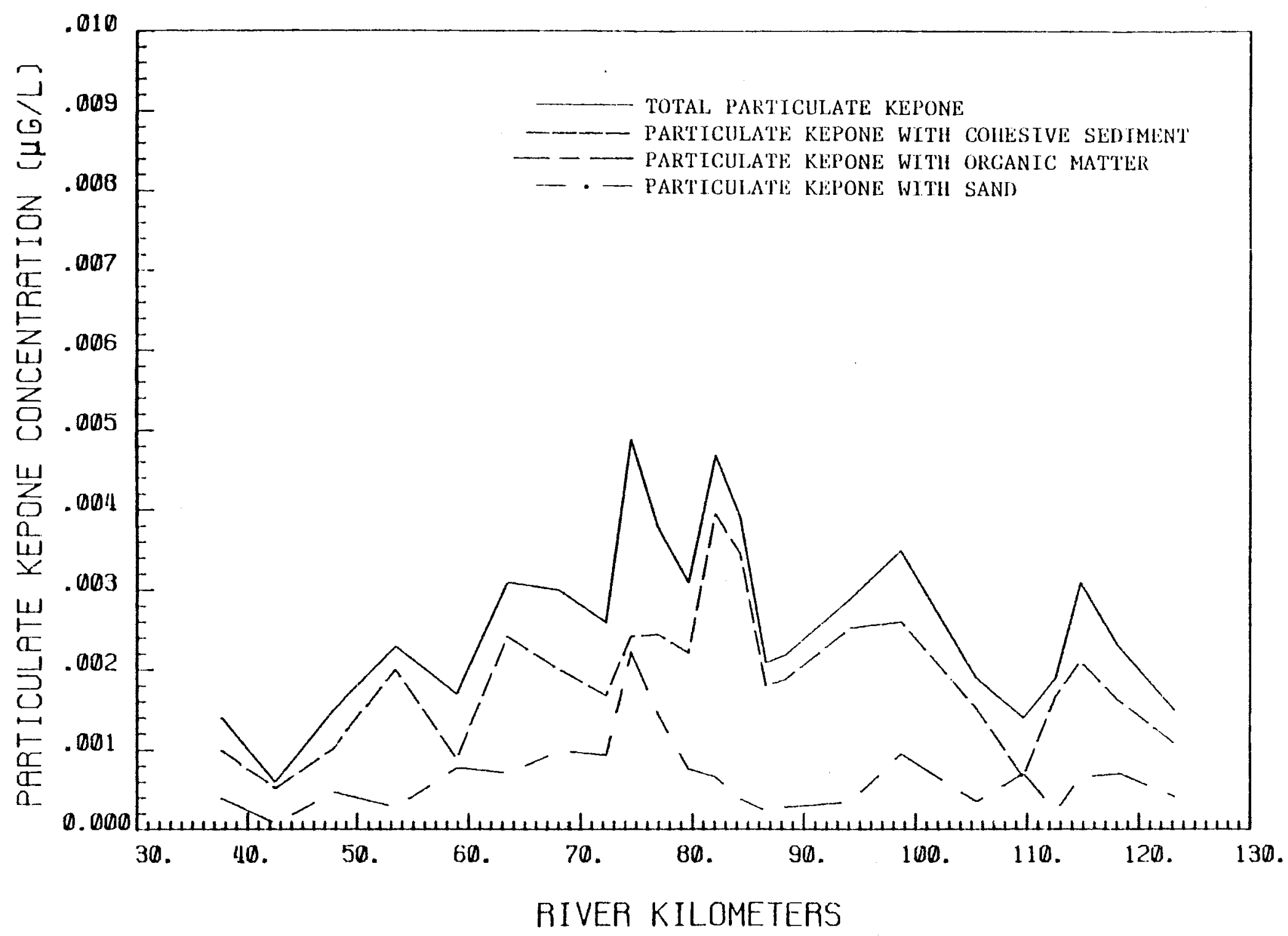

FIGURE 35. Longitudinal Distributions of Particulate Kepone Concentrations per Unit Volume of Water at Maximum Ebb Tide for the Fresh-Water Discharge of $58.3 \mathrm{~m}^{3} / \mathrm{sec}$ 


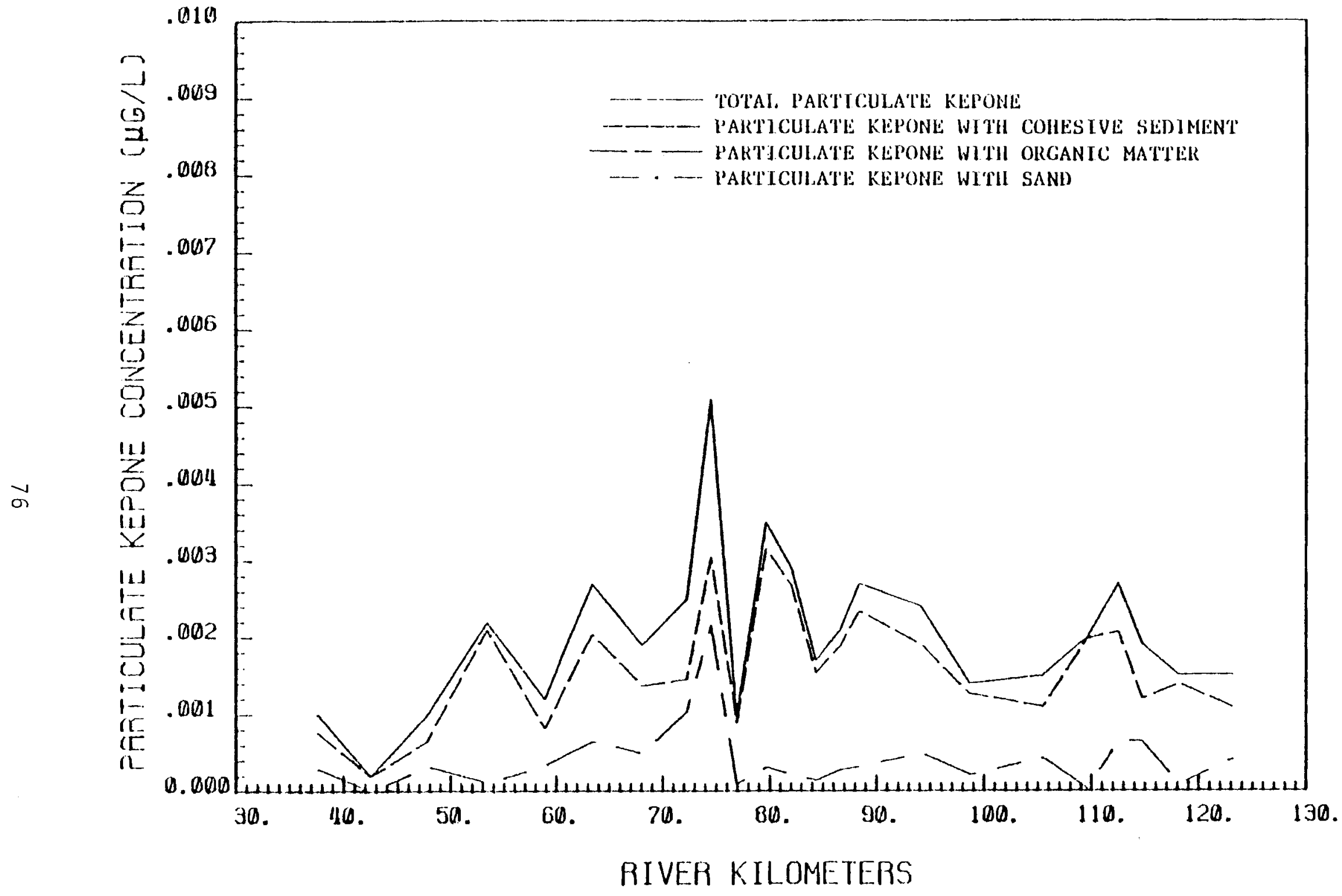

FIGURE 36. Longitudinal Distributions of Particulate Kepone Concentrations per Unit Volume of Water at Slack Tide for the Fresh-Water Discharge of $58.3 \mathrm{~m}^{3} / \mathrm{sec}$ 


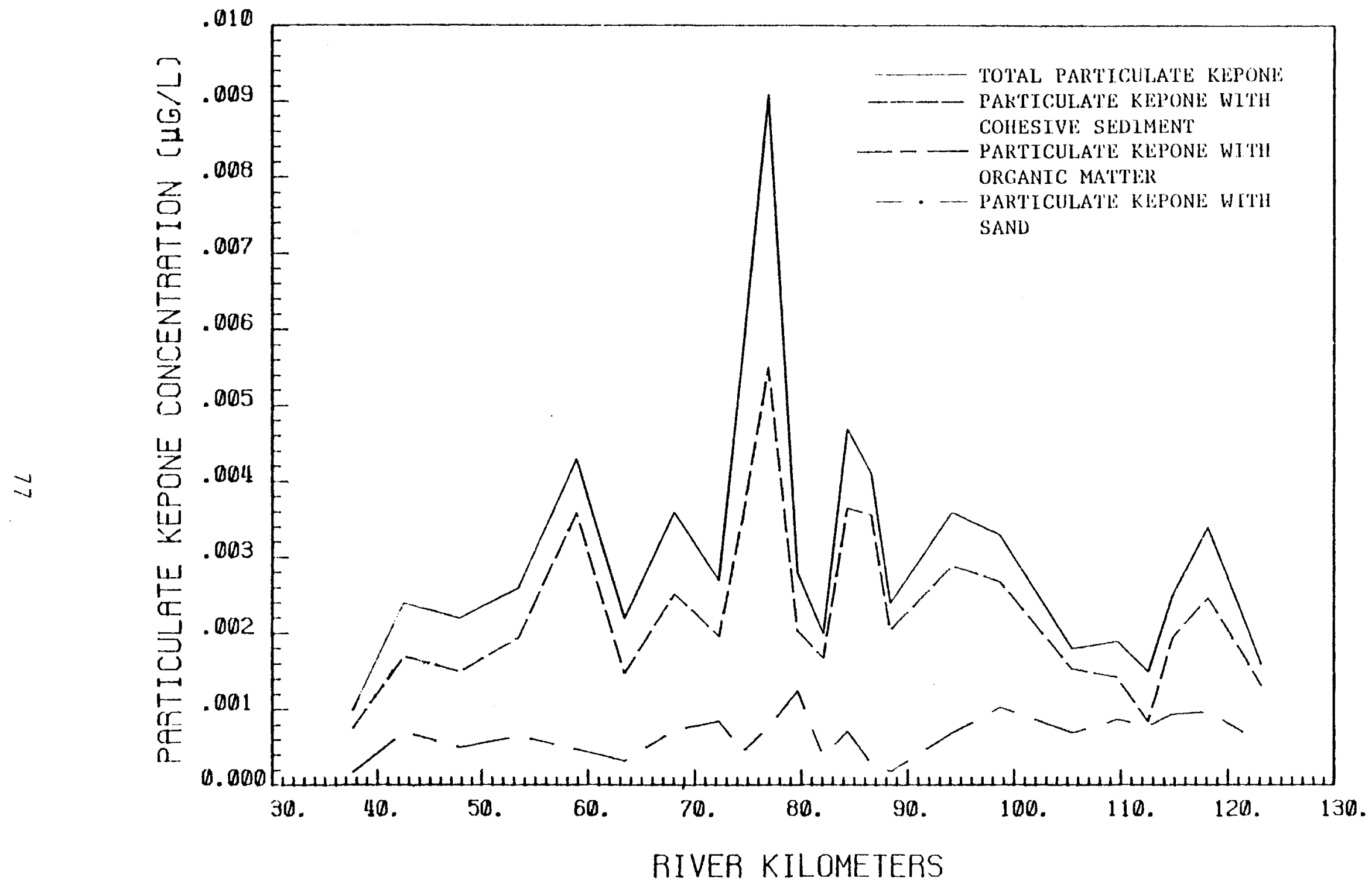

FIGURE 37. Longitudinal Distributions of Particulate Kepone Concentrations per Unit Volume of Water at Maximum Flood Tide for the Fresh-Water Discharge of $58.3 \mathrm{~m}^{3} / \mathrm{sec}$ 


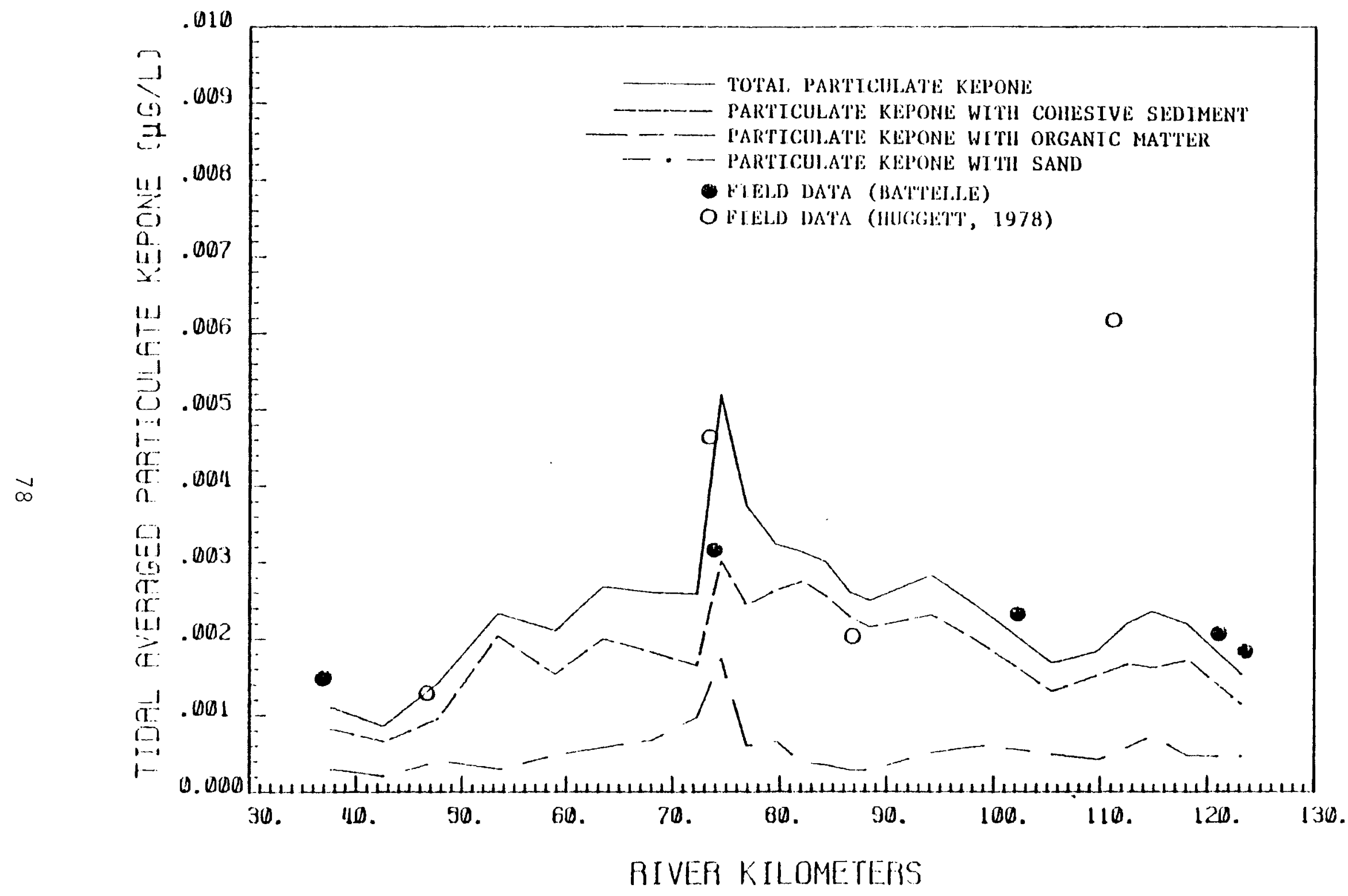

FIGURE 38. Longitudinal Distributions of Tidal Averaged Particulate Kepone Concentrations per Unit Volume of Water for the Fresh-Water Discharge of $58.3 \mathrm{~m}^{3} / \mathrm{sec}$ 


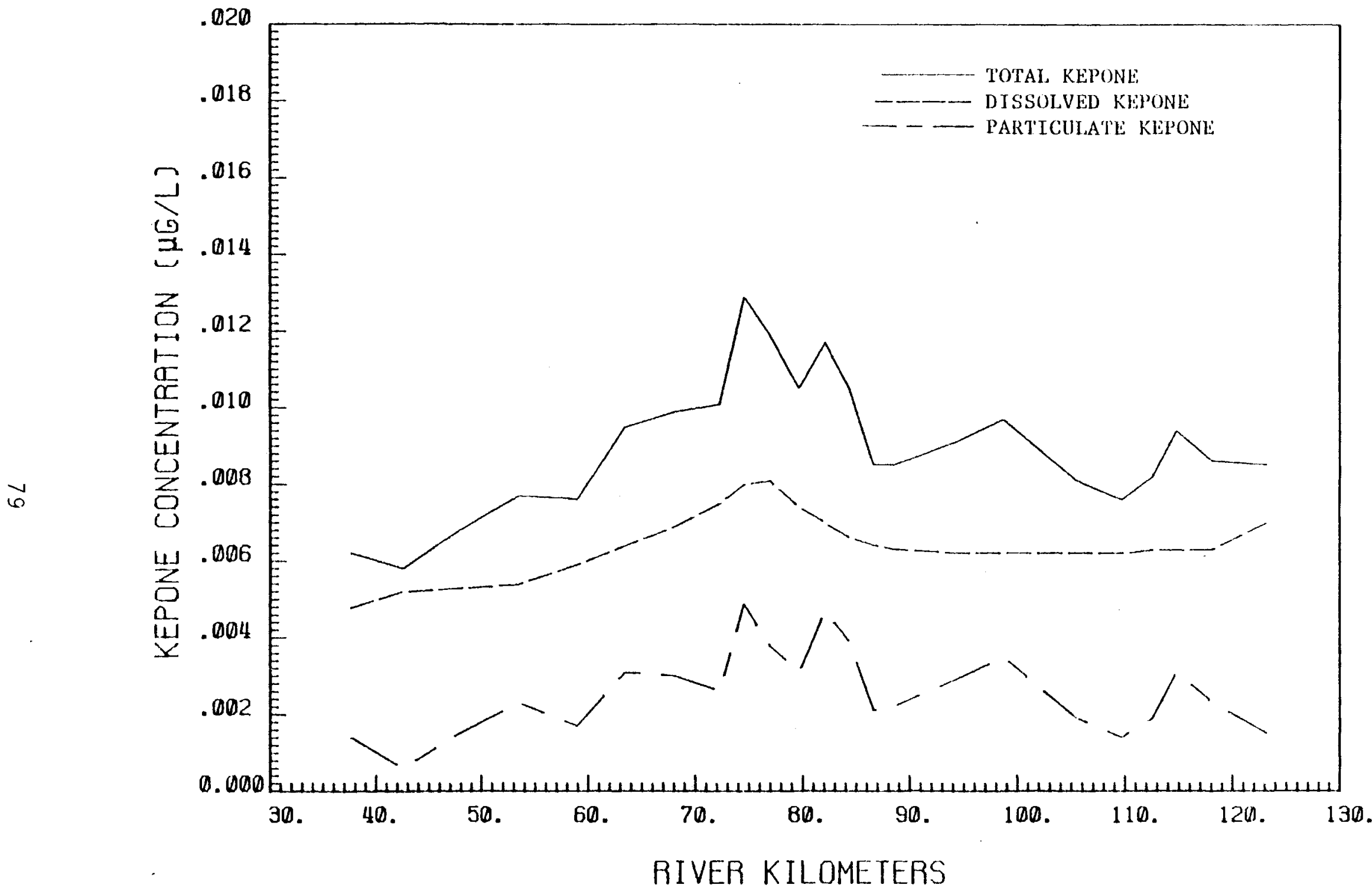

FIGURE 39. Longitudinal Distributions of Total, Dissolved and Particulate Kepone Concentrations at Maximum Ebb Tide for the Fresh-Water Discharge of $58.3 \mathrm{~m}^{3} / \mathrm{sec}$ 


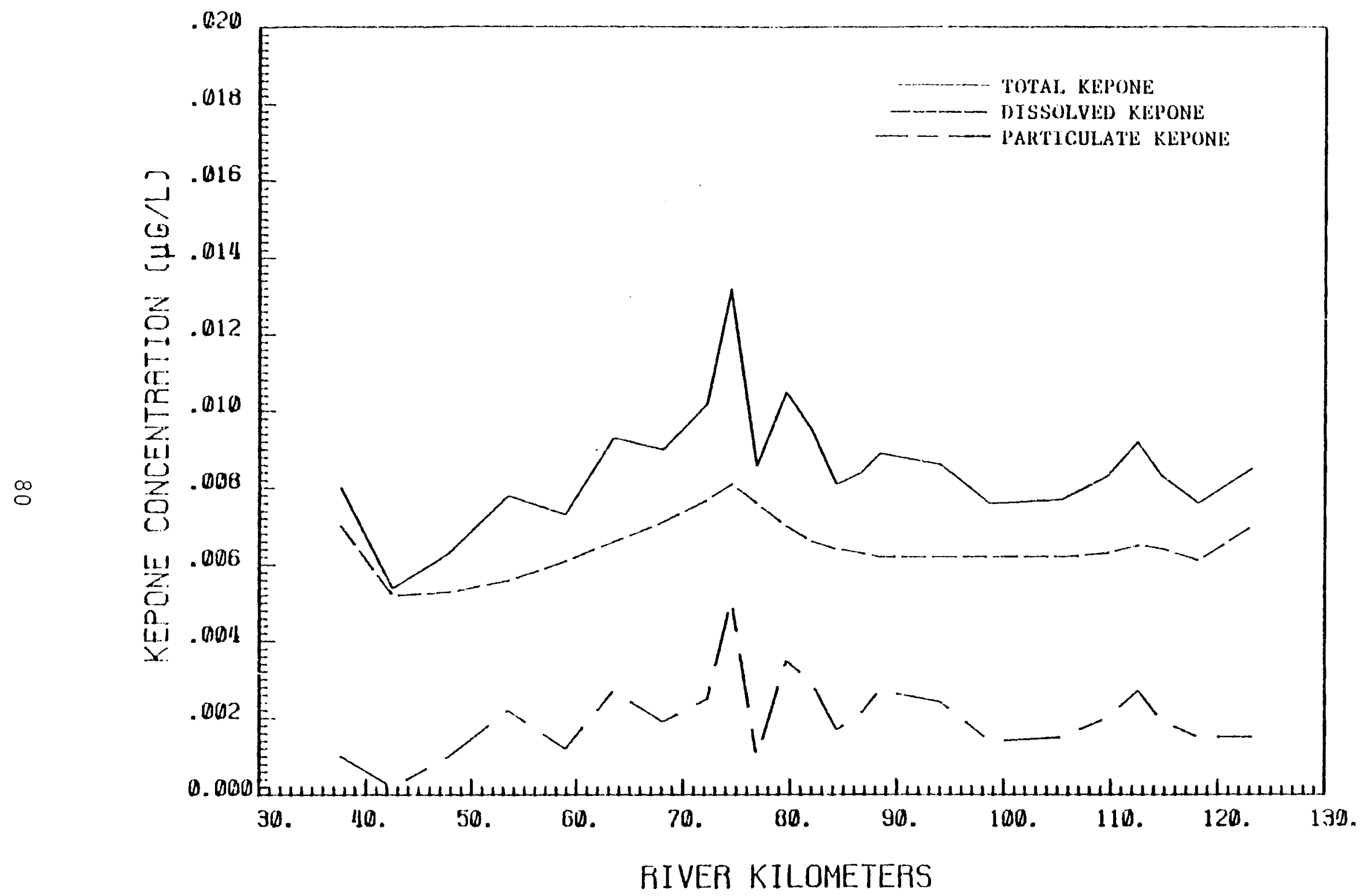

FIGURE 40. Longitudinal Distributions of Total, Dissolved and Particulate Kepone Concentrations at Slack Tide for the Fresh-Water Discharge of $58.3 \mathrm{~m}^{3} / \mathrm{sec}$ 


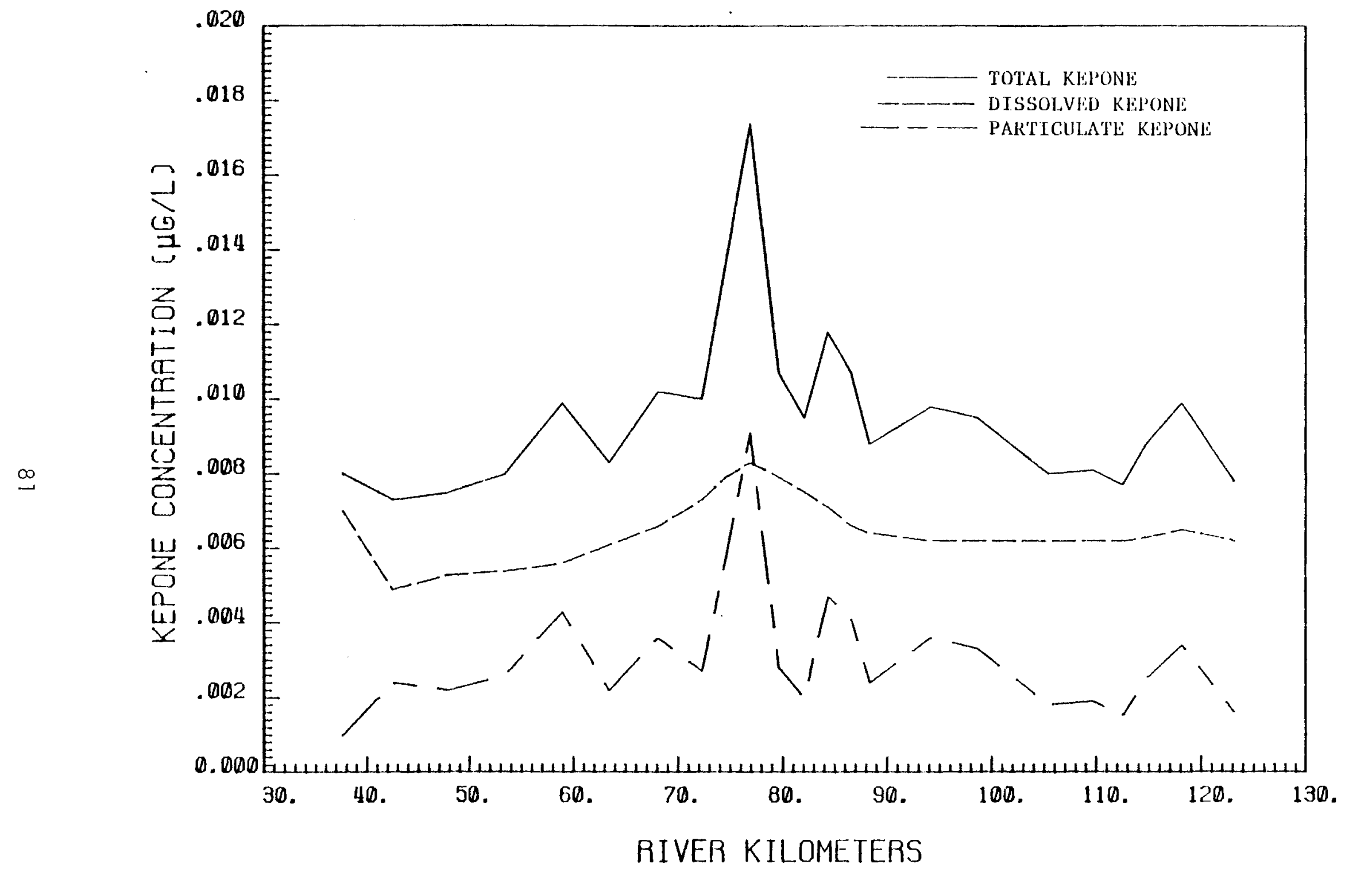

FIGURE 41. Longitudinal Distributions of Total, Dissolved and Particulate Kepone Concentrations at Maximum Flood Tide for the Fresh-Water Discharge of $58.3 \mathrm{~m}^{3} / \mathrm{sec}$ 


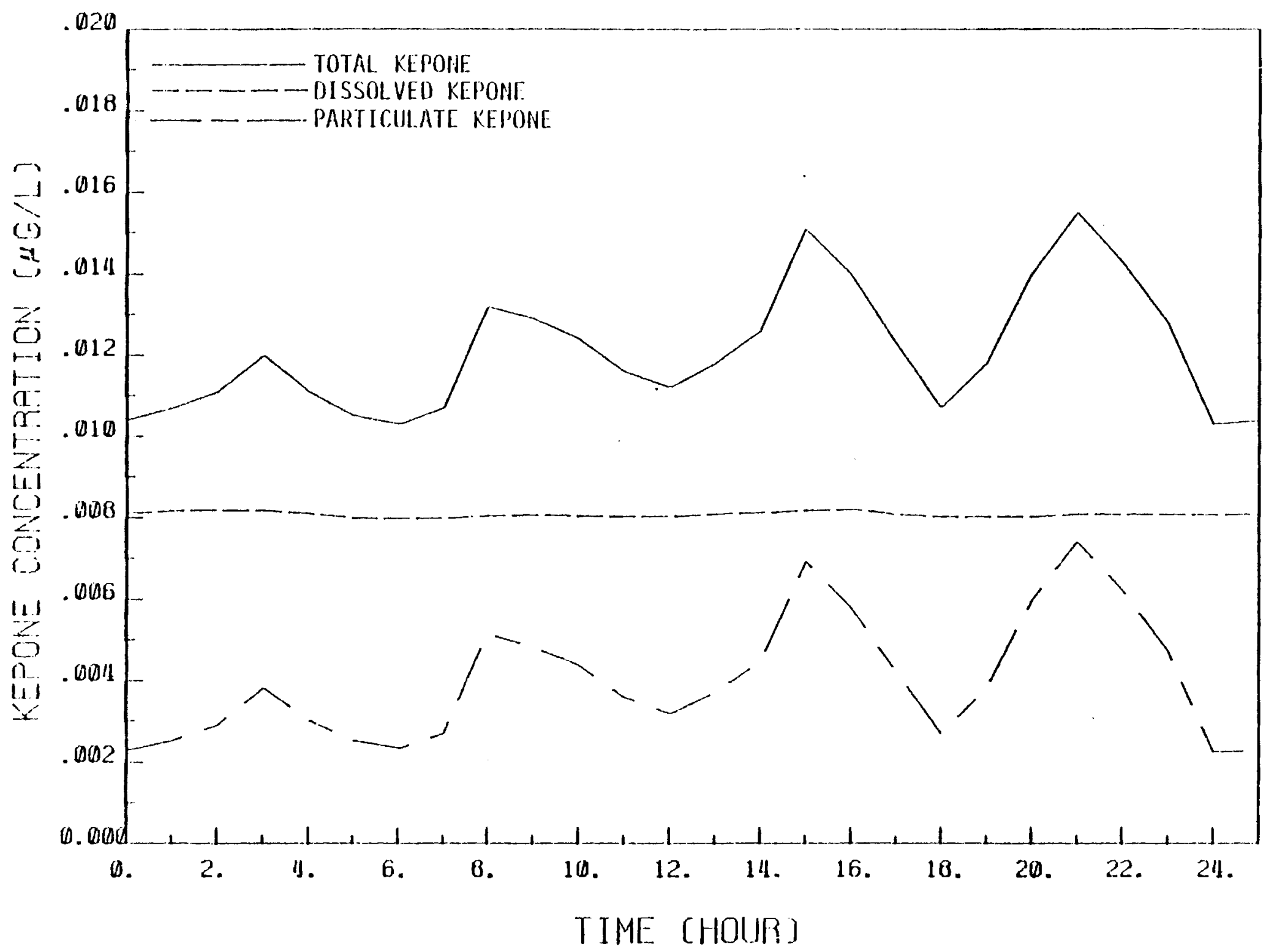

FIGURE 42. Changes of Total, Dissolved and Particulate Kepone Concentration with Time at River Kilometer 75.7 for the Fresh-Water Discharge of $58.3 \mathrm{~m} / \mathrm{sec}$ 


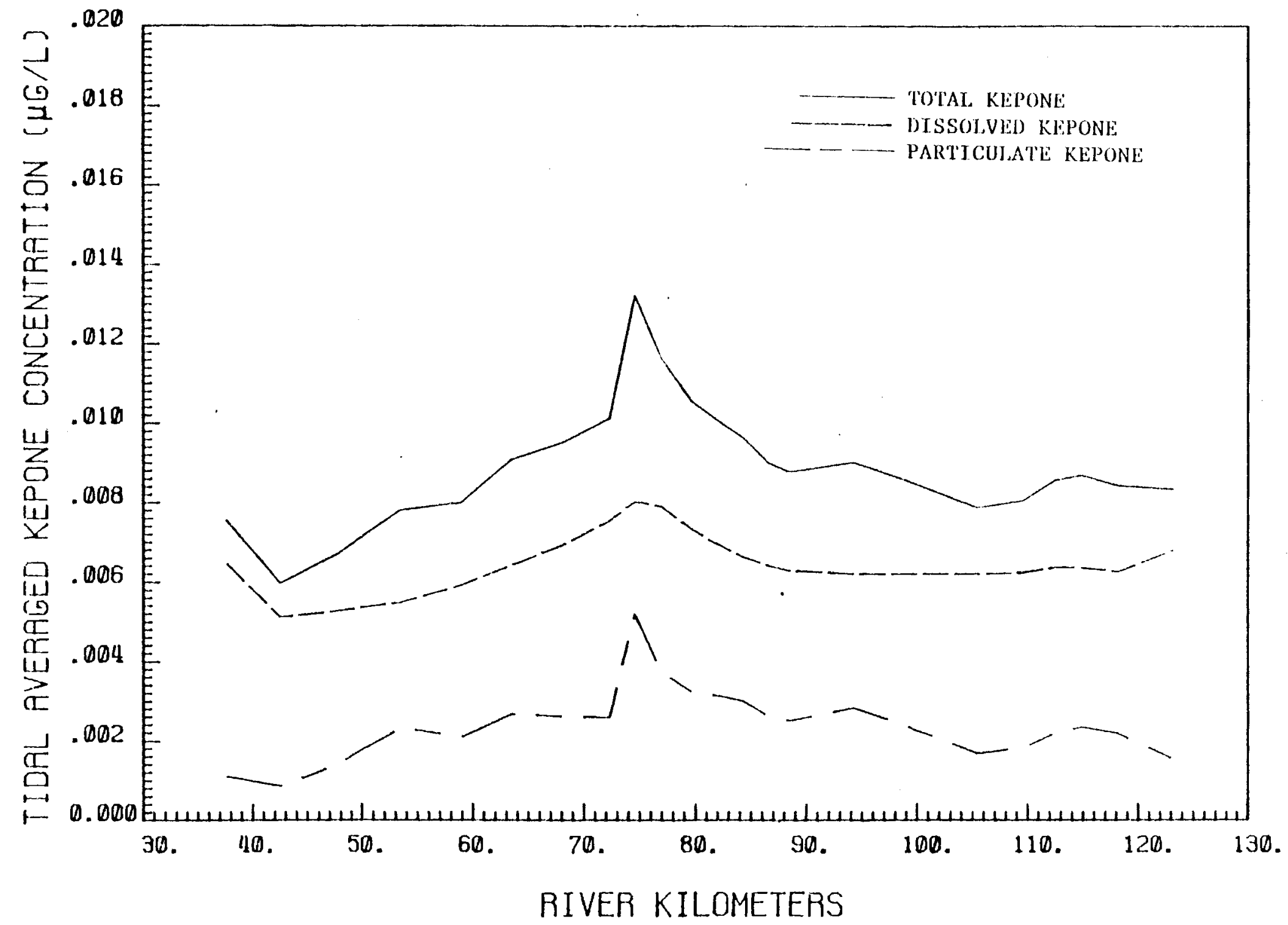

FIGURE 43. Longitudinal Distributions of Tidal Averaged Total, Dissolved and Particulate Kepone Concentrations for the Fresh-Water Discharge of $58.3 \mathrm{~m}^{3} / \mathrm{sec}$ 


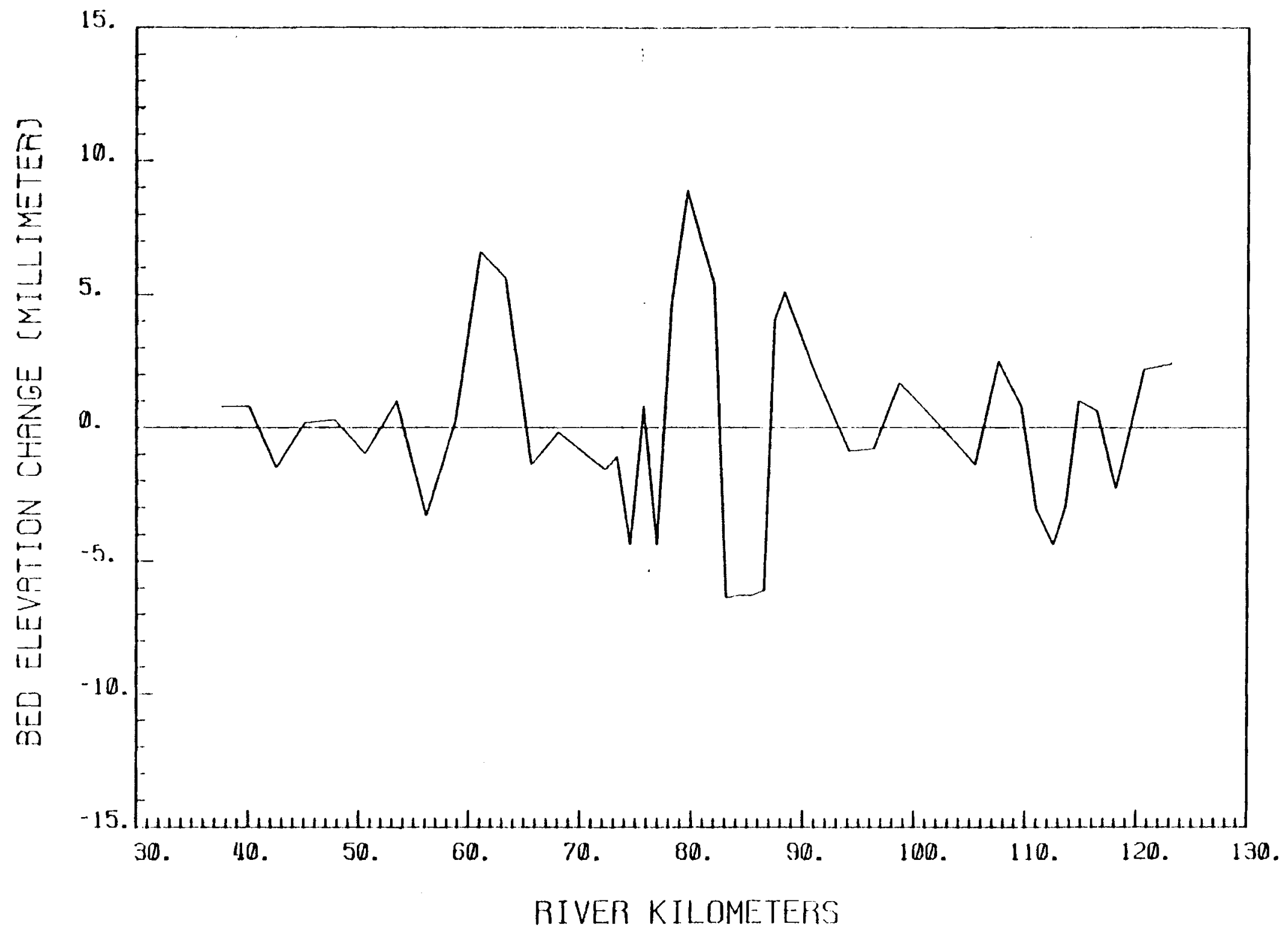

FIGURE 44. Variation of River Bed Elevation Changes Due to Sediment Deposition and/or Bed Scouring at Maximum Ebb Tide for the Fresh-Water Discharge of $58.3 \mathrm{~m}^{3} / \mathrm{sec}$ 


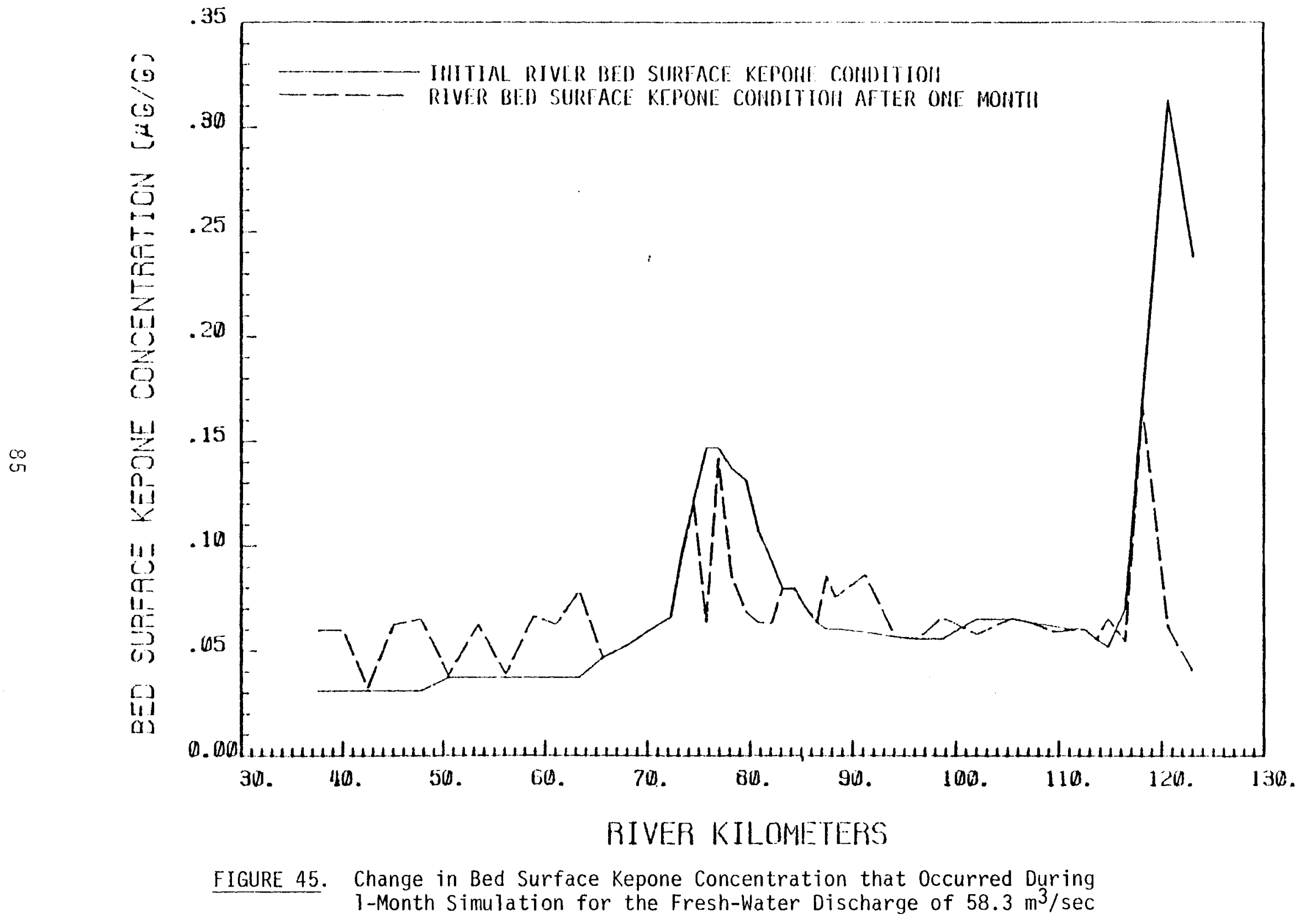




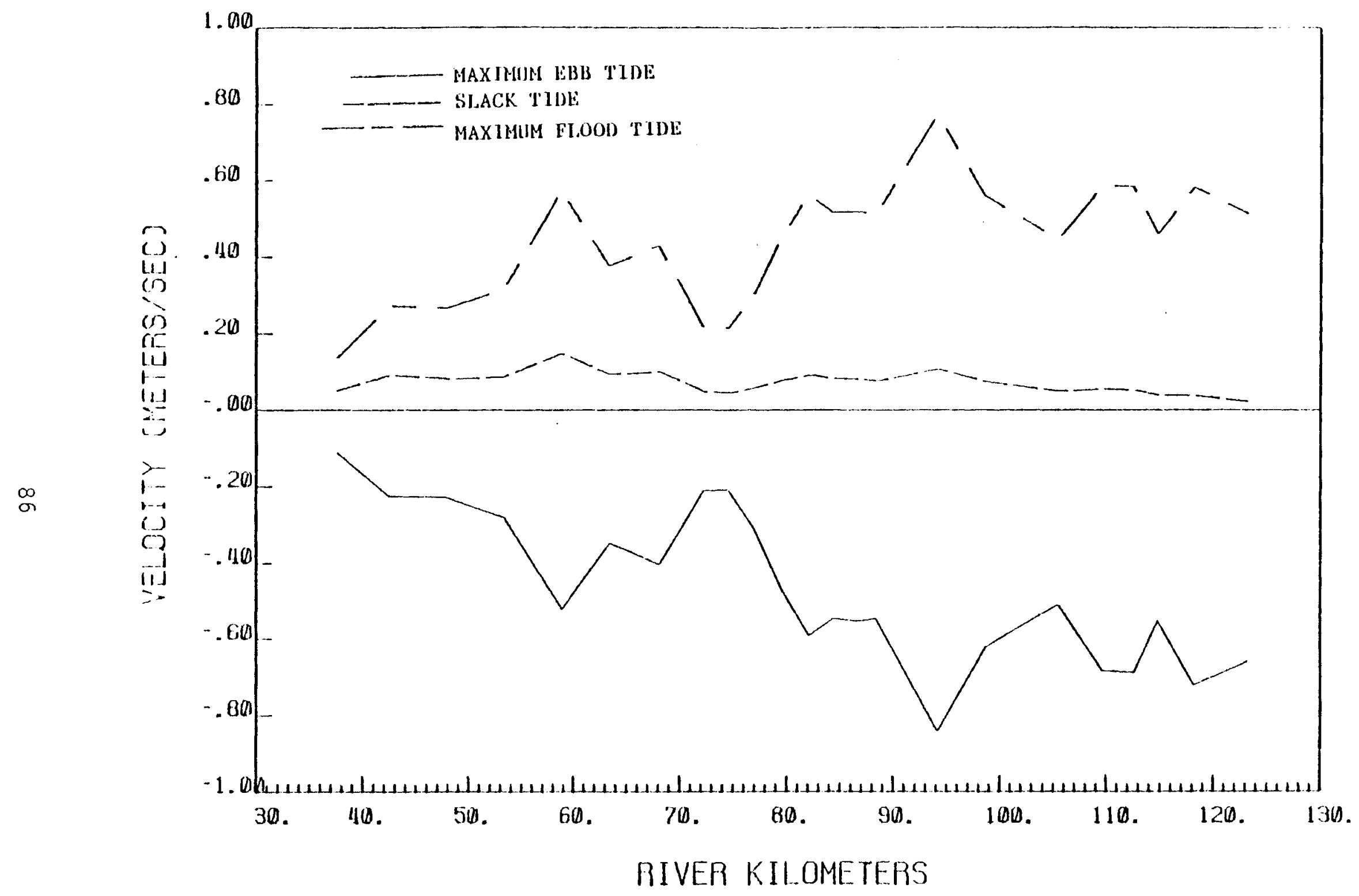

FIGURE 46. Longitudinal Velocity Distributions at Maximum Ebb, Slack and the Maximum Flood Tides for Fresh-Water Input Discharge of $247 \mathrm{~m}^{3} / \mathrm{sec}$ 


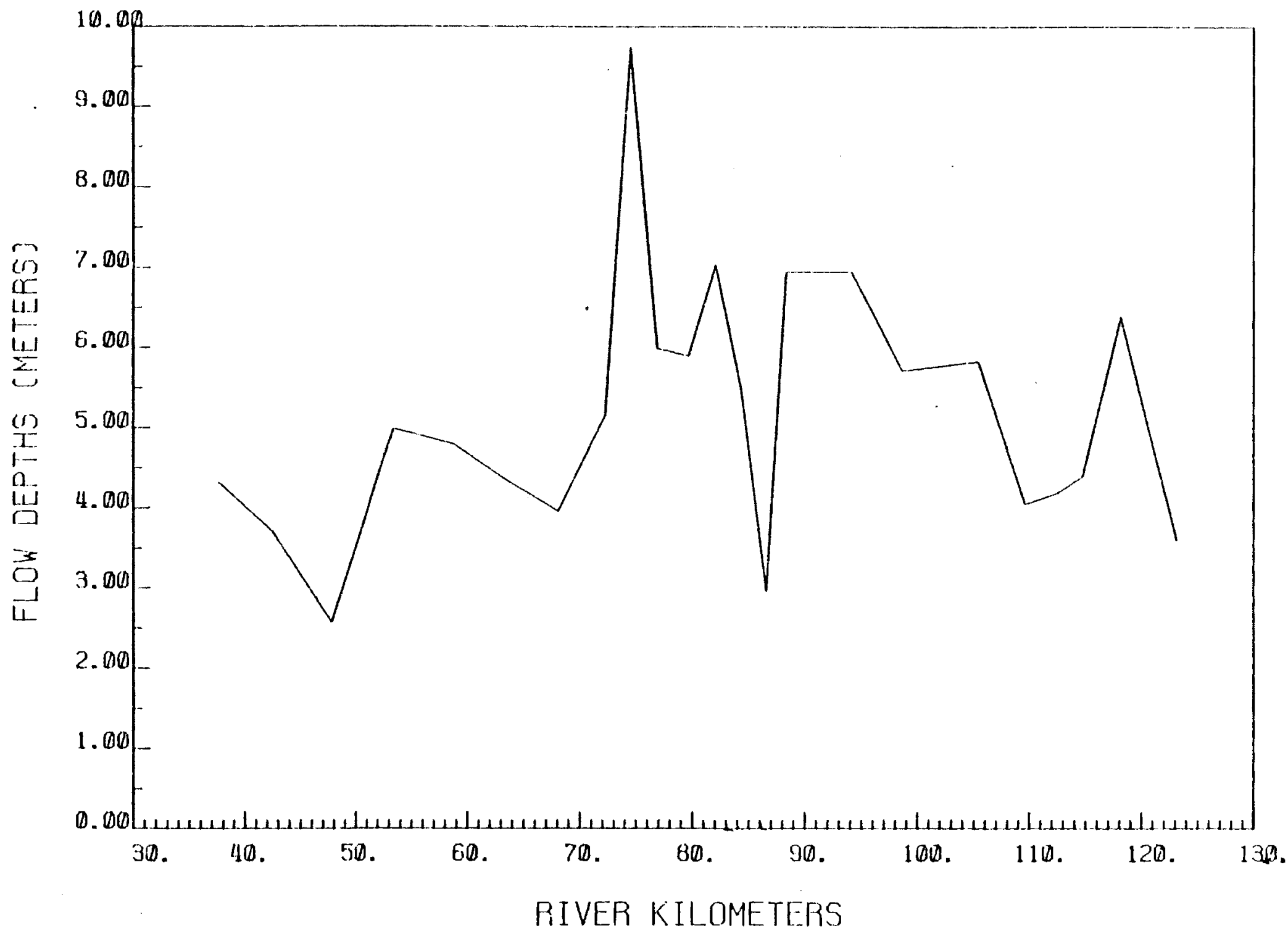

FIGURE 47. Longitudinal Depth Variation at Maximum Ebb Tide for the Fresh-Water Discharge of $247 \mathrm{~m}^{3} / \mathrm{sec}$ 


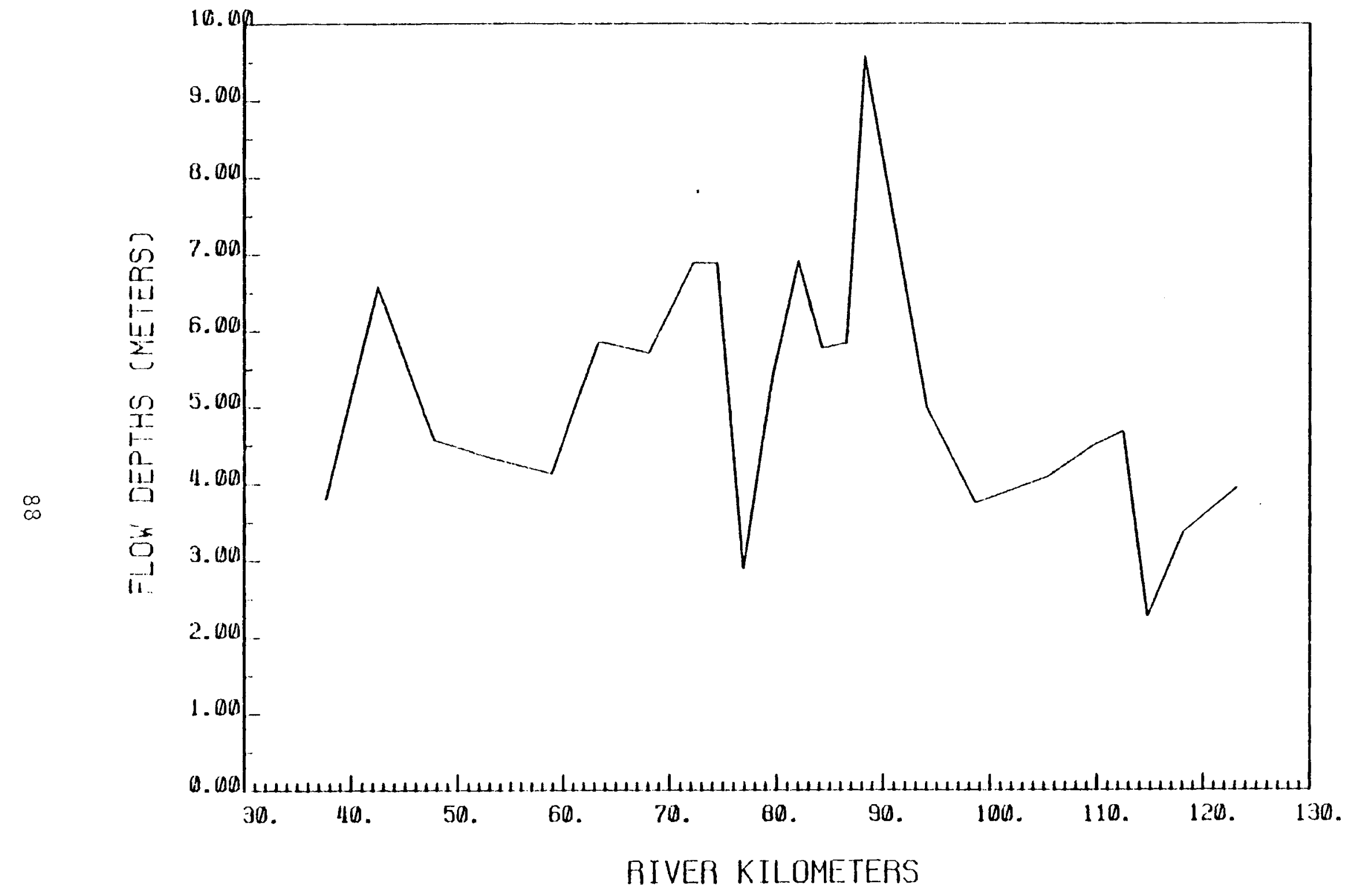

FIGURE 48. Longitudinal Depth Variation at Slack Tide for the Fresh-Water Discharge of $247 \mathrm{~m}^{3} / \mathrm{sec}$ 


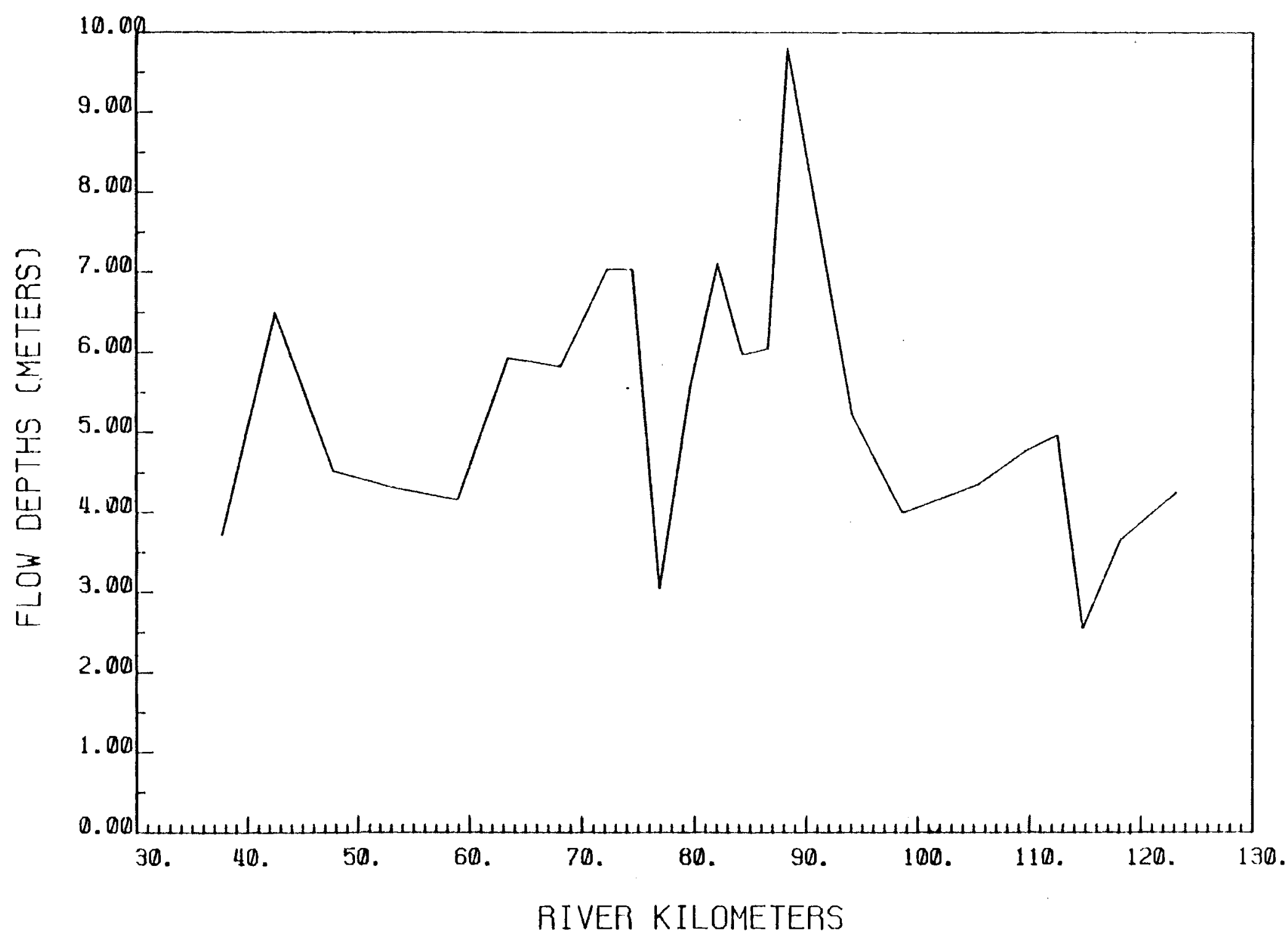

FIGURE 49. Longitudinal Depth Variation at Maximum Flood Tide for the Fresh-Water Discharge of $247 \mathrm{~m}^{3} / \mathrm{sec}$ 


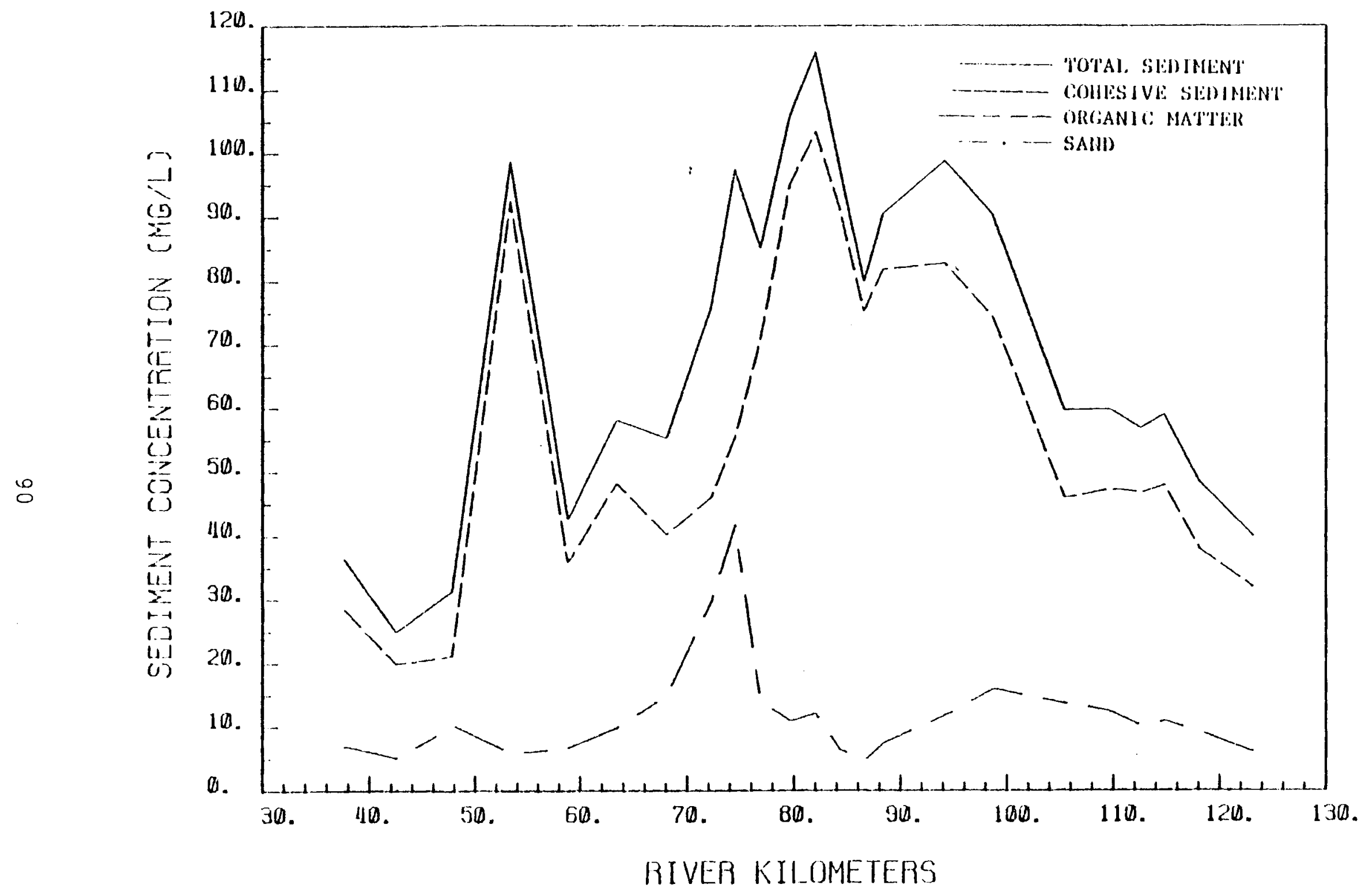

FIGURE 50. Longitudinal Distribution of Sediment Concentration of Each Sediment Type at Maximum Ebb Tide for the Fresh-Water Discharge of $247 \mathrm{ri}^{3} / \mathrm{sec}$ 


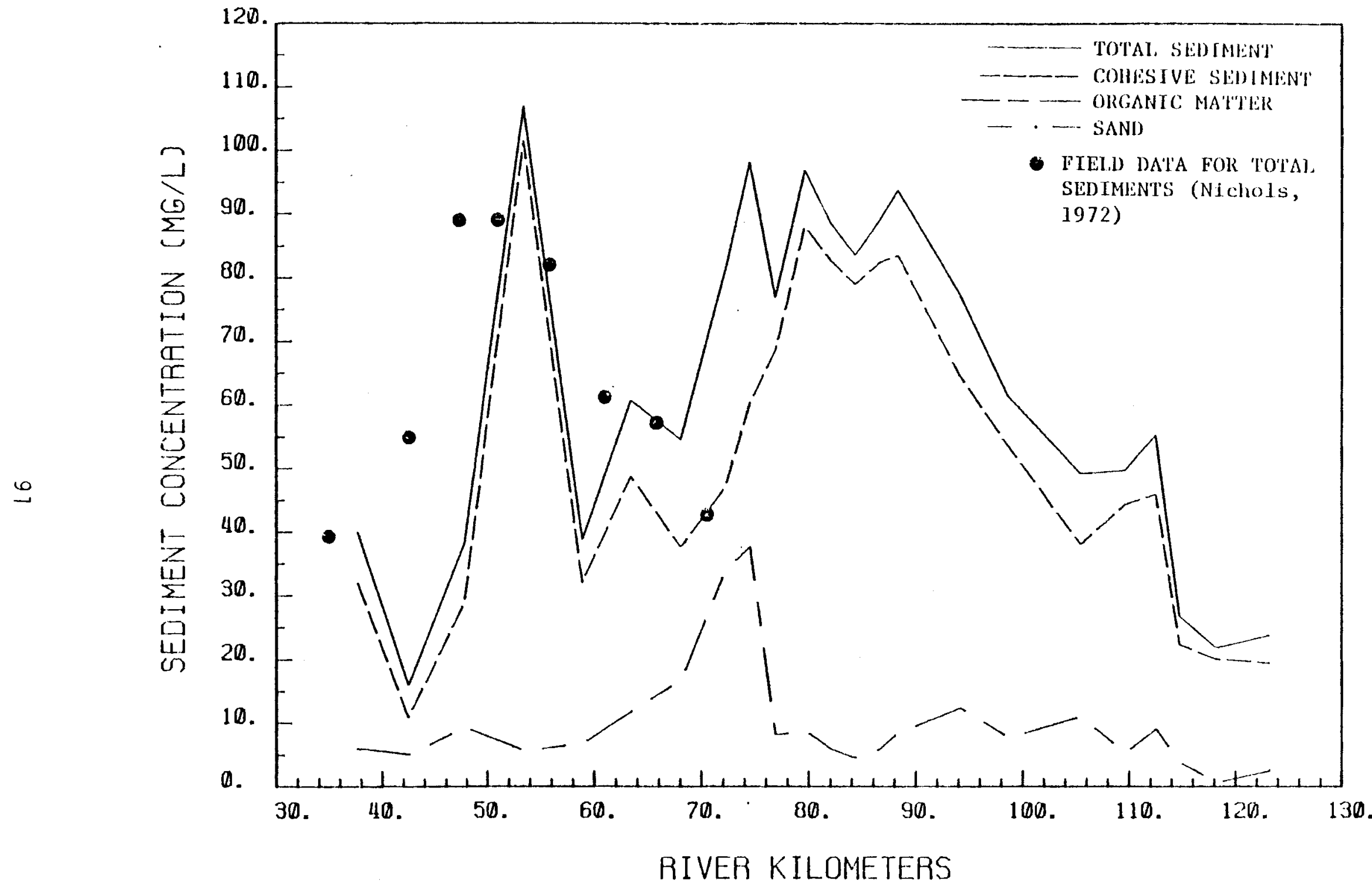

FIGURE 51. Longitudinal Distribution of Sediment Concentration of Each Sediment Type at Slack Tide for the Fresh-Water Discharge of $247 \mathrm{~m}^{3} / \mathrm{sec}$ 


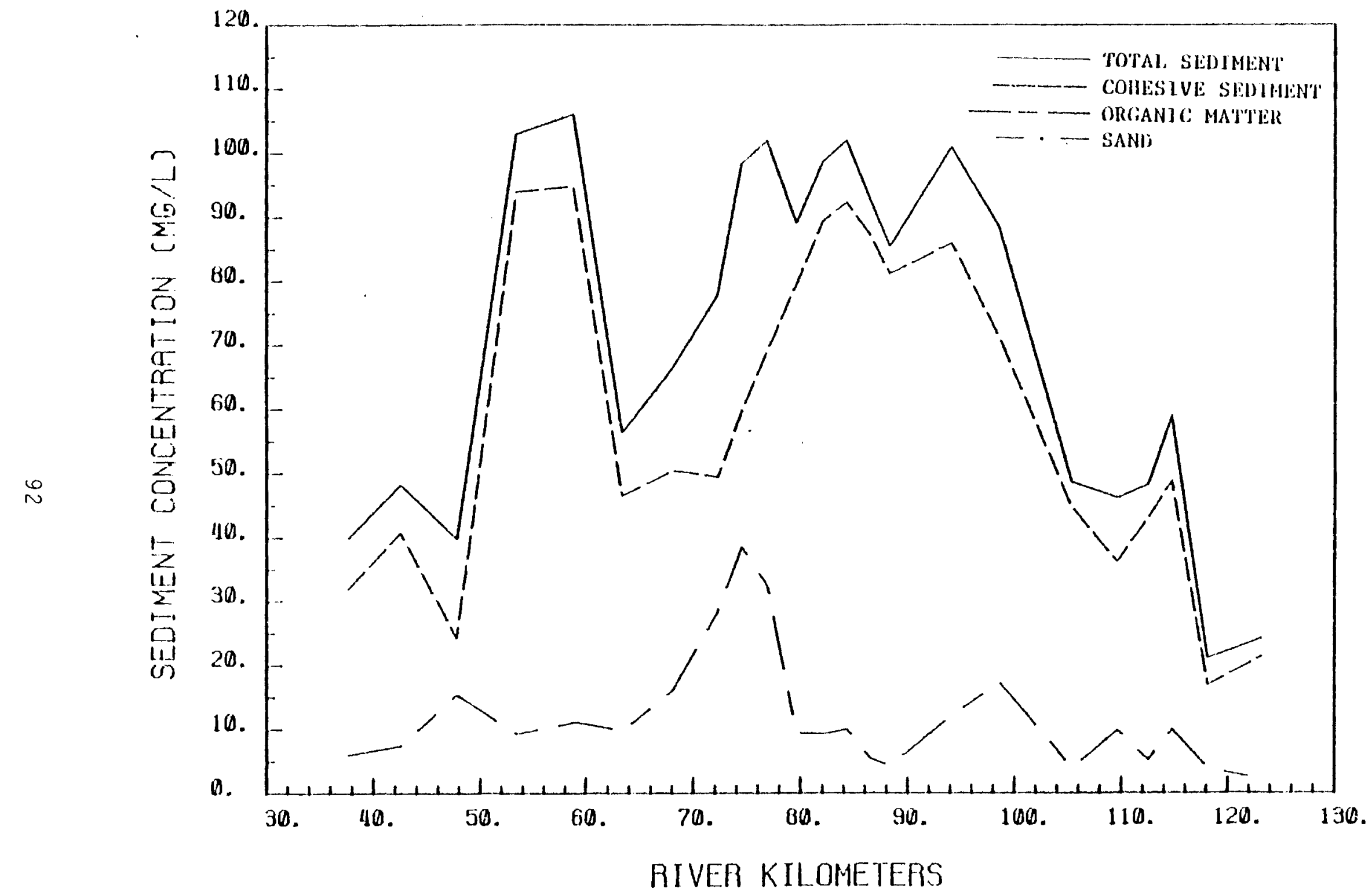

FIGURE 52. Longitudinal Distributions of Sediment Concentration of Each Sediment Type at Maximum Flood Tide for the Fresh-Water Discharge of $247 \mathrm{~m}^{3} / \mathrm{sec}$ 


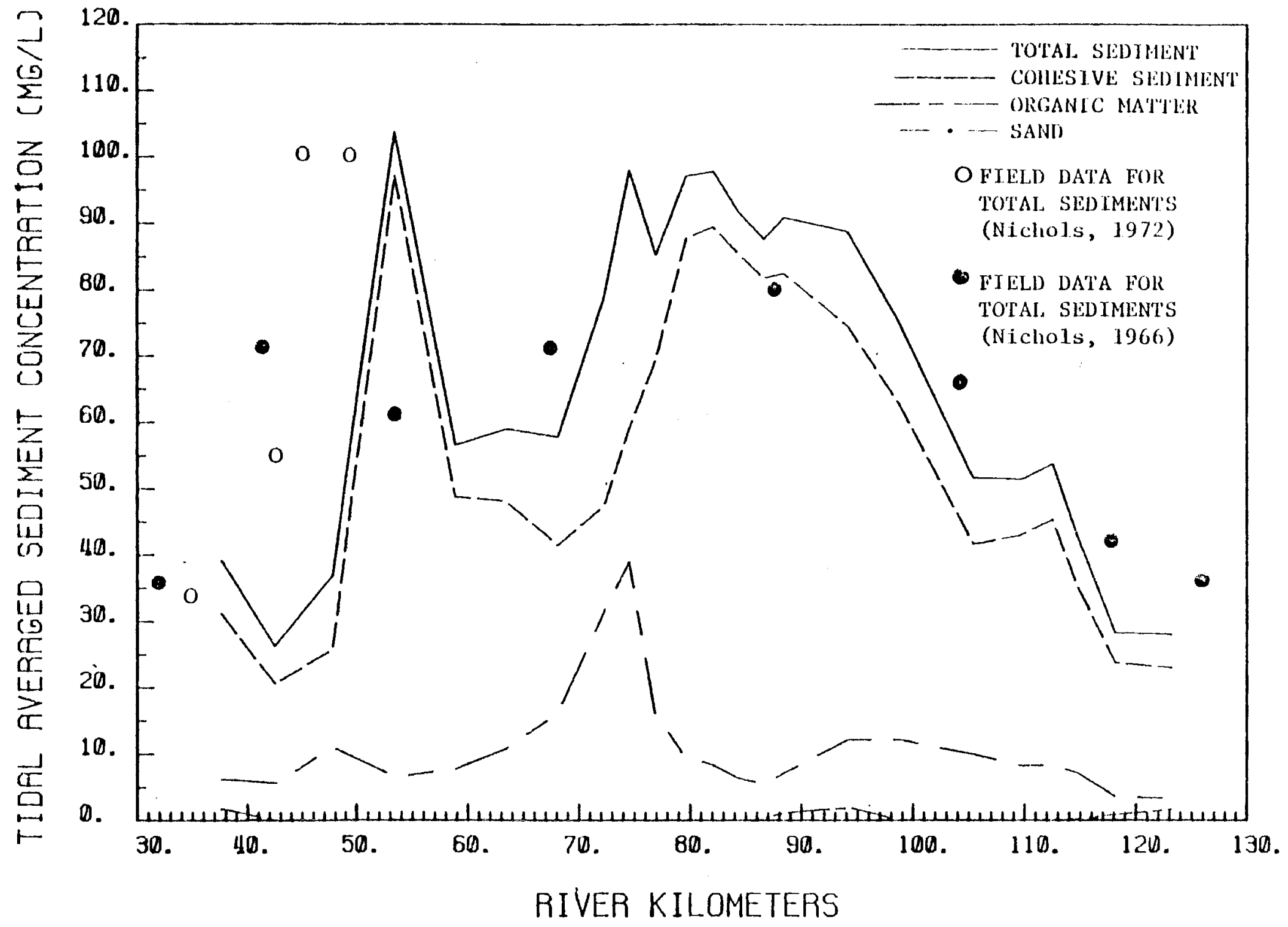

FIGURE 53. Tidal Averaged Sediment Concentration of Each Sediment Type for the Fresh-Water Discharge of $247 \mathrm{~m}^{3} / \mathrm{sec}$ 


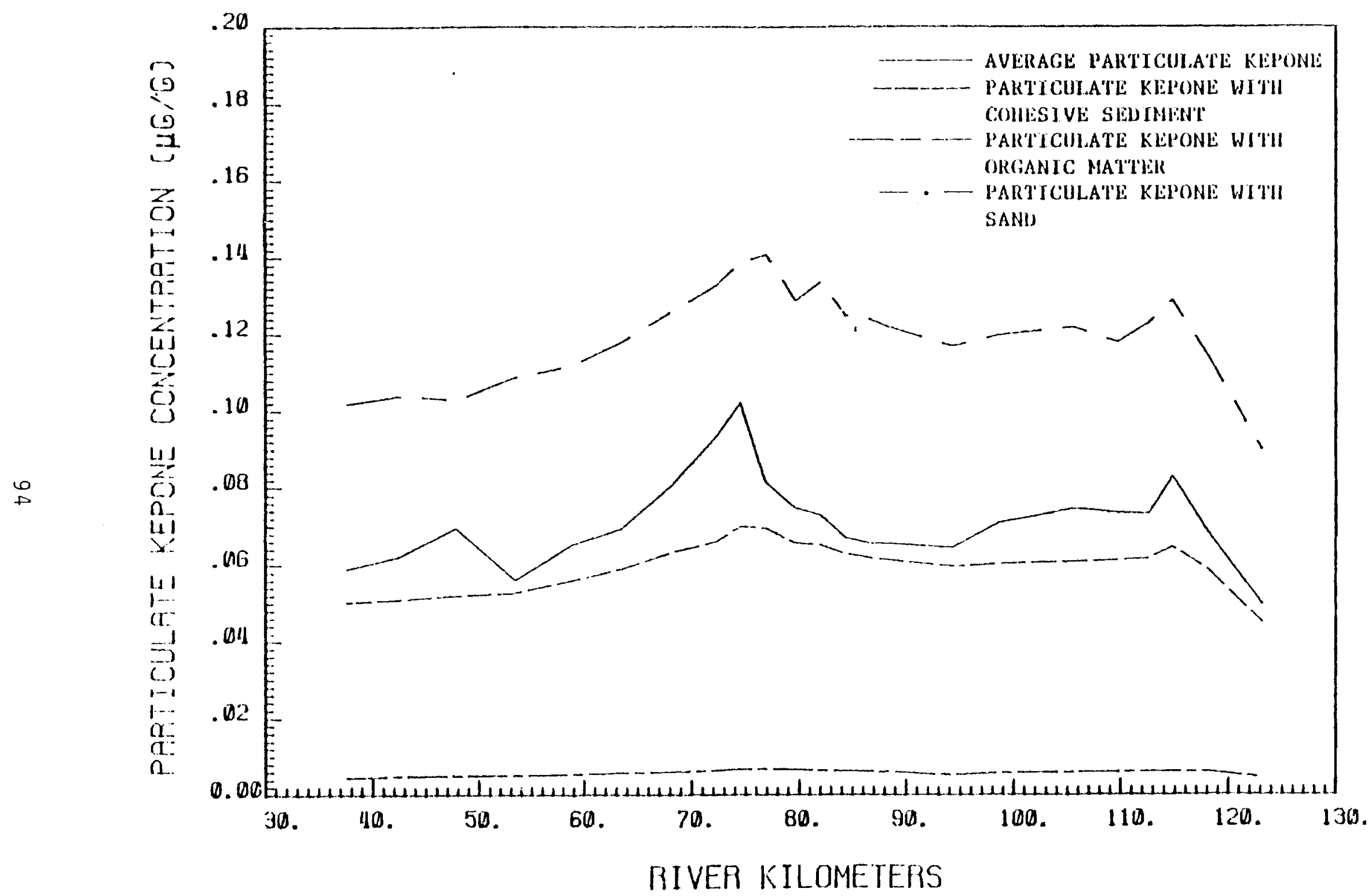

FIGURE 54. Longitudinal Distributions of Particulate Kepone Concentrations at Maximum Ebb Tide for the Fresh-Water Discharge to $247 \mathrm{~m}^{3} / \mathrm{sec}$ 


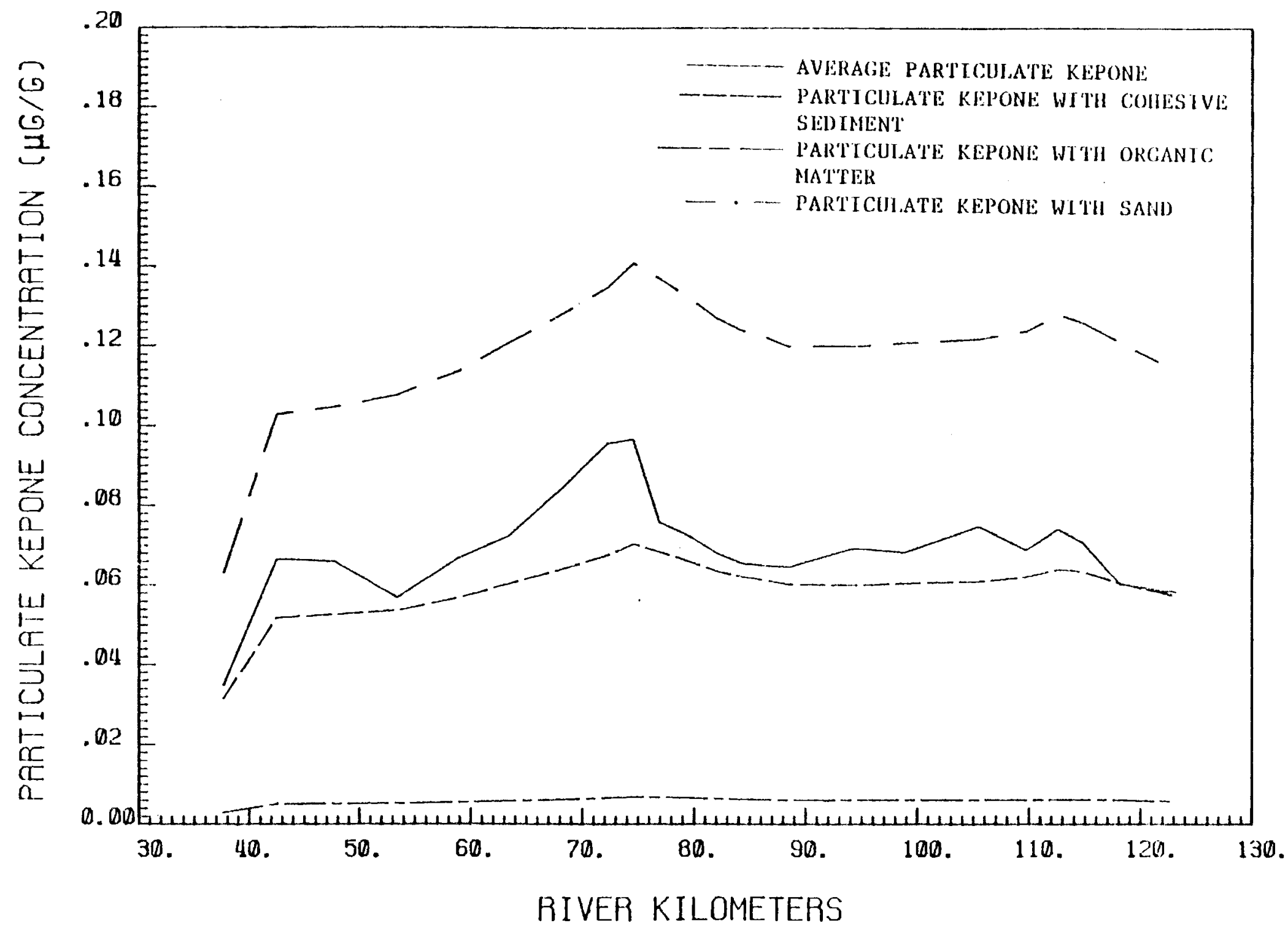

FIGURE 55. Longitudinal Distributions of Particulate Kępone Concentrations at Slack Tide for the Fresh-Water Discharge of $247 \mathrm{~m}^{3} / \mathrm{sec}$ 


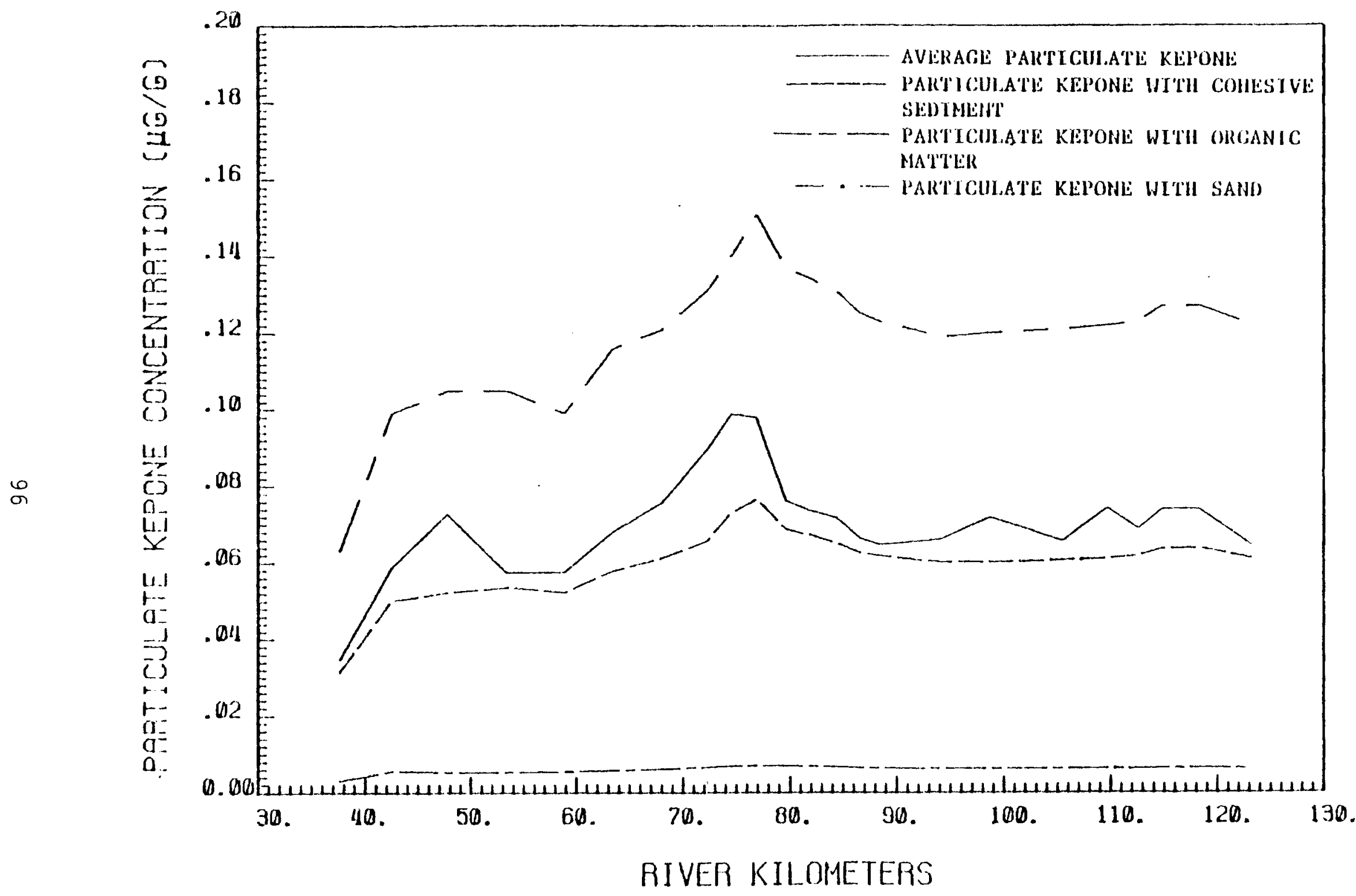

FIGURE 56. Longitudinal Distributions of Particulate Kepone Concentrations at Maximum Flood Tide for the Fresh-Water Discharge $247 \mathrm{~m} 3 / \mathrm{sec}$ 


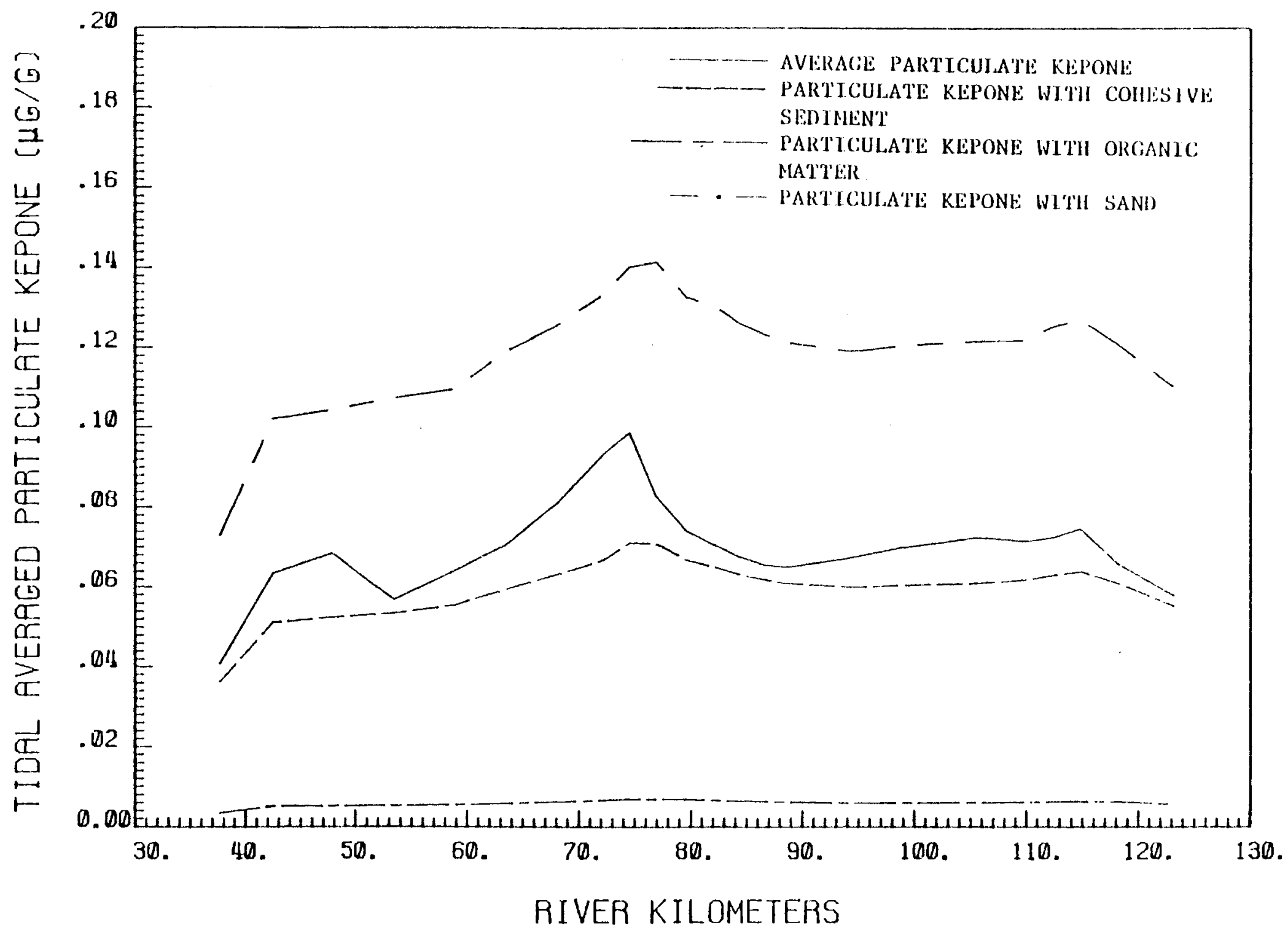

FIGURE 57. Tidal Averaged Particulate Kepone Concentrations for the Fresh-Water Discharge of $247 \mathrm{~m}^{3} / \mathrm{sec}$ 


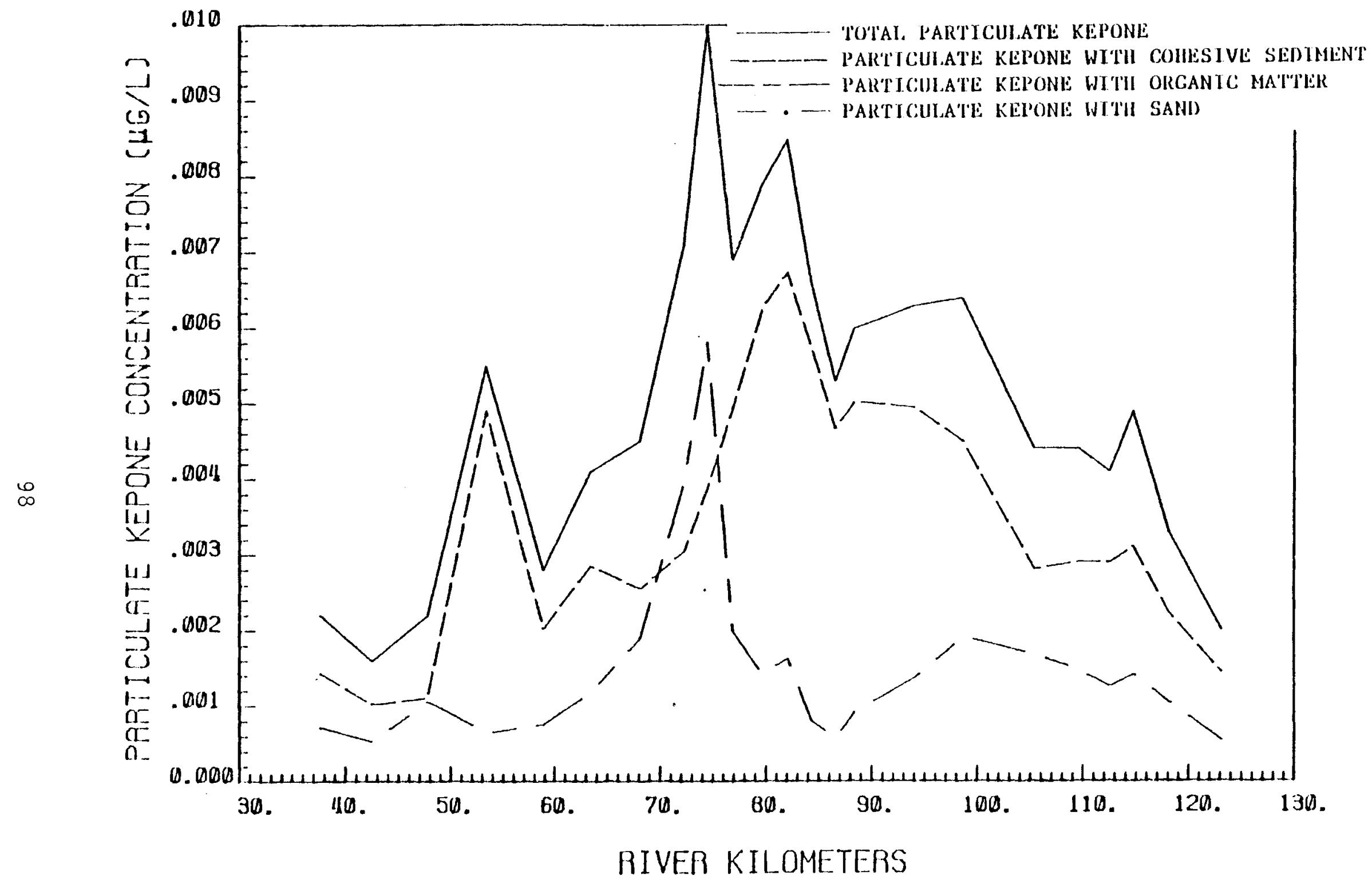

FIGURE 58. Longitudinal Distributions of Particulate Kepone Concentrations per Unit Volume of Water at Maximum Ebb Tide for the Fresh-Water Discharge of $247 \mathrm{~m}^{3} / \mathrm{sec}$ 


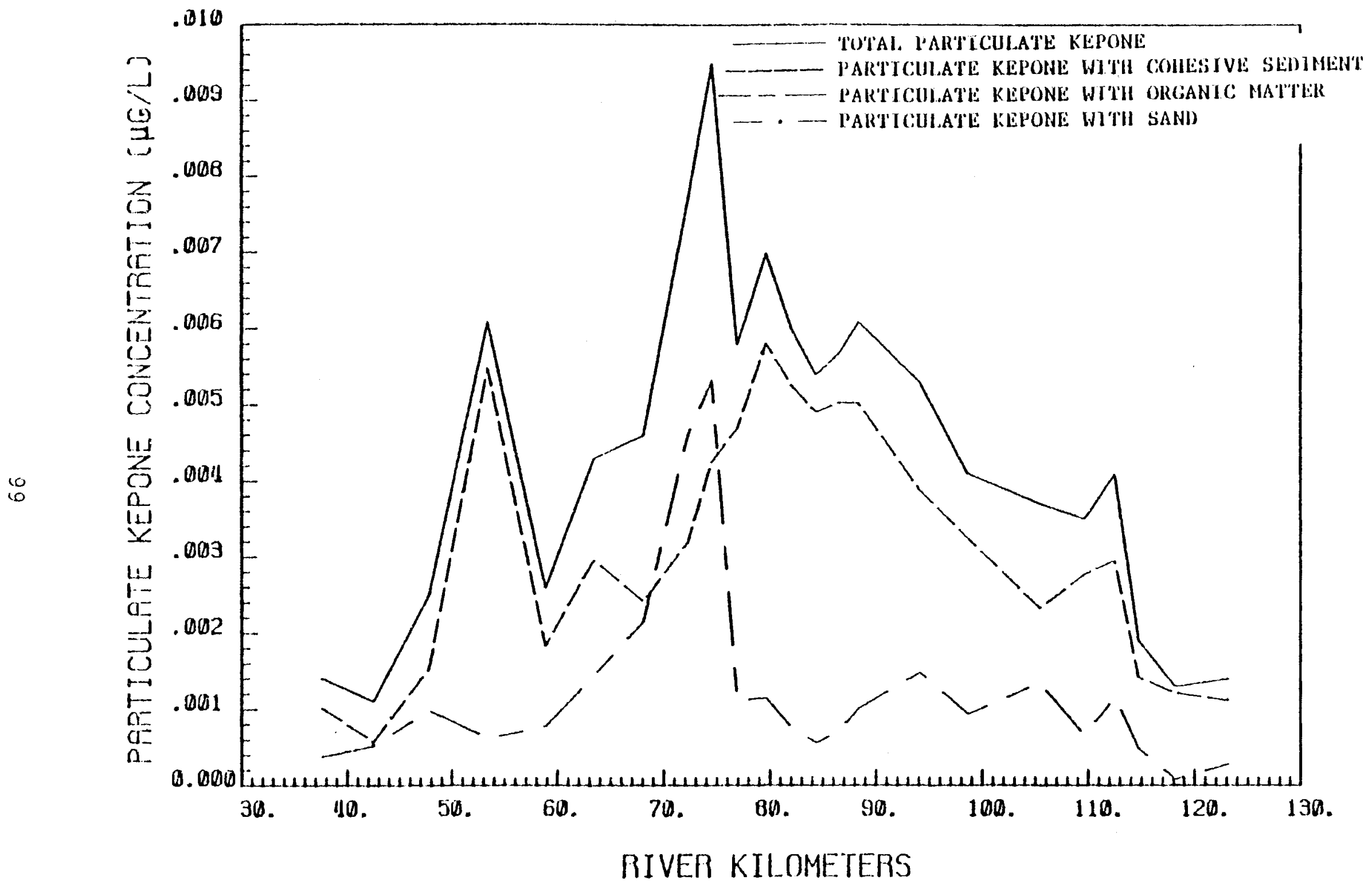

FIGURE 59. Longitudinal Distributions of Particulate Kepone Concentrations per Unit Volume of Water at Slack Tide for the Fresh-Water Discharge of $247 \mathrm{~m}^{3} / \mathrm{sec}$ 


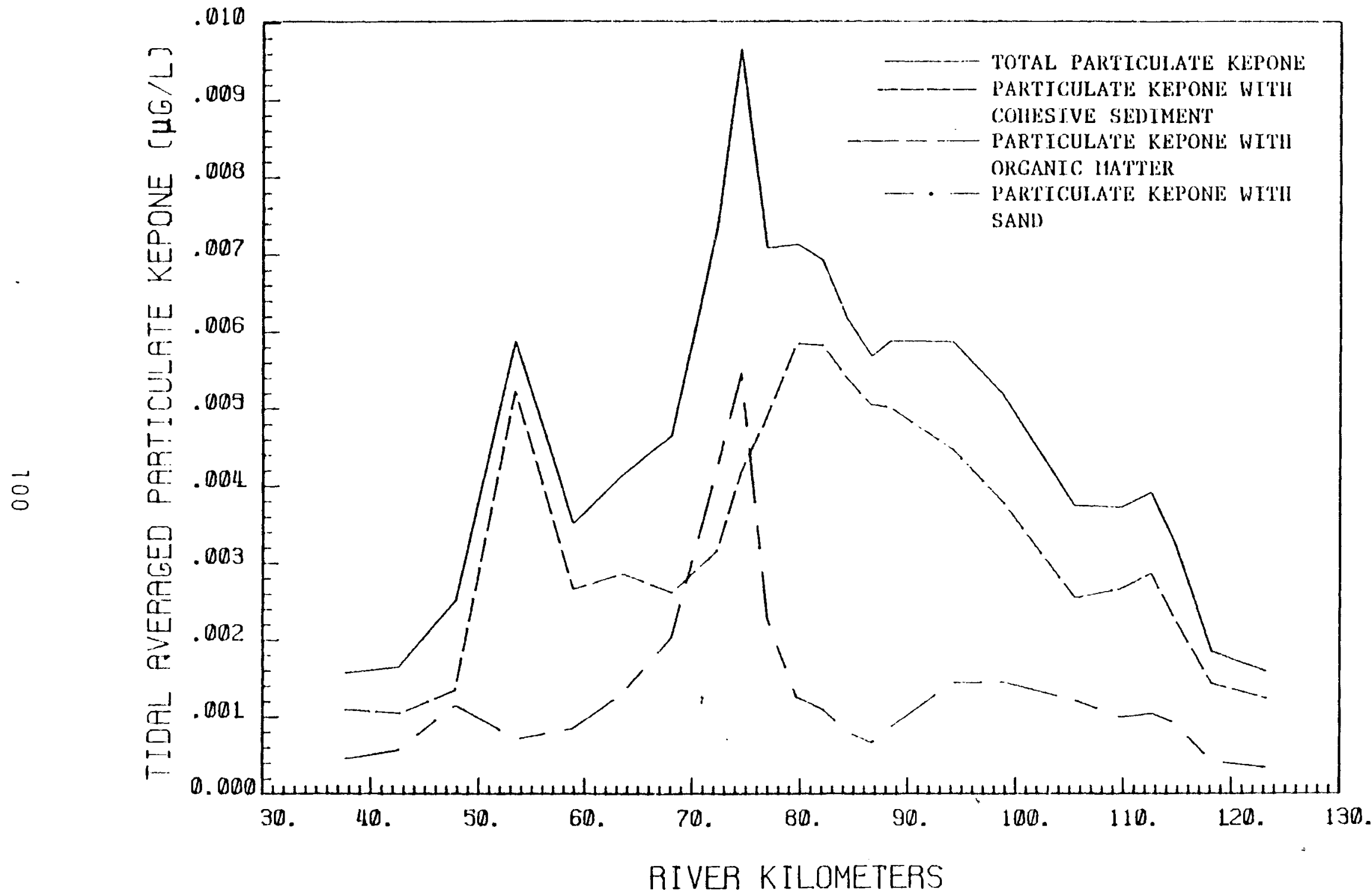

FIGURE 60. Longitudinal Distributions of Particulate Kepone Concentrations per Unit Volume of Water at Maximum Flood Tide for the Fresh-Water Discharge of $247 \mathrm{~m}^{3} / \mathrm{sec}$ 


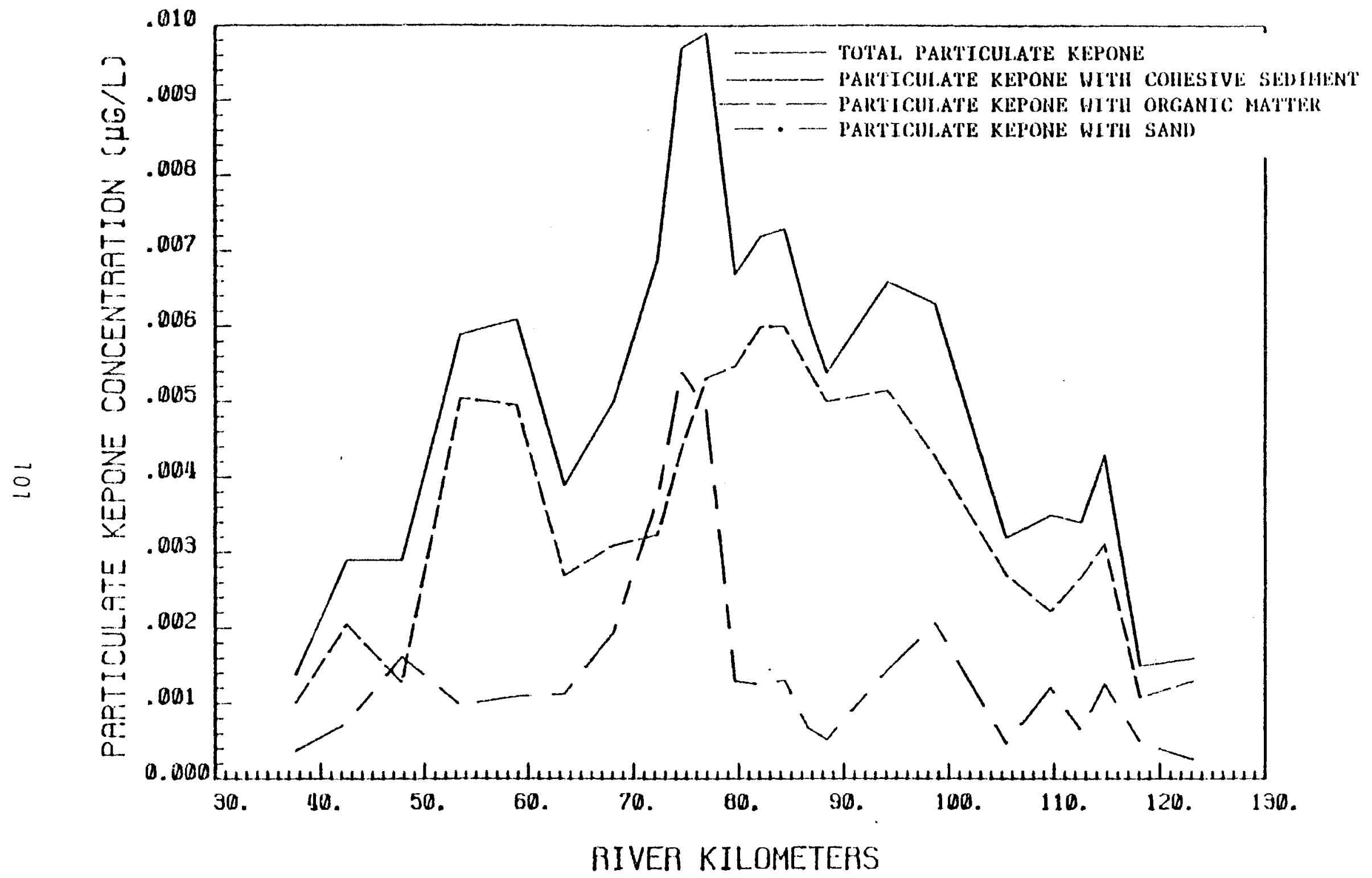

FIGURE 61. Longitudinal Distributions of Tidal Averaged Particulate Kepone Concentrations per Unit Volume of Water for the Fresh-Water Discharge of $247 \mathrm{~m}^{3} / \mathrm{sec}$ 


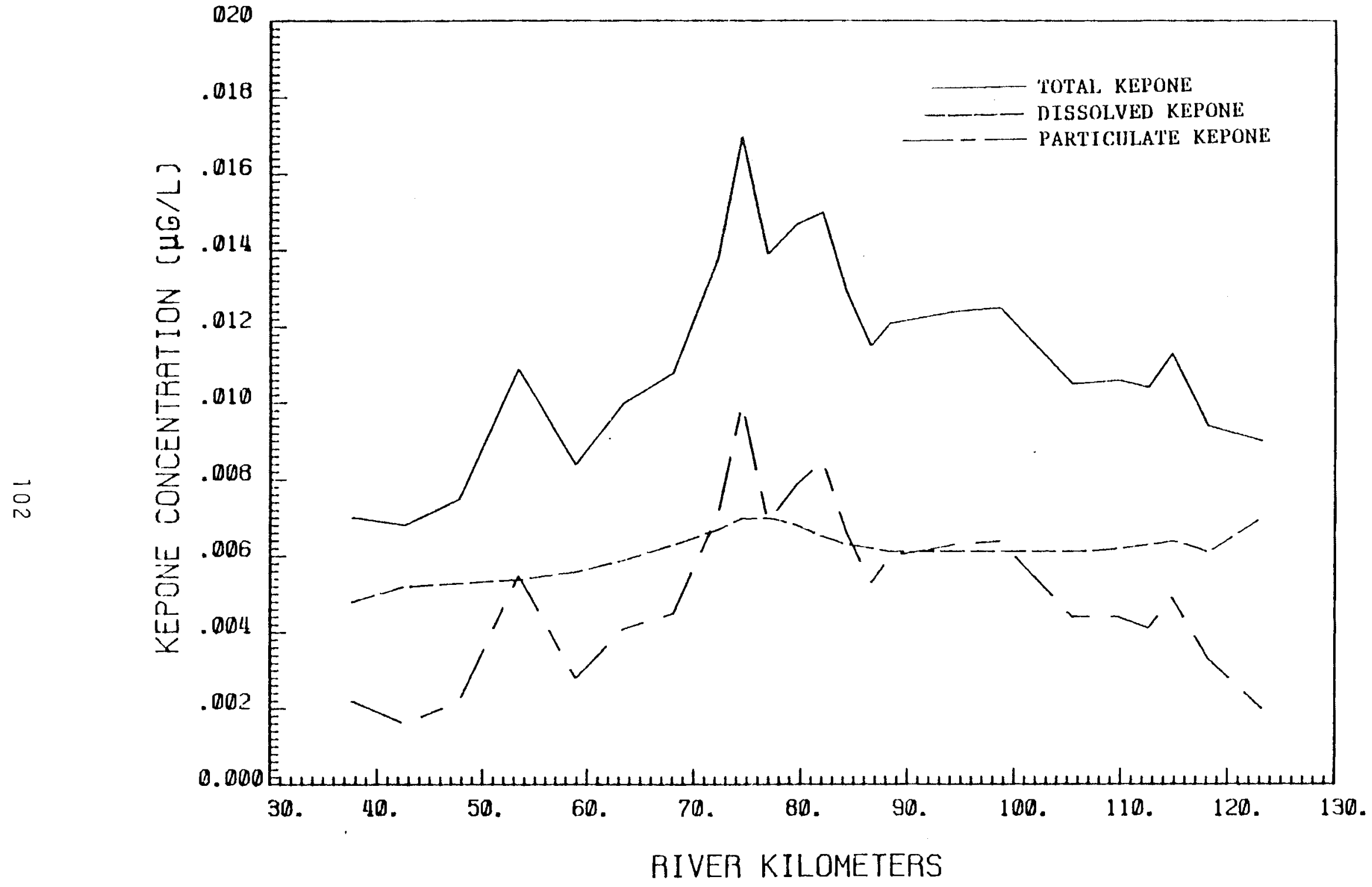

FIGURE 62. Longitudinal Distributions of Total, Dissolved and Particulate Kepone Concentrations at Maximum Ebb Tide for the Fresh-Water Discharge of $247 \mathrm{~m}^{3} / \mathrm{sec}$ 


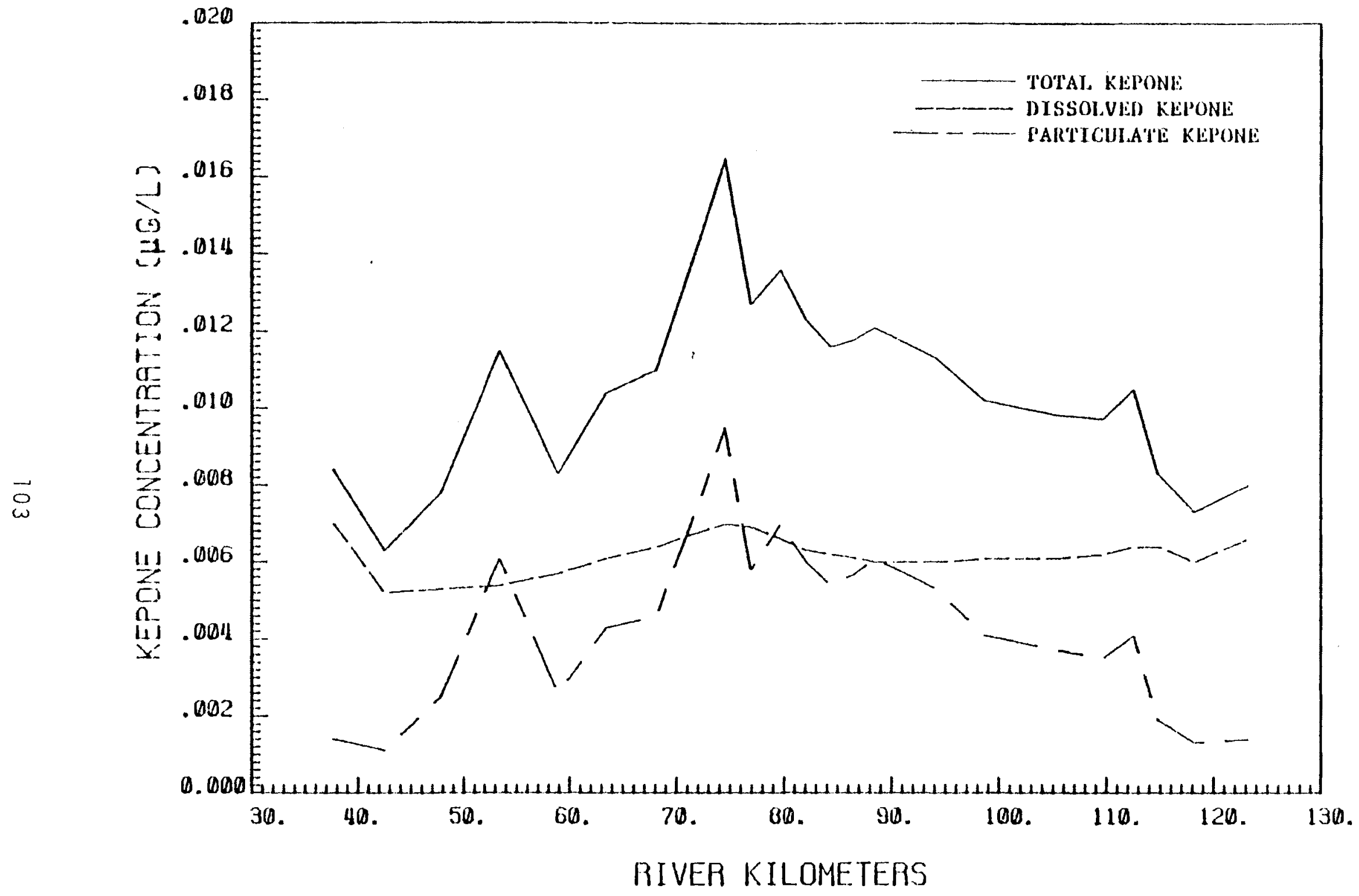

FIGURE 63. Longitudinal Distributions of Total, Dissolved and Particulate Kepone Concentrations at Slack Tide for the Fresh-Water Discharge of $247 \mathrm{~m}^{3} / \mathrm{sec}$ 


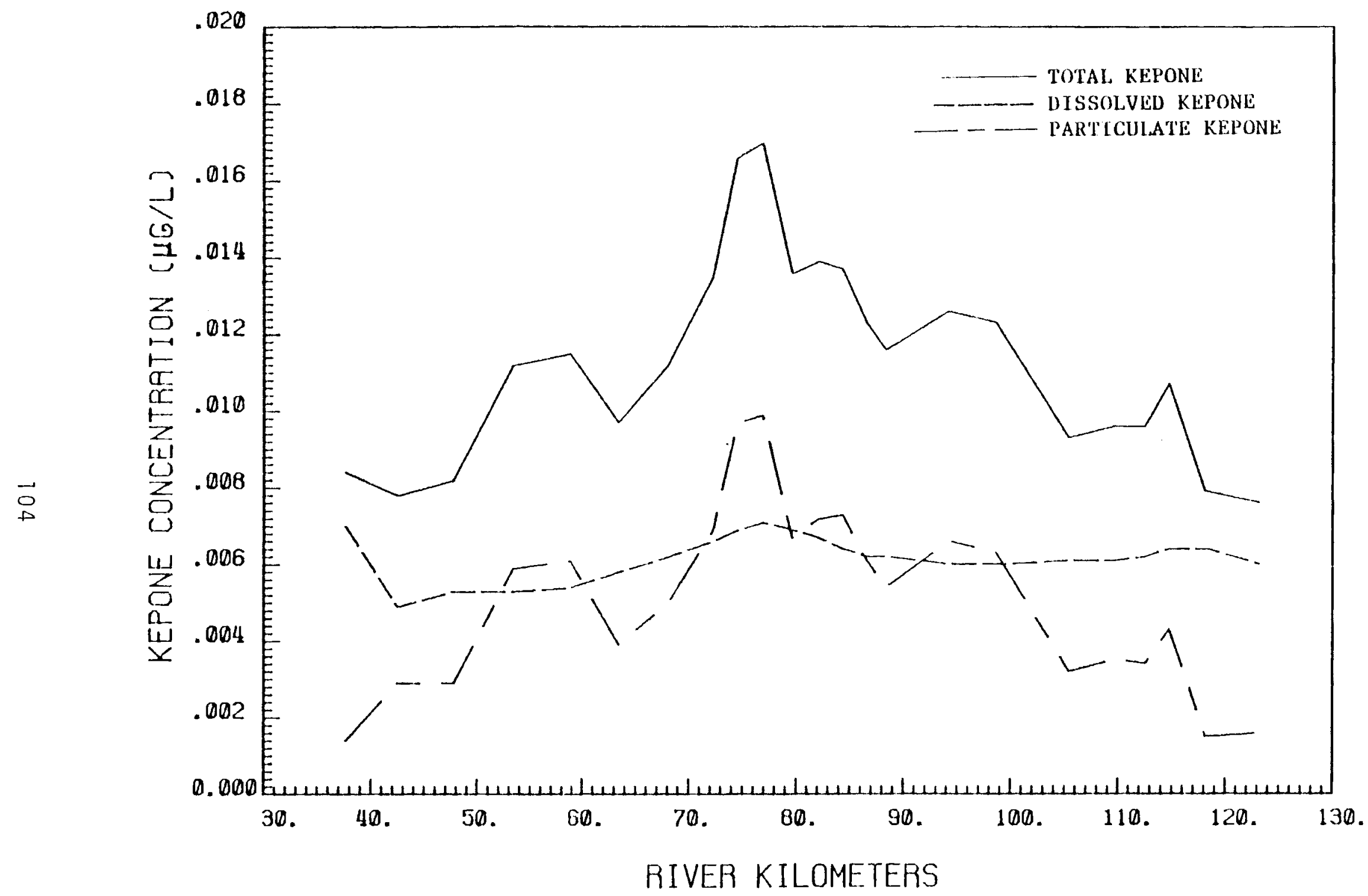

FIGURE 64. Longitudinal Distributions of Total, Dissolved and Particulate Kepone Concentrations at Maximum Flood Tide for the Fresh-Water Discharge of $247 \mathrm{~m}^{3} / \mathrm{sec}$ 


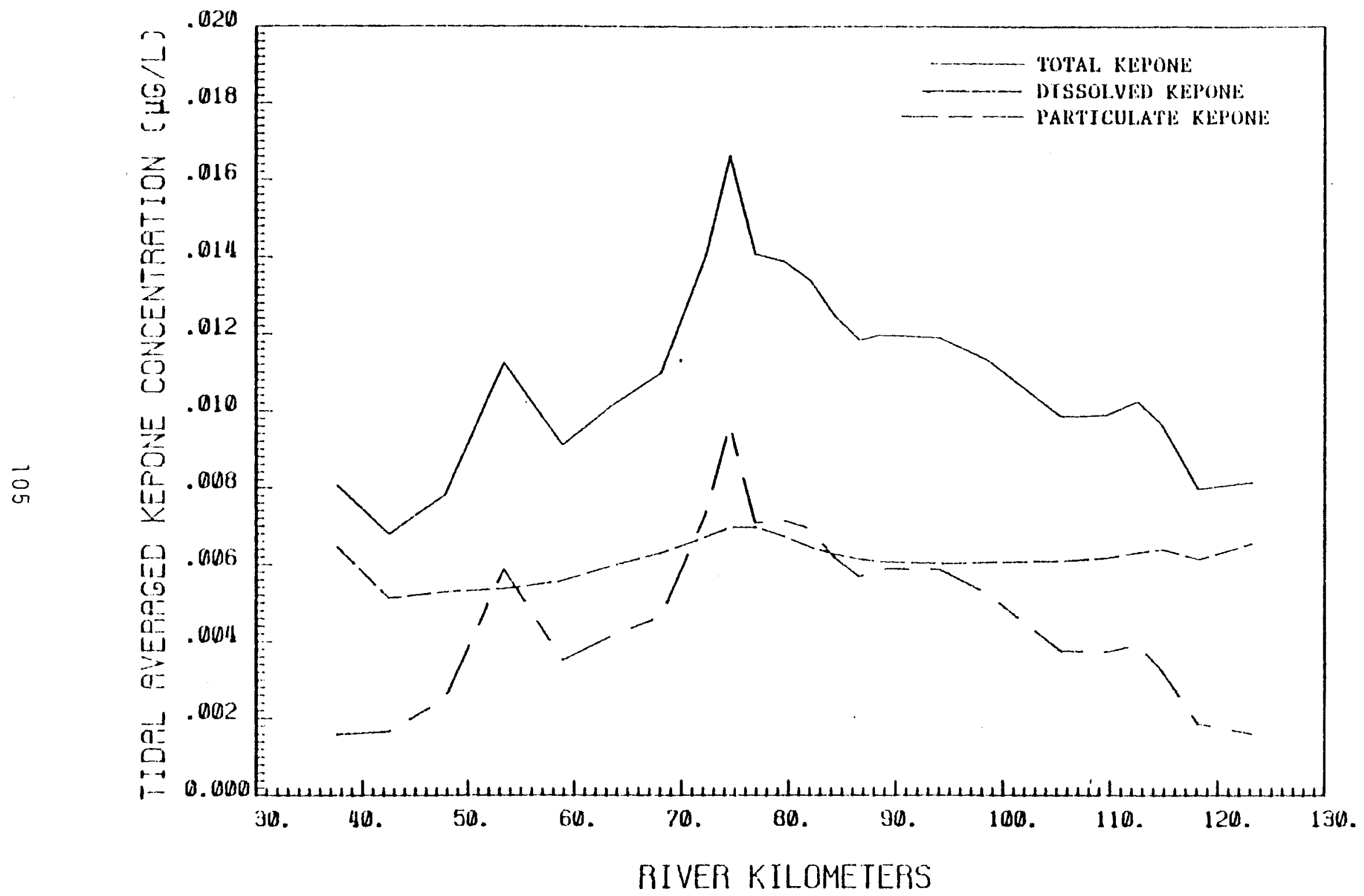

FIGURE 65. Longitudinal Distributions of Tidal Averaged Total, Dissolved and Particulate Kepone Concentrations for the Fresh-Water Discharge of $247 \mathrm{~m}^{3} / \mathrm{sec}$ 


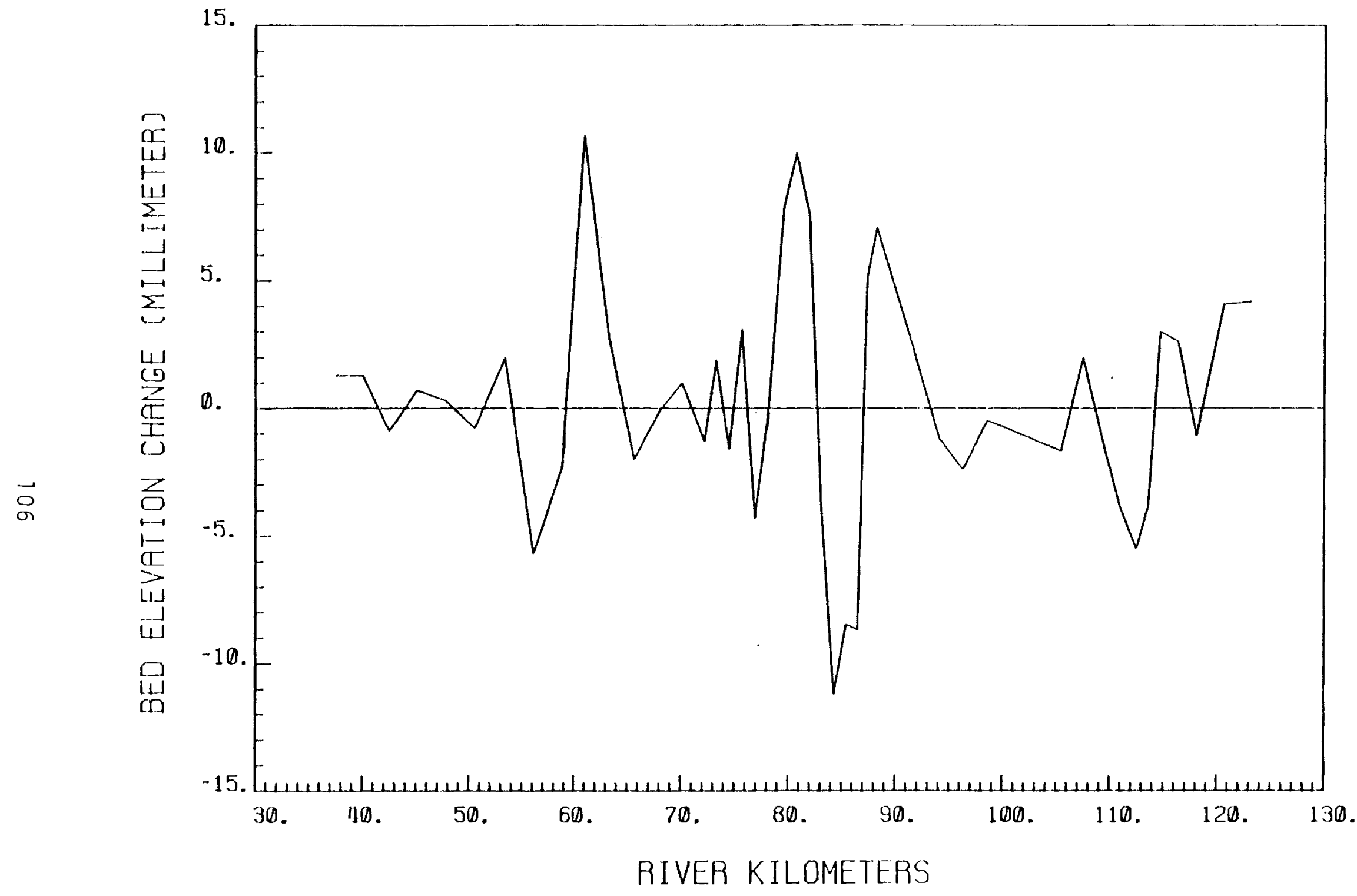

FIGURE 66. Variation of River Bed Elevation Changes Due to Sediment Deposition and/or Bed Scouring at Maximum Ebb Tide for the Fresh-Water Discharge of $247 \mathrm{~m}^{3} / \mathrm{sec}$ 


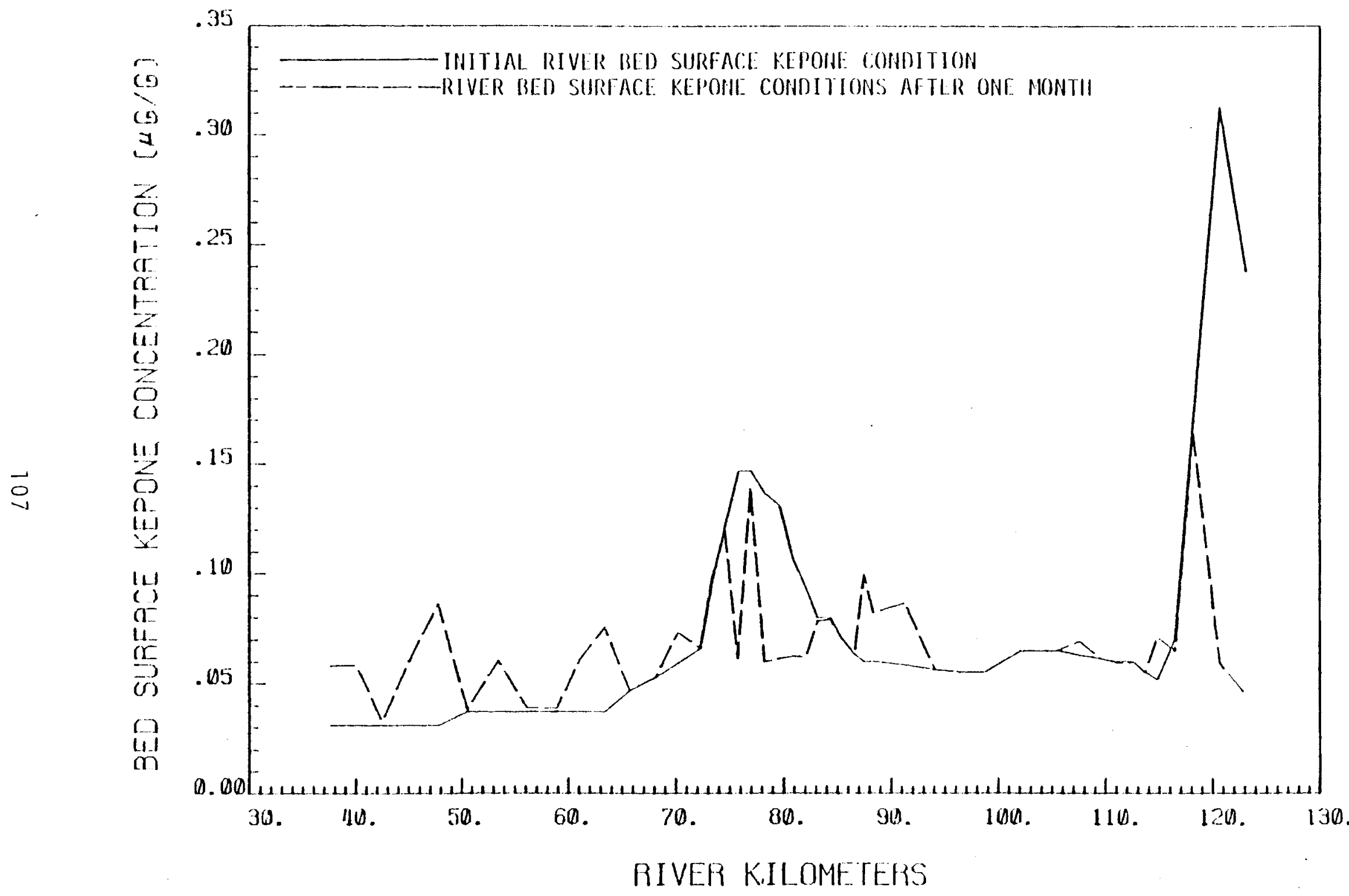

FIGURE 67. Change in Bed Surface Kepone Concentration that Occurred During 1-Month Simulation for the Fresh-Water Discharge of $247 \mathrm{~m}^{3} / \mathrm{sec}$ 


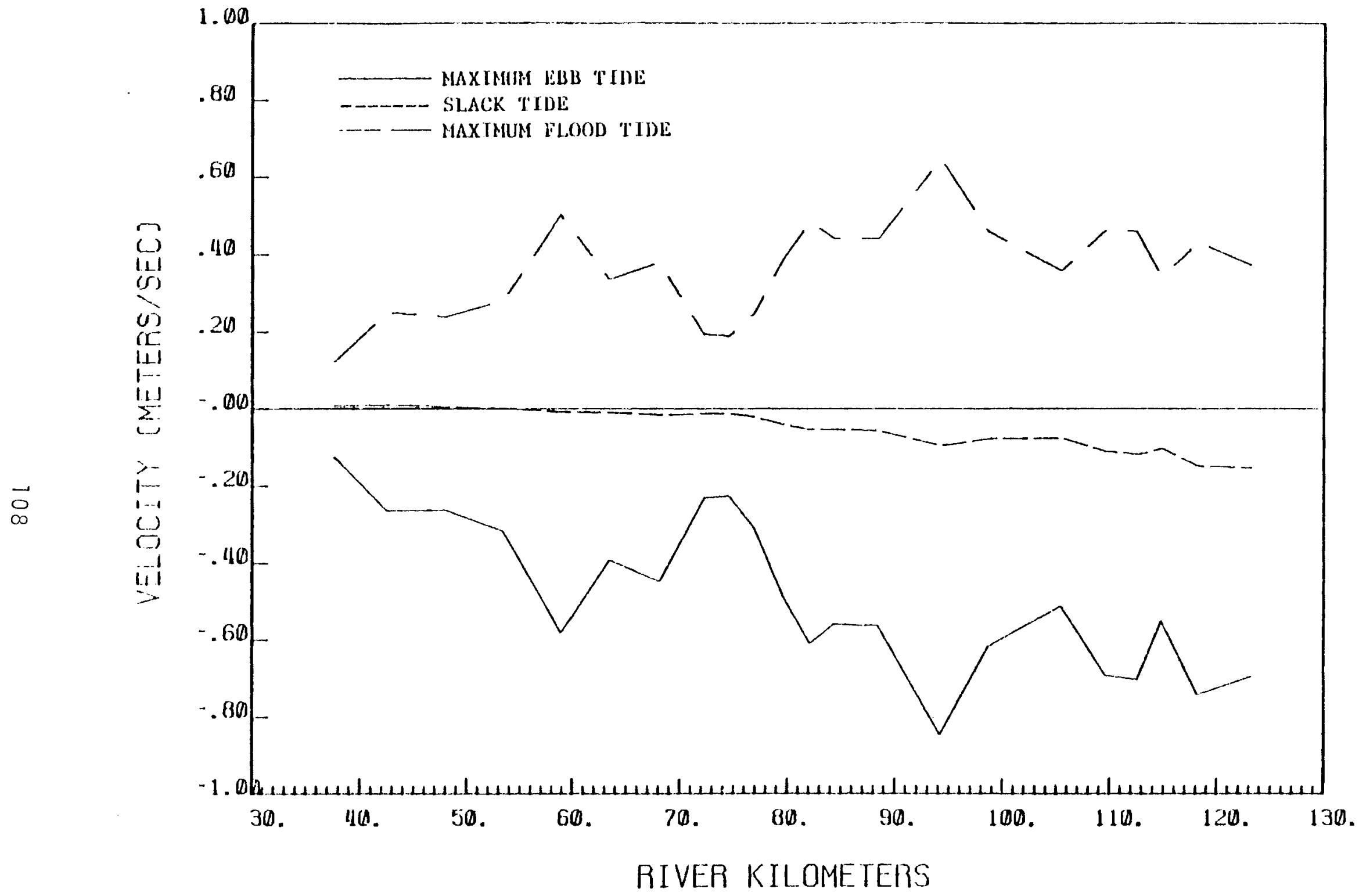

FIGURE 68. Longitudinal Velocity Distributions at Maximum Ebb, Slack and the Maximum Flood Tides for Fresh-Water Input Discharge of $681 \mathrm{~m}^{3} / \mathrm{sec}$ 


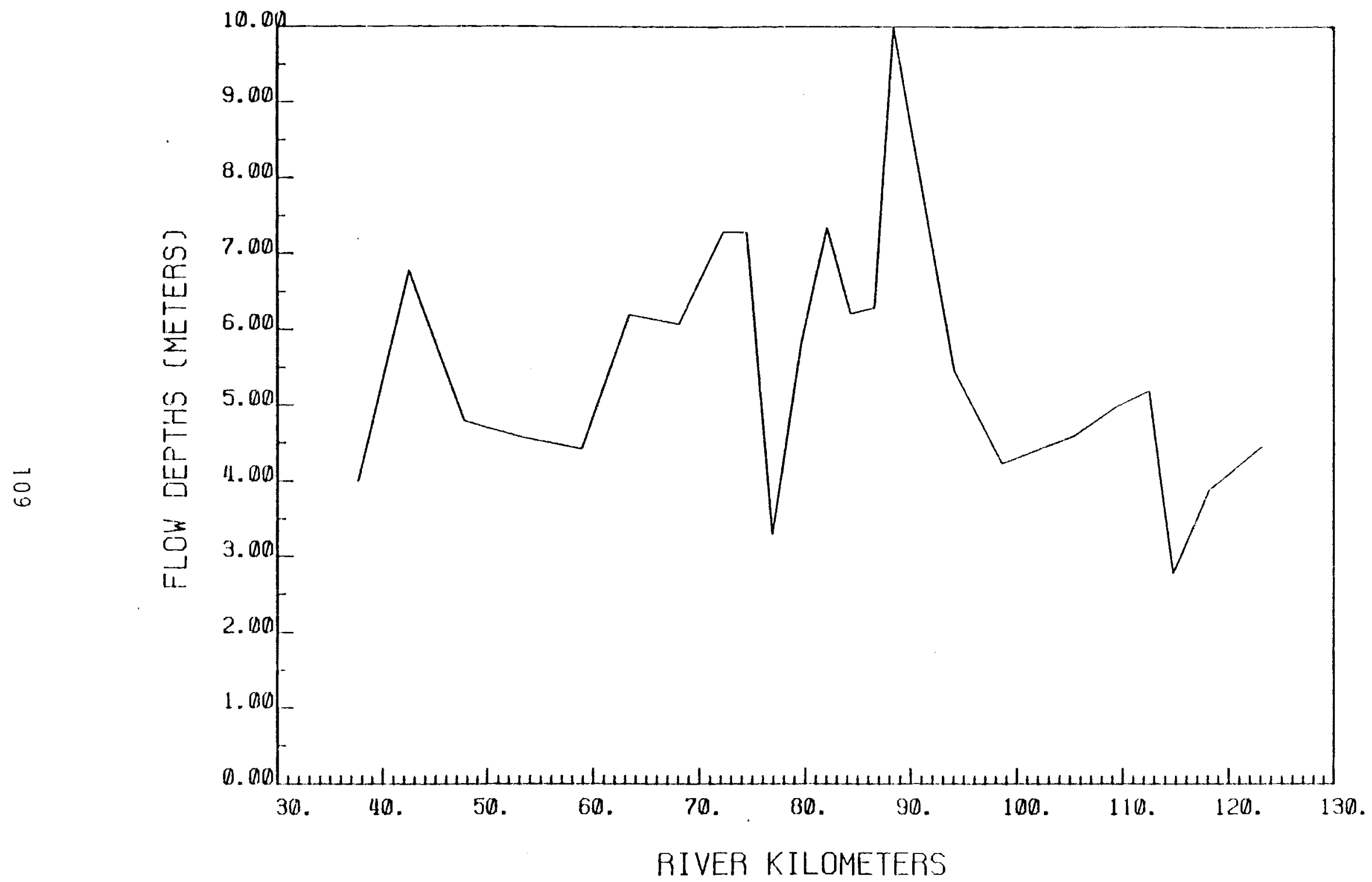

FIGURE 69. Longitudinal Depth Variation at Maximum Ebb Tide for the Fresh-Water Discharge of $681 \mathrm{~m}^{3} / \mathrm{sec}$ 


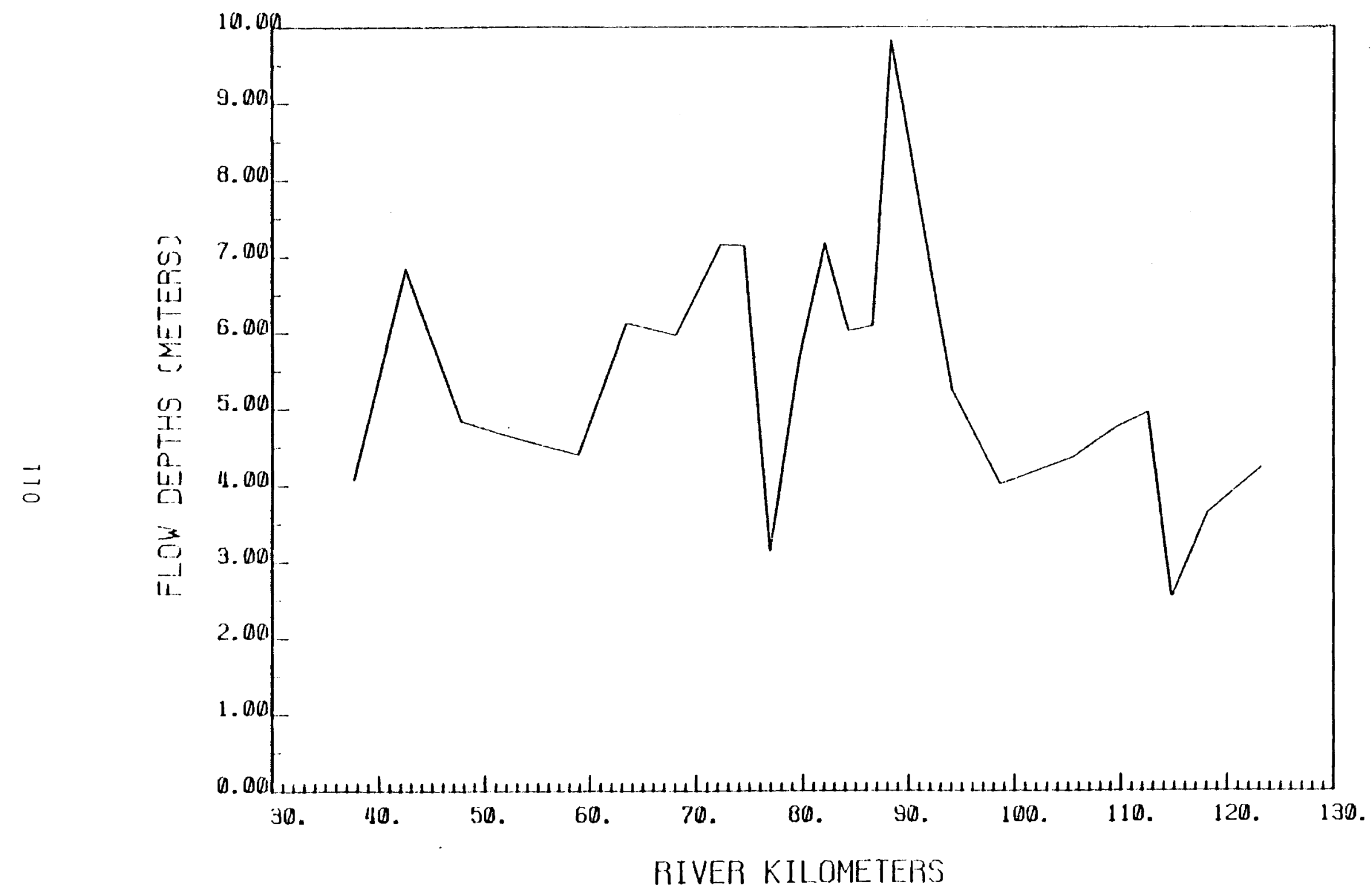

FIgURE 70. Longitudina1 Depth Variation at Slack Tide for the Fresh-Water Discharge of $58.3 \mathrm{~m}^{3} / \mathrm{sec}$ 


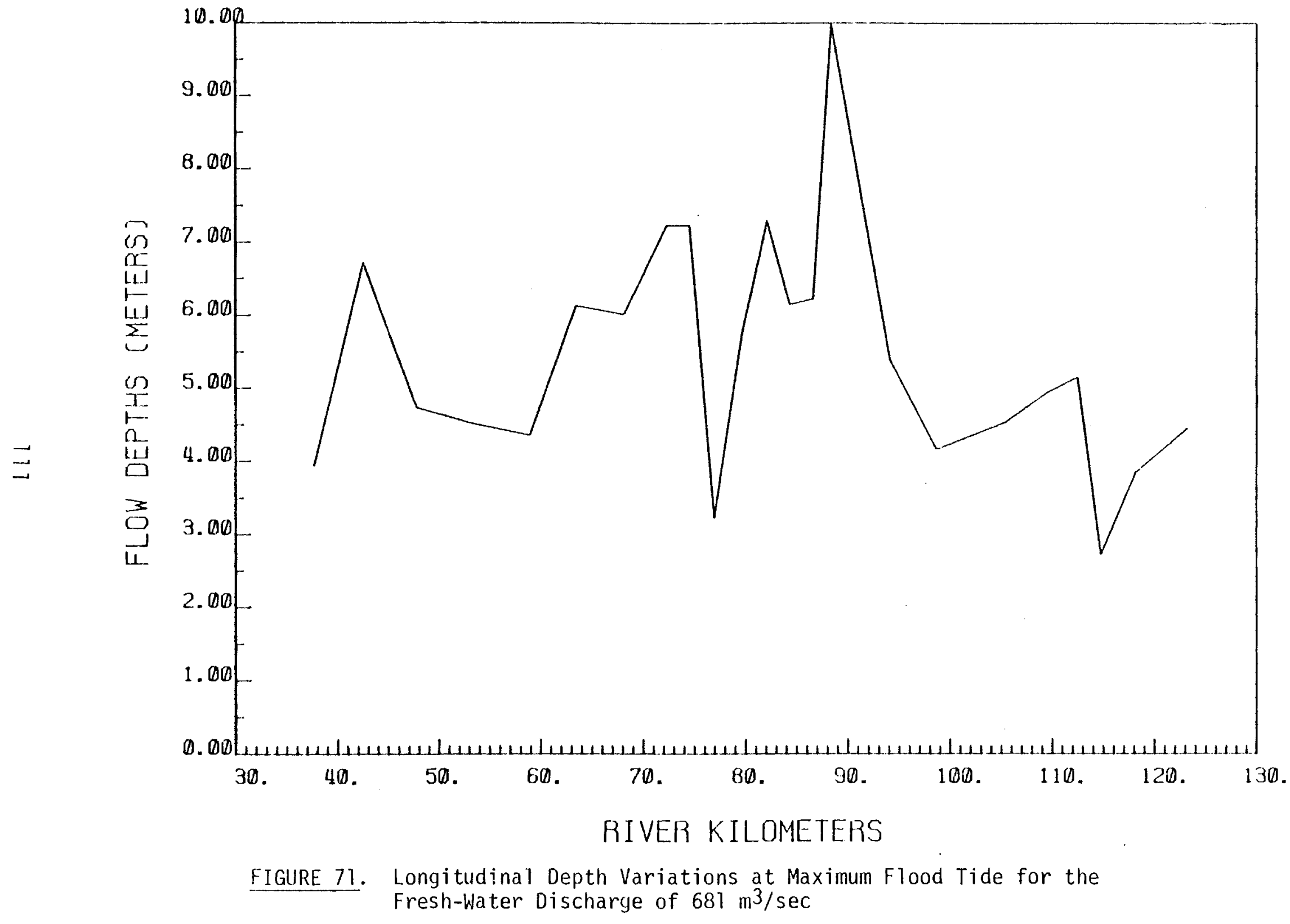




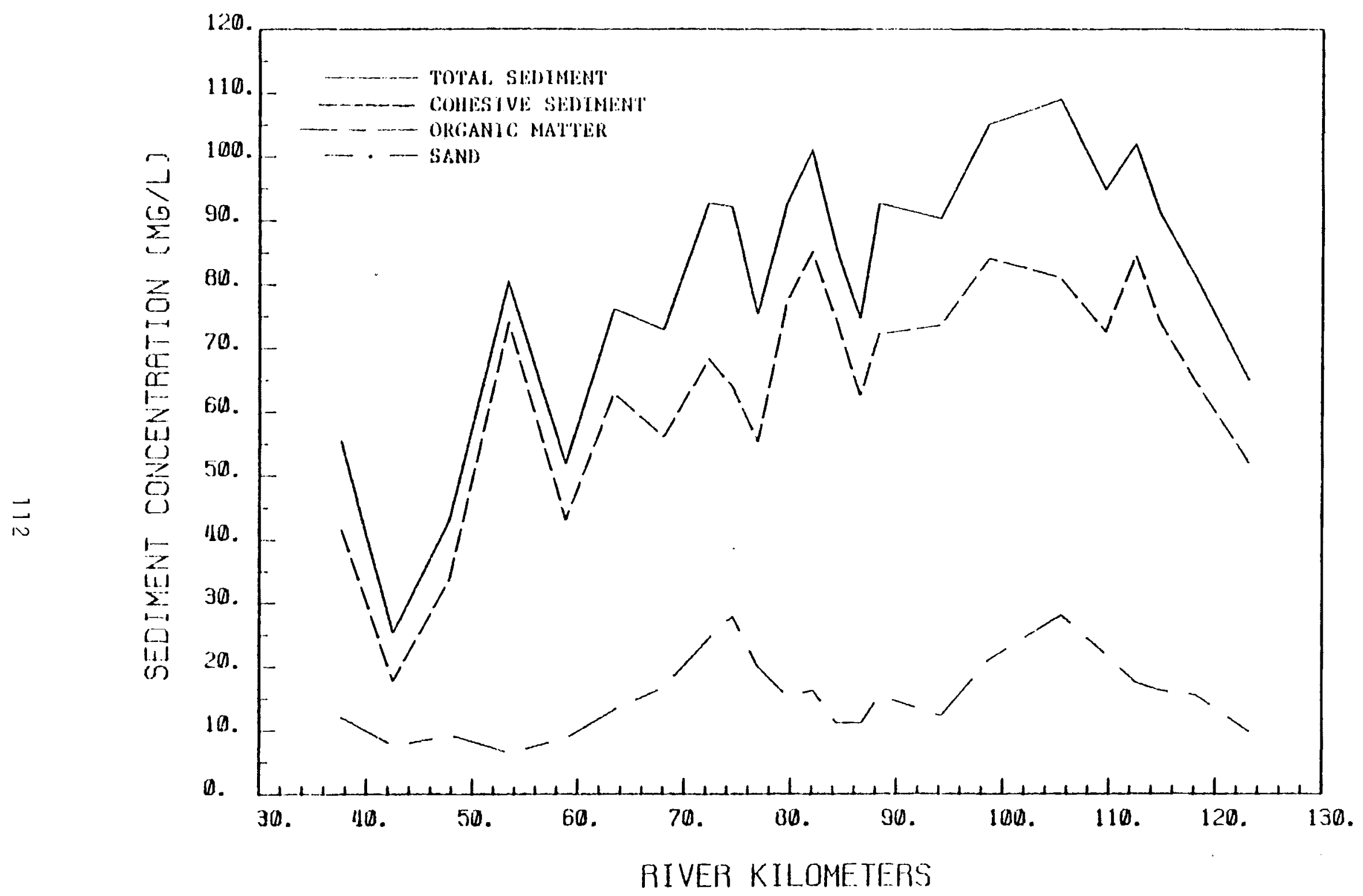

FIGURE 72. Longitudinal Distribution of Sediment Concentration of Each Sediment Type at Maximum Ebb Tide for the Fresh-Water Discharge of $681 \mathrm{~m}^{3} / \mathrm{sec}$ 


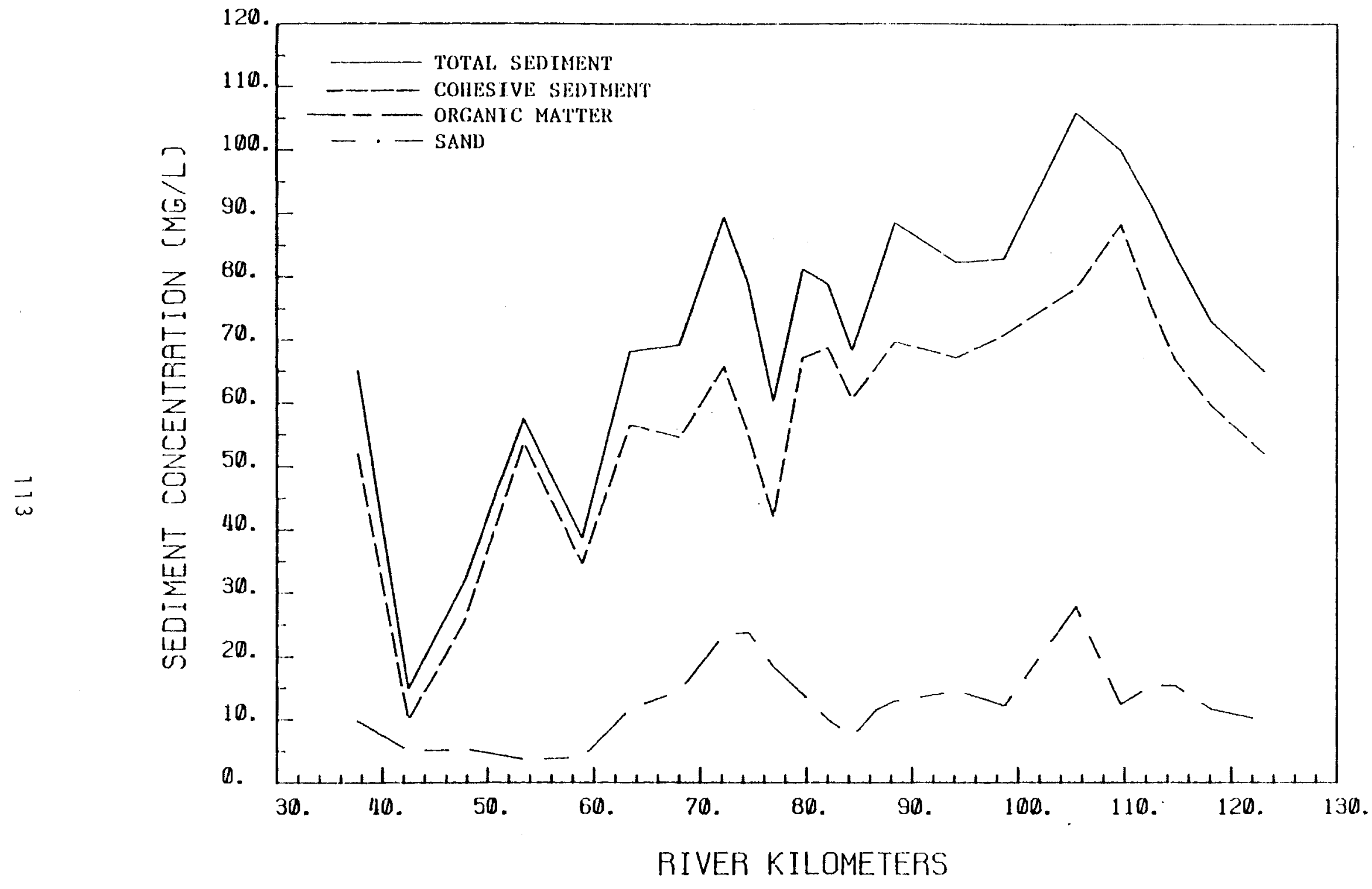

FIGURE 73. Longitudinal Distribution of Sediment Concentration of Each Sediment Type at Slack Tide for the Fresh-Water Discharge of $681 \mathrm{~m}^{3} / \mathrm{sec}$ 


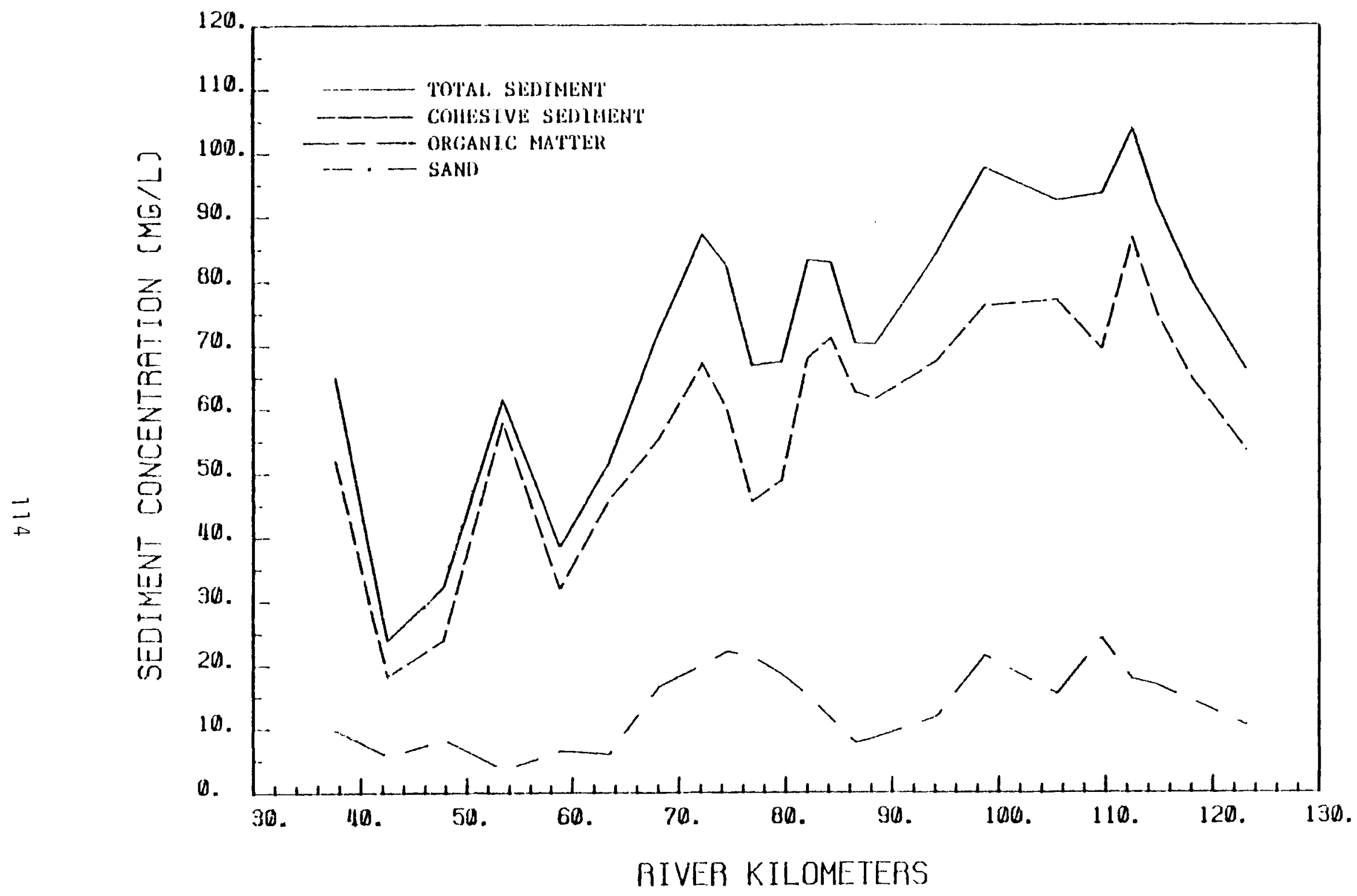

FIGURE 74. Longitudinal Distributions of Sediment Concentration of Each Sediment Type at Maximum Flood Tide for the Fresh-Water Discharge of $681 \mathrm{~m}^{3} / \mathrm{sec}$ 


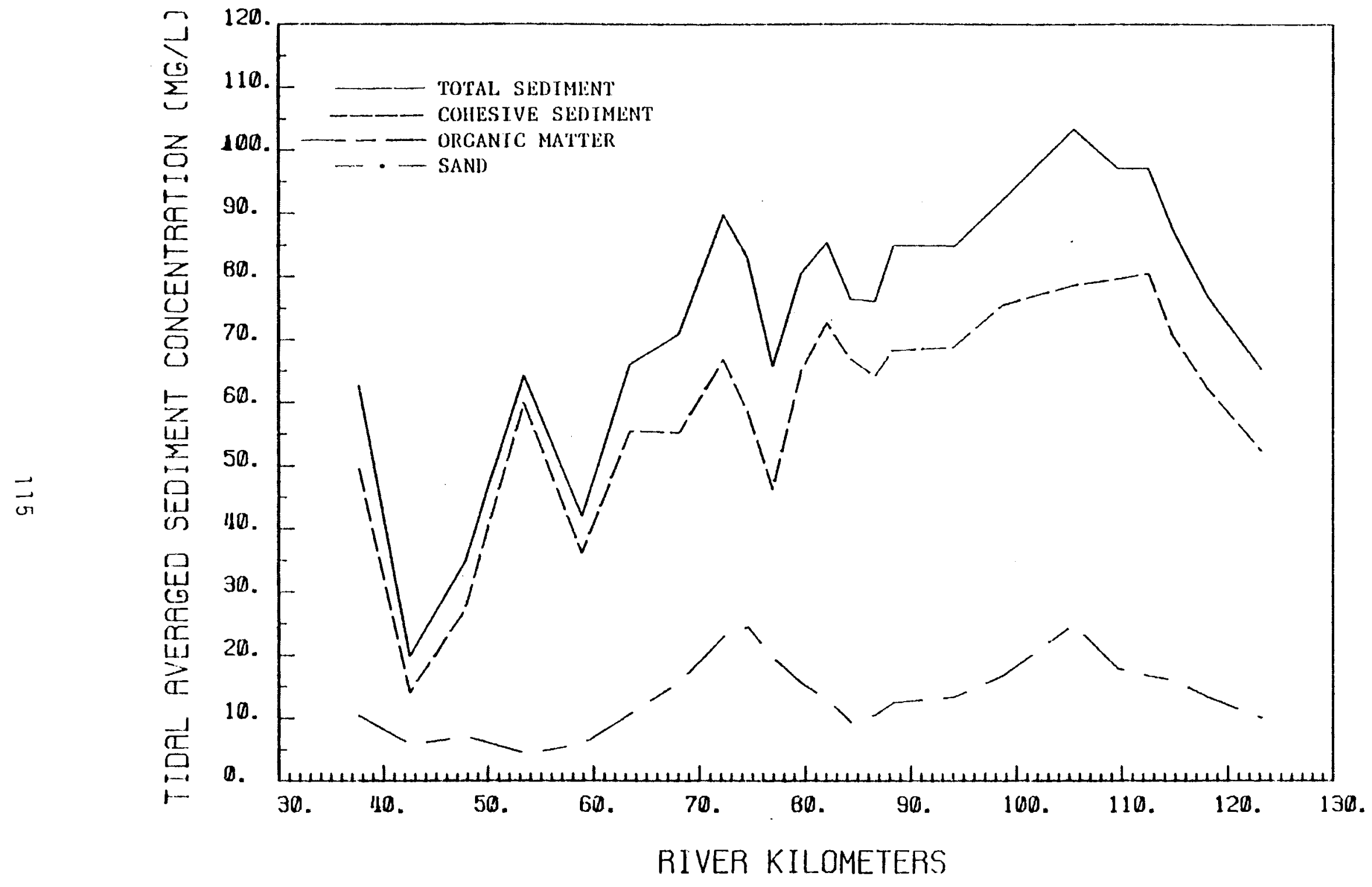

FIGURE 75. Tidal Averaged Sediment Concentration of Each Sediment Type for the Fresh-Water Discharge of $681 \mathrm{~m}^{3} / \mathrm{sec}$ 


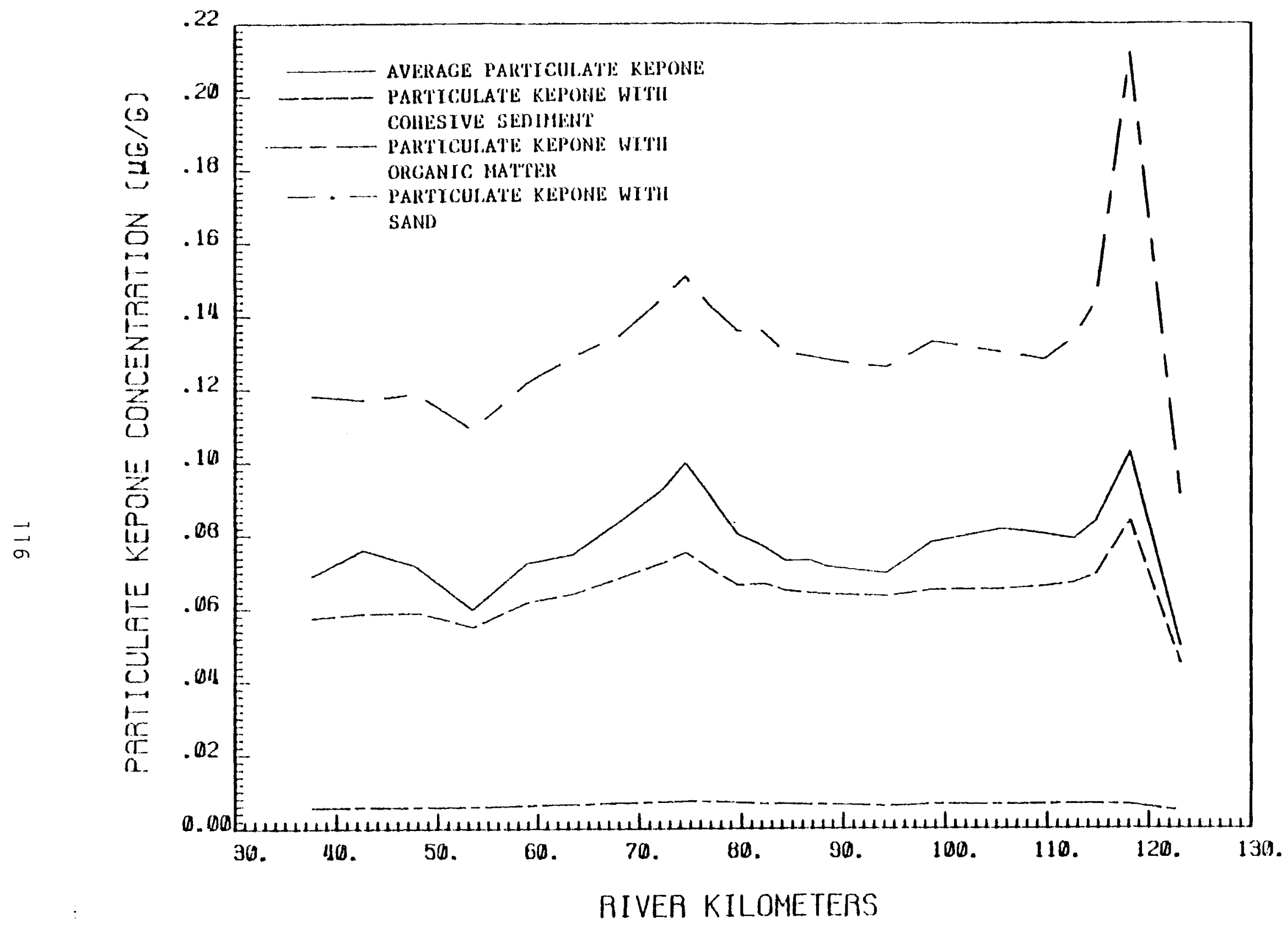

FIGURE 76. Longitudinal Distributions of Particulate Kepone Concentrations at Maximum Ebb Tide for the Fresh-Water Discharge to $681 \mathrm{~m}^{3} / \mathrm{sec}$ 
FIGURE 77. Longitudinal Distributions of Particulate Kepone Concentrations at Slack Tide for the Fresh-Water Discharges of $681 \mathrm{~m}^{3} / \mathrm{sec}$ 


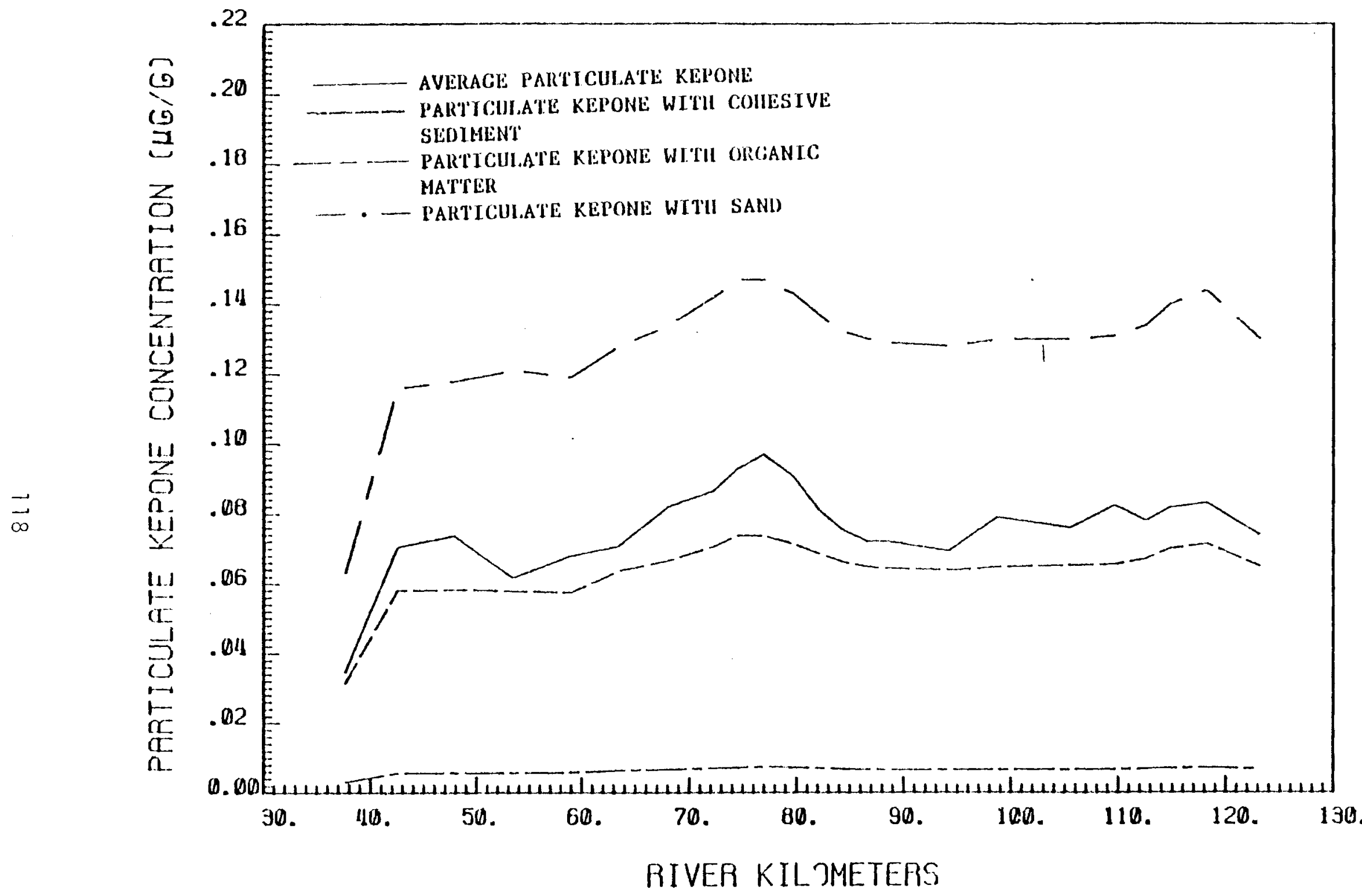

FIGURE 78. Longitudinal Distributions of Particulate Kepone Concentrations at Maximum Flood Tide for the Fresh-Water Discharge of $681 \mathrm{~m}^{3} / \mathrm{sec}$ 


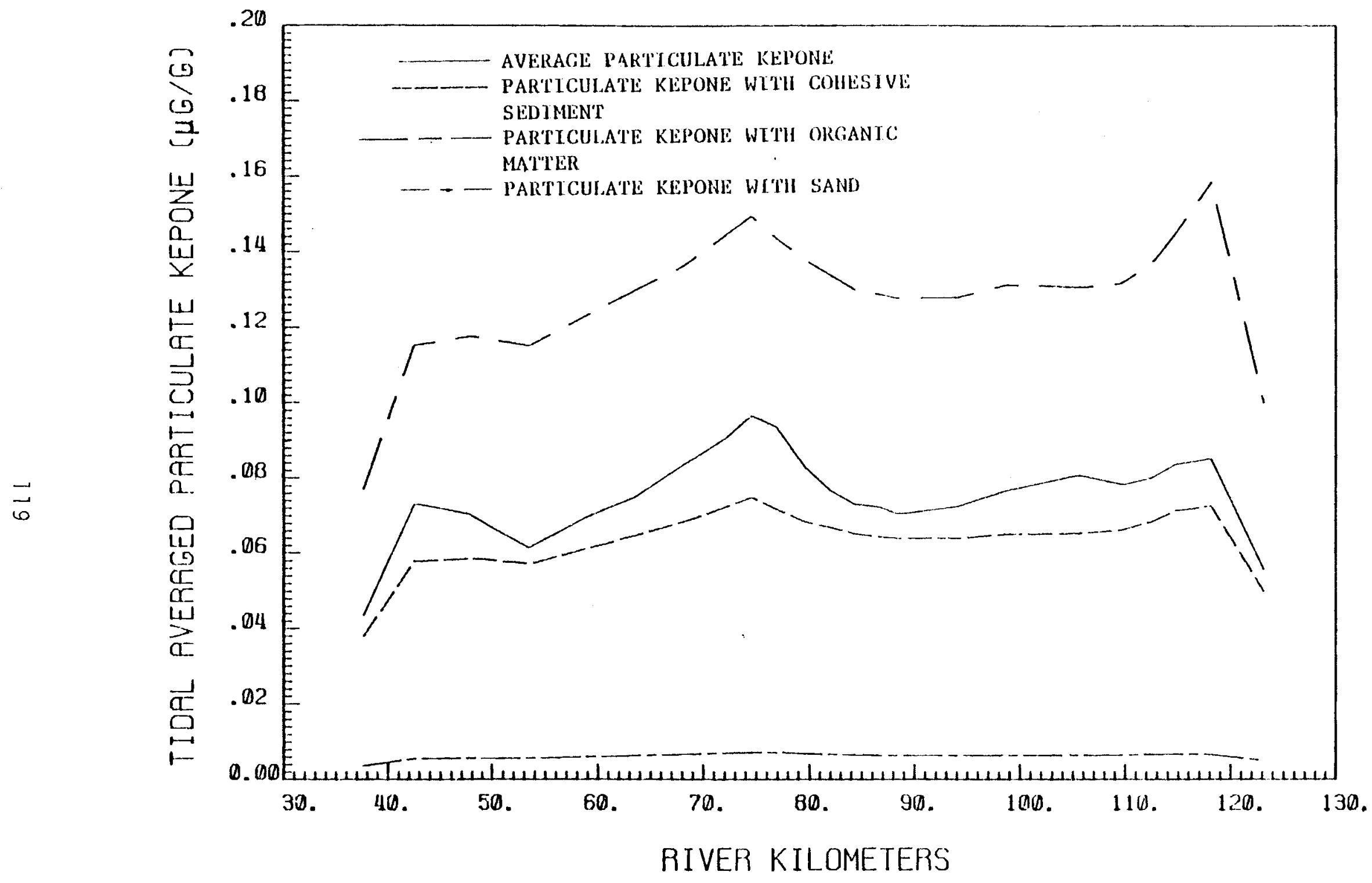

FIGURE 79. Tidal Averaged Particulate Kepone Concentrations for the Fresh-Water Discharge of $681 \mathrm{~m}^{3} / \mathrm{sec}$ 


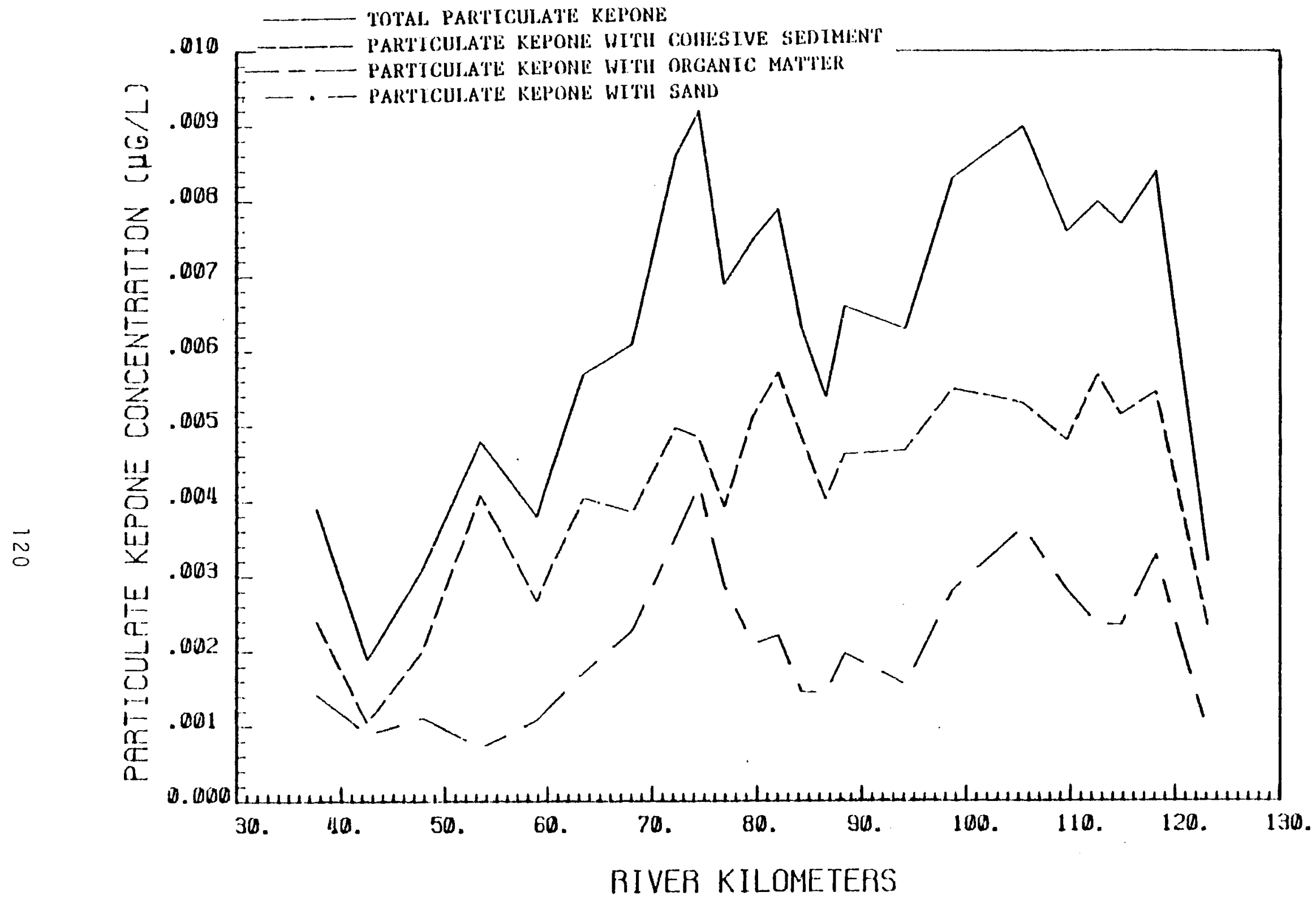

FIGURE 80. Longitudinal Distributions of Particulate Kepone Concentrations per Unit Volume of Water at Maximum Ebb Tide for the Fresh-Water Discharge of $681 \mathrm{~m}^{3} / \mathrm{sec}$ 


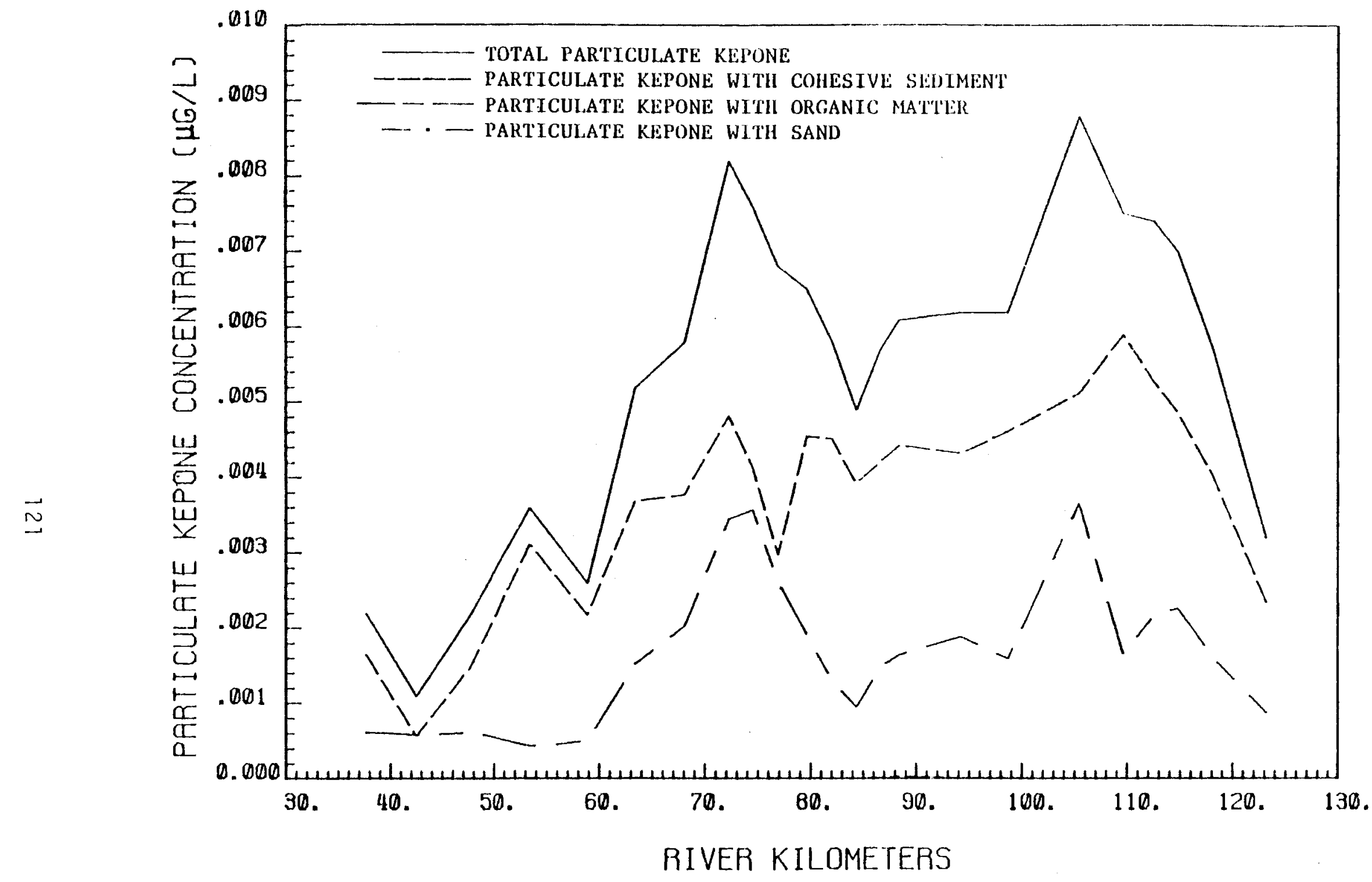

FIGURE 31. Longitudinal Distributions of Particulate Kepone Concentrations per Unit Volume of Water at Slack Tide for the Fresh-Water Discharge of $681 \mathrm{~m} 3 / \mathrm{sec}$ 


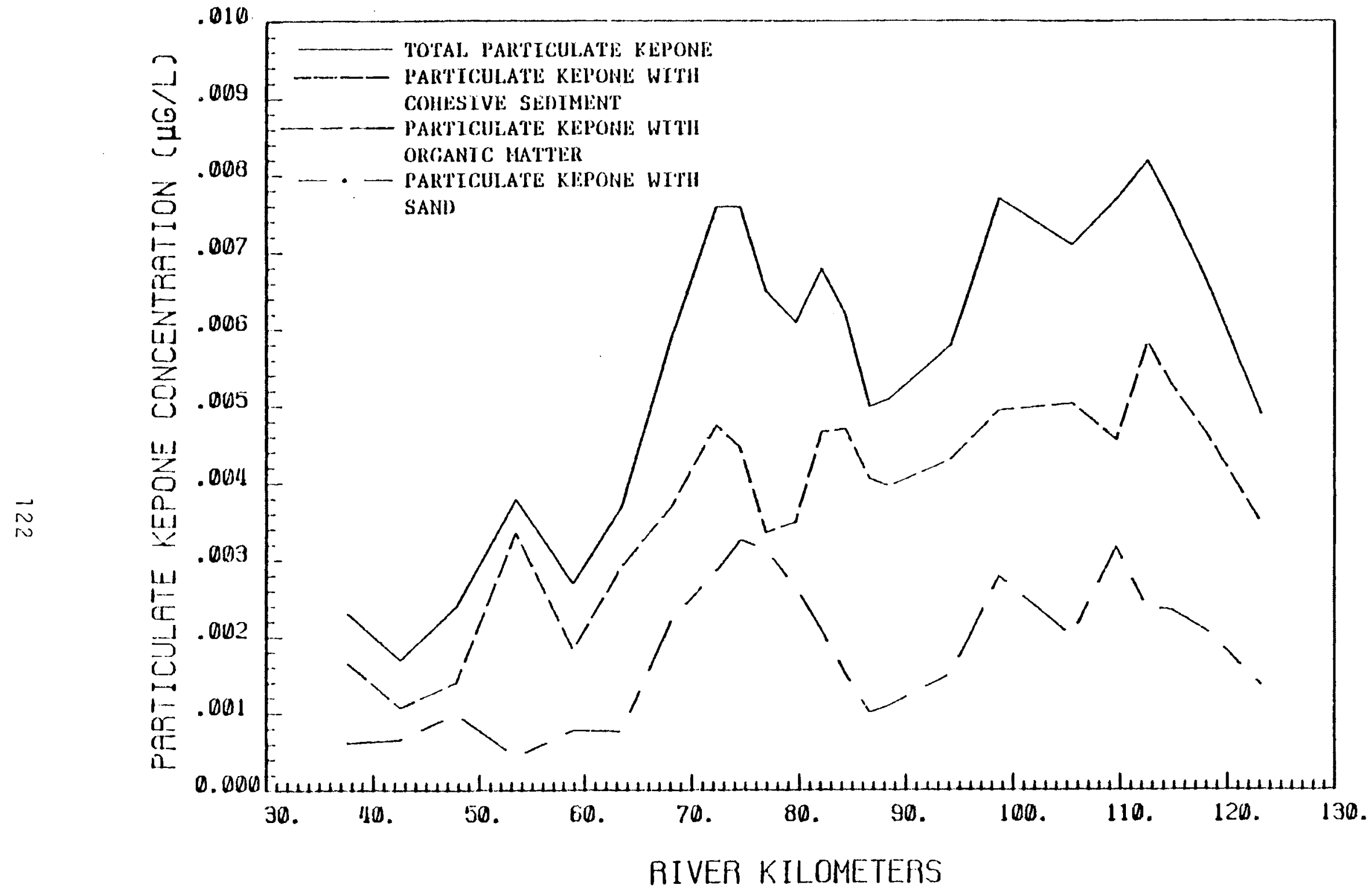

FIGURE 82. Longitudinal Distributions of Particulate Kepone Concentrations per Unit Volume of Water at Maximum Flood Tide for the Fresh-Water Discharge of $681 \mathrm{~m}^{3} / \mathrm{sec}$ 


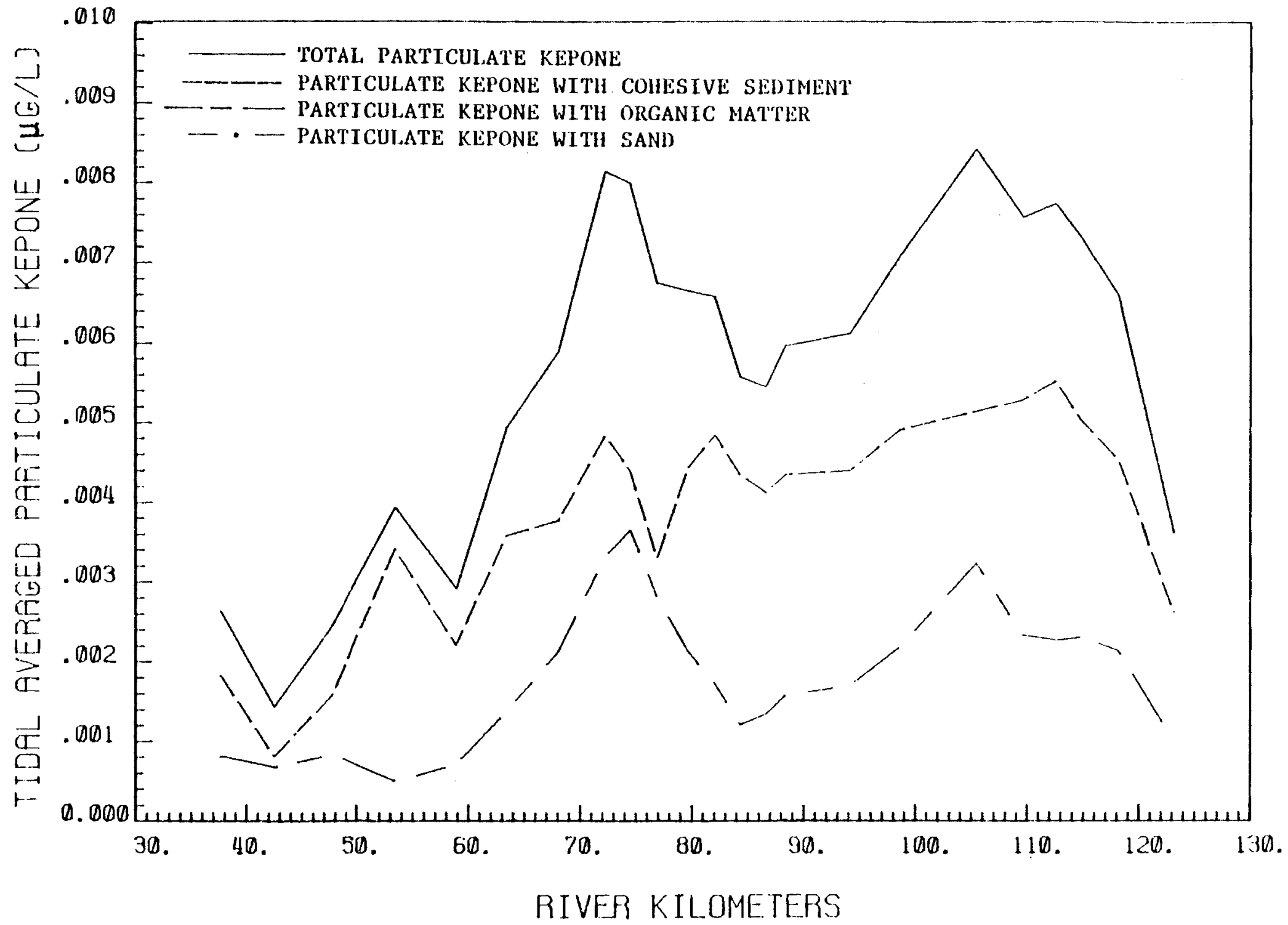

FIGURE 83. Longitudinal Distributions of Tidal Averaged Particulate Kepone Concentrations per Unit Volume of Water for the Fresh-Water Discharge of $681 \mathrm{~m}^{3} / \mathrm{sec}$ 


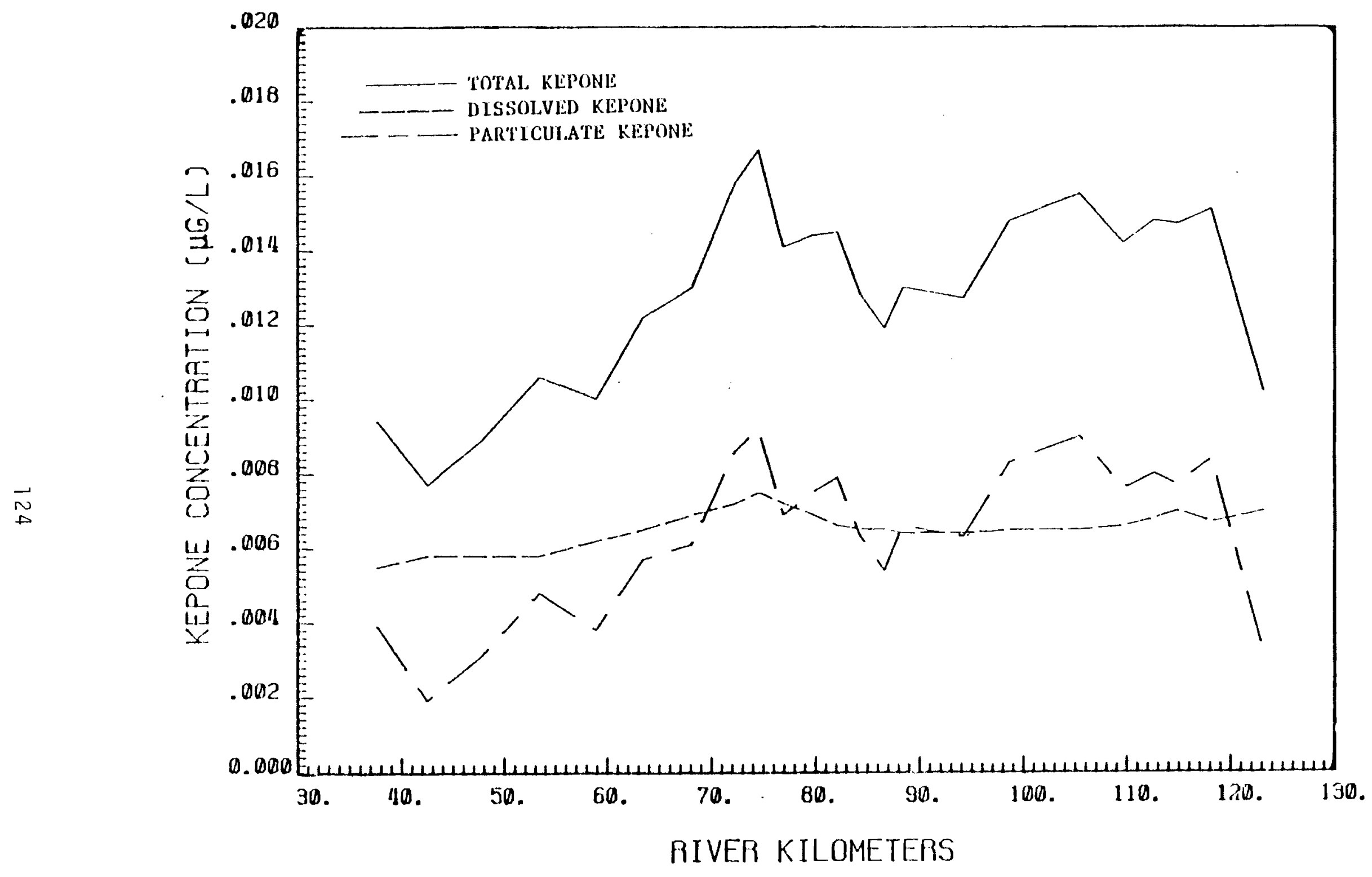

FIGURE 84. Longitudinal Distributions of Total, Dissolved and Particulate Kepone Concentrations at Maximum Ebb Tide for the Fresh-Water Discharge of $681 \mathrm{~m}^{3} / \mathrm{sec}$ 


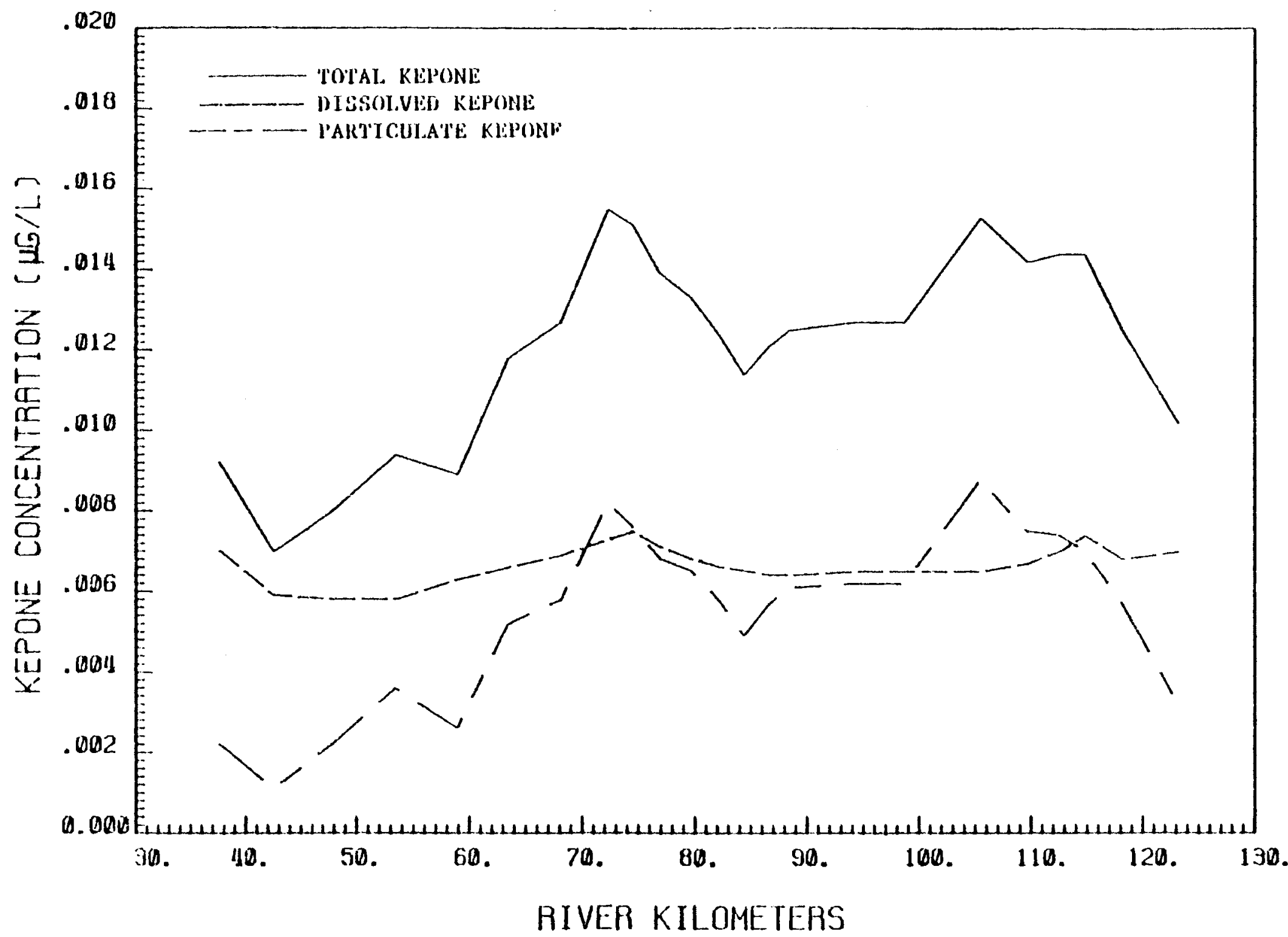

FIGURE 85. Longitudinal Distributions of Total, Dissolved and Particulate Kepone Concentrations at Slack Tide for the Fresh-Water Discharge of $681 \mathrm{~m}^{3} / \mathrm{sec}$ 


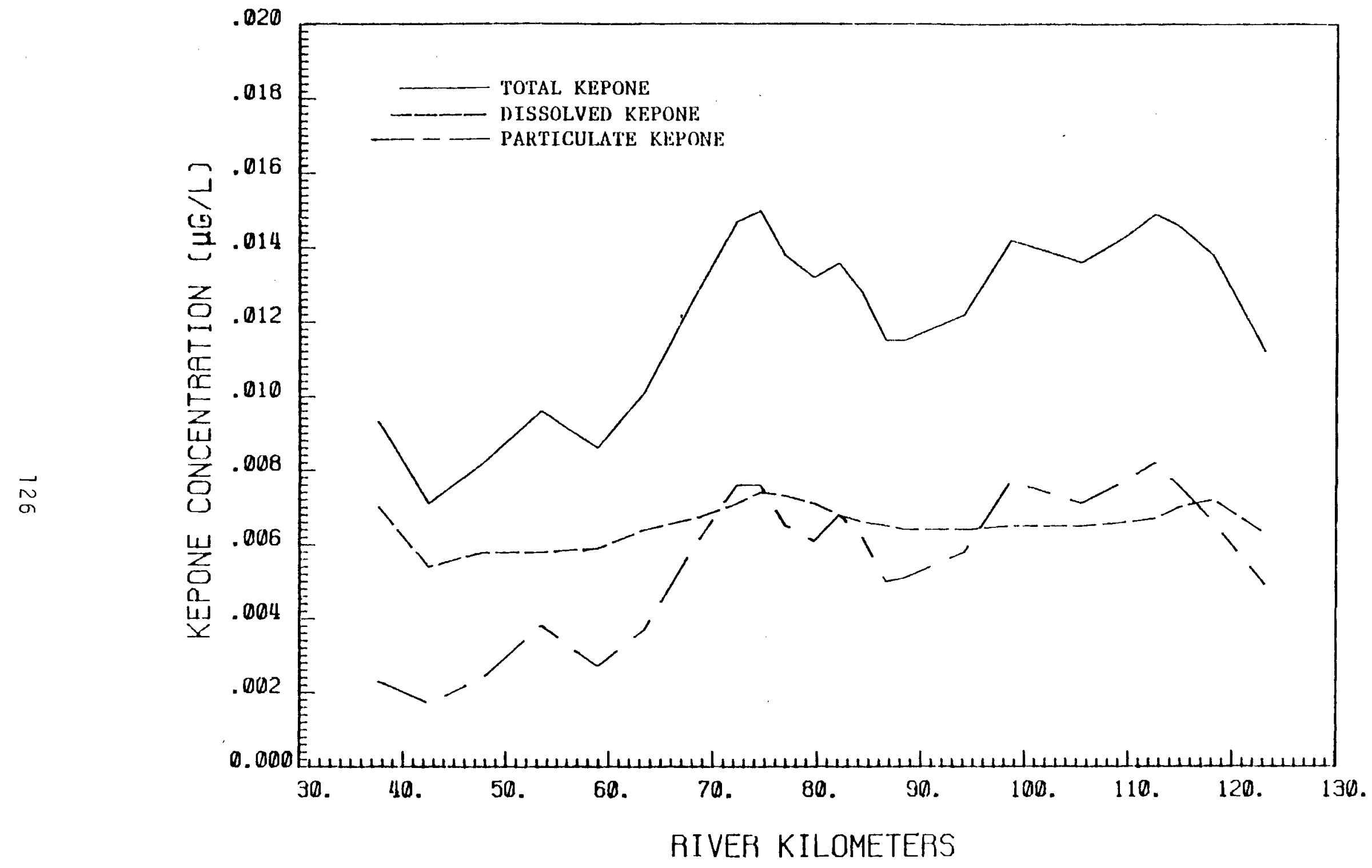

FIGURE 86. Longitudinal Distributions of Total, Dissolved and Particulate Kepone Concentrations at Maximum Flood Tide for the Fresh-Water Discharge of $681 \mathrm{~m}^{3} / \mathrm{sec}$ 


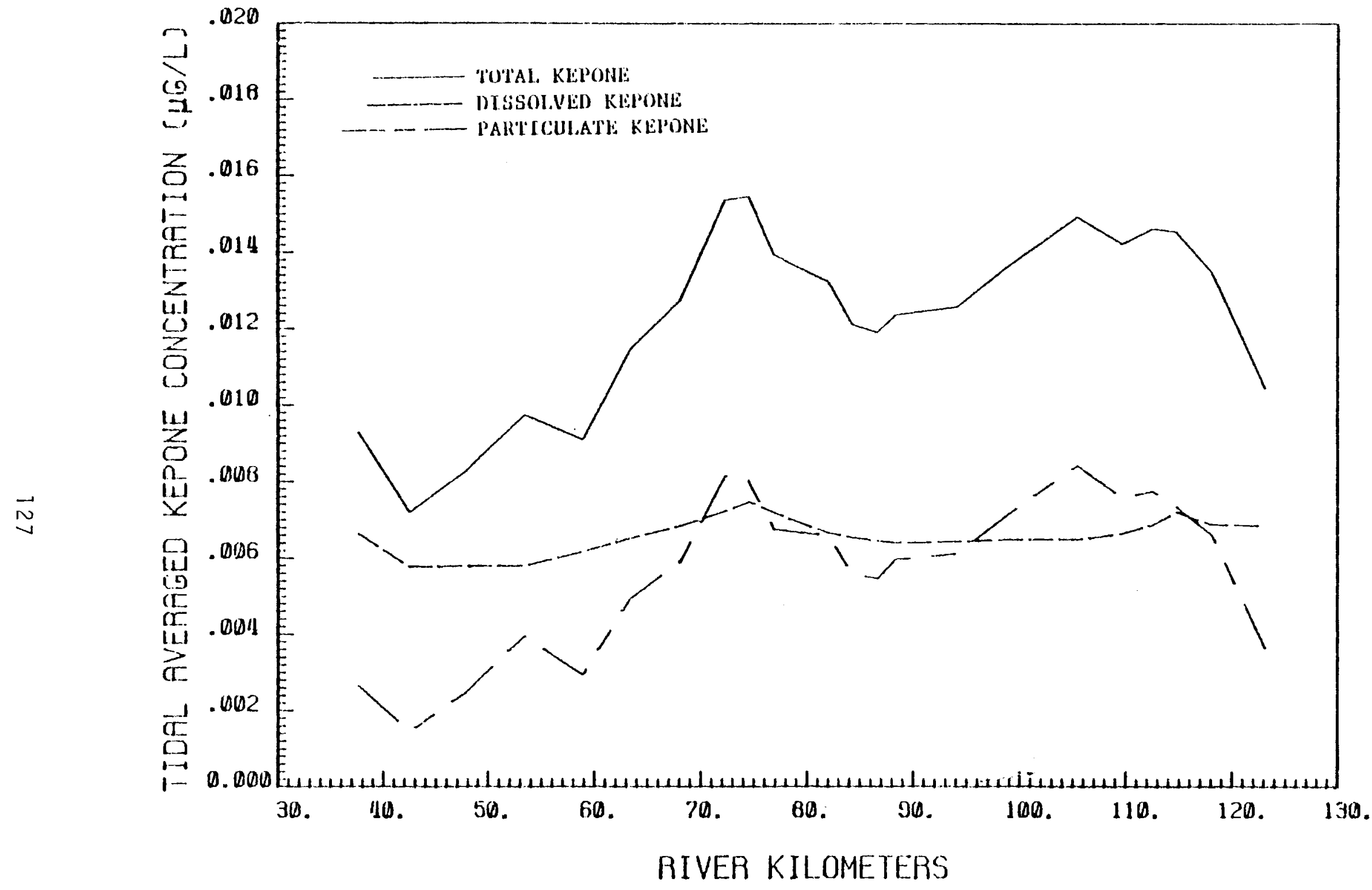

FIGURE 37. Longitudinal Distributions of Tidal Averaged Total, Dissolved and Particulate Kepone Concentrations for the Fresh-Water Discharge of $681 \mathrm{~m}^{3} / \mathrm{sec}$ 


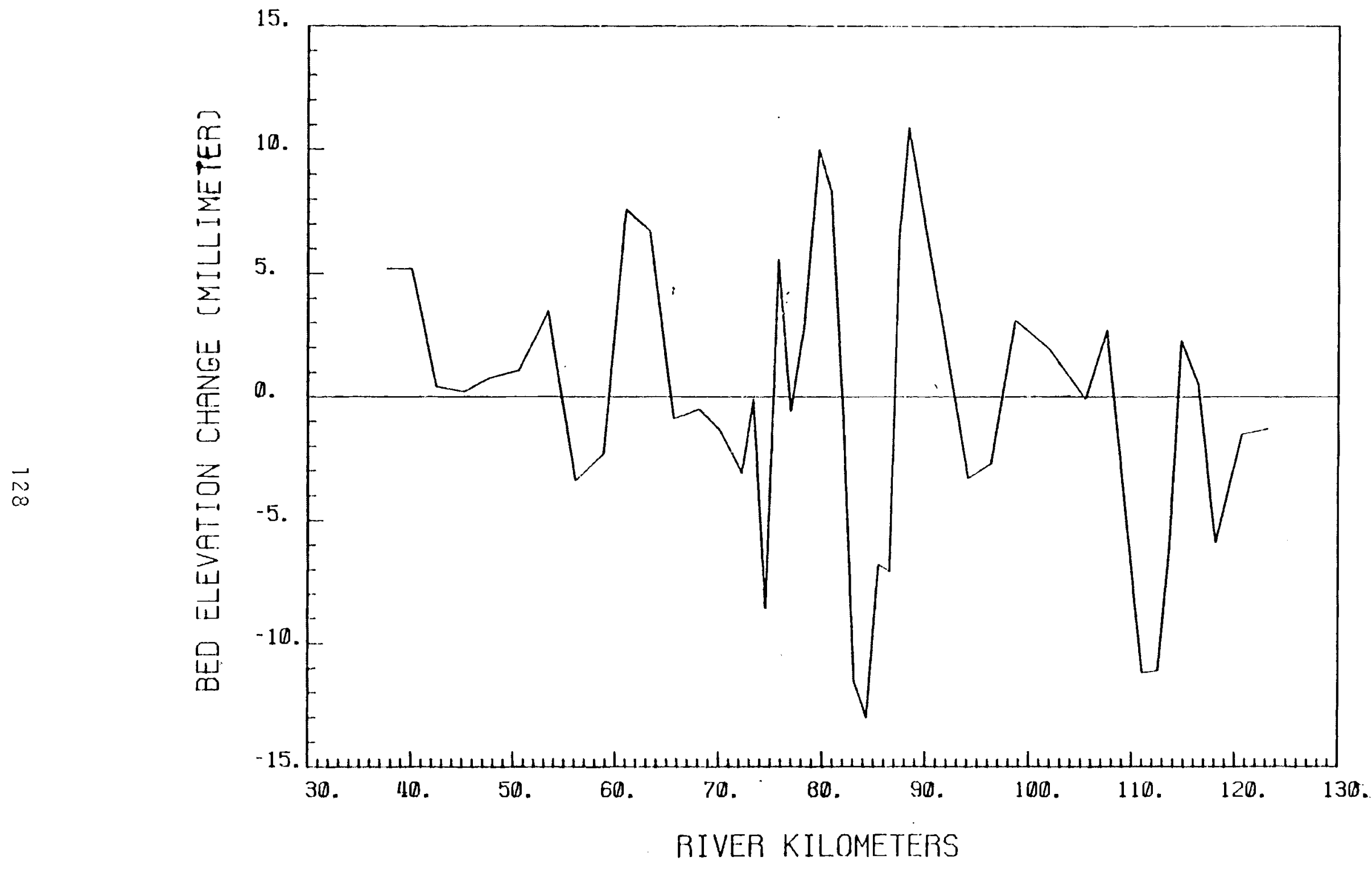

FIGURE 88. Variation of River Bed Elevation Changes Due to Sediment Deposition and/or Bed Scouring at Maximum Ebb Tide for the Fresh-Water Discharge of $681 \mathrm{~m} / \mathrm{sec}$ 


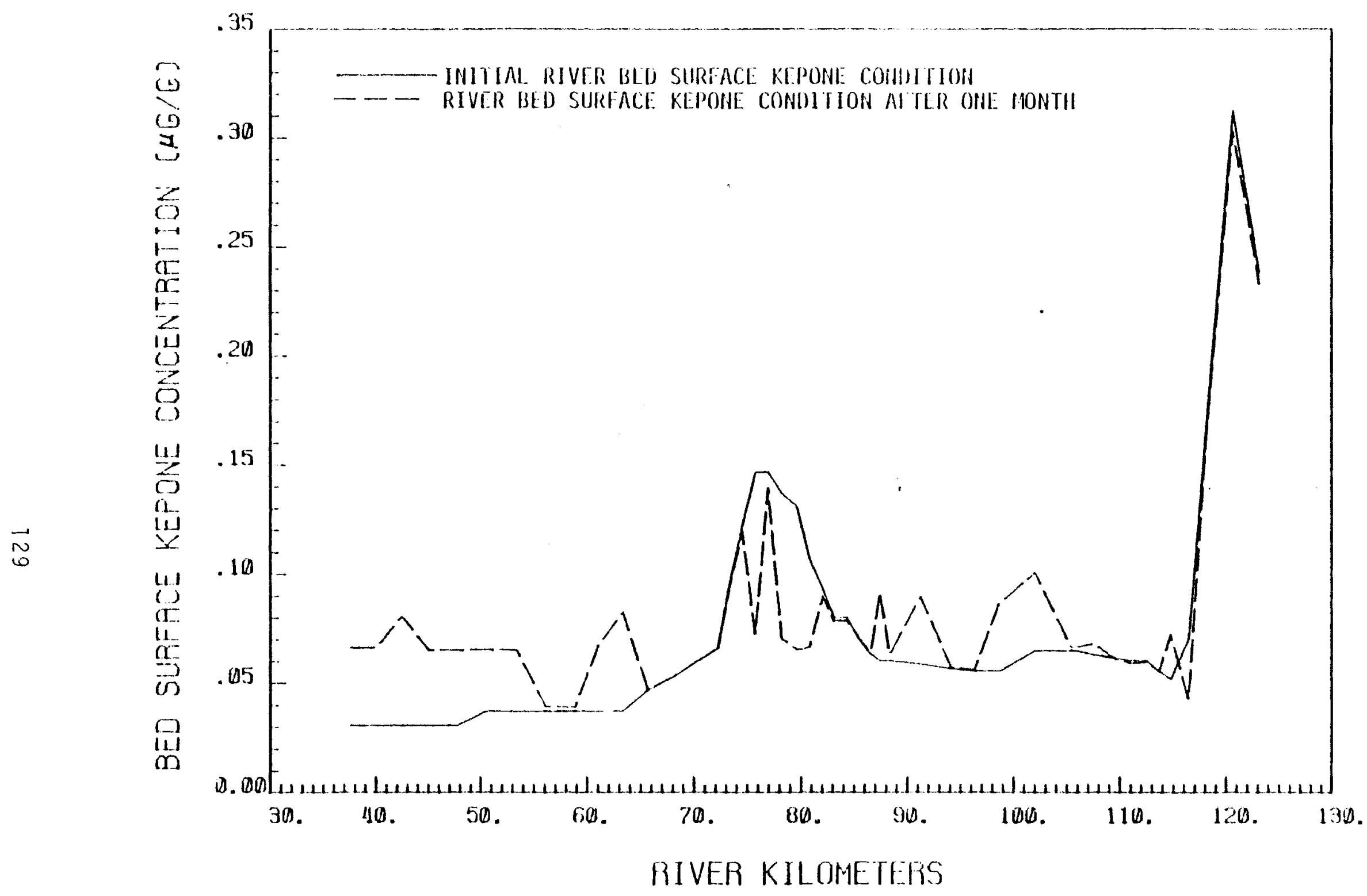

FIGURE 89. Change in Bed Surface Kepone Concentration that Occurred During 1-Month Simulation for the Fresh-Water Discharge of $681 \mathrm{~m}^{3} / \mathrm{sec}$ 


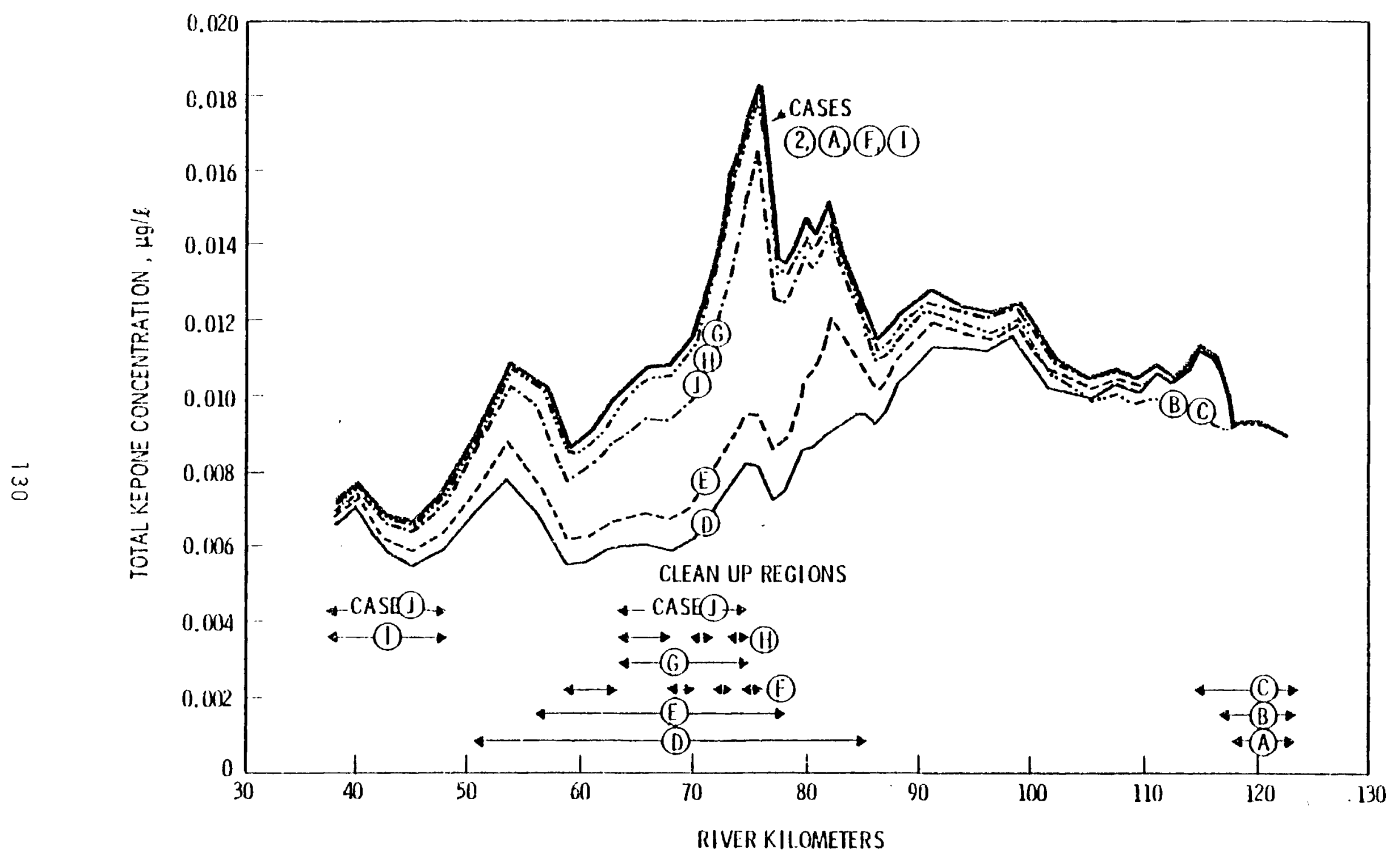

FIGURE 90. Changes in Total Kepone Concentrations Due to Partial Kepone Cleanup Activities 


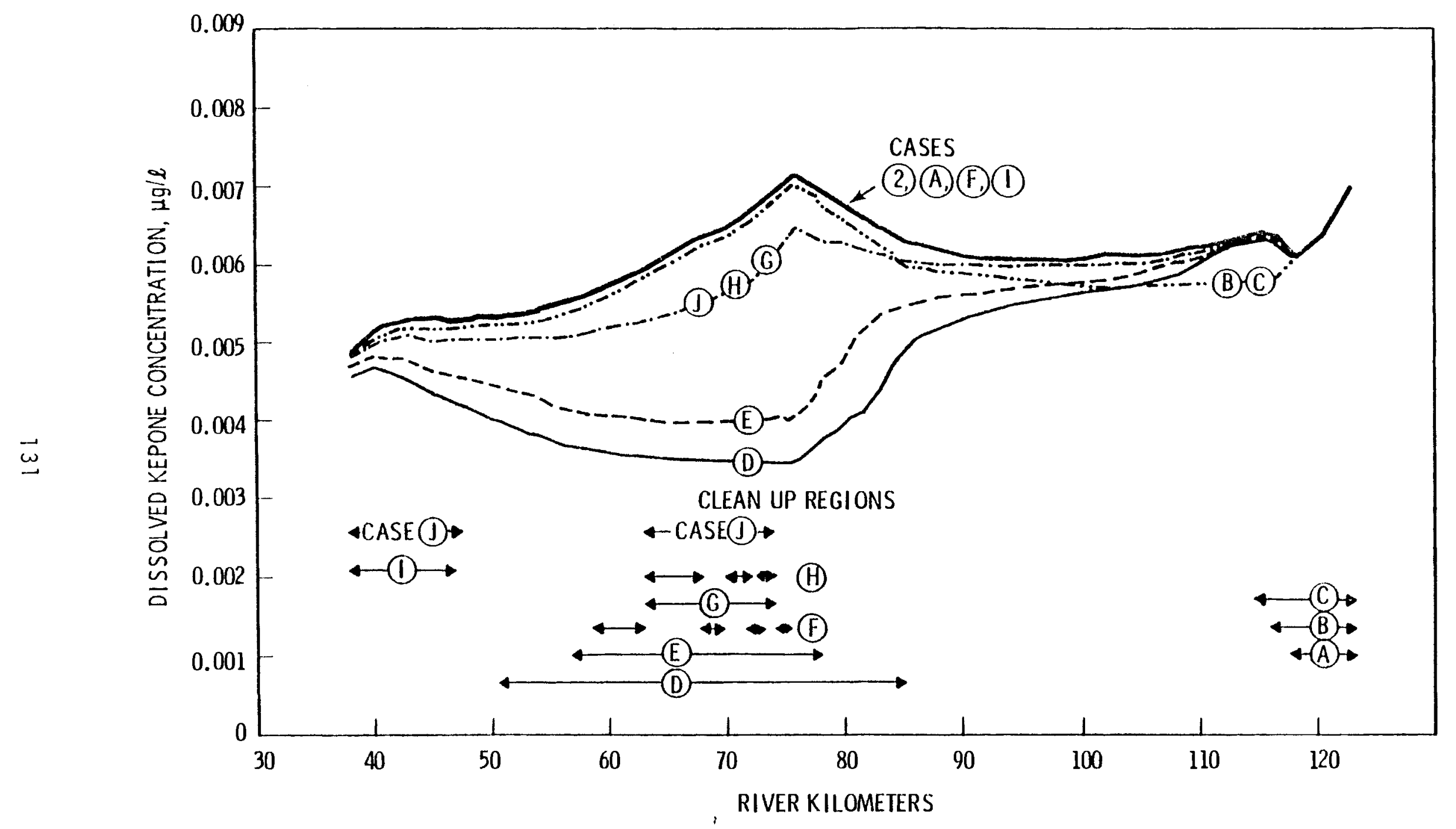

FIGURE 91. Changes in Dissolved Kepone Concentrations Due to Partial Kepone Cleanup Activities 


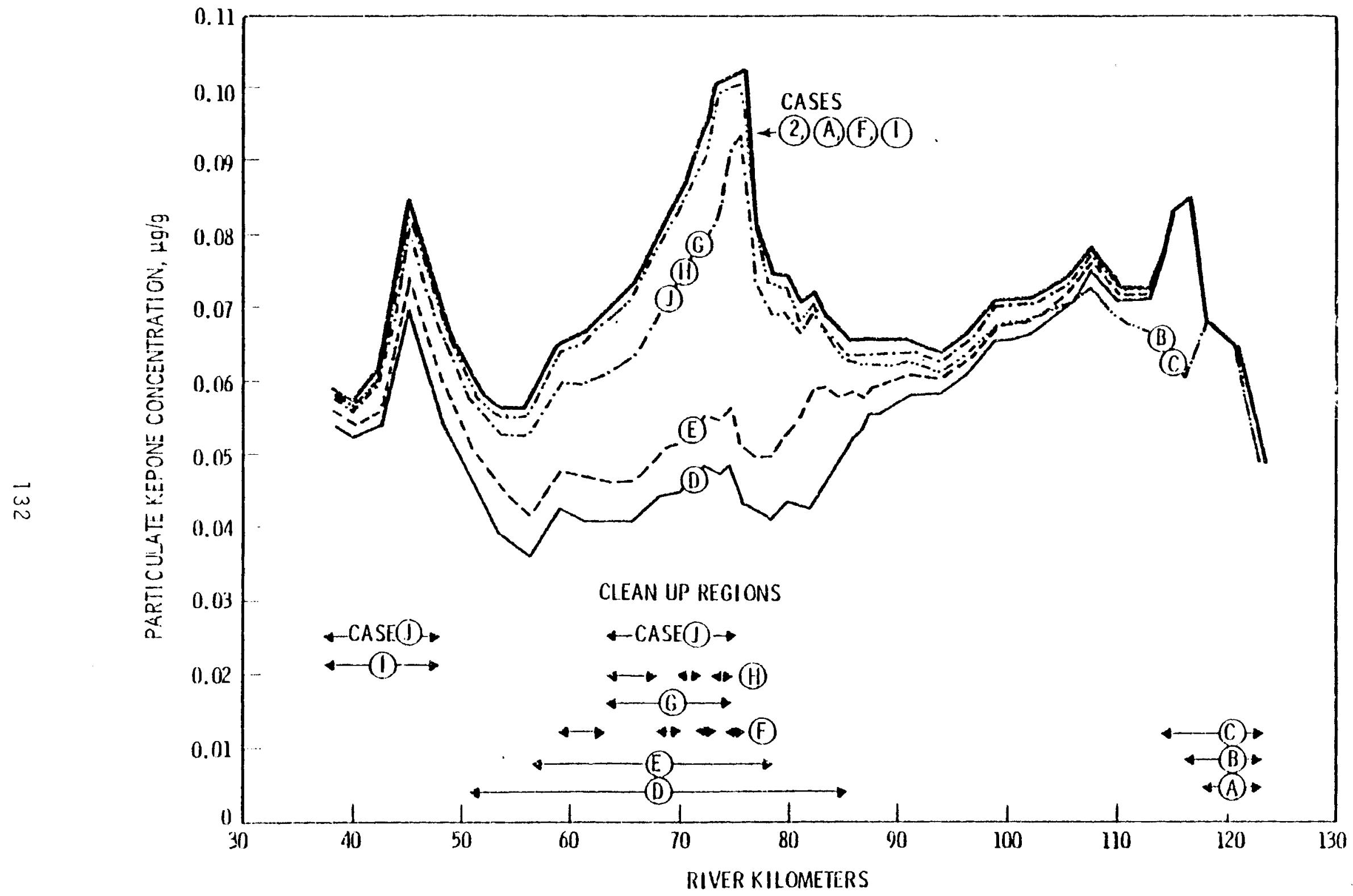

FIGURE 92. Changes in Particulate Kepone Concentrations Due to Partial Kepone Cleanup Activities 


\section{CONCLUSIONS}

The mathematical modeling of sediment and Kepone transport in the James River estuary was conducted by applying the unsteady two-dimensional finite element model, FETRA, to the 86-km river reach between Bailey and Burwell Bays. Effects of sediment on kepone transport, i.e., adsorption and desorption of Kepone and deposition and resuspension of contaminated sediment were included in the mathematical modeling. The FETRA code was verified against field data obtained in the estuary. Results of this study demonstrated that FETRA is capable of predicting sediment transport and migration of various contaminants (both dissolved and particulate) by accounting for sediment-contaminant interaction.

The specific findings are summarized below:

1. Mathematical simulation of Kepone transport under most probable flow conditions (Case 4) yields an estimate of $89.1 \mathrm{~kg} / \mathrm{yr}$ of Kepone transported seaward from Burwell Bay. Of this $89.1 \mathrm{~kg}$ of total Kepone, 25.3\% is carried by sediment, while $74.7 \%$ is in a dissolved phase.

2. Since approximately $9600 \mathrm{~kg}$ of Kepone is estimated to be present in the top $1 \mathrm{ft}$ of bed sediment of the James River, with a seaward flushing rate of $89.1 \mathrm{~kg} / \mathrm{yr}$ of Kepone, it may take approximatly 108 years for the natural water-sediment flushing mechanism alone to clean the James River.

3. Annual average concentrations of particulate, dissolved and total Kepone averaged over the $86-\mathrm{km}$ study reach were estimated to be $0.072 \mu \mathrm{g} / \mathrm{l}$, $0.0064 \mu \mathrm{g} / \mathrm{l}$ and $0.092 \mu \mathrm{g} / \mathrm{l}$, repectively. Twenty-six percent of total Kepone is carried by sediment, while $74 \%$ remains in the dissolved form.

4. Sensitivity analysis under the most probable flow conditions with Kepone bed values twice as high and a 5-fold increase in partition coefficient $(2,200 \mathrm{ml} / \mathrm{g}$ in place of $11,000 \mathrm{ml} / \mathrm{g})$ yield a prediction of $170 \mathrm{~kg} / \mathrm{yr}$ transported seaward of Burwell Bay, and dissolved Kepone accounts for $92 \%$ of the total load. 
5. Ten partial Kepone clean-up cases (Cases $A$ through J) were simulated by the FETRA code to assess efficiency of Kepone cleanup activities in the James River. Cases $D$ and $E$ are the most promising cases to reduce the Kepone concentrations in the river up to 55 and $48 \%$, respectively. Cases $D$ and $E$ require removing Kepone adsorbed by the river bed sediment in a $34.5-\mathrm{km}$ and a $20.0-\mathrm{km}$ reach within the $86-\mathrm{km}$ study reach. However, these results suggest that little or no effect will be noted in the total Kepone flushed out from Burwell Bay toward Chesapeake Bay and the Atlantic Ocean. 


\section{REFERENCES}

1. Baca, R. G., W. W. Waddel1, C. R. Cole, A. Brandstetter, and D. B. Cearlock. 1973. "EXPLORE-I: A River Basin Water Quality Model." Battelle, Pacific Northwest Laboratories, Richland, Washington.

2. Brandstetter, A., R. G. Baca, A. F. Gasperino and A. S. Myhres. 1976. Water Quality Models for Municipal Water Supply Reservoirs--Part 1, Summary. Battelle, Pacific Northwest Laboratories, Richland, Washington.

3. Dawson, G. W., Project Director. 1978. "The Feasibility of Mitigating Kepone Contamination in the James River Basin." Battelle, Pacific Northwest Laboratory, submitted to U.S. Environmental Protection Agency.

4. Desai, C. S., and J. F. Abe1. 1972. Introduction to the Finite Element Method, for Engineering Analysis. Van Nostrand Reinhold Company, iNew York.

5. Garnas, R. L., A. W. Baurquin, and P. H. Pritchurd. 1977. "Fate and Degradation of Kepone in Estuarine Microcosms." Chesapeake Bay, Program II, Easton, MD. September 20-21, 1977.

6. Huggett, R., D. Haven and M. Nichols. 1978. Kepone-Sediment Relationships in the James River. Final Report to U.S. EPA GuTf Breeze Laboratory.

7. Krone, R. B. 1962. Flume Studies of the Transport of Sediment in Estuarial Shoaling Processes. Hydraulic Engineering Laboratory and Sanitary Engineering Research Laboratory, University of California at Berkeley.

8. Nichols, M. M. 1972. "Sediments of the James River Estuary, Virginia." Geo. Soc. Amer. Mem. 133:169-212.

9. Norton, W. R. and I. P. King. 1977. "Operating Instructions for the Computer Program RMA-2: A Two Dimensional Finite Element Program for Problems in Horizontal Free Surface Hydrodynamics." Resources Management Associates, Lafayette, California.

10. Norton, W. R., I. P. King and G. T. Orlob. 1973. A Finite Element Model for Lower Granite Reservoir. Water Resources Engineers, Inc., Walnut Creek, California.

11. Dak Ridge National Laboratory. 1978. Proceedings of a Workshop on Evaluation of Models Used for the Environmental Assessment of Radionuclide Releases, CONF-770901, September 6-9, 1977, Gatlinburg, TN.

12. Onishi, Y. 1977a. Finite Element Models for Sediment and Contaminant Transport in Surface Waters--Transport of Sediments and Radionuclides in the Clinch River. BNWL-2227, Battelle, Pacific Northwest Laboratories, Richland, Washington. 
13. Onishi, Y. 1977b. Mathematical Simulation of Sediment and Radionuclide Transport in the Columbia River. BNwL-2228, Battelle, Pacific Northwest Laboratories, Richland, Washington.

14. Onishi, Y., and R. M. Ecker. "Mathematical Simulation of Transport of Kepone and Kepone-Laden Sediments in the James River Estuary." Presented at the Kepone II Seminar, Easton, MD, September 1977.

15. Onishi, Y., and S. E. Wise, "Mathematical Modeling of Sediment and Contaminant Transport in the James River Estuary, "Proceedings of the 26th Annual ASCE Hydraulic Division Speciality Conference on Verification of Mathematical and Physical Models in Hydraulic Engineering, College Park, Maryland, August 9-11, 1978, pp. 303-310.

16. Onishi, Y., P. A. Johanson, R. G. Baca and E. L. Hilty. 1976. Studies of Columbia River Water Quality - Development of Mathematical Models tor Sediment and Radionuclide Transport Analysis. BNWL-B-452, Battelle, Pacific Northwest Laboratories, Richland, Washington.

17. Partheniades, E. 1962. A Study of Erosion and Deposition of Cohesive Soils in Salt Water. Ph.D. Thesis, University of California at Berkeley.

18. Shupe, S. J., and G. W. Dawson. 1977. Current Disposition of Kepone Residuals in the James River System. Presented at Kepone Seminar II held at Easton, Maryland.

19. Smitn, W. C. 1976. Kepone Discharges from Allied Chemical Company, Hopewell, Virginia. Internal EPA Memorandum, National Field Investigation Center, U.S. EPA, Denver, CO.

20. U.S. Environmental Protection Agency. 1978. Kepone in the Marine Environment, Publications and Prepublications. Gulf Breeze Environmental Research Laboratory, FL.

21. U.S. Environmental Protection Agency. 1976. 1976-2, Information Memorandum. Review of the Chesapeake Bay Program. Seminar on Kepone held at Virginia Institute of Marine Science, October 12-13.

22. Virginia Institute of Marine Science. 1977. The Role of Sediments in the Storage, Movement and Biological Uptake of Kepone in Estuarine Environments. Annual Report to the U.S. EPA, October 20, 1977.

23. Virginia Department of Conservation and Economic Development. 1970. "James River Basin--Comprehensive Water Resources Plan, Volume III Hydrologic Analysis." Planning Bulletin 215, Division of Water Resources the State of Virginia. 


\section{DISTRIBUTION}

io. of

Copies

OFFSITE

A. A. Churm

DOE Chicago Patent Group

U.S. Department of Energy

9800 South Cass Avenue

Argonne, IL 60439

27 DOE Technical Information Center

R. Franklin

DOE Division of Biomedical and

Environmental Research

Washington, DC 20545

Atomic Industrial Forum, Inc.

475 Park Avenue South

New York, NY 10016

J. K. Sullivan

Chesapeake Bay Center for

Environmental Studies

Smithsonian Institute

Route \#4 Box 622

Edgewater, MD 21037

D. L. Schreiber

P.0. Box 1087

C/O The Colony

Coeur d'Alene, ID 83814

D. Bastian

Corps of Engineers

Chesapeake Bay Model Project

Stevensville, MD 21666

S. P. Cobb

Corps of Engineers

U.S. Army Engineering Waterways Experiment Station

Vicksburg, MS 39180

R. W. Culpepper, Jr.

Corps of Engineers

Norfolk District

803 Front Street

Norfolk, VA 23510
No. of

Copies

D. W. Davis

Corps of Engineers

Hydrologic Engineering Center

609 Second Street

Davis, CA 95616

W. J. Garrett

Corps of Engineers

New Orleans District

P.0. Box 60261

New Orleans, LA 70160

J. Henley

Corps of Engineers

Vicksburg District

Vicksburg, MS 39180

H. P. Keown

Corps of Engineers

U.S. Army Engineering Waterways Experiment Station

Vicksburg, MS 39130

D. Legg

Corps of Engineers

North Pacific Division

Water Quality Section

210 Custom House

Portland, OR 97209

W. McAna $11 y$

Corps of Engineers

U.S. Army Engineering Waterways Experiment Station

Vicksburg, MS 39180

N. McDonald

Corps of Engineers

Seattle District Office

4735 East Marginal Way South

Seattle, WA 98134 
No. of

Copies

H. E. Pape, Jr.

Corps of Engineers

San Francisco District

$100 \mathrm{McAllister}$ Street

San Francisco, CA 94102

W. E. Sivley

Corps of Engineers

North Pacific Division

Walla Walla District Office

B1dg. 206, City-Courity Airport

Walla Walla, WA 99362

R. Smith

Corps of Engineers

Vicksburg District

Vicksburg, MS 39180

W. A. Thomas

Corps of Engineers

U.S. Army Engineering Waterways

Experiment Station

Vicksburg, MS 39180

J. Tuttle

Corps of Engineers

Lower Mississippi River District

Vicksburg, MS 39180

R. Waits

Corps of Engineers

Portland District Office

Portland, OR 97209

B. R. Winkley

Corps of Engineers

Vicksburg District

Vicksburg, MS 39180

R. Goldstein

Electric Power Research

Insti tute

3412 Hillview Avenue

Palo Alto, CA 94304
No. of

Copies

R. P. Ambrose

Environmental Protection Agency

Environmental Research Laboratory

Athens, GA 30603

A. F. Bartsch

Environmental Protection Agency

Corvall is Environmental Research Laboratory

200 S.W. 35th Street

Corvallis, OR 97330

R. Bauer

Environmental Protection Agency

Region $X$

1200 Sixth Avenue

Seattle, WA 98101

M. W. Brossman

Environmental Protection Agency

Room M2830 (WH-585)

401 M Street, S.W.

Washington, DC 20460

J. Falco

Environmental Protection Agency

Environmental Research Laboratory

Athens, GA 30603

J. G. Gardner

Environmental Protection Agency

6th and Walnut Streets

Philadelphia, PA 19106 
No. of

Copies

R. Haque

Environmental Protection Agency

Office of Air, Land and

ORD Water Use

Washington, DC 22040

S. D. Lee

Environmental Protection Agency

Health Effects Research Laboratory

Cincinnati, OH 45268

J. Lichtenberg

Environmental Protection Agency

Environmental Monitoring and Support Laboratory

26 W. St. Clair Street

Cincinnati, OH 45268

L. Mangiaracina

Environmental Protection Agency

Region III

6 th and Walnut Streets

Philadelphia, PA 19106

A. J. McErlean

Environmental Protection Agency

401 M Street, S.W.

Washington, DC 20460

L. Mulkey

Environmental Protection Agency

Environmental Research Laboratory

Athens, GA 30603
Vo. of

Copies

S. Peterson

Environmental Protection Agency

Corvallis Environmental Research Laboratory

200 S.W. 35th Street

Corvallis, OR 97330

1. Shirazi

Environmental Protection Agency

Pacific Northwest Water Laboratory

200 S.W. 35th Street

Corvalitis, OR 9733]

W. Swain

Environmental Protection Agency

Large Lakes Research Station

9311 Groh Road

Grosse Ile, MI 48133

0. Villa

Environmental Protection Agency

Annapol is Science Center

Annapolis, MD 21401

K. K. Wu

Environmental Protection Agency

Region III

6th and Wainut Streets

Philadelphia, PA 19106

R. B. Pojasek

ERCO

185 Alewife Brook

Parkway

Cambridge, MA 02138 
ivo. of

Copies

S. Gilje

Federal Highway Administration

HRS-42

Washington, DC 20590

P. Griffin

General Electric

Research and Development Center

P.0. Box A

Building KS1 - Room 3B33

Schenectady, iN 12345

T. E. Larson

Illinois State Water Survey

Box 232

Urbana, IL 61801

W. G. Gordon

National Marine Fisheries

Service

Northeastern Region

Federal Building

$14 \mathrm{E} 1 \mathrm{~m}$ Street

Gioucester, MA 01930

G. Glass

National Water Quality

Laboratory

6201 Congden Blvd.

Duluth, MN 55804

L. J. Hetling

New York Department of Environmental Conservation

50 Wolf Road

A1bany, NY 11221

L. Deans

NUS Corporation

Cyrus William Rice Division

15 Noble Avenue

Pittsburgh, PA 15205 iio. of

Copies

F. O. Hoffman

Oak Ridge National Laboratory

Oak Ridge, TN 37820

R. J. Jolley

Oak Ridge National Laboratory P.0. Box X

Oak Ridge, TN 37820

T. Tamura

Oak Ridge National Laboratory

Oak Ridge, TN 37820

L. Keith

Radian Corporation

P.0. Box 9948

Austin, TX 78766

D. J. Eatough

Thermochemical Institute

Brigham Young University

267 Fletcher Bldg.

Provo, UT 84602

I. H. Suffet

Department of Environmental

Eng. and Sci.

Abbots Bldg.

Drexel University

Philadelphia, PA 19104

H. E. Allen

Department of Environmental Engineering

Illinois Institute of Technology

Chicago, IL 60616

M. G. Gross

Chesapeake Bay Institute

John Hopkins University

Charles and 34 th

Macaulay Hall

Baltimore, MD 21136 
Ho. of

Copies

G. Gordon

Department of Chemistry

University of Maryland

College Park, MD 20742

R. Hites

Department of Chemical

Engineering

Massachusetts Institute

of Technology

Cambridge, MA 02139

S. J. Eisenreich

Environmental Engineering Program

Department of Civil and Mineral Engineering

University of Minnesota

221 Church Street, S.E.

linneapolis, MN 55455

D. Johnson

vepartment of Environmental

Science and Engineering

University of ilorth Carolina at Chapel Hill

Chapel Hill, NC 27514

C. O'Melia

School of Public Health

University of North Carolina

Chapel Hill, HC 27514

J. Andelman

Graduate School of Public Health

University of Pittsburgh

Pittsburgh, PA 15261

T. F. Yen

Department of Chemical

Engineering

University of Southern California

Los Angeles, CA 90007
No. of

Copies

R. Minear

Department of Civil Engineering

University of Tennessee

Knoxville, TN 37916

E. F. GToyna

College of Engineering

University of Texas

at Austin

Austin, TX 78705

G. F. Lee

Environmental Sciences Program University of Texas at Dallas

Richardson, TX 75080

C. V. Alonso

U.S. Department of Agriculture Sedimentation Laboratory

Scuthern Region, Agricultural

Research Center

P.0. Box 1157

Oxford, MS 38655

D. R. Carder

U.S. Department of Agriculture Forest Service

C.4 Box 4106 H.A.U.

Flagstaff, $A Z 86001$

D. G. DeCoursey

U.S. Department of Agriculture Sedimentation Laboratory

Southern Region, Agricultural Research Center

P.O. Box 1157

Oxford, lis 38655

D. A. Farrell

U.S. Department of Agriculture Agriculture Research Service Room 234, B-005, BARC-W

Beltsville, ME 20704 
No. of

\section{Copies}

R. Lippson

U.S. Department of Commerce

National Oceanographic and

Atmospheric Administration

ilational Marine Fisheries

Service

Oxford Laboratories

Oxford, MD 21654

E. A. Jenne

U.S. Department of the Interior

Water Resources Division

345 Middlefield Road

Menlo Park, CA 94025

J. H. Turner

U.S. Food and Drug Administration

900 Madison Avenue

Baltimore, $M 1021201$

P. C. Benedict

U.S. Geological Survey

345 Middlefieid Road

Inenlo Park, CA 94025

J. Adam

U.S. Nuclear Regulatory Commission

Washington, DC 20555

C. B. Bârtlett

U.S. Nuclear Regulatory Commission

Washington, DC 20555

W. Bevins

U.S. Nuclear Regulatory Commission

Washington, DC 20555

W. P. Bishop

U.S. Nuclear Regulatory Commission

Washington, DC 20555
10. of

Copies

R. B. Codel1

U.S. Nuclear Regulatory Commission

Washington, DC 20555

L. G. Hulman

U.S. Nuclear Regulatory Commission

Washington, DC 20555

P. H. Lohaus

U.S. Huclear Regulatory Commission

Washington, DC 20555

P. R. Reed

U.S. Nuclear Regulatory Commission

Washington, DC 20555

F. Swanberg

U. S. Nuclear Regulatory Commission

Washington, DC 20555

W. Hallaeur

Washington State Department of Ecology

OTympià, WA 98504

\section{ONSITE}

2 DOE Richland Operations Office

H. E. Ramson

M. W. Tiernan

13 Pacific Northwest Laboratory

D. B. Cearlock

G. W. Dawson

D. W. Dragnich

Y. Onishi

S. E. Wise

Technical Information (5)

Publishing Coordination (2)

Water and Land Resources Library 